CENTRO UNIVERSITÁRIO FEI

JULIANA PINHEIRO NEMER

DESENVOLVIMENTO DE NANOFIOS TRANSISTORES EM SUBSTRATOS SOI COM ESPESSURAS NANOMÉTRICAS

São Bernardo do Campo 
JULIANA PINHEIRO NEMER

\section{DESENVOLVIMENTO DE NANOFIOS TRANSISTORES EM SUBSTRATOS SOI COM ESPESSURAS NANOMÉTRICAS}

Tese de Doutorado apresentada ao Centro Universitário FEI como parte dos requisitos necessários para a obtenção do título de Doutor em Engenharia Elétrica.

Orientador: Prof. Dr. Marcelo Antonio Pavanello

São Bernardo do Campo 
Pinheiro Nemer, Juliana .

Desenvolvimento de Nanofios Transistores em Substratos SOI com Espessuras Nanométricas / Juliana Pinheiro Nemer. São Bernardo do Campo, 2017.

133 p. : il.

Tese - Centro Universitário FEI.

Orientador: Prof. Dr. Marcelo Antonio Pavanello.

1. SOI. 2. Transistores sem junção. 3. processo de fabricação. 4. JNT.

5. NW transistor.. I. Pavanello, Marcelo Antonio, orient. II. Título.

Elaborada pelo sistema de geração automática de ficha catalográfica da FEI com os dados fornecidos pelo(a) autor(a). 
Título do Trabalho: DESENVOLVIMENTO DE NANOFIOS TRANSISTORES EM SUBSTRATOS SOI COM ESPESSURAS NANOMÉTRICAS.

Área de Concentração: Dispositivos Eletrônicos Integrados

Orientador: Prof. Dr. Marcelo Antonio Pavanello

Data da realização da defesa: 19/05/2017

\section{ORIGINAL ASSINADA}

Avaliação da Banca Examinadora

São Bernardo do Campo, 19 / 05 / 2017.

\section{MEMBROS DA BANCA EXAMINADORA}

Prof. Dr. Marcelo Antonio Pavanello

Ass.:

Prof. a Dr. a Eliane de Fátima Chinaglia

Ass.:

Prof. Dr. Renato Camargo Giacomini

Ass. :

Prof. a Dr.a Carolina Davanzzo Gomes dos Santos

Ass.:

Prof. ${ }^{a}$ Dr. ${ }^{a}$ Katia Franklin Albertin Torres

Ass.:

A Banca Examinadora acima-assinada atribuiu ao aluno o seguinte:

APROVADO $\bigotimes$

REPROVADO

\section{VERSÃO FINAL DA TESE}

ENDOSSO DO ORIENTADOR APÓS A INCLUSÃO DAS RECOMENDAÇÕES DA BANCA EXAMINADORA
Aprovação do Coordenador do Programa de Pós-graduação

Prof. Dr. Carlos Eduardo Thomaz 
A Deus e à minha família, Thiago Conti Nemer, Laura Pinheiro Nemer, Eduardo Pinheiro, Rosangela Ferreira Pinheiro e Bruna Ferreira Pinheiro. 


\section{AGRADECIMENTOS}

Todo agradecimento primeiramente a Deus, a razão da minha existência. Ele quem me sustentou, dando força, disciplina, paciência para enfrentar todas as dificuldades enfrentadas neste projeto.

Ao meu marido Thiago pela compreensão, apoio, incentivo de sempre, por sempre estar ao meu dado. À minha filha Laura pois tem sido minha inspiração. Aos meus pais e irmã que estiveram sempre ao meu lado, auxiliando e encorajando a seguir em frente sempre.

Ao professor Dr Marcelo Antonio Pavanello, meu orientador, que de uma forma indescritível apoiou este desafio, me incentivando o tempo todo.

Aos professores Dr. José Diniz pelo conhecimento compartilhado, incentivo e sugestões durante o período de trabalho no CCS -Campinas. Ao Marcos Puydinger, por compartilhar o conhecimento e auxiliar em todo o projeto. Aos alunos e funcionários do CCS, Lucas, Cássio, Luis, Andressa, António, Emílio, Luana, Regina, que me ajudaram em muitos processos dividindo e agregando duas experiências.

Aos demais amigos, Genaro, Lígia, Ariane, Rafael, Thalles, pelo compartilhamento de experiências, medos e expectativas.

Aos professores do grupo IED Dr. Renato Giacominni, Dra. Michelly de Souza, Dr. Salvador Pinillos Gimenez, Dr. Rodrigo Doria e Dr. Renan Trevisoli pela experiência compartilhada.

Ao Centro Universitário da FEI e ao CCS -UNICAMP, por oferecerem a infraestrutura necessária para a realização desse projeto.

À FAPESP, pelo apoio financeiro indispensável para a realização deste trabalho.

A tantas outras pessoas, que de alguma forma colaboraram para a realização deste trabalho e que, de forma involuntária foram aqui omitidos. 
"Mas a sabedoria que vem do alto é antes de tudo pura; depois, pacífica, amável, compreensiva, cheia de misericórdia e de bons frutos, imparcial e sincera." Tiago 3:17 


\section{RESUMO}

Atualmente, uma série de trabalhos reportados na literatura mundial aponta a tecnologia Silício-sobre-Isolante (Silicon-On-Insulator - SOI) como uma possível substituta da tecnologia MOS convencional na fabricação de transistores com comprimento de canal reduzido, constituindo uma importante alternativa para sustentar a contínua redução das dimensões enfrentada pela tecnologia CMOS. A utilização da tecnologia SOI apresenta melhorias tais como redução nas capacitâncias de junção e maior mobilidade dos portadores na região de canal, minimizando a ocorrência de efeitos parasitários indesejáveis que afetem o desempenho do transistor MOS. Embora o transistor na tecnologia SOI apresente diversas vantagens em comparação com a tecnologia CMOS convencional, em nosso país poucas universidades realizam a fabricação de dispositivos e circuitos em tecnologia SOI CMOS. A crescente miniaturização de dispositivos com comprimentos ainda menores, na ordem dos nanômetros, torna o processo de fabricação das junções de fonte e dreno complexo na região do canal. Devido ao comprimento de canal reduzido, as junções de fonte e dreno devem ser abruptas, de modo que a concentração de dopagem varie ordens de grandeza. Recentemente, uma estrutura de portas múltiplas foi proposta para evitar este problema: o dispositivo MOS sem junções (Junctionless Nanowire Transistors - JNT). Estes dispositivos apresentam excelente inclinação de sublimiar, baixa corrente de fuga, e alta taxa da corrente on/off. Portanto como desafio tecnológico fabricamos transistores sem junção JNT dopados e não dopados (undoped nanowire transistor) utilizando lâmina SOI com filme de silício e óxido enterrado nanométricos. Os transistores fabricados correspondem a uma estrutura tridimensional de múltiplas portas e apresentam um processo de fabricação mais simples que o CMOS tradicional, além de diversos trabalhos na literatura o demonstrarem como uma alternativa viável para substituir os transistores planares. Esses transistores foram fabricados no Centro de Componentes Semicondutores (CCS) da Unicamp e o grande desafio foi fabricar em uma lâmina que nos proporcionava espessuras nanométricas com o laboratório que ultimamente trabalha com espessuras micrométricas. Os dois conjuntos de transistores Junctionless e um nanofio Transistor ambos ultra thin and buried oxide (UTBB), são compostos por 54 transistores com diferentes números de dedos (1, 20, 120, 640 e 1280), W $(0,05 \mu \mathrm{m}, 0,1 \mu \mathrm{m}$ e $0,5 \mu \mathrm{m})$ e $\mathrm{L}(1,5 \mu \mathrm{m}, 1 \mu \mathrm{m}, 0,5 \mu \mathrm{m}$ e $0,1 \mu \mathrm{m})$. Para estes transistores são apresentados, simulação numérica tridimensional, as etapas do processo de fabricação e caracterização elétrica dos transistores e imagens com FIB e MEV foram realizadas para caracterizar o perfil dos transistores. 
Palavras-chave: SOI. Transistores sem junção. Processo de fabricação. JNT. NW transistor. 


\begin{abstract}
Currently, a number of studies reported in the literature points to Silicon-on-Insulator technology (Silicon-On-Insulator - SOI) as an important substitute for conventional MOS technology in the manufacturing process of transistors with reduced channel length, being an important alternative to sustain continuous size reduction faced by CMOS technology. The SOI technology offers improvements such as reduced junction capacitances, higher carrier mobility in the channel region, parasitic effects reduction which affects the performance of the MOS transistor. Although the SOI technology offers several improvements, in our country few universities are manufacturing devices and circuits in SOI CMOS technology. The increasing miniaturization of devices with even smaller lengths, on the order of nanometers makes the manufacturing process of the source and drain junctions with the channel complex. Because of the reduced channel length, the source and drain junctions must be abrupt, so that the doping concentration varies several orders of magnitude in a few nanometers. Recently, a structure of multiple gates was proposed to avoid this problem: the MOS device without junctions (Junctionless Nanowire Transistors - JNT ). These devices exhibit excellent subthreshold slope, low leakage current, and a high rate of current on/off. Therefore, as a technological challenge, we fabricated doped (JNT) and undoped transistors (undoped nanowire transistor) using SOI wafer with nanometer silicon film and buried oxide. The transistors manufactured correspond to a three-dimensional structure of multiple gates and present a simpler manufacturing process than traditional CMOS, besides several works in the literature to demonstrate it as a viable alternative to replace the planar transistors. These transistors were manufactured at Unicamp's Semiconductor Components Center and the great challenge was to manufacture a wafer that provided us nanometric thicknesses with the laboratory that it works with micrometric thicknesses. The set of Junctionless transistors and one nanowire Transistor are both UTBB, are composed of 54 transistors with different number of fingers $(1,20,120,640$ and 1280$), \mathrm{W}(0.05 \mu \mathrm{m}, 0.1 \mu \mathrm{m}$ and $0.5 \mu \mathrm{m})$ and $\mathrm{L}(1.5 \mu \mathrm{m}$, $1 \mu \mathrm{m}, 0.5 \mu \mathrm{m}$ and $0.1 \mu \mathrm{m})$. For transistors are presented, three-dimensional numerical simulation, the steps of the fabrication process, electrical characterization of the transistors and images with FIB and MEV were performed to characterize the profile of the transistors.
\end{abstract}

Keywords: SOI MOSFETs. Junctionless. Process fabrication. JNT. NW Transistor. 


\section{LISTA DE FIGURAS}

Figura 1- Transistores de Múltiplas portas.

Figura 2- Transistor FinFET demonstrando o comprimento de canal (L), a largura do silício ( $\left.\mathrm{W}_{\text {Fin }}\right)$, a altura do silício $\left(\mathrm{H}_{\text {Fin }}\right)$, as espessuras do óxido de porta e do óxido enterrado

Figura 3 - Estrutura multi-fins ou multi-dedos. .25

Figura 4- Esquema de fabricação da lâmina SOI pela técnica Smart Cut...............................26

Figura 5- Perfil transversal do transistor SOI nMOSFET. ....................................................26

Figura 6- Perfil longitudinal do dispositivo SOI pMOS modo acumulação. ..........................27

Figura 7- Funcionamento dispositivo SOI modo acumulação região de sublimiar. .................28

Figura 8- Funcionamento dispositivo SOI modo acumulação com pinçamento do corpo, região de triodo. 28

Figura 9- Funcionamento dispositivo SOI modo acumulação: (A) corpo e camada de acumulação em tríodo; (B) pinçamento da camada de acumulação; (C) pinçamento do corpo e da camada de acumulação.

Figura 10 - Diagramas de faixas de energia: (A) transistor MOS convencional e (B) transistor PD SOI parcialmente depletado.

Figura 11 - Diagrama de faixa de energia para o dispositivo FD SOI. 31

Figura 12 - Variação da tensão de limiar em função da tensão aplicada no substrato, indicando as condições da segunda interface com relação ao potencial aplicado ao substrato [3]

Figura 13 - Curva simulada $\log \left(\mathrm{I}_{\mathrm{DS}}\right)$ x $\mathrm{V}_{\mathrm{GF}}$ evidenciando a região de sublimiar para

$\mathrm{V}_{\mathrm{DS}}=50 \mathrm{mV}$ para um SOI MOSFET de canal $\mathrm{n}$

Figura 14 - Distribuição das cargas de depleção em dispositivos de canal longo, lado esquerdo, e a direita, efeito de canal curto, para dispositivos MOS convencionais e para SOI MOSFETs. Onde $\mathrm{Q}_{\mathrm{dl}}$ é a carga de depleção controlada pela porta. 41

Figura 15- Tensão de limiar em função do comprimento de canal comparando dispositivos MOS com FD SOI MOSFET. 42

Figura 16 - Perfil transversal do transistor Sem Junção - JNT.

Figura 17 - Seção transversal do transistor sem junção nMOS e pMOS. 44

Figura 18 - Comparação das curvas em escala logarítmica da corrente de dreno em função da tensão de porta dos dispositivos modo acumulação (A) e JNT(B) 
Figura 19 - (a) Concentração de portadores mais abundantes na interface silício-óxido num transistor de modo inversão; (b) Concentração de portadores muito presentes na maior parte do transistor (c) Praticamente todos os portadores passam pelo centro da estrutura [54].

Figura 20 - (a) Transistor com mobilidade baixa nas interfaces, modo inversão. (b) JNT com mobilidade efetiva no centro da estrutura [41].

Figura 21 - Esquema da estrutura do transistor UTBB SOI MOSFET. 48

Figura 22- Diagramas esquemáticos da influência do substrato nos NWFETs.

Figura 23- Curva da corrente de dreno em função da tensão de substrato e a porta flutuando.

Figura 24- Esquema para polarização do Pseudo MOS.

Figura 25- Curvas características da estrutura Pseudo MOS em uma lâmina UNIBOND. (a) $\mathrm{I}_{\mathrm{D}}$ versus $V_{D}$, (b) $I_{D}$ versus $V_{G}$ com inversão forte e acumulação forte. (c) $I_{D}$ versus $V_{G}$ em escala logarítmica (d) curva da transcondutância. .52

Figura 26 - Modo de identificação dos Tipos de dopantes e as orientações Cristalográficas de Substratos de Si, vistos de cima. .55

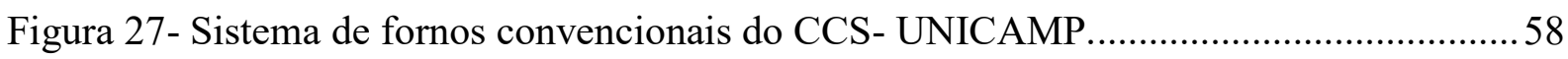

Figura 28- MJB3 sistema de fotolitografia ótica do CCS. ....................................................59

Figura 29- Esquema para de fotogravação pela técnica de fotolitografia ótica de contato. .....60

Figura 30- Equipamento de fotolitografia por feixe de elétrons Raith E-line.........................61

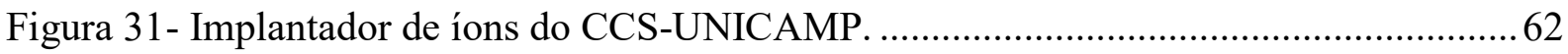

Figura 32- Esquema do perfil de um substrato coberto por um padrão com fotorresiste e mostrando uma corrosão anisotrópica e isotrópica.

Figura 33- ICP (Inductively Coupled Plasmas) do CCS. 64

Figura 34- Perfil de íons de fósforo na estrutura SOI com óxido de sacrifício de $60 \mathrm{~nm}$ de espessura, após implantação (energia de $20 \mathrm{keV}$ e ângulo de ataque de $7^{\circ}$ ). 66

Figura 35- Curvas simuladas do transistor JNT NMOS, com $\mathrm{V}_{\mathrm{DS}}=50 \mathrm{mV}, \mathrm{W}=50 \mathrm{~nm}$ e variando o comprimento de canal em $50 \mathrm{~nm}, 100 \mathrm{~nm}, 400 \mathrm{~nm}$ e $1000 \mathrm{~nm}$.

Figura 36-Curvas $\mathrm{I}_{\mathrm{DS}}$ e $\mathrm{g}_{\mathrm{m}}$ em função da tensão de porta simuladas do transistor JNT NMOS, com $\mathrm{V}_{\mathrm{DS}}=1 \mathrm{~V}, \mathrm{~W}=50 \mathrm{~nm}$ e variando o comprimento de canal em $50 \mathrm{~nm}, 100 \mathrm{~nm}$, $400 \mathrm{~nm}$ e $1000 \mathrm{~nm}$

Figura 37- Curvas $I_{D S}$ e $g_{D}$ em função da tensão aplicada ao dreno simuladas do transistor JNT NMOS, $\mathrm{L}=50 \mathrm{~nm} \mathrm{~W}=50 \mathrm{~nm}$ para $100 \mathrm{mV}>\mathrm{V}_{\mathrm{GT}}>500 \mathrm{mV}$. 
Figura 38- Curva simulada $\mathrm{I}_{\mathrm{DS}}$ e $\mathrm{g}_{\mathrm{D}}$ em função da tensão aplicada ao dreno, com $\mathrm{V}_{\mathrm{GT}}=500 \mathrm{mV}$, $\mathrm{N}_{\mathrm{D}}=2 \mathrm{e} 18 \mathrm{~cm}-3, \mathrm{~W}=100 \mathrm{~nm}$ variando o comprimento de canal.

Figura 39- Curva simulada $\mathrm{I}_{\mathrm{DS}}$ e $\mathrm{g}_{\mathrm{D}}$ em função da tensão aplicada ao dreno, com $\mathrm{V}_{\mathrm{GT}}=500 \mathrm{mV}$, $\mathrm{N}_{\mathrm{D}}=2 \mathrm{e} 18 \mathrm{~cm}-3$, variando o comprimento e largura de canal.

Figura 40- Curvas da transcondutância de saída em função do comprimento do canal...........74

Figura 41 - Curvas da condutância de saída em função do comprimento do canal. ................. 75

Figura 42- Curvas do ganho de saída em função do comprimento do canal............................75

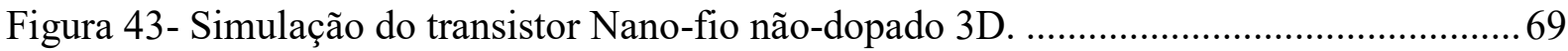

Figura 44- Estrutura JNT não dopada com a concentração de elétrons para $\mathrm{V}_{\mathrm{GB}}=+10 \mathrm{~V} \ldots \ldots . .70$

Figura 45- Estrutura JNT não dopada com a concentração de lacunas para $\mathrm{V}_{\mathrm{GB}}=-10 \mathrm{~V} \ldots \ldots . .70$

Figura 46- Layout dos transistores fabricados com a descrição de número de fins, comprimento de canal, e largura de canal. 77

Figura 47- Layout utilizado para a fabricação do conjunto de transistores alpha. Evidenciando as marcas de alinhamento: laterais em cinza e com fundo rosa as marcas principais.

Figura 48- Foto dos transistores de $\mathrm{N}=1280$, das mesas de silício formadas após a corrosão. 82 Figura 49- Esquema da etapa de processo de oxidação realizada no forno convencional. ......83 Figura 50- Litografia da máscara de abertura de contatos e a abertura realizada com BHF dos transistores $\mathrm{N}=120$. 85

Figura 51 - Foto dos pads de fonte, dreno e porta danificados, transistores com N=1280 87

Figura 52- À direita o transistor com 1 dedo de $\mathrm{L}=1 \mu \mathrm{m}$ e $\mathrm{W}=0,1 \mu \mathrm{m}$ e à esquerda $\mathrm{L}=1,5 \mu \mathrm{m}$ e $\mathrm{W}=0,1 \mu \mathrm{m}$.

Figura 53- Transistor $\mathrm{L}=0,6 \mu \mathrm{m}$ e $\mathrm{W}=0,1 \mu \mathrm{m}$ com magnificação de 50vezes, mostrando os pads de porta, fonte e dreno. 88

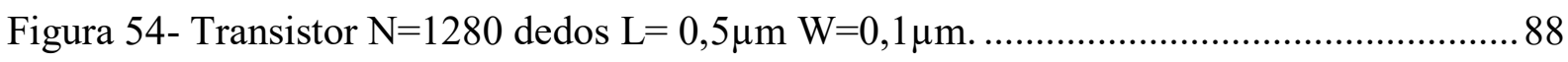

Figura 55- Transistor $\mathrm{N}=1280$ dedos $\mathrm{L}=0,5 \mu \mathrm{m} \mathrm{W}=0,1 \mu \mathrm{m}$ com maior magnitude. 89

Figura 56- Transistor $\mathrm{N}=160, \mathrm{~L}=0,5 \mu \mathrm{m}$ e $\mathrm{W}=0,1 \mu \mathrm{m}$ .89

Figura 57- Transistor $\mathrm{N}=160, \mathrm{~L}=0,5 \mu \mathrm{m}$ e $\mathrm{W}=0,1 \mu \mathrm{m}$ com maior magnitude. 90

Figura 58- Foto do transistor $\mathrm{N}=160, \mathrm{~L}=0,5 \mu \mathrm{m}$ e $\mathrm{W}=0,1 \mu \mathrm{m}$ com uma inclinação e maior magnitude, e ao lado o fio metal (porta) com L aproximadamente igual a 500nm. 91

Figura 59- Imagem feita no MEV da marcas de alinhamento global com 10nm de Ti e 80nm de Ta.

Figura 60- Esquema da litografia máscara 1 (região ativa) e possíveis resultados da corrosão realizada. Resultado 1 seria corroído apenas o silício da região ativo. Resultado 2 
seria corroído o silício e uma parte do óxido enterrado e resultado 3 teria corroído silício, óxido e deixaria o substrato exposto.

Figura 61 - Layout das doses nas máscaras 3 e 2 , nanoestruturas e microestruturas. ..............97

Figura 62- Imagem feita no MEV da lâmina beta.

Figura 63- Imagem do transistor A2 da lamina beta, evidenciando o pad de porta com ligação parcialmente rompida com a via de metal de porta.

Figura 64- Marcas de alinhamento de Titânio e tântalo, (a) marca lateral (b) marcas manuais.

Figura 65- Definição da mesa de silício do transistor com $\mathrm{W}=0,1 \mu \mathrm{m}$ e $\mathrm{L}=0,5 \mu \mathrm{m}$.

Figura 66- Imagens realizadas no FIB da mesa de silício formada do transistor de $\mathrm{W}=0,1 \mu \mathrm{m}$.

(a) Imagem geral do transistor com a mesa de silício para os pads de fonte e dreno,

(b) Imagem com campo de $5 \mu \mathrm{m}$ de magnitude é possível observar o nano fio de silício porém coberto por uma camada de eletroresiste, (c) Imagem do nanofio com magnitude de $1 \mu \mathrm{m}$

Figura 67- Imagem MEV dos transistores da lâmina gama. Os pads estão bem deteriorados.

Figura 68- Imagem da lâmina gama após o lift-off de alumínio. 104

Figura 69- Medição do comprimento de canal $\mathrm{L}=2,11 \mu \mathrm{m}$ no transistor $\mathrm{A} 1 \mathrm{~L}=1,5 \mu \mathrm{m}$ e $\mathrm{W}=0,1 \mu \mathrm{m}$. 105

Figura 70- Imagens tiradas pelo microscópio ótico visualizando a mesa de silício formada $\operatorname{com} \mathrm{L}=1.0 \mu \mathrm{m}$ e $\mathrm{W}=0.5 \mu \mathrm{m}$. 106

Figura 71- Imagens tiradas pelo microscópio ótico visualizando a mesa de silício formada com $\mathrm{L}=0,6 \mu \mathrm{m}$ e $\mathrm{W}=0.1 \mu \mathrm{m}$.

Figura 72- Imagem da mesa de silício formada porém com o nano fio rompido, este transistor apresentaria $\mathrm{L}=0.6 \mu \mathrm{m}$ e $\mathrm{W}=0.1 \mu \mathrm{m}$.

Figura 73- Curva da corrente de dreno, fonte e substrato em função da tensão aplicada na porta. 108

Figura 74- Curva experimental da lâmina alpha transistor $\mathrm{A} 1$, da corrente de dreno, fonte, substrato e porta, em função da tensão aplicada na porta.

Figura 75- Curva C-V dos capacitores testes, com oxidações com tempo de 10min, 15min e $20 \mathrm{~min}$.

Figura 76- Curva da corrente de dreno, fonte, substrato e porta em função da tensão da porta, com $\mathrm{V}_{\mathrm{DS}}=100 \mathrm{mV}$ e $\mathrm{V}_{\mathrm{GB}}=3 \mathrm{~V}$. 
Figura 77- Curva da corrente de dreno, fonte, substrato e porta em função da tensão da porta, com $\mathrm{V}_{\mathrm{DS}}=100 \mathrm{mV}$ e $\mathrm{V}_{\mathrm{GB}}=3 \mathrm{~V}$, do transistor $\mathrm{B} 1$

Figura 79- Curva da corrente de dreno, fonte, substrato e porta em função da tensão da porta, com $\mathrm{V}_{\mathrm{DS}}=100 \mathrm{mV}$ e $\mathrm{V}_{\mathrm{GB}}=3 \mathrm{~V}$ do transistor $\mathrm{B} 8$.

Figura 80- Curva da corrente de dreno em função de $\mathrm{V}_{\mathrm{GF}}$ do transistor B5.

Figura 82- Curva C-V do transistor E1 e F2, extraída pelo pad de porta ( $80 \mu \mathrm{m}$ x $80 \mu \mathrm{m}) . .113$

Figura 83- Curva da corrente de dreno em função da tensão de substrato $\mathrm{V}_{\mathrm{DS}}=0,5$ e $1 \mathrm{~V}$ e 1,5V.

Figura 84- Curvas $\mathrm{I}_{\mathrm{DS}}$ em função de $\mathrm{V}_{\mathrm{DS}}$ para $\mathrm{V}_{\mathrm{GB}}=1 \mathrm{~V}, 1,5 \mathrm{~V}$ e $2 \mathrm{~V}$, transistor $\mathrm{F} 2(\mathrm{~N}=640$ ) com $\mathrm{W}=0,1 \mu \mathrm{m}$ e $\mathrm{L}=0,1 \mu \mathrm{m}$.

Figura 85- Curva $\mathrm{I}_{\mathrm{DS}}$ em função de $\mathrm{V}_{\mathrm{GB}}$ do transistor $\mathrm{G} 6$ com $\mathrm{W}=0,1 \mu \mathrm{m}, \mathrm{L}=0,1 \mu \mathrm{m}$ e $\mathrm{N}=120$.

Figura 86- Curva $\mathrm{I}_{\mathrm{DS}}$ em função de $\mathrm{V}_{\mathrm{DS}}$ do transistor $\mathrm{G} 6$ com $\mathrm{W}=0,1 \mu \mathrm{m}, \mathrm{L}=0,1 \mu \mathrm{m}$ e $\mathrm{N}=120$, para $\mathrm{V}_{\mathrm{GB}}=0,5 \mathrm{~V} 1,0 \mathrm{~V}$ e $1,5 \mathrm{~V}$.

Figura 87- Curva $\mathrm{I}_{\mathrm{DS}}$ vem função de $\mathrm{V}_{\mathrm{GB}}$ do transistor $\mathrm{E} 1$ com $\mathrm{W}=0,1 \mu \mathrm{m}, \mathrm{L}=0,1 \mu \mathrm{m}$ e $\mathrm{N}=1280$

Figura 88- Curva $\mathrm{I}_{\mathrm{DS}}$ em função de $\mathrm{V}_{\mathrm{DS}}$ do transistor $\mathrm{E} 1$ com $\mathrm{W}=0,1 \mu \mathrm{m}, \mathrm{L}=0,1 \mu \mathrm{m}$ e $\mathrm{N}=1280$, para $\mathrm{V}_{\mathrm{GB}}=0,5 \mathrm{~V}, 1,0 \mathrm{~V}, 1,5 \mathrm{~V}$ e $2,0 \mathrm{~V}$

Figura 89- Curvas $\mathrm{I}_{\mathrm{DS}} \mathrm{x} \mathrm{V}_{\mathrm{GB}}$ comparando transistores com $\mathrm{W}=0,1 \mu \mathrm{m}$ e $\mathrm{W}=0,5 \mu \mathrm{m}$. 118

Figura 90- Curva da corrente de dreno em função da tensão aplicada ao substrato com $\mathrm{V}_{\mathrm{GF}}=-$ $0,5 \mathrm{~V}, 0 \mathrm{~V}$ e $+0,5 \mathrm{~V}$, em escala linear e logarítmica.

Figura 91- Curvas experimentais $I_{D} \times V_{D}$ realizadas no transistor com $W=0,1 \mu \mathrm{m}$ e $L=0,5 \mu \mathrm{m}$, para as três lâminas fabricadas neste projeto. 


\section{LISTA DE TABELAS}

Tabela 1- Sequência necessária para oxidação 67

Tabela 2 - Parâmetros (tempo e temperatura) da Oxidação de Porta. 68

Tabela 3- Descrição dos transistores e seus respectivos valores de N, W e L. 78

Tabela 4 Sequência para realizar a litografia da máscara 0 , desde aplicação do resiste até a cura em estufa.

Tabela 5- Sequência para realizar a litografia da máscara 1, desde aplicação do resiste até a cura em estufa.

Tabela 6- Sequência utilizada para oxidação realizada no forno para a lâmina Alpha. 83

Tabela 7- Sequência para realizar a litografia 3, desde aplicação do resiste até a limpeza no plasma ashing. 84

Tabela 8- Sequência de etapas para a realização da litografia dos pads de fonte, dreno e porta. 86

Tabela 9- Descrição da sequencia de fabricação da lâmina beta..............................................92

Tabela 10- Teste de corrosão ICP-Rie e ECR .................................................................. 95

Tabela 11- Sequência para oxidação da lâmina beta.................................................................. 95

Tabela 12- Resultado da oxidação realizada no forno convencional com $\mathrm{O}_{2}$ pureza 4.0 e 6.0. 96

Tabela 13- Sequência de fabricação da lâmina gama. 100

Tabela 14- Tempo de oxidação e óxido de porta extraído. 110

Tabela 15- Parâmetros elétricos dos transistores F2, G6 e E1. 


\section{LISTA DE SÍMBOLOS}

$\mathrm{C}_{\mathrm{D}} \quad$ Capacitância da região de depleção por unidade de área $\left[\mathrm{F} / \mathrm{cm}^{2}\right]$.

$\mathrm{C}_{\text {ox }} \quad$ Capacitância de óxido de porta do transistor MOS convencional por unidade de área $\left[\mathrm{F} / \mathrm{cm}^{2}\right]$.

$\mathrm{C}_{\mathrm{oxb}} \quad$ Capacitância de óxido enterrado por unidade de área $\left[\mathrm{F} / \mathrm{cm}^{2}\right]$.

$\mathrm{C}_{\mathrm{oxf}} \quad$ Capacitância de óxido de porta do transistor SOI por unidade de área $\left[\mathrm{F} / \mathrm{cm}^{2}\right]$.

$\mathrm{C}_{\mathrm{Si}} \quad$ Capacitância da camada de silício por unidade de área $\left[\mathrm{F} / \mathrm{cm}^{2}\right]$.

$\mathrm{E}_{\mathrm{C}} \quad$ Nível de energia inferior da faixa de condução $[\mathrm{eV}]$.

$\mathrm{E}_{\text {eff }} \quad$ Campo elétrico efetivo na primeira interface $[\mathrm{V} / \mathrm{cm}]$.

$\mathrm{E}_{\mathrm{F}} \quad$ Nível de Fermi do semicondutor [eV].

$\mathrm{E}_{\mathrm{i}} \quad$ Nível de Fermi intrínseco [eV].

$\mathrm{E}_{\mathrm{FM}} \quad$ Nível de Fermi do metal $[\mathrm{eV}]$.

$\mathrm{E}_{\mathrm{SF}} \quad$ Campo elétrico na primeira superfície [V/cm].

$\mathrm{E}_{\mathrm{V}} \quad$ Nível de energia superior da faixa de valência $[\mathrm{eV}]$.

$\mathrm{f}_{\mathrm{T}} \quad$ Frequência de ganho unitário $[\mathrm{Hz}]$.

gm Transcondutância de saída do transistor [S].

h Constante de Planck $\left[6,626 \times 10^{-34} \mathrm{~J} . \mathrm{s}\right]$.

$\mathrm{H}_{\text {fin }} \quad$ Altura do fin [nm]

I acc Corrente que flui pela camada de acumulação [A].

$\mathrm{I}_{\mathrm{b}} \quad$ Corrente de corpo em um dispositivo SOI modo acumulação [A].

IDS $\quad$ Corrente de dreno e fonte $[\mathrm{A}]$.

I $\quad$ Corrente de dreno em saturação [A].

I $\quad$ Corrente de lacunas geradas pela ionização por impacto [A].

$\mathrm{I}_{\mathrm{b}} \quad$ Corrente que conduz pelo corpo do dispositivo modo acumulação [A].

$\mathrm{I}_{\mathrm{acc}} \quad$ Corrente formada na superfície do silício do dispositivo modo acumulação [A].

$\mathrm{k} \quad$ Constante de Boltzmann $\left[1.38066 \times 10^{-23} \mathrm{~J} / \mathrm{K}\right]$.

L Comprimento de canal do transistor $[\mu \mathrm{m}]$.

m Fator de correção da equação da mobilidade de baixo campo elétrico.

$\mathrm{m}_{\mathrm{e}} \quad$ Massa efetiva do elétron.

M Fator de multiplicação devido ao elevado campo elétrico.

$\mathrm{N}_{\mathrm{A}} \quad$ Concentração de portadores aceitadores da camada de silício $\left[\mathrm{cm}^{-3}\right]$.

$\mathrm{N}_{\mathrm{D}} \quad$ Concentração de portadores doadores da camada de silício [ $\left.\mathrm{cm}^{-3}\right]$. 
$\mathrm{N}_{\mathrm{it}} \quad$ Densidade de Armadilhas de interface por unidade de área $\left[\mathrm{F} / \mathrm{cm}^{2}\right]$.

$\mathrm{N} \quad$ Fator de corpo (body factor).

$\mathrm{N}_{\mathrm{af}} \quad$ Concentração de portadores aceitadores no canal $\left[\mathrm{cm}^{-3}\right]$.

$\mathrm{n}_{\mathrm{i}} \quad$ Concentração intrínseca de portadores $\left[\mathrm{cm}^{-3}\right]$.

q Carga elementar do elétron $\left[1,6 \times 10^{-19} \mathrm{C}\right]$.

$\mathrm{Q}_{\mathrm{d} 1} \quad$ Carga de depleção controlada pela porta $\left[\mathrm{C} / \mathrm{cm}^{2}\right]$

$Q_{\text {depl }} \quad$ Carga de depleção na camada de silício $\left[\mathrm{C} / \mathrm{cm}^{2}\right]$.

Q depl,ef Fração da carga de depleção na camada de silício $\left[\mathrm{C} / \mathrm{cm}^{2}\right]$.

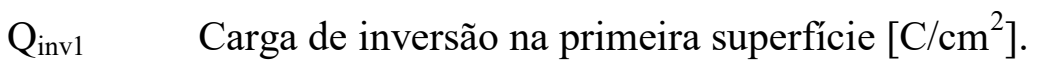

Qox Densidade de carga fina no óxido de porta $\left[\mathrm{C} / \mathrm{cm}^{2}\right]$.

Qoxb Carga efetiva do óxido enterrado por unidade de área $\left[\mathrm{C} / \mathrm{cm}^{2}\right]$.

Qoxf Carga efetiva do óxido de porta por unidade de área $\left[\mathrm{C} / \mathrm{cm}^{2}\right]$.

Q Carga no silício na segunda interface $\left[\mathrm{C} / \mathrm{cm}^{2}\right]$.

rj Profundidade de junção de fonte e dreno [nm]

Rs Resistência de folha [ $\Omega /$ quadrado].

$\mathrm{S} \quad$ Inclinação de Sublimiar on fator S [mV/década].

t Espessura do substrato $[\mu \mathrm{m}]$

T Temperatura absoluta $[\mathrm{K}]$.

$\mathrm{t}_{\mathrm{oxb}} \quad$ Espessura do óxido enterrado $[\mu \mathrm{m}]$.

$t_{\text {oxf }} \quad$ Espessura do óxido de porta $[\mu \mathrm{m}]$.

$\mathrm{t}_{\mathrm{Si}} \quad$ Espessura do camada de silício $[\mu \mathrm{m}]$.

$\mathrm{V}_{\mathrm{DS}} \quad$ Tensão entre dreno e fonte [V].

$\mathrm{V}_{\mathrm{FB}} \quad$ Tensão de Faixa Plana da estrutura MOS [V].

$\mathrm{V}_{\mathrm{GB}} \quad$ Tensão de substrato do transistor SOI convencional e GC SOI [V].

$\mathrm{V}_{\mathrm{GB} \text {,acc2 }}$ Tensão aplicada ao substrato para que a superfície do silício na segunda interface acumule[V].

$\mathrm{V}_{\mathrm{GF}} \quad$ Tensão entre porta e fonte do transistor SOI [V].

$\mathrm{V}_{\mathrm{GS}} \quad$ Tensão entre porta e fonte do transistor MOSFET [V].

$\mathrm{V}_{\mathrm{GT}} \quad$ Sobretensão de limiar [V].

$\mathrm{V}_{\mathrm{ox}} \quad$ Tensão no óxido de porta obtida em um capacitor [V].

$\mathrm{V}_{\text {th }} \quad$ Tensão limiar [V].

$\mathrm{V}_{\mathrm{T}} \quad$ Tensão limiar [V].

$\mathrm{V}_{\text {th,acc2 }}$ Tensão limiar com a $2^{\mathrm{a}}$ interface em acumulação [V]. 
$\mathrm{V}_{\text {th,depl2 }}$ Tensão limiar com a $2^{\mathrm{a}}$ interface em depleção [V].

$\mathrm{V}_{\text {th,inv2 }}$ Tensão limiar com a $2^{\mathrm{a}}$ interface invertida [V].

W Largura do canal do transistor [nm].

$\mathrm{W}_{\text {fin }} \quad$ Largura do fin $[\mathrm{nm}]$.

$\mathrm{W}_{\mathrm{ef}} \quad$ Largura efetiva da porta tripla [nm].

$\mathrm{X}_{\mathrm{dmáx}} \quad$ Profundidade de depleção máxima $[\mu \mathrm{m}]$.

$\alpha \quad$ Acoplamento capacitivo entre canal, a porta e o substrato.

$\alpha_{\mathrm{a}} \quad$ Parâmetro utilizado no cálculo da mobilidade limitada pelo espalhamento por impurezas ionizadas

$\alpha_{\mathrm{Eg}} \quad$ Parâmetro utilizado no cálculo da largura de faixa proibida [eV/K]

$\alpha_{\mathrm{S}} \quad$ Coeficiente de espalhamento [cm/V]

$\beta \quad$ Parâmetro utilizado no cálculo da mobilidade limitada pelo espalhamento de rede

$\beta_{\text {Eg }} \quad$ Parâmetro utilizado no cálculo da largura de faixa proibida [K]

$\beta_{\mathrm{E} 0} \quad$ Parâmetro utilizado no cálculo da variação do mínimo nível energético da banda de condução devido à quantização dos estados.

$\varepsilon_{\mathrm{ox}} \quad$ Permissividade do óxido de silício $\left[3,45 \cdot 10^{-13} \mathrm{~F} / \mathrm{cm}\right]$.

$\varepsilon_{\mathrm{Si}} \quad$ Permissividade do silício $\left[1,6.10^{-12} \mathrm{~F} / \mathrm{cm}\right]$.

$\rho \quad$ Resistividade [ $\Omega . \mathrm{cm}]$.

$\Phi_{\mathrm{F}} \quad$ Potencial de Fermi [V].

$\Phi_{\mathrm{M}} \quad$ Função trabalho do Metal [V].

$\Phi_{\mathrm{MS}} \quad$ Diferença de função trabalho entre o metal de porta e semicondutor no transistor MOS [V].

$\Phi_{\mathrm{MSB}} \quad$ Diferença de função trabalho entre o substrato e a camada de silício [V].

$\Phi_{\mathrm{MSF}} \quad$ Diferença de função trabalho entre o metal de porta e a camada de silício [V].

$\Phi_{\mathrm{Si}} \quad$ Função trabalho do silício [V].

$\Phi_{\mathrm{SB}} \quad$ Potencial de superfície na segunda interface [V].

$\Phi_{\mathrm{SF}} \quad$ Potencial de superfície na primeira interface [V].

$\mu_{0} \quad$ Mobilidade dos portadores independente do campo elétrico $\left[\mathrm{cm}^{2} / \mathrm{V} . \mathrm{s}\right]$.

$\mu_{\mathrm{CC}} \quad$ Mobilidade dos portadores lacunas devido ao espalhamento portador-portador $\left[\mathrm{cm}^{2} / \mathrm{V} . \mathrm{s}\right]$.

$\mu_{\mathrm{ii}} \quad$ Mobilidade dos portadores devido ao espalhamento por impurezas ionizadas $\left[\mathrm{cm}^{2} / \mathrm{V} . \mathrm{s}\right]$.

$\mu_{\mathrm{n}} \quad$ Mobilidade efetiva de elétrons na região do canal $\left[\mathrm{cm}^{2} / \mathrm{V} . \mathrm{s}\right]$. 
$\mu_{\mathrm{ni}} \quad$ Mobilidade dos portadores devido ao espalhamento por impurezas neutras $\left[\mathrm{cm}^{2} / \mathrm{V} . \mathrm{s}\right]$.

$\mu_{\mathrm{pe}} \quad$ Mobilidade dos elétrons devido ao espalhamento por rede $\left[\mathrm{cm}^{2} / \mathrm{V} . \mathrm{s}\right]$.

$\mu_{\mathrm{ph}} \quad$ Mobilidade das lacunas devido ao espalhamento por rede [ $\left.\mathrm{cm}^{2} / \mathrm{V} . \mathrm{s}\right]$.

$\mu_{\mathrm{ps}} \quad$ Mobilidade dos portadores devido ao espalhamento por rede $\left[\mathrm{cm}^{2} / \mathrm{V} . \mathrm{s}\right]$.

$\mu_{\mathrm{psii}} \quad$ Mobilidade dos portadores devido aos espalhamentos por rede e por impurezas ionizadas $\left[\mathrm{cm}^{2} / \mathrm{V} . \mathrm{s}\right]$.

$\mu_{\mathrm{psiih}} \quad$ Mobilidade das lacunas devido aos espalhamentos por rede e por impurezas ionizadas $\left[\mathrm{cm}^{2} / \mathrm{V} . \mathrm{s}\right]$.

$\mu_{\mathrm{psiie}} \quad$ Mobilidade dos elétrons devido aos espalhamentos por rede e por impurezas ionizadas $\left[\mathrm{cm}^{2} / \mathrm{V} . \mathrm{s}\right]$. 


\section{LISTA ABREVIATURAS}

BHF Buffer HF

CCS Centro de Componentes Semicondutores

CI Circuito integrado

CMOS Complementary Metal-Oxide-Semiconductor

CVD Chemical Vapor Deposition

CYNTHIA Cylindrical Thin-Pillar Transistor

DELTA Fully Depleted Lean-Channel Transistor

DI água deionizada

DUV Deep Ultra Violeta

EBL Electron Beam Lithography

ECR Electron Cyclotron Ressonance

EUV Extrema Ultra Violeta

FinFET Fin-type Field Effect Transistor

FD Fully Depleted

FIB Focused Electron Beam

GAA Gate-All-Around

GaFIB Focused Ion Beam with Ga+ions

HD Highly Doped

HMDS Hexamethyldisilazane

ICP Inductively Coupled Plasma

IPA Isopropanol Alcool Isopropílico

JNT Junction Nanowire Transistors

LPLV Low power Low voltage

MIF Metal Ion Free

MIBK Metil Isobutil Cetona

MOSFET Metal-Oxide-Semiconductor Field-Effect Transistor

NW Nanowire

NFD Near-fully Depleted

PD Partially Depleted

PMMA Poly Methyl Metharylate

RCA Radio Corporation of America 
RIE Reactive Ion Etching

RTA Rapid Thermal Annealing

STLU Single-Transistor Latchup

SOI Silicon-on-Insulator

TCE Tricloroetileno $\mathrm{C}_{2} \mathrm{HCl}_{3}$

ULSI Ultra Large Scale Integration

UTBB Ultra Thin and Buried Oxide

UV Luz Ultravioleta

WF Write Field Campo de escrita 


\section{SUMÁRIO}

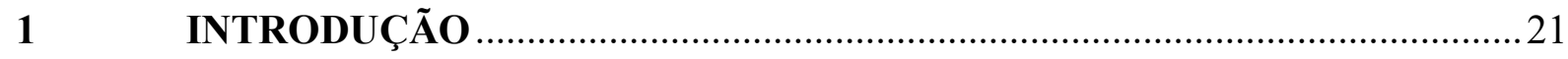

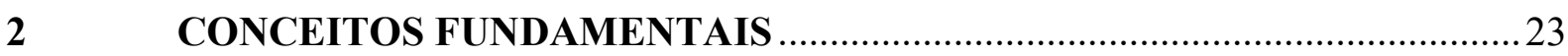

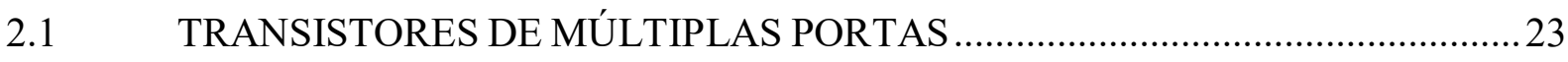

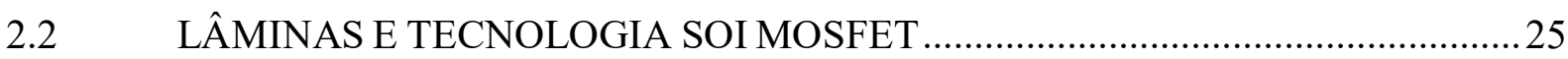

2.2.1 Modos de funcionamento dos SOI MOSFETs ..................................................27

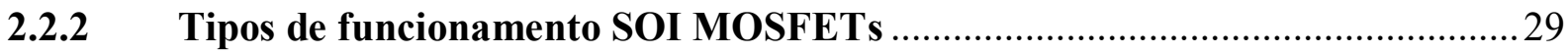

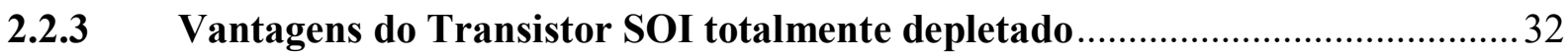

2.2.4 Principais Características Elétricas dos transistores SOI ................................33

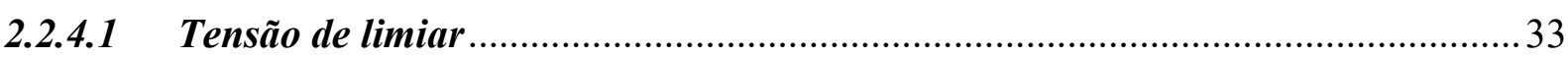

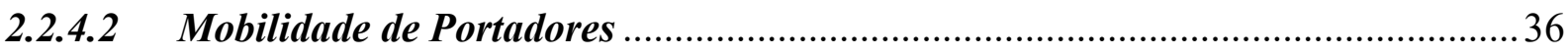

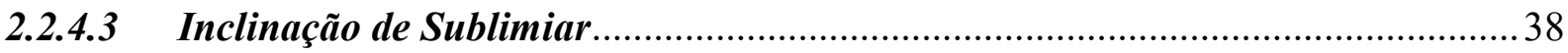

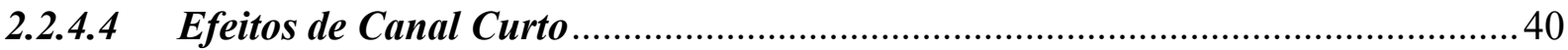

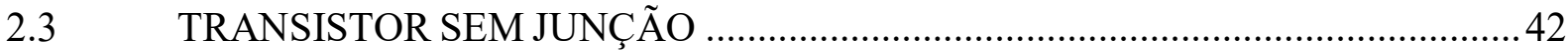

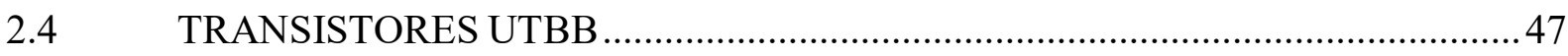

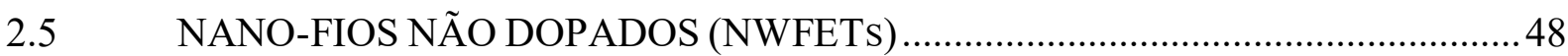

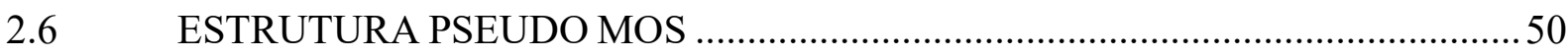

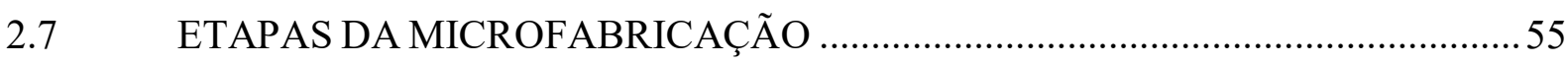

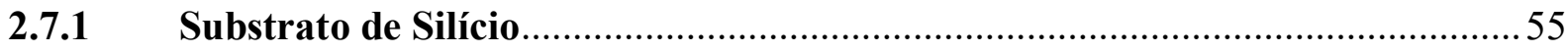

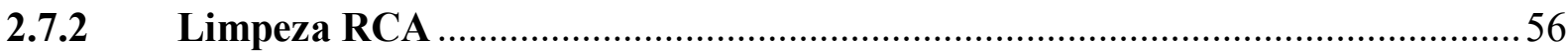

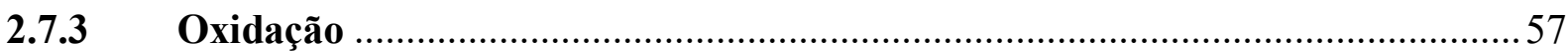

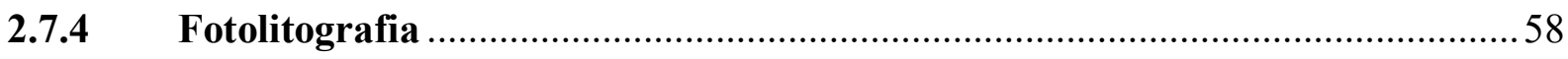

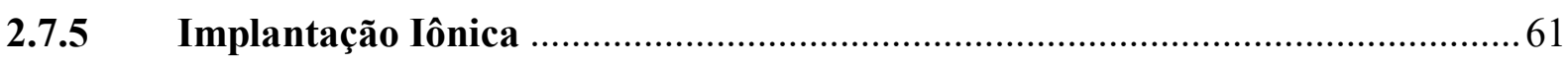

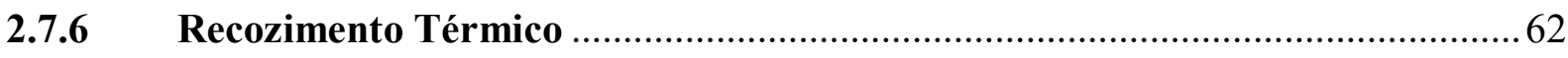

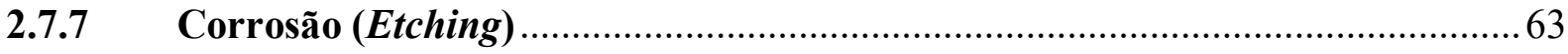

3 PROJETO DO PROCESSO DE FABRICAÇÃO ........................................... 65

3.1 SIMULAÇÃO DO PROCESSO DE FABRICAÇÃO JUNCTINOLESS ..................65

3.2 SIMULAÇÃO DO PROCESSO DE FABRICAÇÃO NWFETS ................................69

3.3 SIMULAÇÃO DAS CARACTERÍSTICAS ELÉTRICAS …................................70

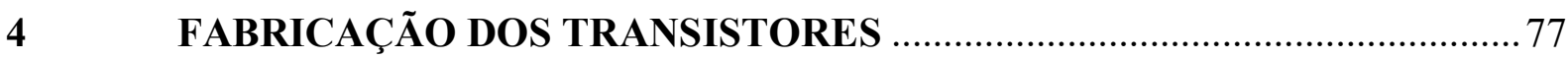

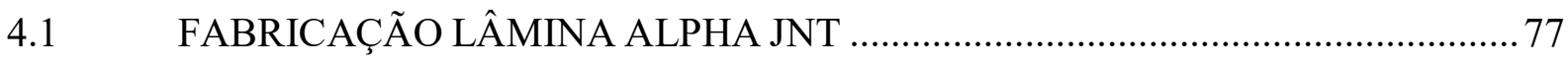

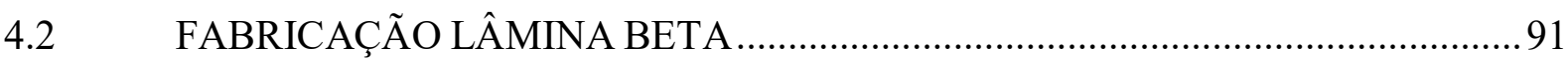

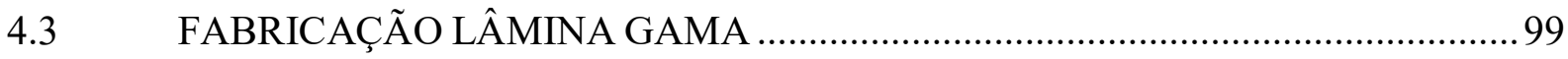




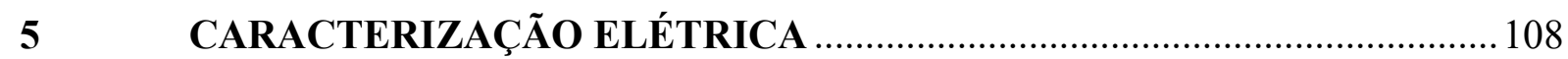

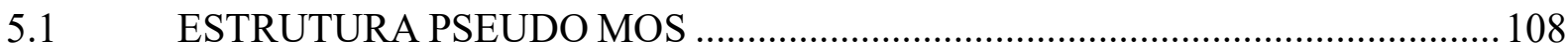

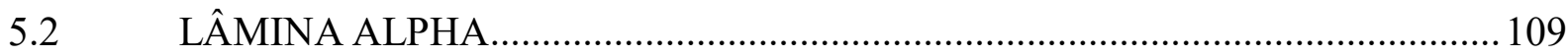

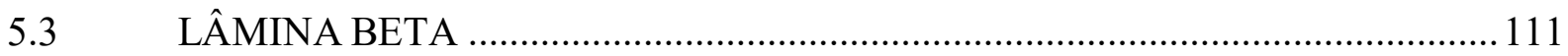

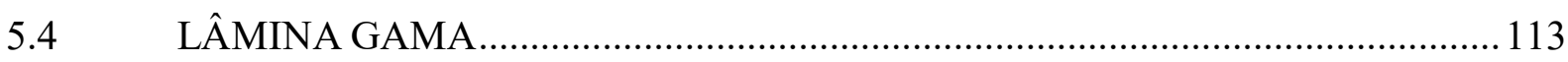

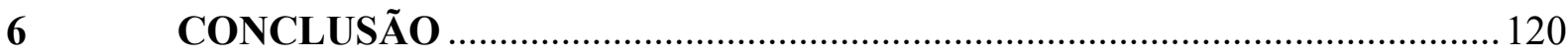

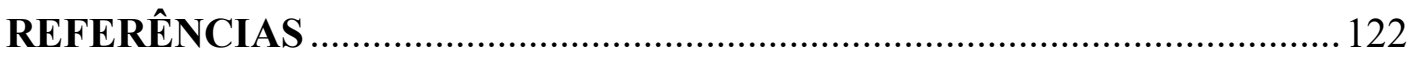

ANEXO A- CÓDIGO SIMULAÇÃO 2D JNT MOSFET …............................. 127

ANEXO B- CÓDIGO SIMULAÇÃO 2D - NWFET MOSFET …..................... 131 


\section{INTRODUÇÃO}

A necessidade de miniaturização dos transistores tipo Metal-Óxido-Semicondutor (MOS) para desenvolvimento de circuitos integrados de altíssima escala de integração ULSI (Ultra large Scale Integration) tem apresentado certos limites [1], que estão relacionados com problemas como os efeitos de canal curto (a diminuição da tensão de limiar com a redução do comprimento do canal do transistor e o aumento da inclinação de sublimiar, degradando a velocidade de chaveamento e aumentando a corrente de fuga) [2].

Com o intuito de proporcionar um melhor resultado, foi desenvolvida a tecnologia silício sobre isolante SOI (Silicon-On-Insulator), que apresenta grande capacidade de integração [3] e diversas vantagens sobre a MOS convencional, como o aumento da mobilidade de portadores [4], da transcondutância, além da diminuição das capacitâncias parasitárias entre fonte e dreno, dos efeitos de canal curto e da inclinação de sublimiar.

Como desvantagem desta tecnologia, seu óxido enterrado funciona como um isolante térmico, prejudicando a dissipação de calor gerado pela condução da corrente elétrica, degradando a mobilidade de portadores, o que ocasiona alterações nas características elétricas dos dispositivos [4]. Outra grande deficiência do SOI convencional, é que ele apresenta intrinsicamente um transistor bipolar parasitário, onde a base (canal do Transistor MOS) fica eletricamente flutuando, resultando na redução da tensão de ruptura [5] [6].

Com objetivo de aumentar o controle eletrostático e consequentemente o nível de corrente dos dispositivos, além de reduzir os efeitos de canal curto, foram propostos os dispositivos de múltiplas portas. Os transistores de múltiplas portas têm apresentado um processo de fabricação complexo, para estruturas com comprimento de canal extremamente reduzidas ( da ordem de nanômetros), isto devido à necessidade de condições rigorosas para ativação dos dopantes das regiões de fonte e dreno, de forma a se evitar a difusão lateral destes dopantes para o canal [7].

Outro dispositivo muito estudado na atualidade e que tem sido uma solução para miniaturização dos dispositivos é o transistor MOS sem junção (Junctionless). Ele apresenta um perfil constante de dopantes no canal do transistor, e foi proposto com objetivo de simplificar o processo de fabricação. O Transistor sem junção possui altas concentrações de dopantes, a fim de se obter uma corrente de corpo considerável. A espessura da camada de silício na qual o dispositivo é fabricado deve ser da ordem de poucas dezenas de nanômetros para que o mesmo funcione adequadamente, permitindo a depleção completa da camada de 
silício na condição de sublimiar [7] e consequente a interrupção na passagem de corrente elétrica.

Apesar de estes dispositivos apresentarem inúmeras vantagens e estarem sendo fabricados em dimensões nanométricas em indústrias e universidades mundiais, no Brasil não há instituições que os fabriquem em espessuras nanométricas. Este trabalho tem como objetivo desenvolver uma tecnologia de fabricação de transistores sem junções em substratos do tipo silício sobre isolante, com lâminas SOI de espessura do óxido enterrado de $20 \mathrm{~nm}$ e espessura da camada de silício inicial de $14 \mathrm{~nm}$.

O projeto do processo foi feito por meio de simulações numéricas tridimensionais e um novo conjunto de fotomáscaras foi desenvolvido. Em seguida, o processo de fabricação projetado foi realizado no Centro de Componentes Semicondutores da Unicamp e os dispositivos fabricados foram caracterizados eletricamente no Centro Universitário FEI.

No capítulo 2, são apresentados conceitos básicos necessários para fundamentar este trabalho. Uma breve introdução ao dispositivo SOI MOSFET é realizada, bem como as suas principais características físicas e elétricas. Também são introduzidos conceitos fundamentais dos transistores sem junção, detalhes do seu funcionamento e características elétricas. Outro ponto a ser levantado são as etapas principais de fabricação dos transistores, nesta seção também serão expostas características e conceitos de etapas de processos como: limpezas, implantação iônica, recozimento térmico entre outros.

No capítulo 3, são detalhadas as etapas de fabricação dos transistores SOI e Junctinoless realizadas no simulador da Synopsys, Sentaurus Sprocess [8] e Athena da Silvaco [9]. Parâmetros de cada etapa do processo também foram propostos nesta seção, bem como todos os resultados tridimensionais simulados e bidimensionais.

Após a simulação dos dispositivos são apresentados no capítulo 4, resultados experimentais do processo de fabricação, como por exemplo, o conjunto de máscaras utilizado, as etapas de cada processo desenvolvidas do transistor sem junção.

No capítulo 5 é apresentada a caracterização elétrica dos transistores Junctionless e não dopados, com extração de parâmetros elétricos.

Por fim no capítulo 6, são apresentadas as conclusões obtidas ao longo do trabalho. 


\section{CONCEITOS FUNDAMENTAIS}

Neste capítulo será apresentada uma revisão bibliográfica sobre a tecnologia SOI, tipos de dispositivos SOI e suas características analógicas. Será apresentado também o transistor MOS sem junção JNT (Junctionless Transistor) demonstrando as suas características físicas e elétricas, as aplicações e as suas particularidades. Os conceitos das etapas principais de fabricação também são expostos nesta seção, a fim de auxiliar na conclusão deste trabalho.

\subsection{TRANSISTORES DE MÚLTIPLAS PORTAS}

Os dispositivos de múltiplas portas foram propostos com o objetivo de minimizar os efeitos de canal curto, proporcionando o maior escalamento dos transistores [10]. Estes transistores apresentam aumento do controle eletrostático das cargas na região de canal, reduzindo a influência do campo elétrico do dreno sobre o canal e, portanto, reduzindo tais efeitos. Alguns dispositivos múltiplas portas são apresentados na Figura 1, como por exemplo: XMOS [11], DELTA [12] (Fully Depleted Lean-Channel - Transistor de canal vertical totalmente depletado), FinFET [13] [14], Gate-All-Around (GAA - dispositivo de porta circundante) [15], porta tripla [10], $\pi$-gate [16], o $\Omega$-gate [17] e CYNTHIA [18] (Cylindrical Thin-Pillar Transistor - Transistor cilíndrico vertical).

Figura 1- Transistores de Múltiplas portas.

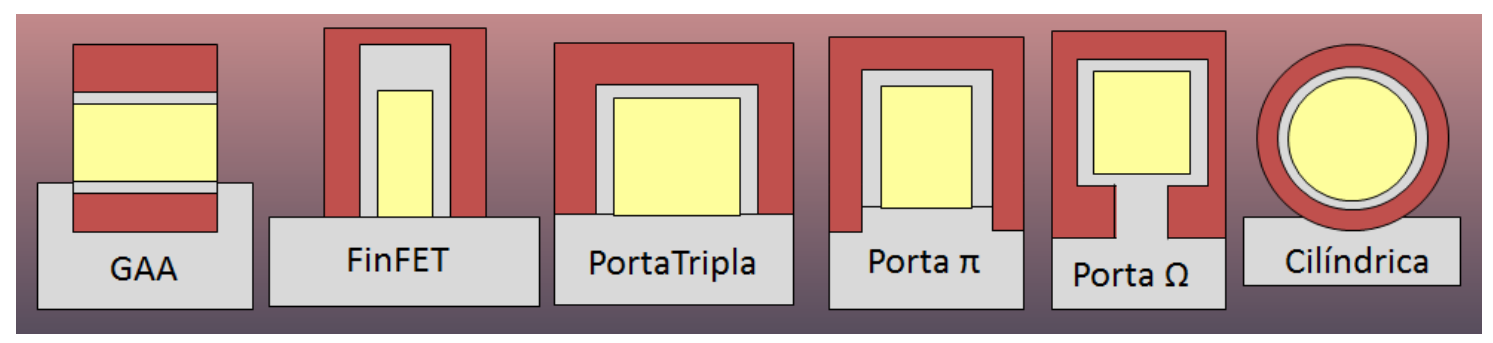

Fonte: Autor.

Na Figura 2 é apresentado o FinFET, um dispositivo de porta tripla, que é constituído de uma fina camada de silício envolta por óxido e material de porta sobre uma camada de óxido enterrado. Nesta figura as dimensões $\mathrm{H}_{\text {fin }}$ representa a altura do canal, $\mathrm{W}_{\mathrm{FIN}}$ largura do canal, $L$ comprimento do canal , $t_{o x f}$ espessura do óxido de porta e $t_{\text {oxb }}$ espessura do óxido enterrado. 
Figura 2- Transistor FinFET .

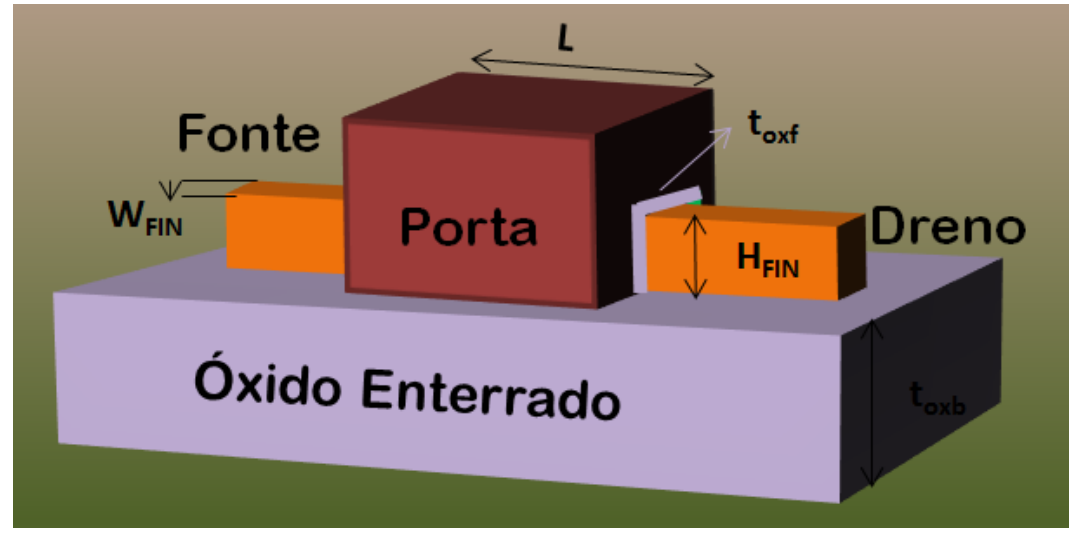

Fonte: Autor.

Legenda: Transistor FinFET demonstrando o comprimento de canal (L), a largura do silício $\left(\mathrm{W}_{\text {Fin }}\right)$, a altura do silício $\left(\mathrm{H}_{\mathrm{Fin}}\right)$, as espessuras do óxido de porta e do óxido enterrado.

Os dispositivos de múltiplas portas apresentam a corrente proporcional ao número de portas, portanto conduz maior quantidade de corrente por unidade de área de silício, quando comparados a um dispositivo planar, isto devido à formação de múltiplos canais de inversão. No entanto, como a mobilidade depende da orientação cristalográfica esta não é a mesma nos canais de inversão formados no topo e nas laterais [19]. Assim, tem-se que, usualmente, a superfície do topo da lâmina apresenta orientação $<100>$ enquanto as laterais apresentam orientação $<110>$, sendo que a mobilidade na primeira orientação é maior que na segunda, fazendo com que a corrente nas laterais seja menor que no topo para a mesma condição de polarização [20].

Para se aumentar a corrente de dreno $\left(\mathrm{I}_{\mathrm{DS}}\right)$ nos dispositivos de múltiplas portas, utilizase a estrutura multi-fins ou multi-dedos [10], onde um dispositivo é composto de diversos fins em paralelo, conforme apresentado pelo perfil transversal do dispositivo na Figura 3. Para que a estrutura multi-dedos seja vantajosa, a corrente nesta estrutura normalizada pelo período da mesma (distância entre dois nanofios consecutivos) deve ser maior que a corrente de um dispositivo planar de mesmas dimensões [10]. 
Figura 3- Estrutura multi-fins ou multi-dedos.

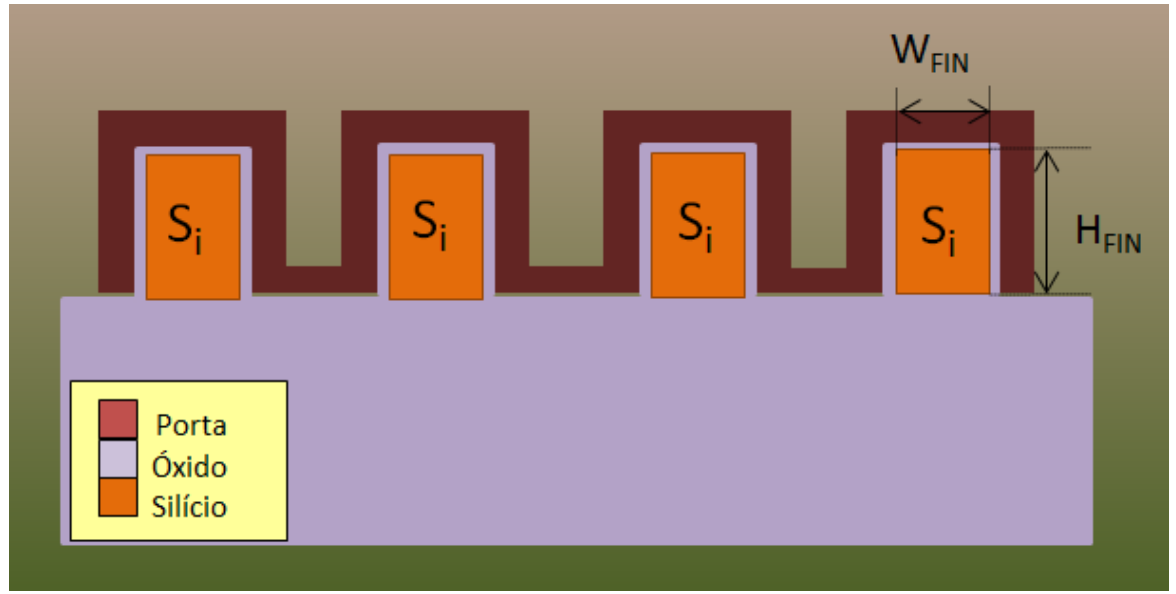

Fonte: Autor.

\subsection{LÂMINAS E TECNOLOGIA SOI MOSFET}

Como alternativa para a tecnologia CMOS convencional na fabricação de circuitos integrados em altíssima escala de integração surgiu a tecnologia silício sobre isolante (SOI Silicon-On-Insulator), que consiste na fabricação de circuitos integrados em uma camada de silício sobre uma camada de material isolante [4].

Esta lâmina utilizada para fabricação destes dispositivos pode ser fabricada através de diversas técnicas. A lâmina utilizada neste trabalho foi fabricada através da técnica denominada Smart Cut ou UNIBOND.

A Figura 4 apresenta o esquema detalhado do processo de fabricação da lâmina SOI pela técnica mencionada. Dois processos principais são utilizados nessa técnica, implantação iônica e união de lâminas. Neste processo são utilizadas duas lâminas SOI, na primeira é realizada a implantação iônica e também é realizada uma oxidação térmica. Na outra lâmina é realizada a oxidação e em seguida é colocada em contato uma com a outra, e depois a mesma é cortada com um jato de hidrogênio. O substrato de silício que resta deste corte é utilizado na fabricação de outra lâmina SOI. Esta técnica proporciona a uniformidade da camada de Si e o baixo custo para sua fabricação quando comparada com outras técnicas. 
Figura 4- Esquema de fabricação da lâmina SOI pela técnica Smart Cut.

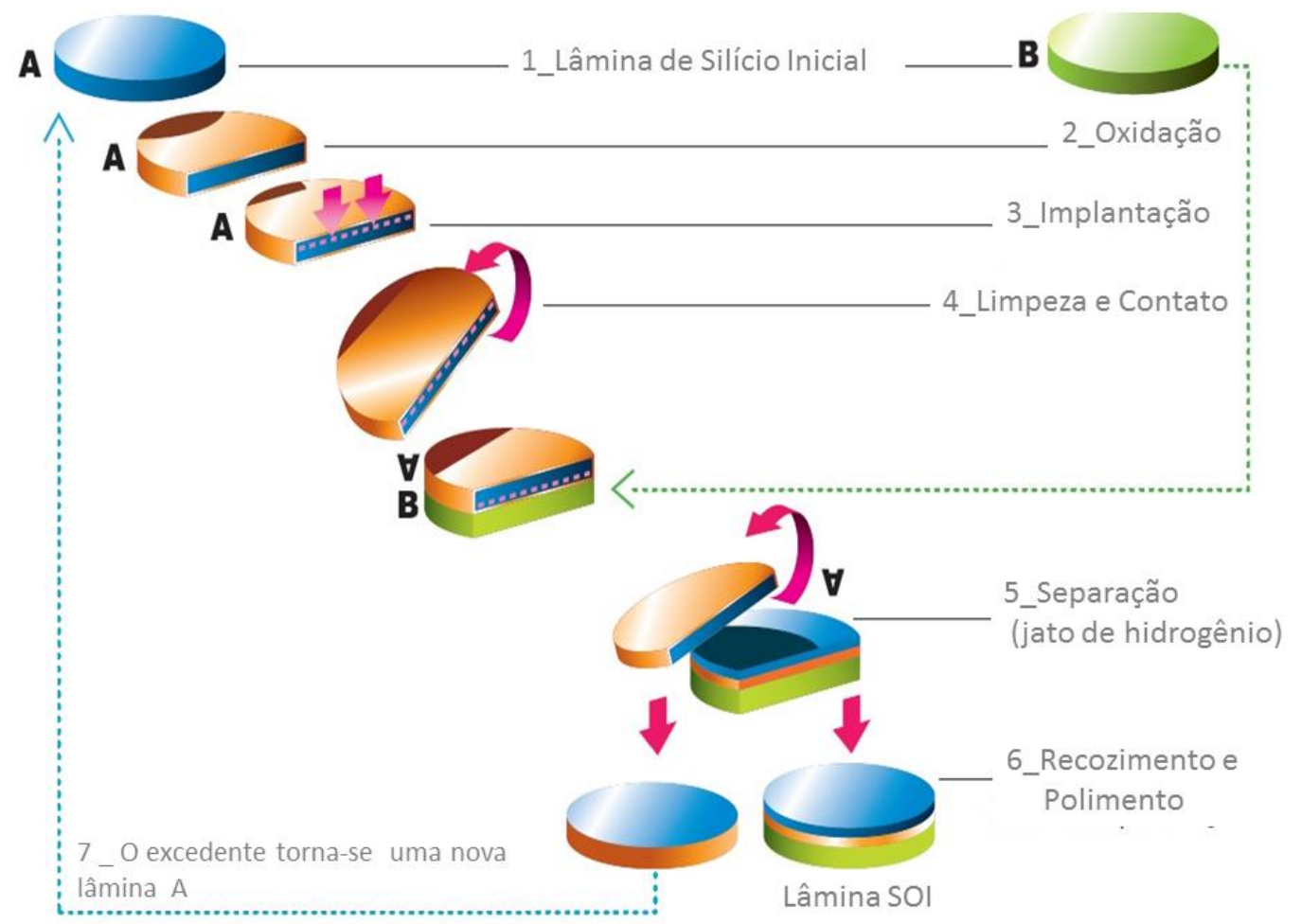

Fonte: Autor.

Este isolamento entre a região ativa dos dispositivos e o substrato, ocasionado pela camada isolante, como apresentado na figura 5 , tem como objetivo eliminar o efeito tiristor parasitário, além de reduzir as capacitâncias parasitárias, decorrentes da redução das dimensões da tecnologia MOS convencional [21].

Figura 5- Perfil transversal do transistor SOI nMOSFET.

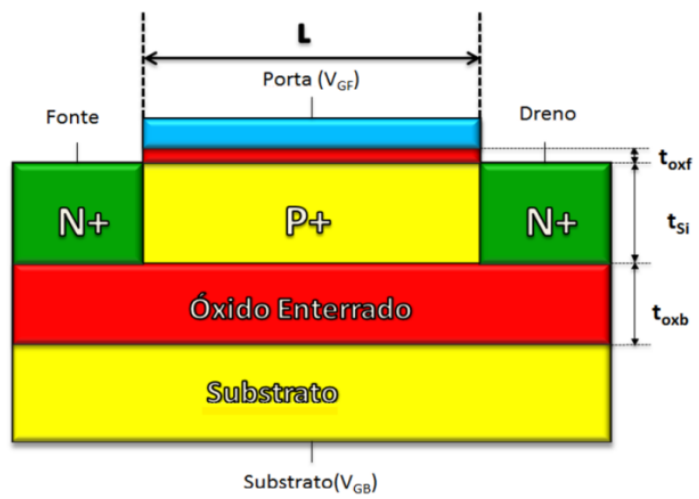

Fonte: Autor. 
Onde $\mathrm{t}_{\mathrm{oxf}}$ é espessura do óxido de porta, $\mathrm{t}_{\mathrm{Si}}$ espessura da camada de silício, $\mathrm{t}_{\mathrm{oxb}}$ espessura do óxido enterrado.

\subsubsection{Modos de funcionamento dos SOI MOSFETs}

De acordo com o modo de funcionamento, os dispositivos SOI MOSFET podem ser classificados em modo enriquecimento (ou inversão) ou modo acumulação. No caso dos transistores SOI de canal tipo N, o modo enriquecimento é o mais comum [4].

$\mathrm{O}$ transistor modo acumulação apresenta o mesmo tipo de dopantes no canal, porém fonte e dreno são mais dopadas, como pode ser visto na Figura 6.

Figura 6- Perfil longitudinal do dispositivo SOI pMOS modo acumulação.

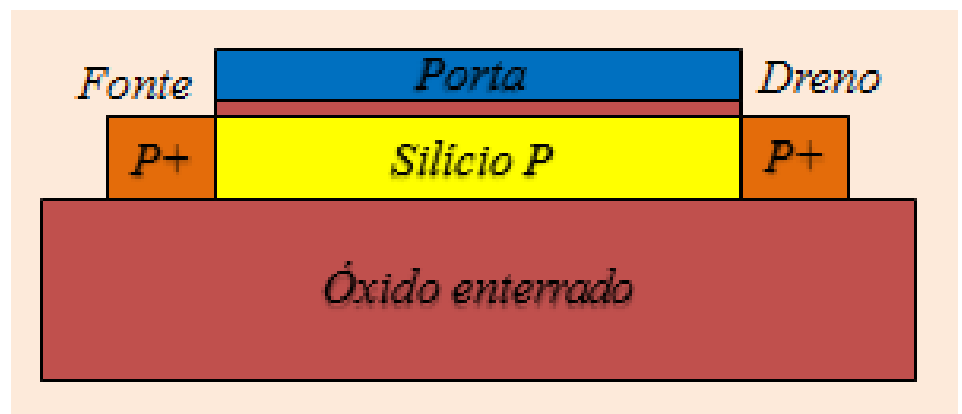

Fonte: Autor.

Quando não é aplicada nenhuma tensão na porta não há passagem de corrente entre fonte e dreno como apresentado na Figura 7, pois devido à diferença entre as funções trabalho do material de porta (usualmente silício policristalino $\mathrm{N}^{+}$) e do silício $\left(\Phi_{\mathrm{MS}}\right)$ e a presença de cargas positivas na interface do óxido de porta/silício fazem com que a camada de silício esteja totalmente depletada. 
Figura 7- Funcionamento dispositivo SOI modo acumulação região de sublimiar.

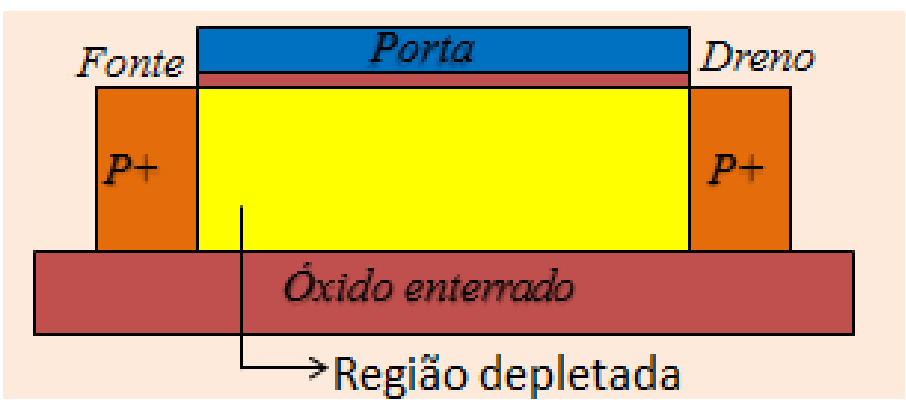

Fonte: Autor.

Quando o dispositivo está ligado, a camada de silício não está totalmente depletada e a condução ocorre tanto no corpo do dispositivo como na camada de acumulação da superfície. Portanto este dispositivo apresenta dois caminhos da condução apresentando mais de uma tensão de limiar $\left(\mathrm{V}_{\mathrm{T}}\right)$ [22] [23].

Se $V_{\mathrm{GS}}>\mathrm{V}_{\mathrm{T}}$, haverá uma redução na camada de depleção, permitindo a passagem de corrente pelo corpo. Caso $\mathrm{V}_{\mathrm{GS}}$ seja menor que a tensão de faixa plana $\left(\mathrm{V}_{\mathrm{FB}}\right)$, ela não será suficiente para induzir a formação de uma camada de acumulação na superfície. Neste caso, as condições possíveis são as apresentadas na Figura 8 onde, dependendo da tensão aplicada entre dreno e fonte $\left(\mathrm{V}_{\mathrm{DS}}\right)$, ocorrerá ou não o pinçamento do corpo.

Figura 8- Funcionamento dispositivo SOI modo acumulação com pinçamento do corpo, região de triodo.

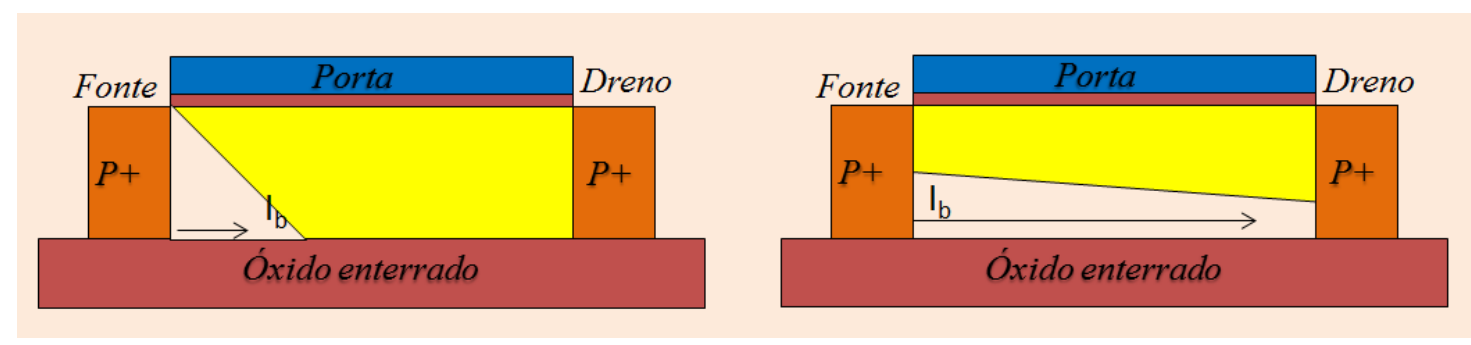

Fonte: Autor.

Ocorrerá a formação de uma camada de acumulação próxima a fonte que pode ou não se estender até o dreno se $\mathrm{V}_{\mathrm{GS}}>\mathrm{V}_{\mathrm{FB}}$. Neste caso, as condições possíveis de condução, dependendo de $\mathrm{V}_{\mathrm{DS}}$, são apresentadas na Figura 9. 
Figura 9- Funcionamento dispositivo SOI modo acumulação.
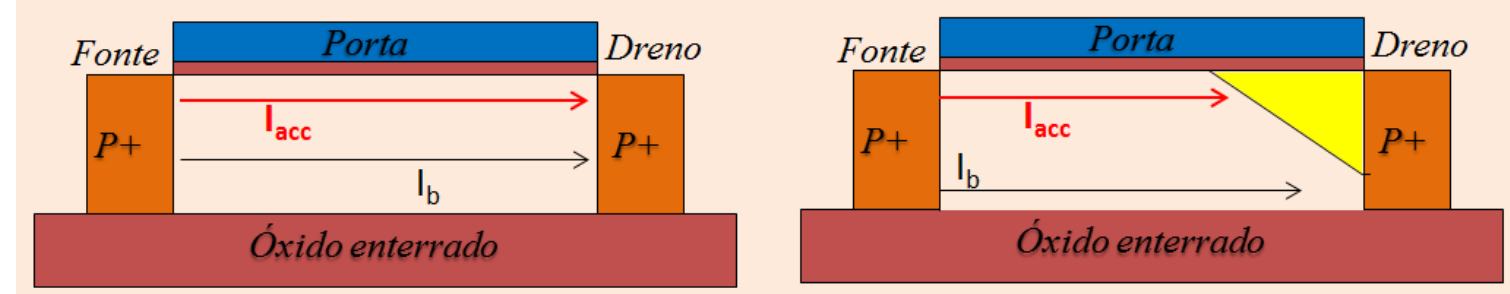

(A)

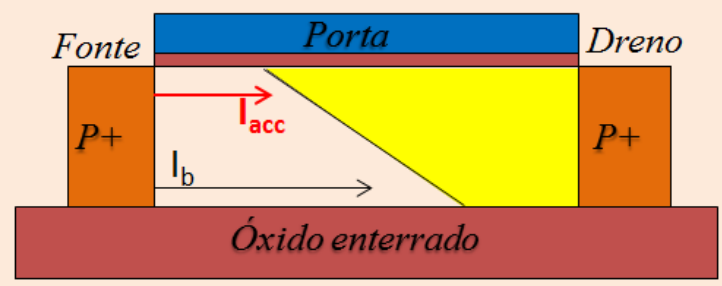

(B)

Fonte: Autor.

Legenda: (A) corpo e camada de acumulação em tríodo; (B) pinçamento da camada de acumulação; (C) pinçamento do corpo e da camada de acumulação.

Na Figura 9 (A) e (B) nota-se que não há pinçamento do corpo, sendo que em (A) a acumulação ocorre desde a fonte até o dreno e em (B) há o pinçamento da camada de acumulação. No item (C), ocorre o pinçamento dos dois canais de condução (corpo e camada de acumulação).

\subsubsection{Tipos de funcionamento SOI MOSFETs}

O transistor SOI MOSFETs modo enriquecimento apresenta dois tipos de funcionamento, dependendo da condição do corpo do transistor. Estes tipos de funcionamento dependem da espessura, da concentração de dopantes e da temperatura, que influenciam na extensão da camada de depleção.

Estes tipos de funcionamento podem ser classificados como: SOI totalmente depletado (FD- fully depleted) e SOI parcialmente depletado (PD- partially depleted) e dispositivos que tem a camada de depleção perto da depleção total (NFD SOI - Near fully depleted), depletado dependendo da tensão aplicada ao substrato.

A princípio, para analisar o tipo de funcionamento do SOI MOSFET, é necessária a determinação da profundidade máxima de depleção $\left(\mathrm{x}_{\mathrm{dmáx}}\right)$, que está representada na equação 1 [24]: 


$$
x_{d m a ́ x}=\sqrt{\frac{4 \varepsilon_{S i} \Phi_{F}}{q \cdot N_{A}}}
$$

onde $\varepsilon_{\mathrm{Si}}$ é a permissividade do silício, q é a carga elementar do elétron, $\mathrm{N}_{\mathrm{A}}$ é a concentração de impurezas aceitadoras do substrato e $\Phi_{\mathrm{F}}$ é o potencial de Fermi, dado por $\phi_{\mathrm{F}}=\frac{\mathrm{kT}}{\mathrm{q}} \cdot \ln \left(\frac{\mathrm{N}_{\mathrm{A}}}{\mathrm{n}_{\mathrm{i}}}\right)[24]$, onde $\mathrm{k}$ é a constante de Boltzmann, T é a temperatura absoluta e $\mathrm{n}_{\mathrm{i}}$ é a concentração intrínseca de portadores.

Se a espessura da camada de silício $\left(\mathrm{t}_{\mathrm{Si}}\right)$ for maior que $2 . \mathrm{x}_{\text {dmáx }}$, então o dispositivo é caracterizado como parcialmente depletado (PD) e portanto não há interação entre as camadas de depleção induzidas a partir da primeira interface e da segunda interface, existindo uma região neutra entre elas.

Os diagramas de faixas de energia para o transistor MOS convencional (A) e para o transistor PD SOI (B), são apresentados na Figura 10, onde $\mathrm{E}_{\mathrm{C}}$ representa o nível energético inferior da faixa de condução, $E_{V}$ o nível energético superior da faixa de valência, $E_{i}$ o nível intrínseco, $\mathrm{E}_{\mathrm{F}} \mathrm{o}$ nível de Fermi da camada do semicondutor (silício, no caso da tecnologia $\mathrm{SOI}), \mathrm{E}_{\mathrm{FM}}$ o nível de energia do eletrodo de porta e $\mathrm{E}_{\mathrm{F}}$ o nível de Fermi do substrato.

Figura 10 - Diagramas de faixas de energia.

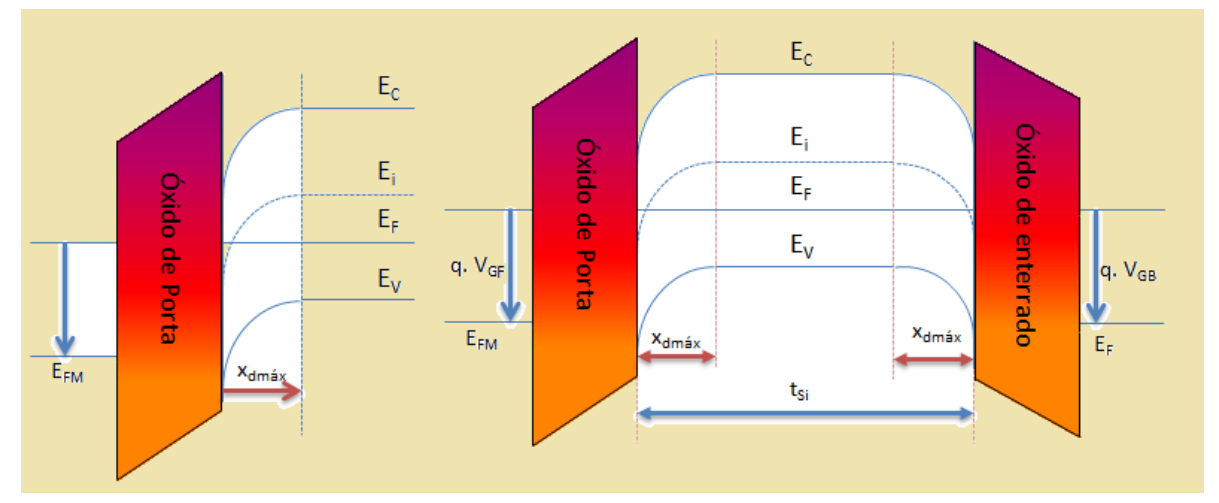

(A)

(B)

Fonte: Autor.

Lengenda: (A) transistor MOS convencional e (B) transistor PD SOI parcialmente depletado.

Na Figura 10 (B) o diagrama de faixas de energia do transistor PD SOI apresenta uma região neutra entre as regiões de depleção. Caso exista o contato elétrico com o corpo e este já aterrado, o dispositivo terá comportamento semelhante ao de um transistor MOS convencional. Caso contrário, esta região ficará eletricamente flutuando e o transistor 
apresentará efeitos de corpo flutuante [25], como efeito da elevação abrupta de corrente (Efeito Kink) e efeito bipolar parasitário.

Devido a similaridade de operação em relação aos MOSFETs convencionais, combinado com a redução das capacitâncias de junção [26], os transistores parcialmente depletados foram utilizados nas primeiras aplicações industriais da tecnologia SOI [27] [28] [29].

Os transistores do tipo totalmente depletado se caracterizam por ter a espessura da camada de silício menor que $\mathrm{x}_{\mathrm{dmáx}}$, ou seja, as regiões de depleção da primeira e segunda interfaces tem interação, como apresentado no diagrama de faixas de energia da Figura 11. Assim, certamente, a camada de silício estará totalmente depletada para tensões de porta maiores que a tensão de limiar, independente da tensão aplicada ao substrato. Com exceção da possível presença de uma fina camada de acumulação ou inversão na segunda interface, se uma alta tensão negativa ou positiva for aplicada ao substrato, respectivamente.

Esta interação entre as regiões de depleção faz com que os potenciais de superfície da primeira e segunda interfaces $\left(\Phi_{\mathrm{SF}}\right.$ e $\left.\Phi_{\mathrm{SB}}\right)$ estejam relacionados, promovendo acoplamento eletroestático da estrutura. Os dispositivos FD SOI (totalmente depletado), apresentam características mais atrativas entre os transistores SOI, tais como redução do campo elétrico horizontal [16], maior mobilidade dos portadores na região do canal [30], menor variação da tensão de limiar com a temperatura [31], menor ocorrência de efeitos de canal curto [32], entre outras.

Figura 11 - Diagrama de faixa de energia para o dispositivo FD SOI.

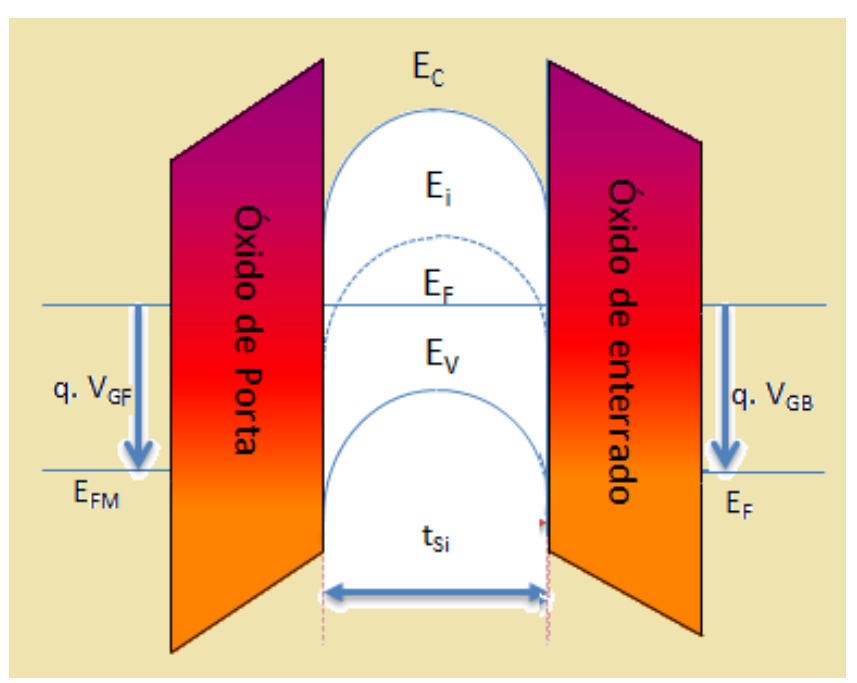

Fonte: Autor. 
Os dispositivos de camada média, NFD SOI MOSFET, podem apresentar comportamento elétrico de parcialmente ou totalmente depletado. Apresentam $\mathrm{x}_{\mathrm{dmáx}}<\mathrm{t}_{\mathrm{Si}}<2 . \mathrm{x}_{\mathrm{dmáx}}$, ou seja, as regiões de depleção da primeira e segunda interface poderão ou não, interagir dependendo da tensão aplicada ao substrato $\left(\mathrm{V}_{\mathrm{GB}}\right)$.

\subsubsection{Vantagens do Transistor SOI totalmente depletado}

Os dispositivos FD SOI MOSFET apresentam melhores características elétricas em comparação ao transistor MOS convencional e ao dispositivo PD SOI MOSFET. Ultimamente tem sido utilizados pelas indústrias de semicondutores, devido às vantagens em relações aos outros dispositivos convencionais [33] [34] [35], como resultados temos a redução de mais de $60 \%$ no consumo da potência [33] e a redução da tensão de alimentação de circuitos analógicos para $0,5 \mathrm{~V}$, comprovando a sua eficiência quando comparados com os dispositivos MOS convencionais [35].

Esta vantagem está associada ao fator de corpo (body factor) [36], o qual está relacionado diretamente com a corrente fornecida pelo dispositivo e a sua inclinação de sublimiar. Este fator pode ser interpretado como uma força contrária ao controle que a porta tem sobre o potencial de superfície na interface óxido de porta silício [36], dado por:

$$
\mathrm{n}=1+\alpha
$$

onde $\alpha$ é o fator de acoplamento capacitivo do transistor MOS, portanto apresenta um fator diferente para cada tipo de dispositivo SOI:

$$
\alpha=\frac{C_{D}}{C_{o x}}
$$

para transistores MOS convencionais e PD SOI;

$$
\alpha=\frac{\mathrm{C}_{\mathrm{Si}}}{\mathrm{C}_{\mathrm{oxf}}}
$$

para transistores FD SOI com a segunda interface acumulada; 


$$
\alpha=\frac{\mathrm{C}_{\mathrm{Si}} \mathrm{C}_{\mathrm{oxb}}}{\mathrm{C}_{\mathrm{oxf}}\left(\mathrm{C}_{\mathrm{Si}}+\mathrm{C}_{\mathrm{oxb}}\right)}
$$

para transistores FD SOI com a segunda interface depletada.

Onde $\mathrm{C}_{\mathrm{D}}$ é capacitância da região de depleção por unidade de área igual a $\frac{\varepsilon_{S i}}{x_{d m a ́ x}} ; \mathrm{C}_{\mathrm{oxf}}$ é a capacitância de óxido de porta por unidade de área, igual a $\frac{\varepsilon_{o x}}{t_{o x f}} ; \mathrm{C}_{\text {oxb }}$ é a capacitância de óxido enterrado por unidade de área, igual a $\frac{\varepsilon_{o x}}{t_{o x b}} ; \mathrm{C}_{\mathrm{Si}}$ é a capacitância da camada de silício por unidade de área, igual a $\frac{\varepsilon_{S i}}{t_{S i}} ; \varepsilon_{\mathrm{ox}}$ é a permissividade do óxido e $\varepsilon_{S \mathrm{i}}$ é a permissividade do silício.

É notório que o valor de $\mathrm{n}$ é menor nos dispositivos SOI totalmente depletados que nos dispositivos MOS convencionais [25], se aproximando da unidade. Os valores numéricos de $n$ seguem a seguinte tendência:

$$
\mathrm{n}_{\text {SOI totalmente depletado }}<\mathrm{n}_{\text {MOS convencional }}<\mathrm{n}_{\text {SOI com a segunda interface acumulada }}
$$

\subsubsection{Principais Características Elétricas dos transistores SOI}

Nesta seção serão apresentados alguns parâmetros elétricos importantes dos transistores SOI MOSFET, como a tensão de limiar, o efeito de corpo, a característica da corrente de dreno em função da tensão aplicada à porta, inclinação de sublimiar, entre outros.

\subsubsection{Tensão de limiar}

A tensão aplicada à porta capaz de inverter a superfície de silício, formando um canal de condução entre fonte e dreno é chama de tensão de limiar $\left(\mathrm{V}_{\mathrm{T}}\right)$ [1]. Esta tensão é obtida quando o potencial induzido na superfície do silício é aproximadamente $2 \Phi_{\mathrm{F}}$.

A tensão de limiar de um transistor MOS convencional com canal do tipo n, é dada pela equação (6) [24]. 


$$
\mathrm{V}_{\mathrm{T}}=\mathrm{V}_{\mathrm{FB}}+2 \phi_{\mathrm{F}}+\frac{\mathrm{qN}_{\mathrm{af}} \mathrm{X}_{\mathrm{dmáx}}}{\mathrm{C}_{\mathrm{ox}}}
$$

onde $\mathrm{V}_{\mathrm{FB}}$ é a tensão de faixa plana, igual a $\phi_{\mathrm{MS}}-\left(\frac{\mathrm{Q}_{\mathrm{ox}}}{\mathrm{C}_{\mathrm{ox}}}\right)$, $\Phi_{\mathrm{MS}}$ é a diferença de função trabalho entre metal de porta e semicondutor, Qox é a densidade de carga fixa no óxido de porta por unidade de área, $\mathrm{x}_{\text {dmáx }}$ é a espessura máxima de depleção, $\mathrm{N}_{\mathrm{af}}$ é a concentração de impurezas aceitadoras do canal, Cox é a capacitância do óxido de porta por unidade de área $\left(\mathrm{C}_{\mathrm{ox}}=\varepsilon_{\mathrm{ox}} / \mathrm{t}_{\mathrm{oxf}}\right), \mathrm{t}_{\mathrm{oxf}}$ é a espessura do óxido de porta e $\varepsilon_{\mathrm{ox}}$ é a permissividade do óxido de silício.

Como já apresentado na seção 2.1.2 no transistor PD SOI não há interação entre as duas interfaces pois $\mathrm{t}_{\mathrm{Si}}>2 \mathrm{x}_{\text {dmáx }}$, pois há uma região neutra entre as duas. Deste modo, a tensão de limiar da primeira interface deste dispositivo é a mesma como no MOS convencional, dada pela equação(6).

Através das equações de Lim \& Fossum [36] pode-se obter sua tensão de limiar do transistor FD SOI, onde há interação entre as regiões de depleção, assim desprezando as armadilhas de interface temos:

$$
\begin{gathered}
V_{G F}=\phi_{M S F}-\frac{Q_{o x f}}{C_{o x f}}+\left(1+\frac{C_{S i}}{C_{o x f}}\right) \phi_{S F}-\frac{C_{S i}}{C_{o x f}} \phi_{S B}-\frac{\frac{1}{2} Q_{\text {depl }}+Q_{n f}}{C_{o x f}} \\
V_{G B}=\phi_{M S B}-\frac{Q_{o x b}}{C_{o x b}}-\frac{C_{S i}}{C_{o x b}} \phi_{S F}+\left(1+\frac{C_{S i}}{C_{o x b}}\right) \phi_{S B}-\frac{\frac{1}{2} Q_{d e p l}+Q_{S B}}{C_{o x b}}
\end{gathered}
$$

onde $\mathrm{Q}_{\mathrm{oxf}}$ são as densidades de carga fixa no óxido de porta por unidade de área e $\mathrm{Q}_{\mathrm{nf}}$ são as densidades de carga de inversão na primeira interface $\left(\mathrm{Q}_{\mathrm{nf}}<0\right)$ do transistor SOI, $\mathrm{Q}_{\text {depl }}$ é a densidade de carga de depleção total na camada de silício por unidade de área, igual a - $\mathrm{qN}_{\mathrm{A}} \mathrm{t}_{\mathrm{S}}$, Q ${ }_{\text {oxb }}$ corresponde à densidade de carga fixa no óxido enterrado por unidade de área e $\mathrm{Q}_{\mathrm{SB}}$ é a densidade de carga de inversão $\left(\mathrm{Q}_{\mathrm{SB}}<0\right)$ ou de acumulação $\left(\mathrm{Q}_{\mathrm{SB}}>0\right)$ na segunda interface, ambos por unidade de área, $\Phi_{\mathrm{MSF}}$ e $\Phi_{\mathrm{MSB}}$ são diferenças de função trabalho entre o eletrodo de porta e de camada de silício e entre o substrato e a camada de silício.

Na Figura 12 o comportamento da tensão de limiar em função da variação da tensão aplicada ao substrato é apresentado:

Figura 12 - Variação da tensão de limiar em função da tensão aplicada no substrato, indicando as condições da segunda interface com relação ao potencial aplicado ao substrato. 


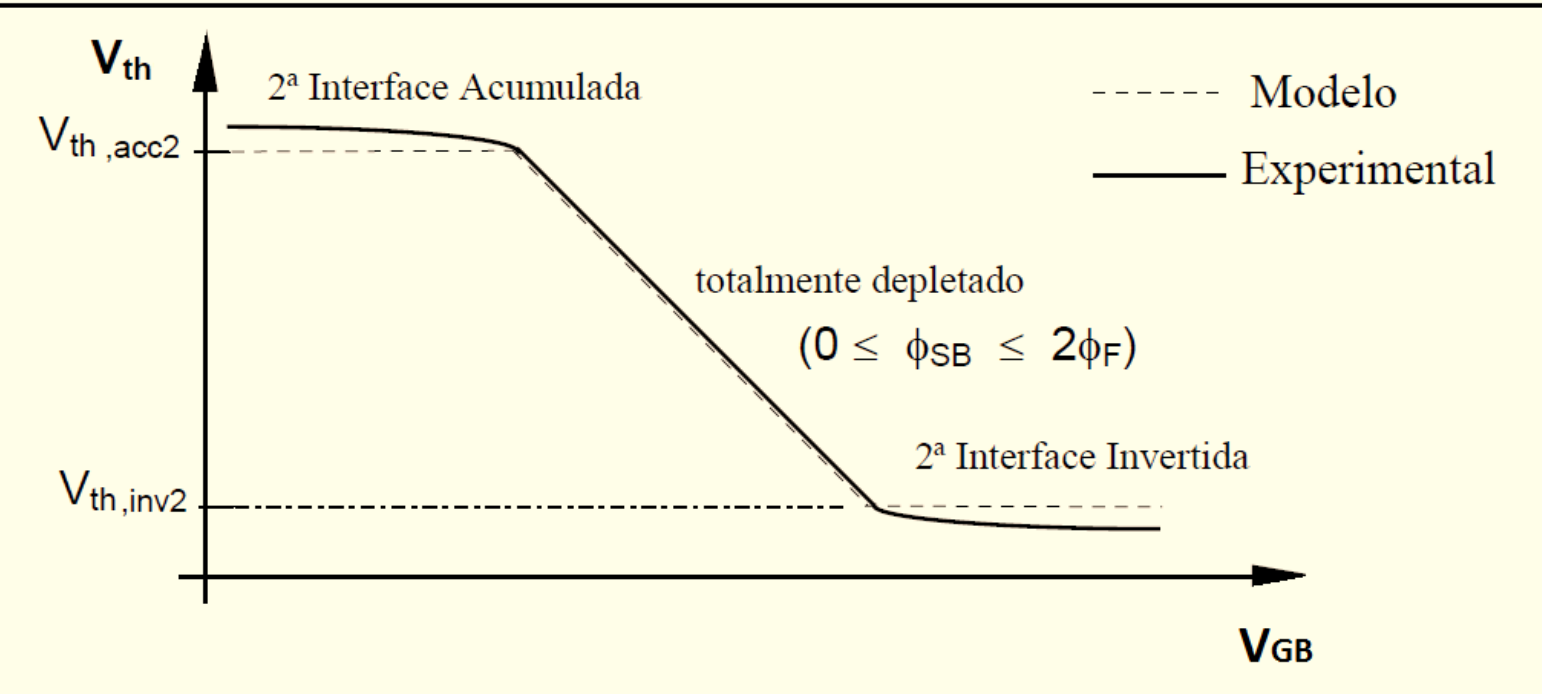

Fonte: RYKASZEWSKI, E. J., 1989, p. 219.

Devido ao acoplamento entre os potenciais aplicados à porta e ao substrato, que resultam em uma dependência da tensão de limiar do SOI nMOSFET de camada fina com polarização de substrato, há equações diferenciadas segundo os seguintes casos abaixo. Lembrando que estas equações abaixo só são válidas se a espessura das camadas de inversão e acumulação forem desprezíveis em relação à espessura da camada de silício.

a) Com a segunda interface acumulada $\left(\mathrm{V}_{\mathrm{T}, \mathrm{acc} 2}\right)$, onde $\Phi_{\mathrm{SB}}=0$, $\mathrm{Q}_{\mathrm{inf}}=0, \Phi_{\mathrm{SF}}=2 \Phi_{\mathrm{F}}$ :

$$
V_{T, a c c 2}=\phi_{M S F}-\frac{Q_{o x f}}{C_{o x f}}+\left(1+\frac{C_{S i}}{C_{o x f}}\right) 2 \phi_{F}-\frac{Q_{\text {depl }}}{2 C_{o x f}}
$$

b) Com a segunda interface invertida $\left(\mathrm{V}_{\mathrm{T}, \text { inv2 }}\right)$, onde $\Phi_{\mathrm{SB}}=2 \Phi_{\mathrm{F}}, \mathrm{Q}_{\mathrm{inf}}=0, \Phi_{\mathrm{SF}}=2 \Phi_{\mathrm{F}}$ :

$$
V_{T, i n v 2}=\phi_{M S F}-\frac{Q_{o x f}}{C_{o x f}}+2 \phi_{F}-\frac{Q_{\text {depl }}}{2 C_{o x f}}
$$

c) Com a segunda interface depletada $\left(\mathrm{V}_{\mathrm{T}}\right.$, depl2 $)$, onde $0<\Phi_{\mathrm{SB}}<2 \Phi_{\mathrm{F}}$, $\mathrm{Q}_{\text {inf }}=0$, $\Phi_{\mathrm{SF}}=2 \Phi_{\mathrm{F}}$ :

$$
V_{T, d e p l 2}=V_{T f, a c c 2}-\frac{C_{s i} \cdot C_{o x b}}{C_{o x f}\left(C_{S i}+C_{o x b}\right)} \cdot\left(V_{G B}-V_{G B, a c c 2}\right)
$$


onde $\mathrm{V}_{\mathrm{GB} \text {,acc2 }}$ é a tensão aplicada ao substrato para que a segunda interface acumule, $\operatorname{com} \Phi_{\mathrm{SB}}=0,2 \Phi_{\mathrm{F}}=\Phi_{\mathrm{SF}}$ e $\mathrm{Q}_{\mathrm{SB}}=0$.

\subsubsection{Mobilidade de Portadores}

A mobilidade dos portadores é definida como a facilidade com que os elétrons e lacunas atravessam a rede cristalina de um material. Quanto menor for à resistência do material, menor será a perda de energia, e assim, maior mobilidade dos portadores [4].

O movimento dos portadores em um cristal semicondutor não é livre e é limitado por mecanismos de espalhamento que reduzem sua mobilidade. Estes mecanismos de degradação que são fortemente dependentes da temperatura, podem ser classificados como: espalhamento de rede, espalhamento por impurezas ionizadas, espalhamento portador-portador e espalhamento por impurezas neutras [38]. A seguir serão apresentados os principais mecanismos de espalhamentos e suas respectivas dependências com a temperatura:

Espalhamento de rede ou por fônons (lattice scattering): o espalhamento de rede está relacionado com a interação entre portadores e as vibrações na rede cristalina, que são os fônons. Com a redução da temperatura estas vibrações diminuem, aumentando a mobilidade. Para os elétrons, esse espalhamento pode ser descrito através do modelo de Sah et al [39] :

$$
\mu_{p s e}=\frac{1}{\left(\frac{1}{\mu_{0 e a}\left(\frac{T}{300}\right)^{-\alpha e}}+\frac{1}{\mu_{0 e b}\left(\frac{T}{300}\right)^{-\beta e}}\right)}
$$

onde $\mu_{0 \mathrm{ea}}=4195 \mathrm{~cm}^{2} / \mathrm{Vs}, \mu_{0 \mathrm{eb}}=2153 \mathrm{~cm}^{2} / \mathrm{Vs}, \alpha_{\mathrm{e}}=1.5$ e $\beta_{\mathrm{e}}=3.13$. Para o caso das lacunas, o índice $e$ deve ser substituído por $h$ e os coeficientes são dados por $\mu_{0 \mathrm{ha}}=2502 \mathrm{~cm}^{2} / \mathrm{Vs}, \mu_{0 \mathrm{hb}}=$ $591 \mathrm{~cm}^{2} / \mathrm{Vs}, \alpha_{\mathrm{e}}=1.5$ e $\beta_{\mathrm{e}}=3.25$. Neste modelo a combinação dos fônons ópticos e acústicos é feita pela regra de Mathiessen [38].

Espalhamento por impurezas ionizadas (ionized impurity scattering) : Este mecanismo refere-se à redução da mobilidade dos portadores devido à alta concentração de dopantes. $\mathrm{O}$ modelo empírico de Caughey e Thomas [40] considera os mecanismos de espalhamento por rede e por impurezas em uma única equação 


$$
\mu_{p s i i e}=\mu_{\min , e}+\frac{\mu_{p s e}-\mu_{\min , e}}{1+\left(\frac{N_{A}^{-}}{N_{r e f, e}}\right)^{\alpha a e}}
$$

onde $\mu_{\min , \mathrm{e}}=197,17-45.505 \cdot \log (\mathrm{T}) ; \mathrm{N}_{\text {ref,e }}=1,12.10^{17}\left(\frac{T}{300}\right)^{3,2}$ e $\alpha_{\mathrm{ae}}=0,72\left(\frac{T}{300}\right)^{0,065}$. Para as lacunas, o índice $e$ deve ser substituído por $h$ e os coeficientes são dados por onde $\mu_{\min , \mathrm{h}}$ $=110,9-25 \cdot 597 \cdot \log (\mathrm{T}) ; \mathrm{N}_{\text {ref,h }}=2,23 \cdot 10^{17}\left(\frac{T}{300}\right)^{3,2}$ e $\alpha_{\mathrm{ae}}=\alpha_{\mathrm{ah}}$.

Espalhamento portador-portador (carrier-to-carrier scattering): Este mecanismo apresenta grande influência em dispositivos que possuem alta densidade de portadores (quando esta se torna maior que a de dopantes)[29] como transistores submicrométricos ou dispositivos de potência. Para um semicondutor com concentração de dopantes aceitadores o mecanismo é dado por [41]:

$$
\mu_{C C}=\frac{2 \cdot 10^{17}}{\sqrt{N_{A}} \cdot \ln \left(1+8,28 \cdot 10^{8} \cdot T^{2} \cdot N_{A}^{-1 / 3}\right)}
$$

Para semicondutor tipo $\mathrm{n}$, deve-se apenas substituir $\mathrm{N}_{\mathrm{A}}$ por $\mathrm{N}_{\mathrm{D}}$ na equação (14).

Espalhamento por impurezas neutras (neutral-impurity scattering): Este mecanismo de espalhamento está relacionado com as impurezas não ionizadas devido à baixa temperatura e tem influência na mobilidade apenas para concentrações de dopante acima de $10^{18} \mathrm{~cm}^{-3}$. Para elétrons, este mecanismo pode ser modelado por [42]:

$$
\mu_{n i}=C_{0} \cdot\left[\frac{2}{3} \sqrt{\frac{k T}{E_{n i, e}}}+\frac{1}{3} \sqrt{\frac{E_{n i, e}}{k T}}\right]
$$

onde $C_{0}=\left(\frac{2 \pi^{3} q^{3} m_{e}^{*}}{5 \varepsilon_{S i} h^{3}\left(N_{A}-N_{A}^{-}\right)}\right) 10^{-2}$ e $E_{n i, e}=1,136 \cdot 10^{-19}\left(\frac{m_{e}^{*}}{m_{0}}\right)\left(\frac{\varepsilon_{0}}{\varepsilon_{S i}}\right)^{2}$, sendo $\mathrm{m}_{\mathrm{e}}{ }^{*}$ a massa efetiva dos elétrons, $\mathrm{m}_{0}$ a massa do elétron e $\varepsilon_{0}$ a permissividade do vácuo [26]. Para o caso de lacunas deve-se substituir na equação (15) a massa efetiva dos elétrons pela das lacunas.

Estes mecanismos de espelhamento não dependem das tensões aplicadas e combinados pela regra de Mathiessen, definem a mobilidade independente do campo elétrico $\mu_{0}$ : 


$$
\mu_{0}=\left(\frac{1}{\frac{1}{\mu_{p s i i}}+\frac{1}{\mu_{C C}}+\frac{1}{\mu_{n i}}}\right)
$$

Pode-se observar na equação (16) que o mecanismo de espalhamento por rede, dado por $\mu_{\mathrm{ps}}$, não entra no cálculo de $\mu_{0}$, pois o termo $\mu_{\mathrm{psii}}$ já considera tal espalhamento juntamente com o espalhamento por impurezas ionizadas.

\subsubsection{Inclinação de Sublimiar}

A inclinação de sublimiar (S) é um importante parâmetro utilizado para medir a velocidade de chaveamento do transistor. Quanto menor seu valor, mais rápido e eficiente será o chaveamento (corte e condução) do dispositivo. É expressa pelo inverso da taxa de variação logarítmica da corrente de dreno $\left(\mathrm{I}_{\mathrm{DS}}\right)$ pela tensão aplicada na porta $\left(\mathrm{V}_{\mathrm{GF}}\right)$ na região sublimiar e define a variação da tensão de porta, para tensões abaixo da tensão de limiar, necessária para variar a corrente de dreno em uma década. É dada pela equação (17) [43].

$$
\mathrm{S}=\frac{\mathrm{dV}_{\mathrm{GF}}}{\mathrm{d}\left(\log \mathrm{I}_{\mathrm{DS}}\right)}
$$

Figura 13 - Curva simulada $\log \left(\mathrm{I}_{\mathrm{DS}}\right)$ x $\mathrm{V}_{\mathrm{GF}}$ de um SOI MOSFET de canal $\mathrm{n}$.

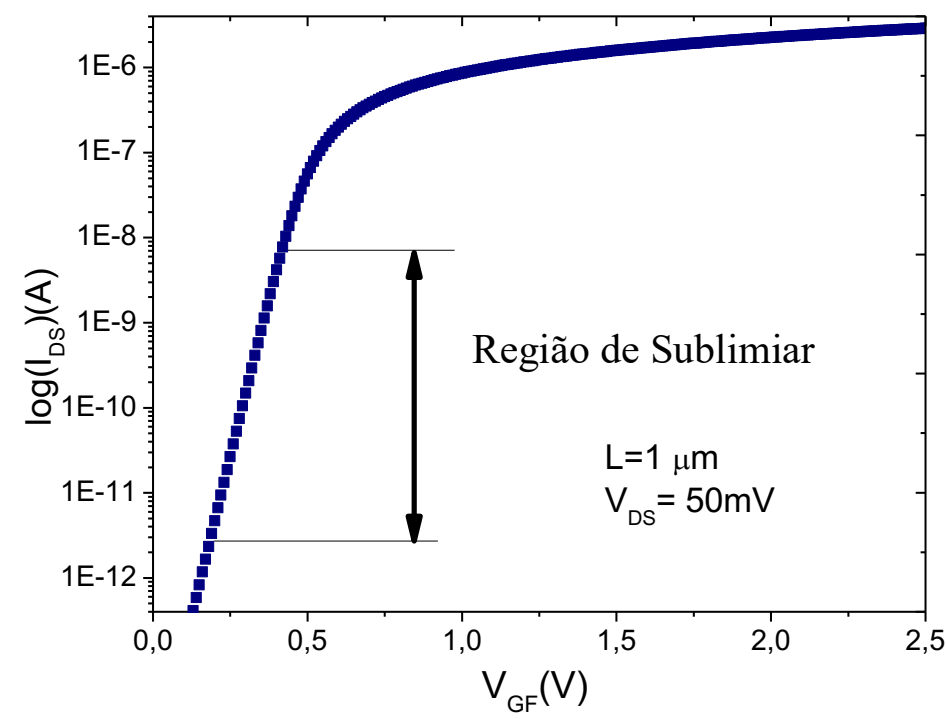

Fonte: Autor. 
Na Figura 13 a inclinação de sublimiar é extraída na região de sublimiar, onde a passagem de corrente elétrica deve-se predominantemente pelo mecanismo da difusão [24].

Utilizando a equação da corrente de dreno em sublimiar, e algumas simplificações [44], obtém-se:

$$
\mathrm{S}=\frac{\mathrm{kT}}{\mathrm{q}} \cdot \ln (10)(1+\alpha)=\mathrm{n} \frac{\mathrm{kT}}{\mathrm{q}} \cdot \ln (10)
$$

onde $\mathrm{k}$ é a constante de Boltzmann, $\mathrm{T}$ a temperatura absoluta, q a carga elementar do elétron e $\alpha$ o acoplamento capacitivo.

Nota-se, então, a partir da equação (18), que a inclinação de sublimiar depende diretamente do fator de corpo do transistor. Como visto na seção 2.1.2, transistores SOI totalmente depletados apresentam menor fator de corpo que os outros dispositivos apresentados. Como resultado, temos que:

$$
\mathrm{S}_{\mathrm{FD} \mathrm{SOI}}<\mathrm{S}_{\mathrm{MOS} \text { convencional }}<\mathrm{S} \text { SOI com segunda interface acumulada }
$$

A inclinação de sublimiar dos transistores SOI totalmente depletados aproxima-se muito do limite teórico de $60 \mathrm{mV} / \mathrm{dec}$ em temperatura ambiente, enquanto que nos transistores MOS convencionais este valor é de aproximadamente $100 \mathrm{mV} / \mathrm{dec}$ dependendo do limite da tecnologia. Assim, menores valores de tensão de limiar podem ser utilizados em FD SOI, sem elevar o valor da corrente de fuga dos transistores, o que é significante para reduzir as tensões de alimentação [45].

Considerando as armadilhas de interface, podemos reescrever as equações de acoplamento capacitivo do MOS convencional (19) e do SOI totalmente depletado (20), respectivamente demonstradas abaixo:

$$
\begin{gathered}
\alpha=\frac{\mathrm{C}_{\mathrm{D}}+\mathrm{C}_{\mathrm{it} 1}}{\mathrm{C}_{\mathrm{ox}}} \\
\alpha=\frac{\mathrm{C}_{\mathrm{it} 1}}{\mathrm{C}_{\mathrm{ox} 1}}+\frac{\mathrm{C}_{\mathrm{Si}}}{\mathrm{C}_{\mathrm{ox} 1}}-\frac{\frac{\mathrm{C}_{\mathrm{Si}}^{2}}{\mathrm{C}_{\mathrm{ox} 1} \cdot \mathrm{C}_{\mathrm{ox} 2}}}{1+\frac{\mathrm{C}_{\mathrm{it} 2}}{\mathrm{C}_{\mathrm{ox} 2}}+\frac{\mathrm{C}_{\mathrm{Si}}}{\mathrm{C}_{\mathrm{ox} 2}}}
\end{gathered}
$$


onde $C_{D}$ é a capacitância da região de depleção, $C_{i t 1}=q . N_{i t 1}$ e $C_{i t 2}=q . N_{i t 2}$, respectivamente, as capacitâncias das armadilhas de interface na primeira e segunda interface, onde $\mathrm{N}_{\mathrm{it1}}$ e $\mathrm{N}_{\mathrm{it} 2}$ são as densidades de armadilhas da interface na primeira e segunda interface.

\subsubsection{Efeitos de Canal Curto}

Devido à miniaturização dos dispositivos e consequentemente à redução do comprimento de canal, surgem efeitos indesejáveis, chamados de efeito de canal curto [46]. Por consequência as regiões de depleção do dreno e fonte tendem a se aproximar, interferindo no controle de cargas pela porta, ou seja, a carga de depleção controlada pela porta não pode ser mais expressa por $\mathrm{Q}_{\mathrm{depl}}=-\mathrm{q} . \mathrm{N}_{\mathrm{A} .} \mathrm{X}_{\mathrm{dmax}}$, como no MOS convencional, mas sim como uma fração dela $\left(\mathrm{Q}_{\text {depl,ef }}\right)$. Assim, quando $\mathrm{Q}_{\text {depl,ef }}<\mathrm{Q}_{\text {depl, }}$ haverá uma redução na tensão de limiar e um aumento da inclinação de sublimiar [24] [47] [48].

É apresentado um esquema do comportamento do efeito de canal curto nos dispositivos convencionais e SOI MOSFETs conforme a

Figura 14. No transistor MOS convencional de canal longo, apresentado na

Figura 14(a), notam-se as regiões de depleção tanto do dreno como da fonte distanciadas, então o dispositivo é controlado praticamente pela porta $\left(\mathrm{Q}_{\mathrm{d} 1}\right)$ e podem ser calculada considerando a geométrica de sua área como um retângulo, onde a base maior e a base menor são aproximadamente do tamanho do comprimento de canal(L), resultando na equação (21) [4]:

$$
Q_{d 1}=Q_{d e p l}=-q \cdot N_{A} \cdot x_{d \max }
$$

De maneira oposta para transistores MOS de canal curto,

Figura 14(b), a base inferior é reduzida significativamente, devido à região de depleção próxima. Assim a área das cargas a ser calculada se aproxima de um triângulo e pode ser expressa por [4]:

$$
Q_{d 1}=Q_{\text {depl }} \cdot\left[1-\frac{r_{j}}{L} \cdot\left(\sqrt{1+\frac{2 \cdot x_{d \max }}{r_{j}}}-1\right)\right]
$$


onde rj é a profundidade de junção de fonte e dreno, definida na

Figura 14(b).

Figura 14 - Distribuição das cargas de depleção em MOS convencional e SOI.

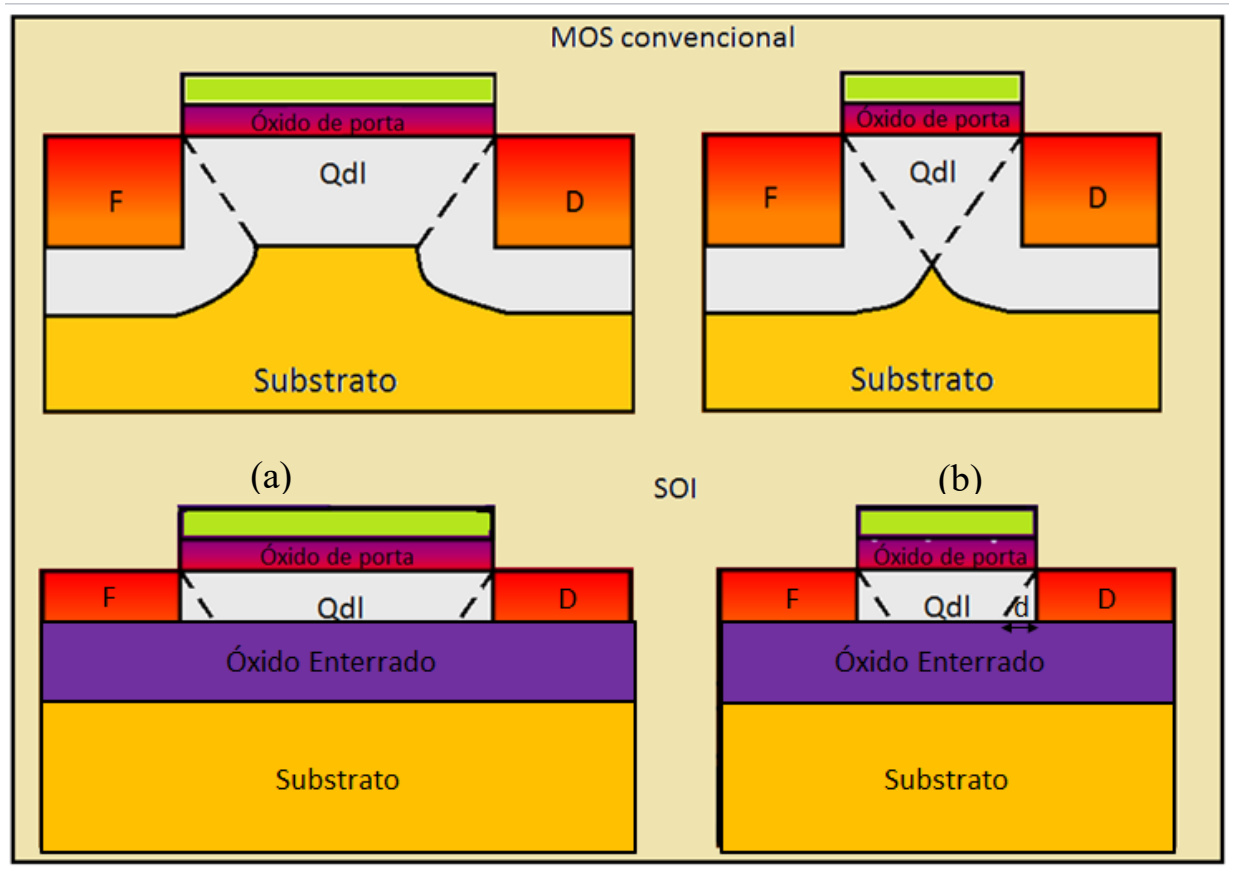

Fonte: Autor.

Legenda: em dispositivos de canal longo, lado esquerdo, e a direita, efeito de canal curto, para dispositivos MOS convencionais e para SOI MOSFETs. Onde $\mathrm{Q}_{\mathrm{dl}}$ é a carga de depleção controlada pela porta.

Para transistores FD SOI esse efeito de redução do comprimento de canal torna-se menos pronunciado, devido à presença do óxido enterrado e a redução da espessura do filme de silício, à vista disso a redução do controle das cargas da região de depleção pela porta é menor. Deste modo é possível ver na figura 15 que os dispositivos SOI MOSFET totalmente depletados apresentam uma menor redução da tensão de limiar com o comprimento de canal quando comparados aos dispositivos MOS [49]. 
Figura 15- Tensão de limiar em função do comprimento de canal comparando dispositivos MOS com FD SOI MOSFET.

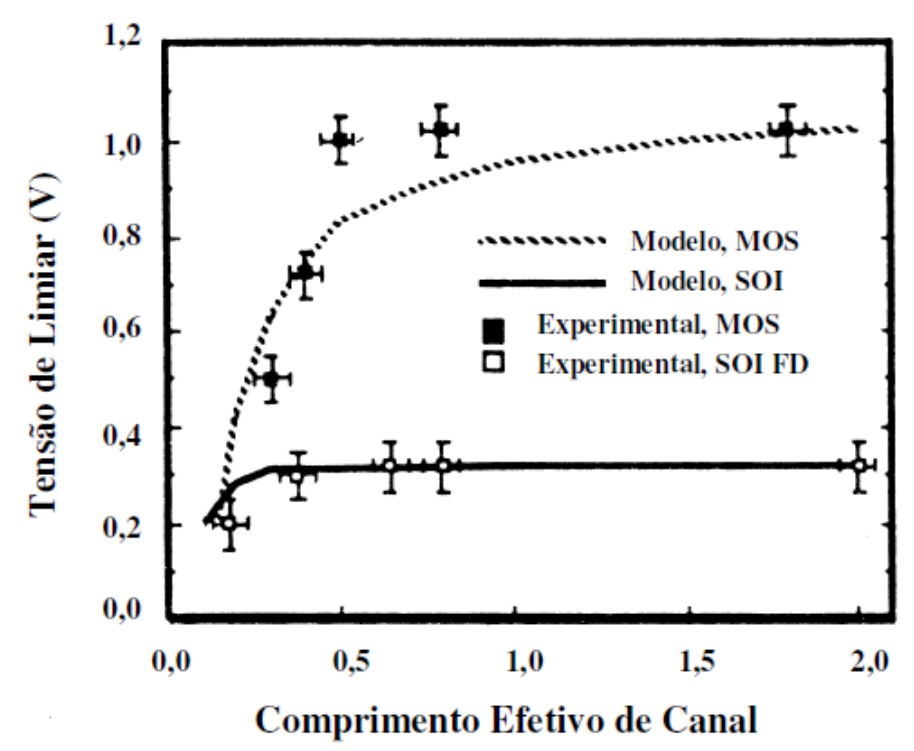

Fonte: Colinge 1989,pg 3.

Em transistores FD SOI MOSFETs a carga de depleção controlada pela porta nos transistores de canal longo e canal curto são dadas, respectivamente, pelas equações (23) e (24):

$$
\begin{gathered}
Q_{d 1}=Q_{d e p l}=-q \cdot N_{A} \cdot t_{S i} \\
Q d 1=Q d e p l\left(1-\frac{d}{L}\right)
\end{gathered}
$$

onde d é a distância definida na

Figura 14(b) inferior.

Portanto, podemos afirmar que os transistores SOI apresentam menor efeito de canal curto, pois a redução das cargas de depleção controladas pela porta é menor. 


\subsection{TRANSISTOR SEM JUNÇÃO}

Com objetivo de minimizar efeitos de canal curto, permitindo maior escalamento de dispositivos, os transistores de múltiplas portas foram desenvolvidos. O efeito de canal curto é reduzido devido ao fato de acrescentarmos mais uma porta nos dispositivos, obtendo maior controle eletrostático das cargas na região do canal pela porta, e consequentemente reduzindo a influência do campo elétrico, causado pelo potencial de dreno, na região do canal.

Porém com o a redução das dimensões dos transistores abaixo de dezenas de nanômetros um obstáculo adicional a ser superado é encontrado, a variação da concentração de dopantes aceitadores para doadores no canal que deve ser abrupta. Desta forma uma estrutura denominada transistores sem junção foi proposta a fim de eliminar este obstáculo [7].

Os transistores sem junção, apresentados na Figura 16, foram propostos com base no transistor concebido por Lilienfeld, o qual apresentava uma fina camada de semicondutor sobreposto em uma fina camada de isolante, além de um metal depositado sobre o semicondutor [50]. O dispositivo de Lilienfeld pode ser comparado a um resistor controlado pelo eletrodo de porta, onde uma variação da tensão na porta permite que os portadores sejam depletados permitindo o controle da condutividade [51]. Em operação, a corrente neste resistor flui entre os dois eletrodos de contato do mesmo modo que a corrente de dreno flui entre fonte e dreno em um transistor MOSFET modo inversão.

Figura 16 - Perfil transversal do transistor Sem Junção - JNT.

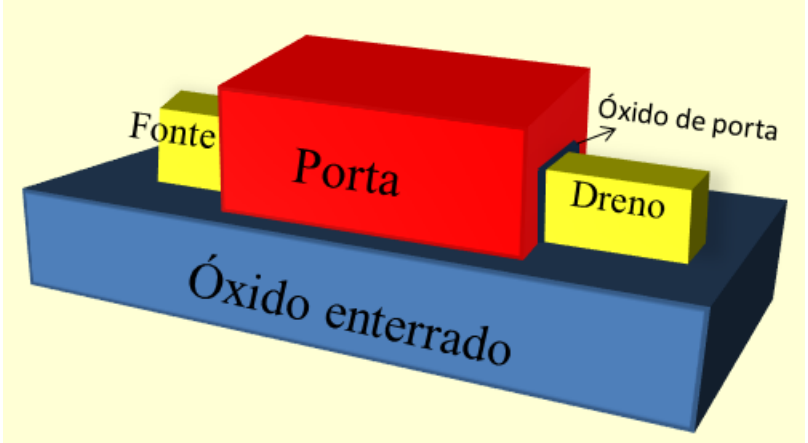

Fonte: Autor.

Com a miniaturização dos transistores modernos há maior necessidade de concentrações de dopantes abruptas, ou seja, a dopagem deve variar de tipo n com concentração de $10^{19} \mathrm{~cm}^{-3}$ a tipo p com concentração de $10^{18} \mathrm{~cm}^{-3}$ em poucos nanômetros. Este processo tem se tornado 
cada vez mais difícil de ser implementado exigindo melhorias nas técnicas de difusão, implantação e recozimento. Por outro lado, no transistor sem junção a concentração de dopantes no filme de silício é a mesma. Devido ao gradiente da concentração de dopantes entre a fonte e canal ou canal e dreno ser nula, nenhuma difusão pode ocorrer, o que elimina a necessidade de novas técnicas de recozimento e permite fabricar os dispositivos com canais mais curtos. A figura 17 apresenta perfil constante de concentração de dopantes da fonte até o dreno o qual impressa grande vantagem quanto a sequência de fabricação mais simples.

Figura 17 - Seção transversal do transistor sem junção nMOS e pMOS.
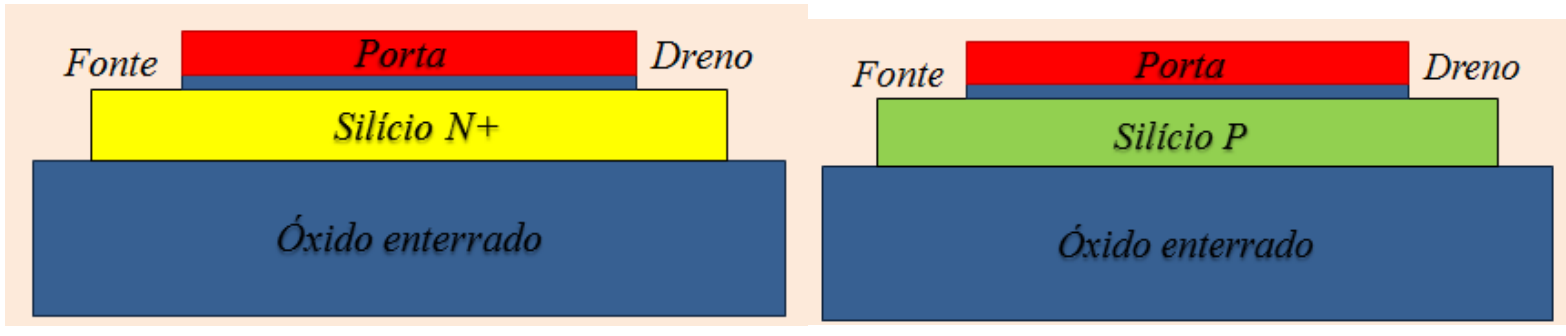

Fonte: Autor.

A chave para a fabricação de um Junctionless é a formação de uma camada de silício fina e suficientemente estreita para permitir a depleção completa dos portadores quando o dispositivo estiver desligado. O semicondutor também necessita ser fortemente dopado para permitir uma quantidade razoável de fluxo de corrente quando o dispositivo está ligado, geralmente apresenta o canal com concentração de dopantes aproximadamente $10^{19} \mathrm{~cm}^{-3}$. O material de porta usualmente é o silício policristalino tipo P (nMOS) e tipo N (pMOS) ou um Midgap (material que apresenta função trabalho próxima à do silício intrínseco).

Apesar de apresentar modo de funcionamento muito similar ao SOI modo acumulação, o JNT não poder ser considerado como um transistor operando em modo acumulação, pois a maior parte da condução ocorre pelo corpo e não pela camada superficial da acumulação.

Quando a porta não está polarizada, a camada de silício está toda depletada devido à diferença entre a função trabalho do material de porta e da camada de silício. Se a tensão aplicada à porta for positiva, a profundidade da camada de depleção diminuirá e haverá condução entre fonte e dreno através desta região que não estará depletada, no caso de um transistor nMOS.

A figura 18 apresenta as curvas da corrente de dreno em escala logarítmica em função da tensão aplicada à porta para dispositivos nMOS modo acumulação $(\mathrm{A})$ e JNT (B). Fica claro 
que para o dispositivo JNT a tensão de faixa plana fica mais distante da tensão de limiar que no transistor modo acumulação, deste modo a maior parcela da condução no Junctionless ocorre no regime de depleção parcial, onde há apenas uma componente da corrente de corpo.

Figura 18 - Comparação corrente de dreno em função da tensão de porta dos dispositivos modo acumulação (A) e JNT(B) .

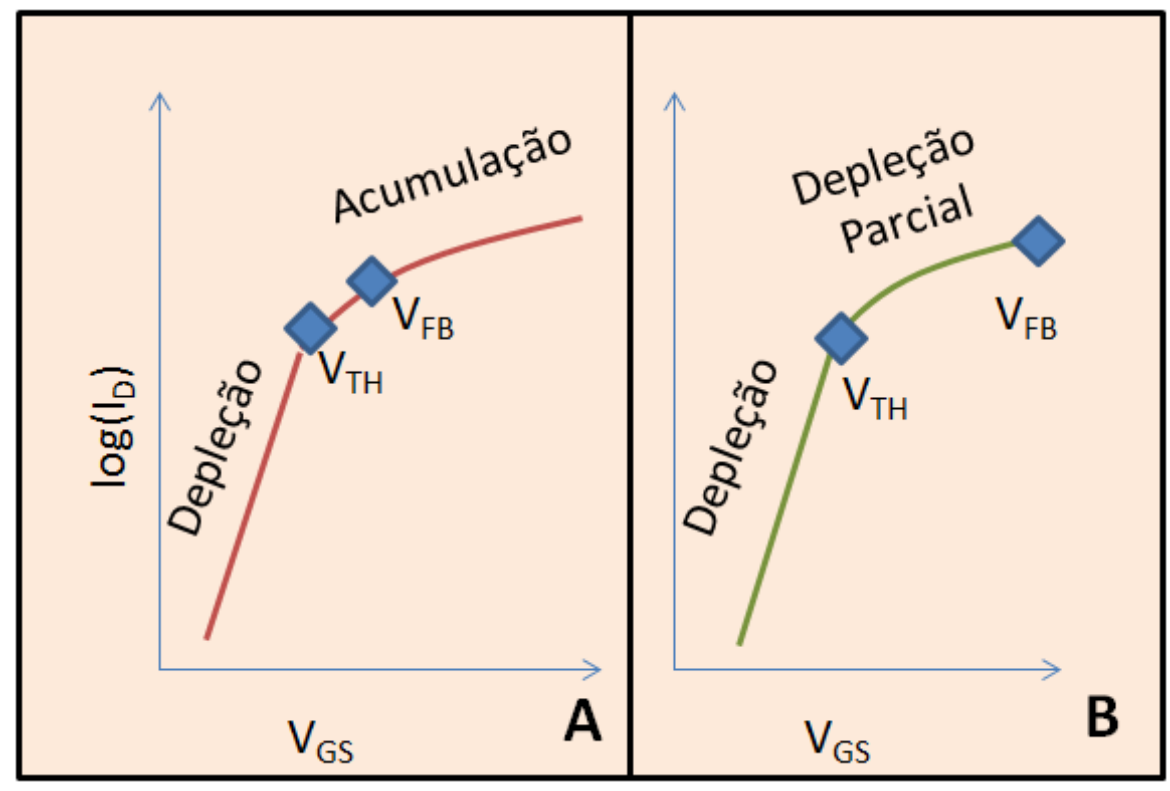

Fonte: Autor.

Estes dispositivos apresentam inclinação de sublimiar próxima do ideal [52], baixa corrente de fuga, e uma alta taxa de corrente on/off [52].

$\mathrm{O}$ valor de $\mathrm{V}_{\mathrm{T}}$ nos transistores JNTs, depende principalmente da concentração de dopantes da estrutura, da espessura do óxido de porta, da secção transversal do dispositivo e do material de porta utilizado na confecção do transistor.

Segundo consta em literaturas, os JNTs de múltiplas portas, funcionam como um "resistor com porta" em modo acumulação. Num transistor modo inversão nota-se que os portadores se acumulam em maior quantidade nas interfaces como demonstra a Figura 19 a. Porém, nos transistores sem junção (Figura 19 b e c) verifica-se que os portadores se distribuem em praticamente toda a região do canal, conduzindo a corrente elétrica também pelo corpo do transistor. Nota-se que esta condução ocorre com maior intensidade onde há o aumento da concentração dos portadores como ocorre na Figura 19(c): 
Figura 19 - Concentração de portadores no canal dos dispositivos.

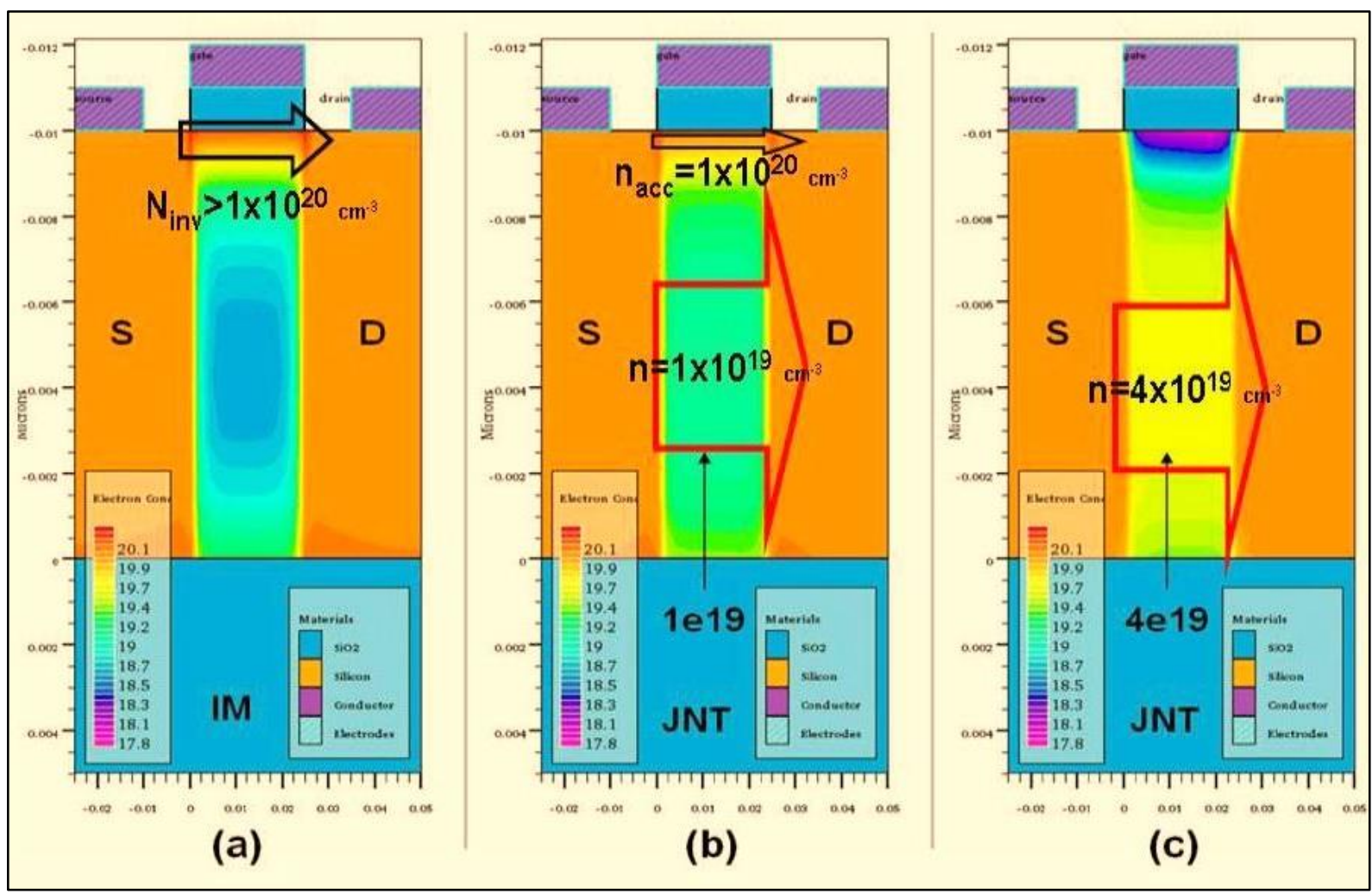

Fonte: COLINGE, J. P, 2011.

Legenda: (a) Concentração de portadores mais abundantes na interface silício-óxido num transistor de modo inversão; (b) Concentração de portadores muito presentes na maior parte do transistor (c) Praticamente todos os portadores passam pelo centro da estrutura [54].

A mobilidade nos transistores sem junção deve ser analisada diferentemente dos transistores comuns em modo inversão pois, como podemos observar na figura 20 (b), este atinge menor mobilidade nas interfaces.

Sabe-se que com o aumento da dopagem nos JNTs, a mobilidade é menor neste tipo de transistor. Porém, vale ressaltar que a mobilidade presente em toda a camada de silício no JNT é maior do que a mobilidade na interface no transistor modo-inversão [53]. 
Figura 20 - Mobilidade Transistor Modo inversão e JNT.

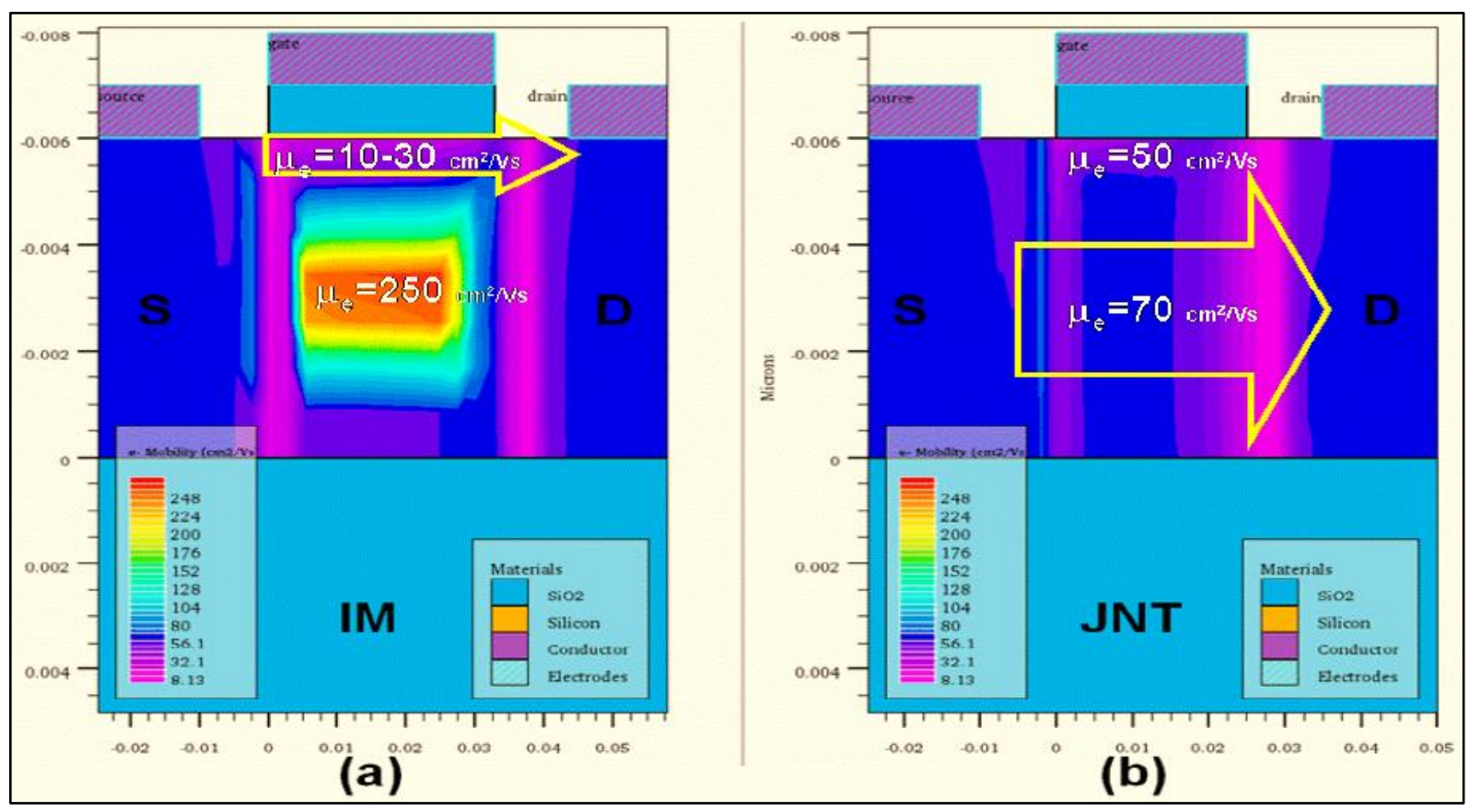

Fonte: COLINGE, J. P, 2011.

Legenda: (a) Transistor com mobilidade baixa nas interfaces, modo inversão. (b) JNT com mobilidade efetiva no centro da estrutura.

\subsection{TRANSISTORES UTBB}

O nome vem do inglês Ultra-Thin Body and Buried oxide (UTBB), ou seja, é um dispositivo que apresenta camada de silício e óxido enterrado ultrafinos. Os dispositivos UTBB, ultimamente, tem $\mathrm{t}_{\mathrm{BOX}}$ entre 10 e $30 \mathrm{~nm}, \mathrm{t}_{\mathrm{Si}}$ entre 7 e $10 \mathrm{~nm}$. Ao diminuir as espessuras da camada de silício e do óxido enterrado, a fina região ativa passa a estar sob forte influência do potencial aplicado ao substrato, que por sua vez, funciona efetivamente como segunda porta do dispositivo. Deste modo, estes transistores FDSOI planares permitem diferentes polarizações da segunda interface (back-gate) permitindo a implementação de circuitos de baixa potência e de alto desempenho no mesmo circuito integrado [54].

A figura 21 apresenta o esquema do dispositivo planar SOI UTBB, com a descrição de cada região. 
Figura 21 - Esquema da estrutura do transistor UTBB SOI MOSFET.

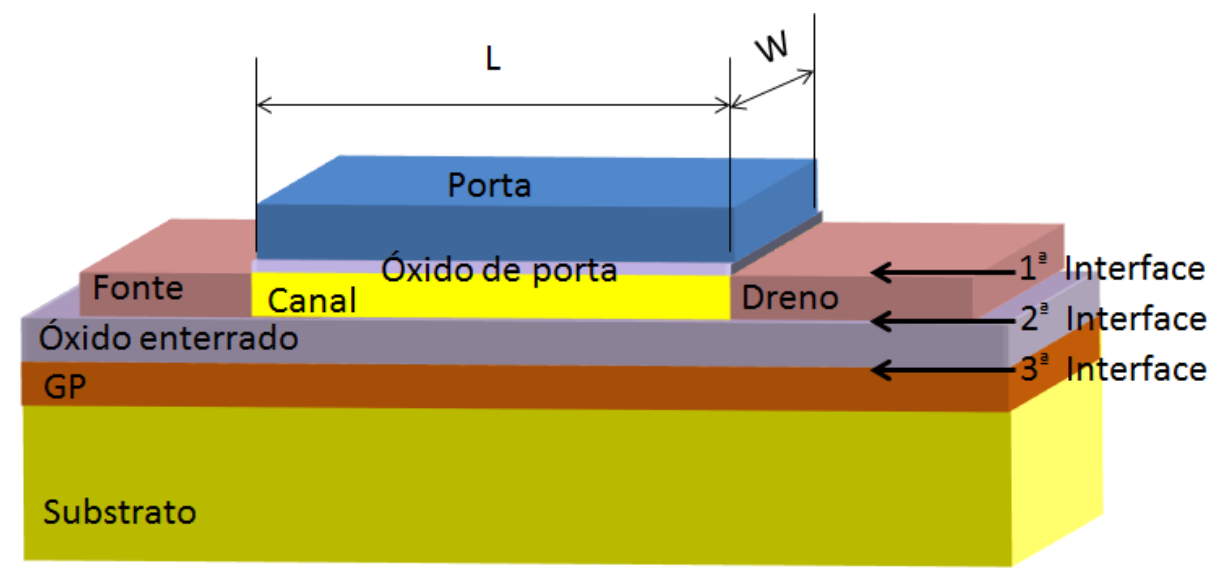

Fonte:Autor.

Pode-se notar uma região abaixo do óxido enterrado denominada GP (ground plane) ou plano terra, que pode conter ou não em um dispositivo UTBB. È uma região de alta dopagem que visa reduzir a depleção do silício abaixo do óxido enterrado na terceira interface. A combinação do uso de GP e a polarização do substrato favorecem o ajuste da tensão de limiar do dispositivo, além da possibilidade de dispositivos com multi- $V_{T}$ ou $V_{T}$ dinâmico.

\subsection{NANO-FIOS NÃO DOPADOS (NWFETs)}

Os nano-fios FETs consistem em um transistor com efeito de campo, porém apresenta no lugar do canal do dispositivo um filamento de silício com a dopagem natural da lâmina em toda sua extensão (de fonte a dreno), geralmente dopada com boro em concentração de $1 \mathrm{e} 15 \mathrm{~cm}^{-2}$ [55]. Estes transistores surgiram da necessidade da simplificação ainda mais na fabricação dos transistores e adicionam um grande diferencial: a versatilidade de poder selecionar o tipo de transistor N-Type ou P-Type pela aplicação de tensão pelo substrato do dispositivo [56]. 
Diferentes comportamentos, apresentados nos diagramas de faixas de energia simplificados, podem ser observados nos NWFETs, através da tensão aplicada nos substratos, na figura 22.

Figura 22- Diagramas esquemáticos da influência do substrato nos NWFETs.

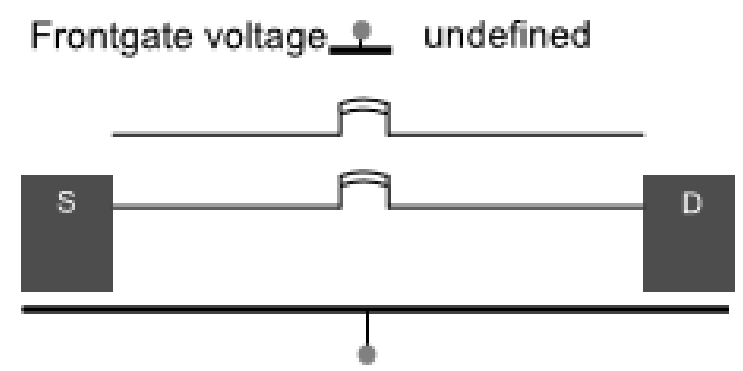

(a) Backgate voltage $=0 \mathrm{~V}$

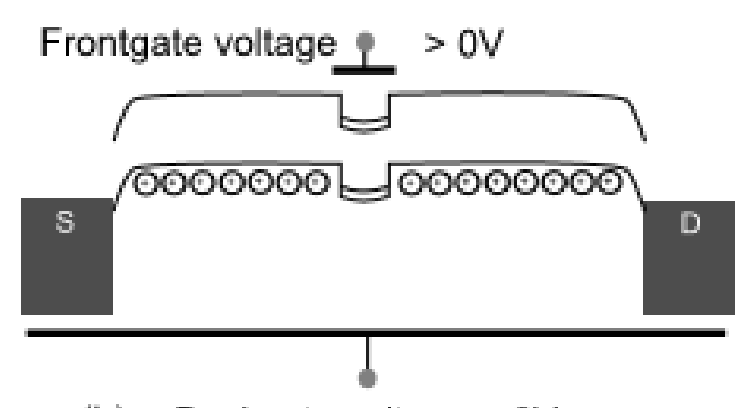

(b) Backgate voltage $<0 \mathrm{~V}$

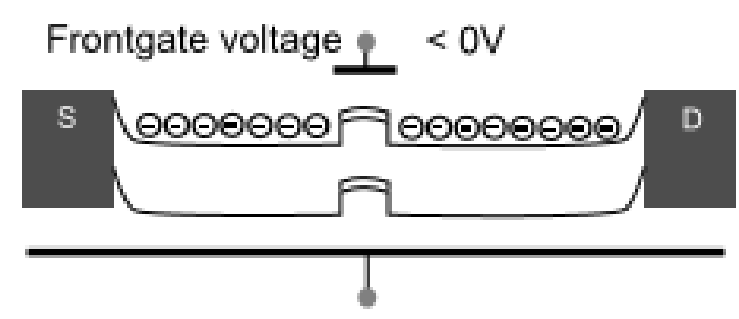

(c) Backgate voltage $>0 \mathrm{~V}$

Fonte: J. Appenzeller, p. 2827,2008.

Na figura 22 (a) nenhuma tensão é aplicada no substrato e pode se observar que no canal não há a quantidade suficiente de portadores de cargas livres, apenas o fluxo de corrente sublimiar é observado. O diagrama (b) mostra o comportamento do dispositivo ao aplicar uma tensão $\mathrm{V}_{\mathrm{GB}}$ negativa, assim as lacunas são acumuladas na interface de substrato-óxido 
enterrado/NW. No diagrama (c) uma tensão positiva é aplicada ao substrato atraindo os elétrons. Os portadores de carga deste modo surgem dos contatos midgap da barreira Shottky.

Na curva abaixo é apresentada o comportamento de um transistor NWFET, e como o canal é "selecionável” através da aplicação de tensão feita pelo substrato.

Figura 23- Curva da corrente de dreno em função da tensão de substrato e a porta flutuando.

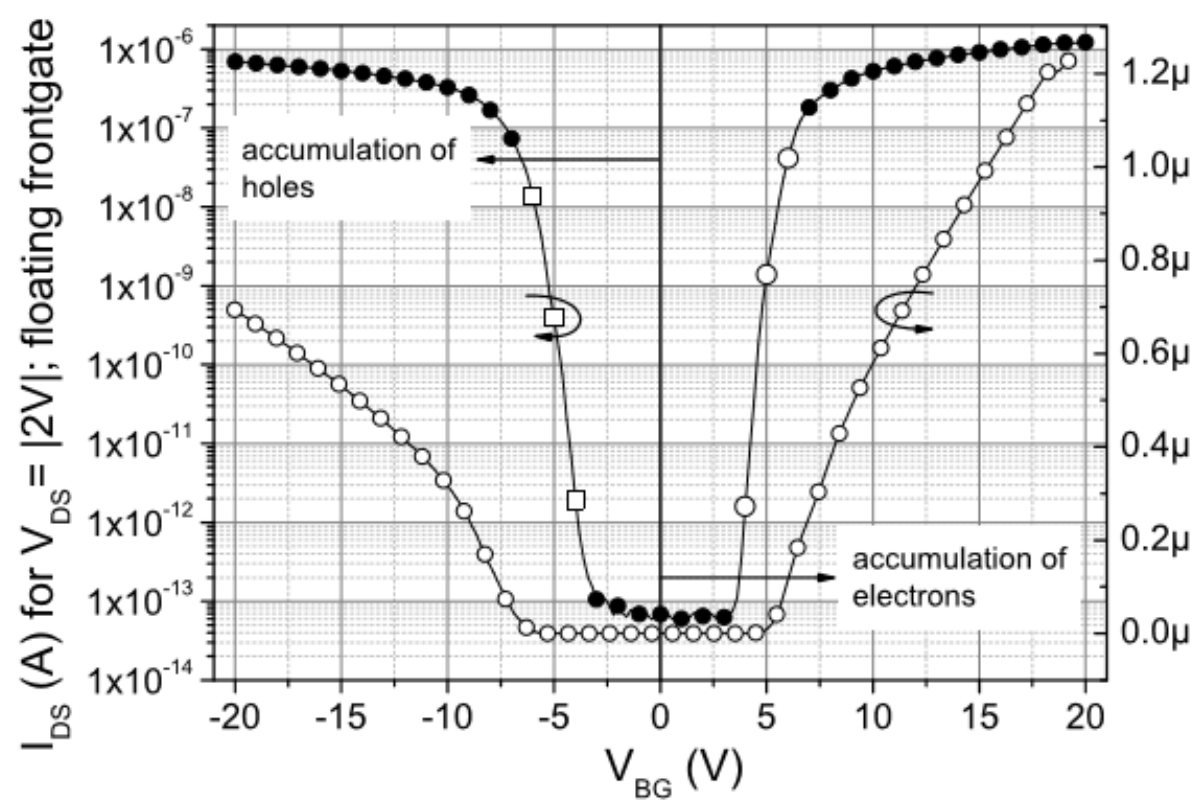

Fonte: J. Appenzeller, 2008, p. 2828

Na figura 23, as curvas da corrente de dreno em função de substrato é apresentada em escala logarítmica e linear. Foram aplicados $-20 \mathrm{~V}>\mathrm{V}_{\mathrm{GB}}>+20 \mathrm{~V}, \mathrm{~V}_{\mathrm{DS}}=|2 \mathrm{~V}|$ e a $\mathrm{V}_{\mathrm{GF}}$ fica flutuando. No lado direito da curva notamos a presença de elétrons e para $\mathrm{V}_{\mathrm{GB}}$ negativo notamos a acumulação de lacunas. Chega-se a esta conclusão devido a $\mu_{\mathrm{e}}>=2 \mu_{\mathrm{h}}$.

\subsection{ESTRUTURA PSEUDO MOS}

A estrutura Pseudo MOS foi desenvolvida para caracterizar lâminas de silício antes de da fabricação de dispositivos na mesma. Qualquer material SOI apresenta uma configuração MOS natural a lâmina, ou seja, a composição da lâmina de filme de silício óxido enterrado e substrato de silício [57]. O filme de silício representa o corpo do transistor e o óxido enterrado funcionaria como o óxido de porta. Por sua vez o substrato funcionaria como porta e pode ser polarizado através de um contato de metal (uma ponta de prova), como apresentado na Figura 24, o que induziria um canal na interface entre o filme de silício e o óxido enterrado. 
Dependendo da polarização aplicada no substrato, positiva ou negativa podemos observar uma indução do canal por inversão ou acumulação.

A fonte e o dreno são formados pelo posicionamento das pontas de provas com uma leve pressão na superfície da lâmina e a distância entre as pontas deve variar entre $100 \mu \mathrm{m}$ até 1 a $5 \mathrm{~mm}$.

Figura 24- Esquema para polarização do Pseudo MOS.

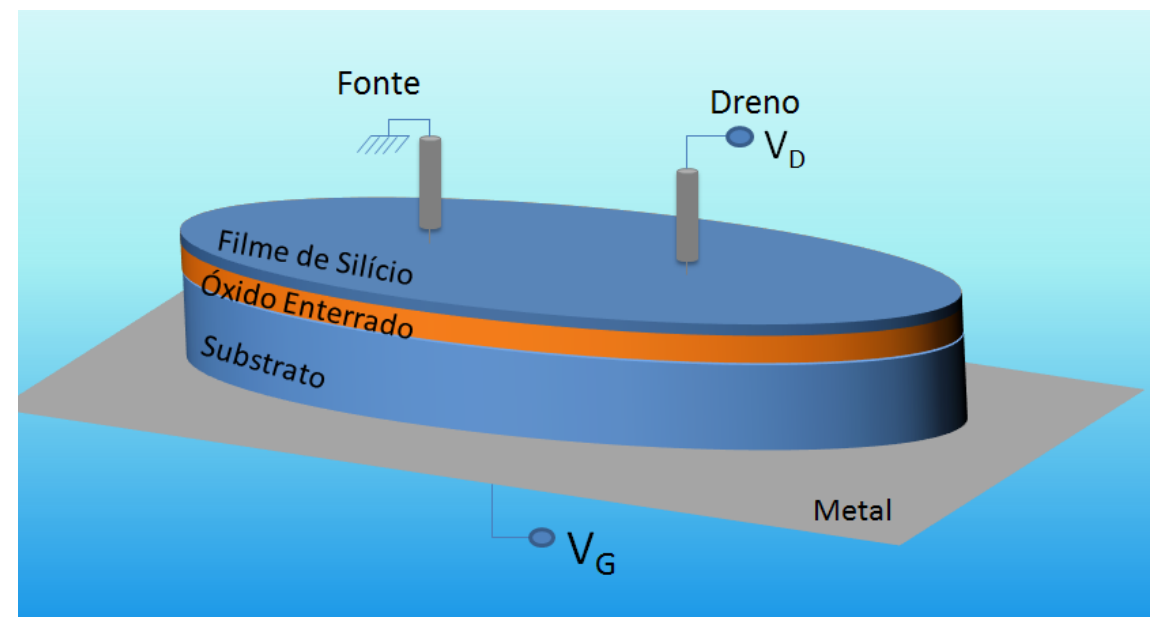

Fonte: Autor.

Geralmente estas medidas são realizadas em ilhas de silício feitas com uma máscara e corrosão e variam de $1 \mathrm{~mm}^{2}$ a $1 \mathrm{~cm}^{2}$. Este processo tem uma vantagem em apresentar uma verificação rápida da uniformidade e a densidade de defeitos no óxido enterrado, medindo a corrente de fuga através do óxido.

Além disso, a superfície da lâmina deve ser estar livre de qualquer óxido inativo e deve estar limpa para evitar degradação das características elétricas por contato deficiente das pontas de prova.

Duas pontas de provas de qualquer sistema podem ser usadas para realizar os contatos de fonte e dreno, no entanto pontas de provas com ajuste de pressão apresentam melhores resultados quando implicam $50 \mathrm{~g}$ de pressão. Assim a resistência série é reduzida e a transcondutância atinge máximo pico. Para $10 \mathrm{~g}$ de pressão as pontas penetram aproximadamente em $10 \mathrm{~nm}$ no filme de silício.

Algumas curvas extraídas de uma lâmina SOI são apresentadas, na Figura 25.São elas: $I_{D}$ em função de $V_{D}$; $I_{D}$ em função de $V_{G}$ e $g_{m}$ em função de $V_{G}$ com $V_{D S}$ de $0,1 \mathrm{~V}$ à $1,4 V$. 
Figura 25- Curvas características da estrutura Pseudo MOS em uma lâmina UNIBOND
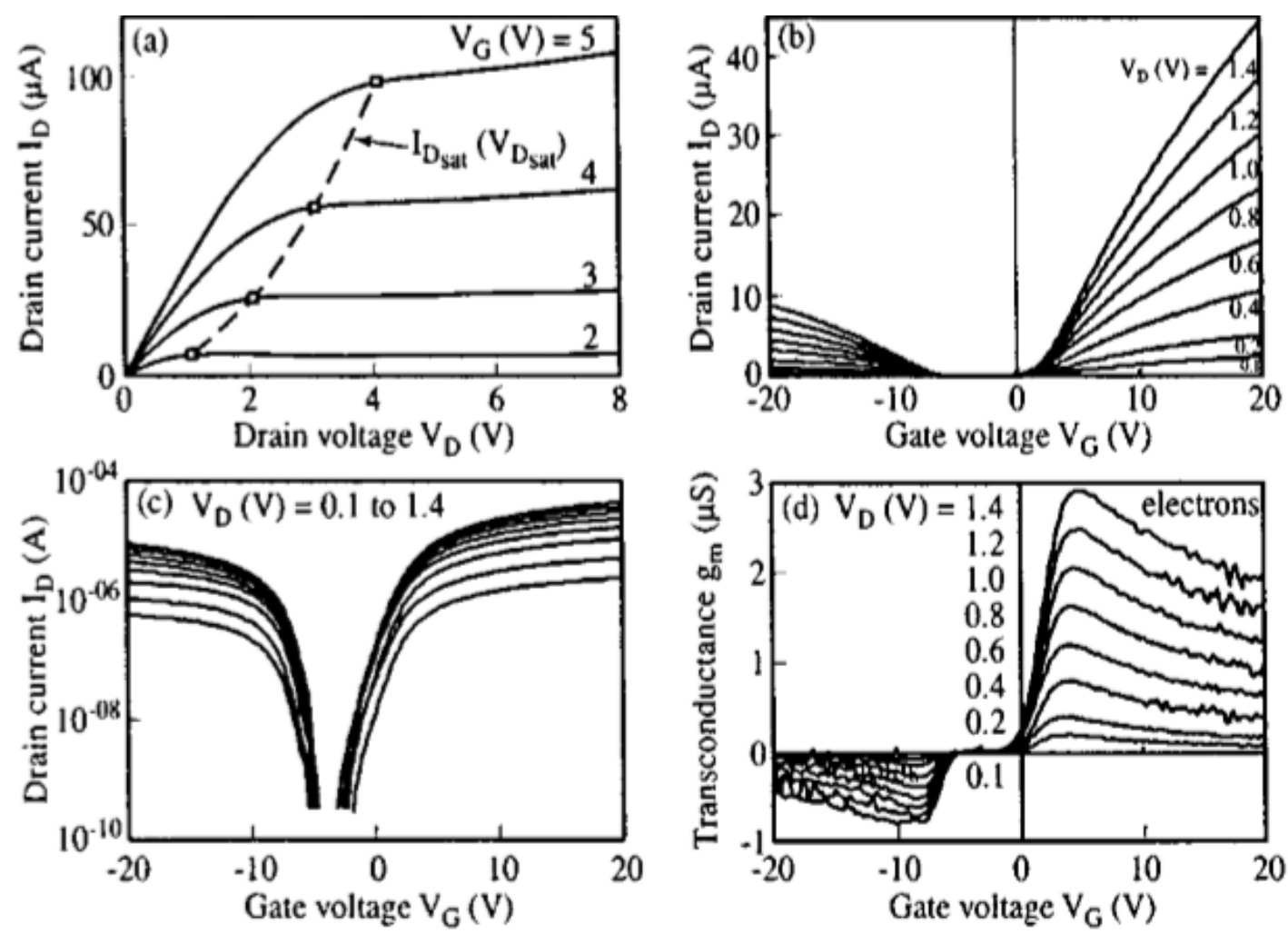

Fonte: S. Cristoloveanu, p.1019, 2000.

Legenda: . (a) $I_{D}$ versus $V_{D}$, (b) $I_{D}$ versus $V_{G}$ com inversão forte e acumulação forte. (c) $I_{D}$ versus $V_{G}$ em escala logarítmica $(\mathrm{d})$ curva da transcondutância.

Curvas com $V_{D}=100 \mathrm{mV}$ foram extraídas de uma lâmina SOI UNIBOND. Foram aplicados a polarização negativa e positiva de $-20 \mathrm{~V}$ à $20 \mathrm{~V}$. Através da curva b podemos extrair a tensão de limiar através da extrapolação das curvas $I_{d} V_{G}$ e interceptação com o eixo horizontal. As mobilidades de elétron e de lacuna podem ser extraídas diretamente através do pico da transcondutância (Figura 25 d).

Para a maioria das lâminas SOI, o filme de silício é totalmente depletado. As características da $I_{D} \times V_{D}$ em inversão ou acumulação forte do Pseudo MOS é descrita pela equação dos transistor MOS convencional para região de saturação e triodo:

$$
I_{D}=\mu . f_{g} \cdot C_{O X} \cdot V_{D}\left(V_{G}-V_{T, F B}-\frac{V_{D}}{2}\right)
$$


onde, Cox é a capacitância do óxido enterrado, $\mathrm{V}_{\mathrm{T}}$ é a tensão de limiar, $\mathrm{V}_{\mathrm{FB}}$ tensão de faixa plana ( que age como $\mathrm{V}_{\mathrm{T}}$ para o canal acumulado),e $\mu$ é a mobilidade dos elétrons e da lacunas, $\mathrm{f}_{\mathrm{g}}$ é o coeficiente geométrico igual $\mathrm{W} / \mathrm{L}$, que não pode ser determinada com precisão devido ao não paralelismo das linhas de corrente entre os dois pontos de contato.

As linhas tracejadas na Figura 25 (a) apresentam $\mathrm{I}_{\mathrm{D}(\mathrm{VDsat})}$ e indicam que a tensão de saturação $\mathrm{V}_{\text {Dsat }}$ comprovam o modelo MOSFET : $\mathrm{V}_{\text {Dsat }}=\sim \mathrm{V}_{\mathrm{G}}-\mathrm{V}_{\mathrm{T}}$.

Para a região linear de operação temos:

$$
I_{D}=f_{G} \cdot C_{o x} V_{D} \frac{\mu_{0}}{1+\theta\left(V_{G}-V_{T, F B}\right)}\left(V_{G}-V_{T, F B}\right)
$$

onde o coeficiente $\theta$ mede a redução da mobilidade pura com o campo elétrico vertical e em função da resistência série $\mathrm{R}_{\mathrm{SD}}$.

$$
\theta=\theta_{0}+\mu_{0} f_{g} C_{o x} R_{S D}
$$

A transcondutância presente na figura Figura 25 (d) é dada pela expressão:

$$
g_{m}=f_{g} C_{o x} V_{D} \frac{\mu_{0}}{\left[1+\theta\left(V_{G}-V_{T, F B}\right)\right]^{2}}
$$

Para inversão fraca as características $\mathrm{Id}\left(\mathrm{V}_{\mathrm{G}}\right)$ seguem :

$$
\begin{gathered}
I_{D}=I_{0} \exp \left(\frac{V_{G}}{S}\right) \\
S=2,3 \frac{K T}{q}\left(1+\frac{C_{S i}+q D_{i t}}{C_{o x}}\right)
\end{gathered}
$$

Onde a tensão de sublimiar depende da capacitância do óxido, do filme depletado $\mathrm{C}_{\mathrm{Si}} \mathrm{e}$ da densidade de armadilhas na interface $\mathrm{D}_{\mathrm{it}}$.

A tensão de limiar para canal tipo $\mathrm{N}$ ou tipo p, é obtida através da extrapolação linear da curva $I_{D} \times V_{G}$ com apresentada na Figura 25 (b). A mobilidade de elétrons e lacunas pode ser extraída do pico da transcondutância como podemos ver na Figura 25 (d).

Para uma abordagem mais precisa, que evitaria efeitos de resistência série de primeira ordem, é necessário plotar a curva linear $\mathrm{I}_{\mathrm{D}} / \mathrm{g}_{\mathrm{m}}$ versus $\mathrm{V}_{\mathrm{G}}$. A mobilidade dos portadores é determinada pela inclinação, $\sqrt{\mu_{0} f_{g} C_{o x} V_{D}}$, e a tensão de limiar é dada pela interceptação com eixo horizontal $\mathrm{x}$. 
A polaridade de dopagem (tipo $\mathrm{n}$ ou p) da sobreposição de silício é induzida pela comparação das resistências em série, extraídas com fórmula (27) a partir do valores de $\theta$, para polarização positiva e negativa de $\mathrm{V}_{\mathrm{G}}$. A resistência da série é sempre menor na acumulação do que no regime de inversão, onde a corrente tem de atravessar a região depletada entre os contatos de fonte / dreno e o canal debaixo.

Filmes de silício dopados com aproximadamente $5 \times 10^{15} \mathrm{~cm}^{-3}$ são precisamente determinados usando valores experimentais de $\mathrm{V}_{\mathrm{FB}}$ e $\mathrm{V}_{\mathrm{T}}$. Para filmes totalmente depletados temos:

$$
V_{T}-V_{F B} \cong 2 \Phi_{F}+\frac{q N_{A}}{C_{o x}} t_{S i}+\frac{q D_{i t}}{C_{o x}} \times 2 \Phi_{F}
$$

Onde a densidade de armadilhas de interface nem sempre é desprezível. Lembrando que os filmes totalmente depletados são reconhecidos pela ausência de corrente de fuga para $\mathrm{V}_{\mathrm{FB}}<\mathrm{V}_{\mathrm{G}}<\mathrm{V}_{\mathrm{T}}$. (Figura $25 \mathrm{a}$ ).

Outro parâmetro relevante, que afeta a capacitância geral dos circuitos integrados SOI, é a concentração de dopante. A concentração de dopante inicial da lâmina de Si pode ter sido modificado (via contaminação, ativação do oxigênio, etc.) durante o processo de fabricação da lâmina SOI. A dopagem do substrato é aproximadamente avaliada a partir do pequeno pico da transcondutância visível na Figura 25 (c). Este pico simplesmente indica que uma região de depleção está se desenvolvendo no substrato. A combinação em série da capacitância de depleção de óxido e substrato é equivalente a um óxido enterrado mais espesso ou a uma redução no valor efetivo de Cox e $g_{m}$. A posição da corcunda reflete o tipo de dopagem enquanto a sua magnitude está relacionada com a magnitude de dopagem.

A caracterização de cargas fixas, $Q_{o x}$ no óxido enterrado procede da análise da tensão de faixa plana como segue:

$$
V_{F B} \cong \Phi_{m e}-\frac{Q_{o x}}{C_{o x}}
$$

onde a diferença de função trabalho de metal semicondutor $\Phi_{m e}$ depende da dopagem no filme de silício e no substrato: $\Phi_{m e}=(k t / q) \ln \left(N_{S i} / N_{s u b}\right)$ para uma estrutura com canal e substrato tipo $\mathrm{n}$.

A densidade de armadilhas de interface é determinada a partir da equação de tensão de sublimiar do lado da inversão: 


$$
S=2,3 \frac{K T}{q}\left(1+\frac{C_{S i}+q D_{i t}}{C_{o x}}\right)
$$

\subsection{ETAPAS DA MICROFABRICAÇÃO}

Nesta seção serão apresentadas as etapas de fabricação utilizadas para a fabricação dos dispositivos.

\subsubsection{Substrato de Silício}

O tipo de dopante, a orientação cristalina e a resistividade do substrato de $\mathrm{Si}$, que são utilizados, são características importantes na fabricação e no desempenho dos dispositivos.

O tipo de dopante, $\mathrm{p}$ ou $\mathrm{n}$, determina os portadores majoritários, lacunas ou elétrons, respectivamente, presentes no substrato e qual processo MOS, pMOS ou nMOS [58]. Em lâminas tipo n, executa-se o processo pMOS, enquanto em tipo p, o nMOS, pois o canal de modo enriquecimento ou depleção do transistor MOS é formado por portadores minoritários presentes no substrato. Dispositivos nMOS apresentam mobilidade maior que os pMOS, pois a mobilidade de elétrons é cerca de três vezes maior que a de lacunas. O tipo de dopante pode ser determinado por um sistema de ponta-quente ou indicado pelo formato do substrato, como indicado na Figura 26.

Figura 26 - Modo de identificação dos Tipos de dopantes e as orientações Cristalográficas de Substratos de Si. 


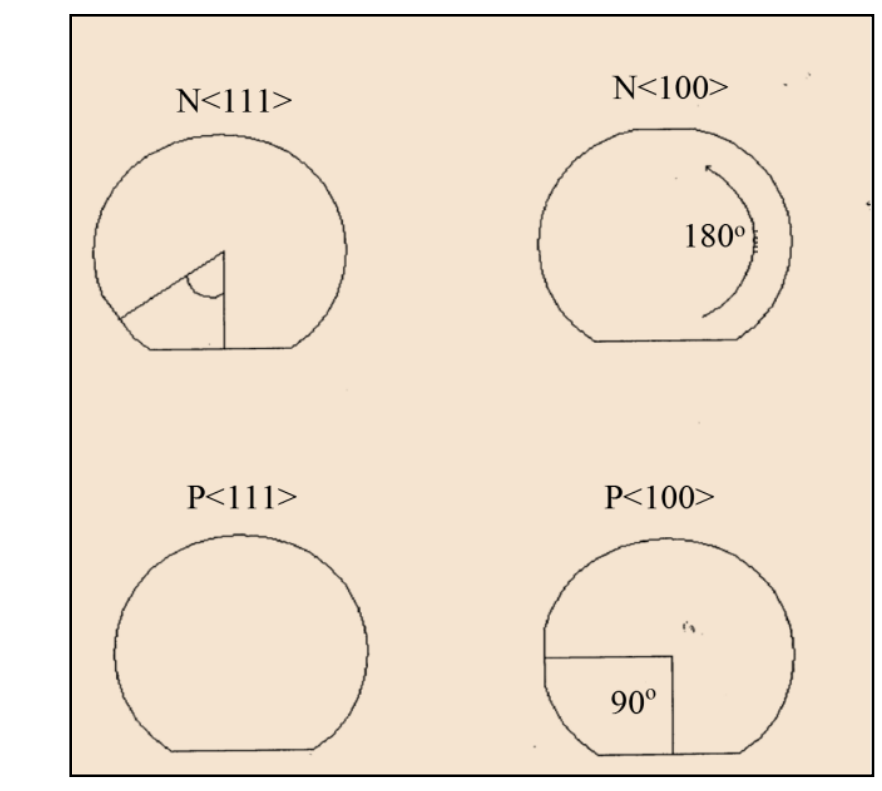

Fonte: Autor.

A Figura 26 mostra que a orientação cristalográfica e o tipo de semicondutor podem ser obtidos por inspeção visual do formato da lâmina. Normalmente, para o Si utilizam-se duas possibilidade de crescimento ou orientação direcional $<111>$ ou $<100>$. O tipo $\mathrm{n}$ ou $\mathrm{p}$ de semicondutor pode ser identificado pela presença e pelo posicionamento dos chanfros laterais. A orientação cristalográfica pode influir principalmente na taxa de oxidação do substrato e na densidade de defeitos no óxido de $\mathrm{Si}$ crescido sobre a lâmina, que originam centros de armadilhamento de cargas no isolante. Estas cargas podem responder de forma indesejável ao campo elétrico aplicado ao dispositivo, reduzindo seu desempenho. Óxidos crescidos sobre lâminas com orientação $<100>$ apresentam menos defeitos que os crescidos sobre substratos com orientação $<111>$. Para fabricação o processo pMOS são utilizadas lâminas tipo n, e com orientação $<100>$, o que resulta em menos defeitos nos óxidos crescidos.

A resistividade $\rho$ indica qual a concentração de dopantes (portadores majoritários) do substrato de Si. É calculada pelas expressões (36)

$$
\begin{gathered}
R_{S}=4,53 \frac{V}{I} \\
\rho=R_{S} * t
\end{gathered}
$$


onde V/I são a tensão e corrente medidos em um equipamento de quatro pontas, Rs é a resistência de folha e t é a espessura do substrato. Quanto menor a concentração de dopantes maior a resistividade na lâmina. Normalmente, utilizam-se substratos com concentrações da ordem de $10^{14}$ a $10^{16} \mathrm{~cm}^{-3}$, resultando em correspondentes resistividades de 1 a $22 \Omega . \mathrm{cm}$.

\subsubsection{Limpeza RCA}

A limpeza das lâminas de silício é fundamental num processo de micro fabricação. Para garantir uma limpeza eficaz, com a menor quantidade possível de impurezas, segue-se um processo padrão RCA (Radio Corporation of America) que consiste na seguinte sequência de etapas, mergulhando-se as lâminas em soluções de:

a) $\mathrm{H}_{2} \mathrm{SO}_{4} / \mathrm{H}_{2} \mathrm{O}_{2}$ com proporção de $(4: 1)$, em $80^{\circ} \mathrm{C}$, por $10 \mathrm{~min}$ : esta solução denominada "piranha", utiliza-se para remover principalmente quantidades de gordura presentes na superfície das lâminas de silício;

b) $\mathrm{HF} / \mathrm{H}_{2} \mathrm{O}$ com proporção de (1:10), em temperatura ambiente por 10s: nesta etapa de limpeza remove-se o óxido de $\mathrm{Si}(\mathrm{SiO} 2)$ nativo na superfície do silício. A reação química do processo é a seguinte: $\mathrm{SiO}_{2}+4 \mathrm{HF} \rightarrow \mathrm{SiF}_{4}+\mathrm{H}_{2} \mathrm{O}$.;

c) $\mathrm{NH}_{4} \mathrm{OH} / \mathrm{H}_{2} \mathrm{O}_{2} / \mathrm{H}_{2} \mathrm{O}$ com proporção de $(1: 1: 5)$, em $80^{\circ} \mathrm{C}$, por 10 min: nesta etapa, removem-se a gordura e os metais do grupo IB e IIIB $(\mathrm{Cu}, \mathrm{Ag}, \mathrm{Zn}, \mathrm{Cd})$;

d) $\mathrm{HCl} / \mathrm{H}_{2} \mathrm{O}_{2} / \mathrm{H}_{2} \mathrm{O}$ com proporção de $(1: 1: 5)$ em $80^{\circ} \mathrm{C}$ por $10 \mathrm{~min}$ : nesta etapa dissolvem-se os íons alcalinos e hidróxidos de $\mathrm{Fe}^{+3}, \mathrm{Al}^{+3}$ e $\mathrm{Mg}^{+3}$ das superfícies dos substratos.

Entre uma solução e outra, as lâminas são submetidas a um enxágue com água DI (deionizada) $18 \mathrm{M} \Omega . c m$ por $3 \mathrm{~min}$. A secagem destas lâminas é feita com jato de nitrogênio.

\subsubsection{Oxidação}

A oxidação refere-se ao processo químico no qual o oxigênio reage com o silício para formar o dióxido de silício $\left(\mathrm{SiO}_{2}\right)$. Para se alcançar uma camada contínua e de alta qualidade de $\mathrm{SiO}_{2}$, usa-se a oxidação térmica onde a temperatura do "wafer" varia de $1000^{\circ} \mathrm{C}$ a $1200^{\circ} \mathrm{C}$. 
Um filme de $\mathrm{SiO}_{2}$ de qualidade inferior pode ser obtido através de outros processos [57]. A oxidação é um dos passos mais frequentes no processo de fabricação do Circuito Integrado e é usada como:

a) máscara, durante a difusão do dopante;

b) passivação;

c) óxido isolante;

d) dielétrico de porta de dispositivos MOS.

A oxidação térmica neste trabalho foi obtida através de duas técnicas diferentes: oxidação térmica seca através do forno convencional e oxidação por plasma ECR (Electron Cyclotron Resonance) .

A oxidação no forno convencional, Figura 27, é obtida expondo-se o silício a uma alta temperatura em um ambiente contendo oxigênio de alta pureza. A oxidação pode ser seca ("dry oxide") ou úmida ("wet oxide"), usando-se vapor de água. A oxidação usando vapor de água é mais rápida, porém a oxidação usando oxigênio conduz a melhores características elétricas. A espessura da camada de $\mathrm{SiO}_{2}$ varia de $0,02 \mu \mathrm{m}$ a $2 \mu \mathrm{m}$, sendo a temperatura do processo, a concentração de impurezas e o tempo fatores que determinam a espessura real. Uma vez que um átomo de silício, relativamente pequeno (raio de $0.042 \mu \mathrm{m}$ ), associa-se com 2 átomos de oxigênio, relativamente grandes (raio de $0.132 \mu \mathrm{m}$ ), a molécula de dióxido de silício formada é muito maior do que a molécula de silício original. Ocorre também neste processo, o consumo da lâmina de silício, ou seja, o silício consumido é equivalente a $46 \%$ da espessura final do oxido crescido [59].

Figura 27- Sistema de fornos convencionais do CCS- UNICAMP.

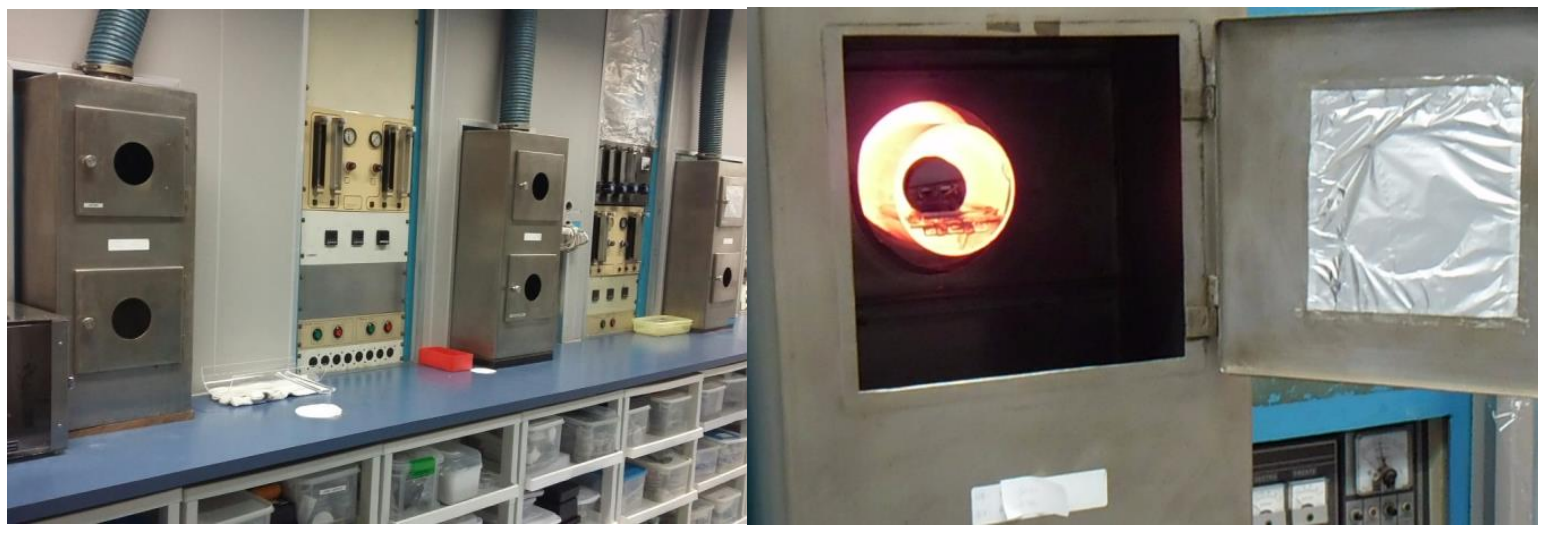

Fonte: Autor. 
O outro sistema utilizado foi o equipamento ECR assistido por plasma que se caracteriza por um sistema de deposição CVD (processo de deposição química a vapor) por plasma. O sistema ECR utiliza uma fonte de microondas para a geração do plasma com frequências entre $916 \mathrm{MHz}$ e 3,5 GHz, empregando também, um campo magnético estático (ímãs permanentes), possibilitando assim, densidades da ordem de 1011 a 1013 íons/cm3). Este sistema trabalha com pressões baixas $(<10$ mTorr), apresentando uma alta densidade com baixos potenciais de plasma, possibilitando obter-se filmes de excelente qualidade com temperaturas baixas $\left(<120^{\circ} \mathrm{C}\right)[60]$.

\subsubsection{Fotolitografia}

Fotolitografia é a técnica usada na fabricação de CIs para transferir um padrão desejado para a superfície da lâmina de Silício, sendo considerada a etapa fundamental de todo o processo de miniaturização.

Neste projeto utilizamos duas técnicas diferentes das etapas fotolitográficas, ótica (utilizando MJB3 da Figura 28) e por feixe de elétrons.

Para estas duas técnicas é necessário a aplicação do fotoresiste (que é um líquido orgânico polimérico) e eletroresiste para as técnicas de litografia ótica e litografia por feixe de elétrons respectivamente. Para isto utiliza-se um sistema de "spinner" em alta velocidade de rotação, maior que $3000 \mathrm{rpm}$ e por centrifugação espalha-se sobre a camada do óxido uma resina como apresentada na Figura 29 (a). Para a litografia ótica é utilizada uma máscara com áreas transparentes e opacas, que representam o padrão a ser transferido para a lâmina, é colocada sobre o material fotossensível e, por exposição à luz ultravioleta, este material será polimerizado nas regiões expostas à luz UV, Figura 29 (b). A seguir, Figura 29 (c), o "photoresist" não polimerizado (as áreas não expostas à luz) é removido expondo o Si em regiões que seguem o mesmo padrão original da mascara utilizada, Figura 29 (d).

Figura 28- MJB3 sistema de fotolitografia ótica do CCS. 


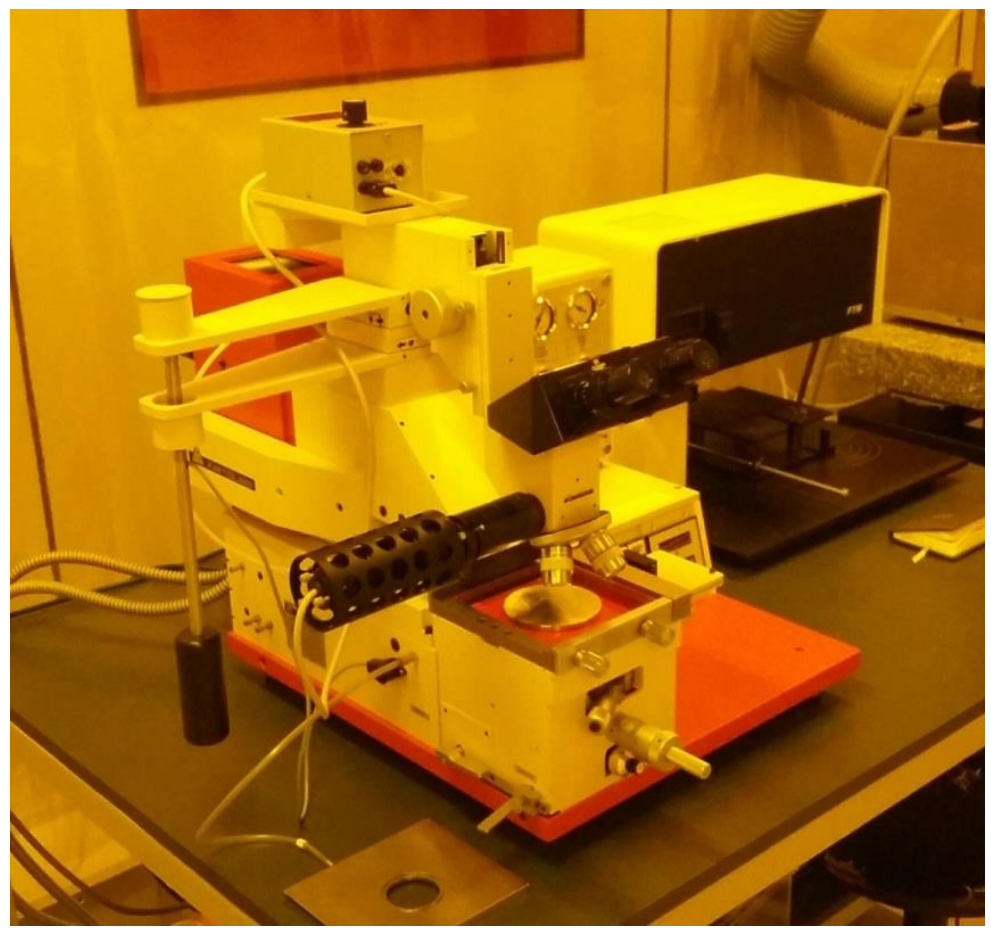

Fonte: Autor.

Figura 29- Esquema para de fotogravação pela técnica de fotolitografia ótica de contato.

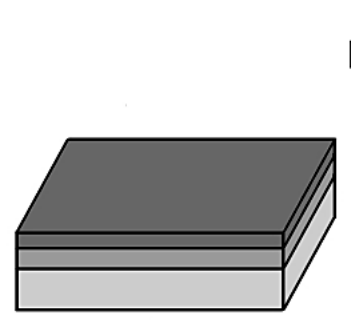

a)

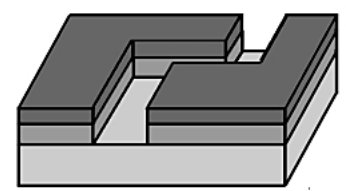

d)

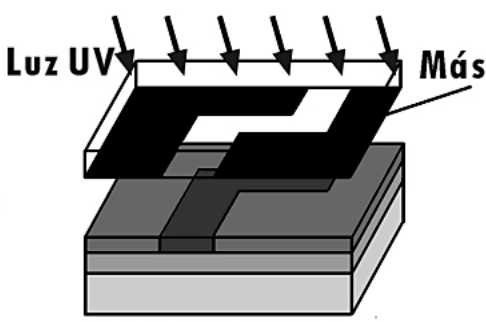

b)

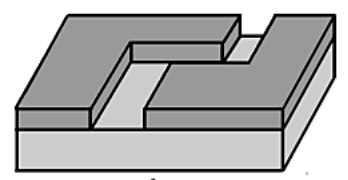

e)

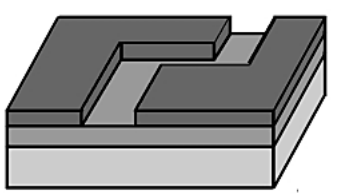

c)

Fotorresiste

$\mathrm{SiO}_{2}$

$\mathrm{Si}-\mathbf{n}$

Fonte: Swart, J. W, 2008.

A seguir a lâmina de Si pode ser submetida a uma variedade de processos (deposição de metais, corrosão, implantação iônica, etc.) que alcançarão o Si apenas nas regiões expostas, 
Figura 29 (e). O procedimento descrito é corresponde ao fotoresiste positivo, no qual as áreas expostas à luz UV é que são removidas. A precisão da transferência de geometrias da máscara para a lâmina de Si determina a resolução do processo fotolitográfico.

A litografia por feixe de elétrons é um processo diferente dos convencionais (óticos) pois não utiliza máscaras de transferência de padrões. Esta litografia consiste basicamente em um feixe de elétrons focado que pode ser defletido e interrompido através de comandos programáveis por computador e usado para desenhar uma dada estrutura. A exposição do resiste ao feixe modifica suas características químicas de tal forma que pode ser realizar uma remoção seletiva do material exposto criando um padrão desejado. Este padrão funciona como uma máscara para próximas etapas como corrosão, deposição e etc.

A litografia ótica neste trabalho foi realizada com uma fotoalinhadora Karl Kuss-MJB3 com resolução de lum e a litografia por feixe de elétrons foi realizada com equipamento apresentado na Figura 30, Raith E-line com resolução de 0,5nm de linha.

Figura 30- Equipamento de fotolitografia por feixe de elétrons Raith E-line. 


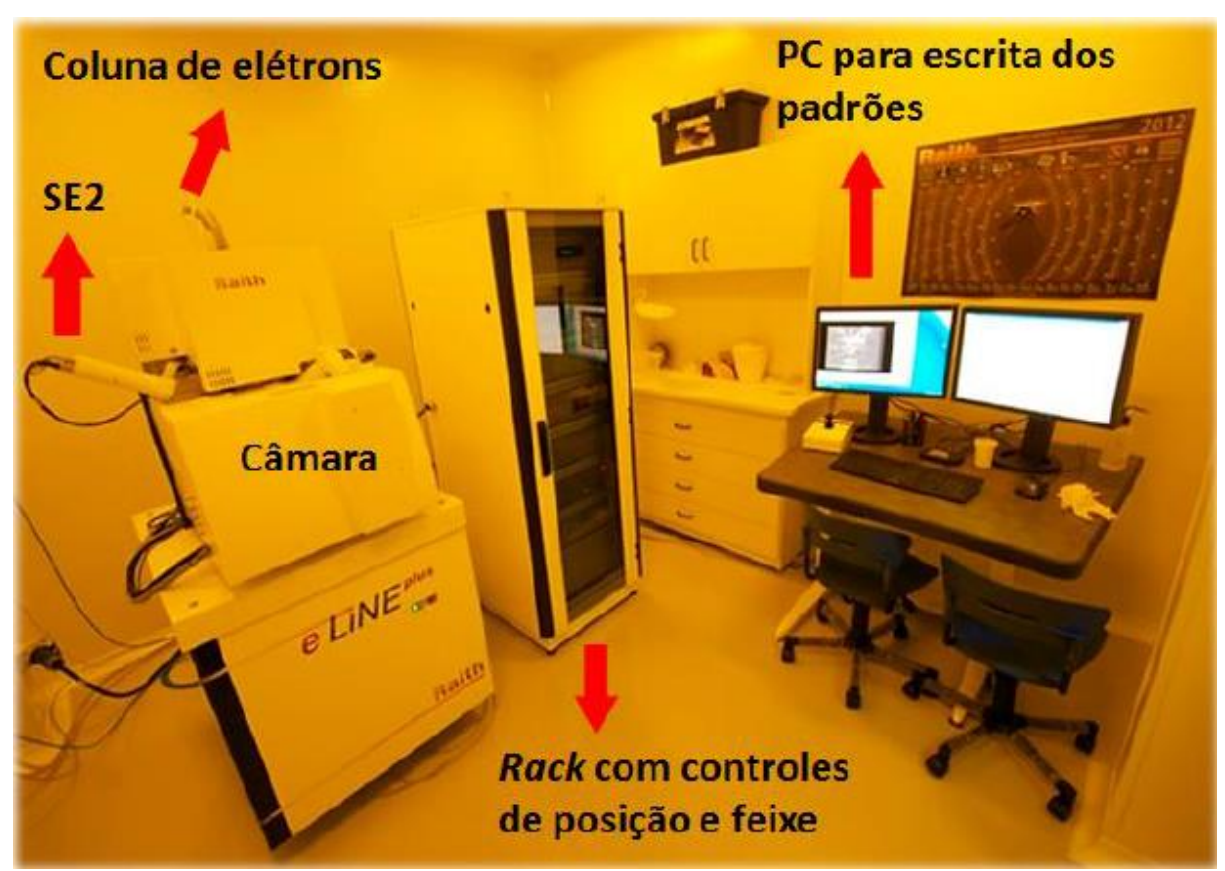

Fonte: Puydinger M., 2016 [64].

\subsubsection{Implantação Iônica}

Um método de se introduzir impurezas é a implantação iônica. Em um ambiente de baixa pressão (idealmente vácuo), íons apropriados (Boro para tipo p e Fósforo para tipo n) são acelerados de forma a adquirirem uma alta energia cinética em direção à lâmina. A profundidade de penetração está relacionada com a energia do feixe de íons, a qual pode ser controlada pela intensidade do campo de aceleração. A quantidade de íons implantada pode ser controlada pela variação da corrente do feixe (fluxo dos íons). Uma vez que a voltagem e a corrente podem ser medidas e controladas com precisão, a implantação iônica resulta em perfis mais precisos e que podem ser reproduzidos mais facilmente. Como outra vantagem, a implantação iônica é feita a temperatura ambiente [58]. Abaixo na figura 31 uma imagem do implantador utilizado para a fabricação do dispositivo.

Figura 31- Implantador de íons do CCS-UNICAMP. 


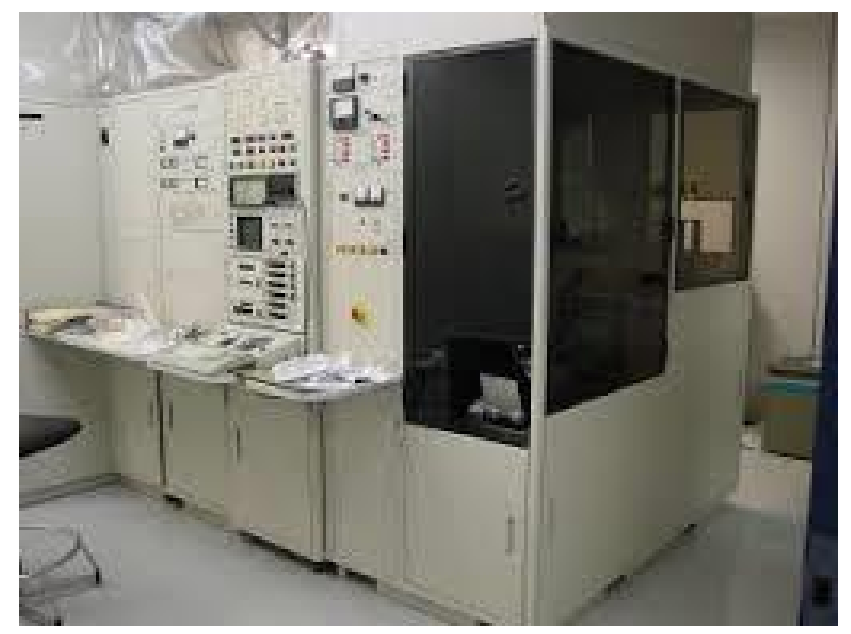

Fonte: Autor.

\subsubsection{Recozimento Térmico}

A introdução de íons no material por implantação iônica resulta em uma grande quantidade de defeitos na estrutura do material degradando suas propriedades. Características como mobilidade dos portadores de carga e tempo de vida de minoritários são alteradas. Os dopantes implantados não estão eletricamente ativos, pois não estão substitucionais aos átomos da rede. Contudo para ativar os dopantes e diminuir as quantidades de defeitos é necessária a realização de um recozimento através de tratamentos térmicos em combinação adequada de temperatura e tempo de recozimento.

O tempo de recozimento é diretamente proporcional à difusão de dopantes no substrato. Recozimentos com temperaturas tão baixas quanto $600^{\circ} \mathrm{C}$ são suficientes para ativação elétrica, porém haverá a formação de muitos defeitos na interface, devido ao lento rearranjo dos átomos nas posições substitucionais. Para eliminar estes defeitos o recozimento deve ser efetuado à temperaturas em torno de $1000^{\circ} \mathrm{C}$.

Há duas maneiras de realizar este recozimento, em forno convencional (Furnace Annealing) e os recozimentos RTA (Rapid Thermal Annealing).

Um forno convencional consiste em resistências em um tubo de quartzo onde as lâminas são inseridas e este garante um controle preciso da temperatura com passos de aproximadamente $1^{\circ} \mathrm{C}$. Este método é utilizado para recozimentos com tempos mais longos. Já RTA fornece um aumento rápido da temperatura e tem como objetivo manter as lâminas na temperatura de recozimento por segundos ou alguns minutos 


\subsubsection{Corrosão (Etching)}

Corrosão na fabricação de dispositivos semicondutores consiste na remoção ou modificação de uma material não protegido por um fotorresiste. A corrosão úmida pode ser anisotrópica (dependente da orientação do cristal) ou isotrópica (independente da orientação do cristal) com apresentada na Figura 32. A corrosão anisotrópica realiza a corrosão em sentido vertical já na isotrópica corrói também no sentido horizontal ocasionando o underetching. Neste trabalho foram utilizadas a corrosão úmida isotrópica para abertura de contatos e a corrosão seca por plasma anisotrópica para definição das mesas de Si.

Figura 32- Substrato coberto por um padrão com fotorresiste e mostrando uma corrosão anisotrópica e isotrópica.

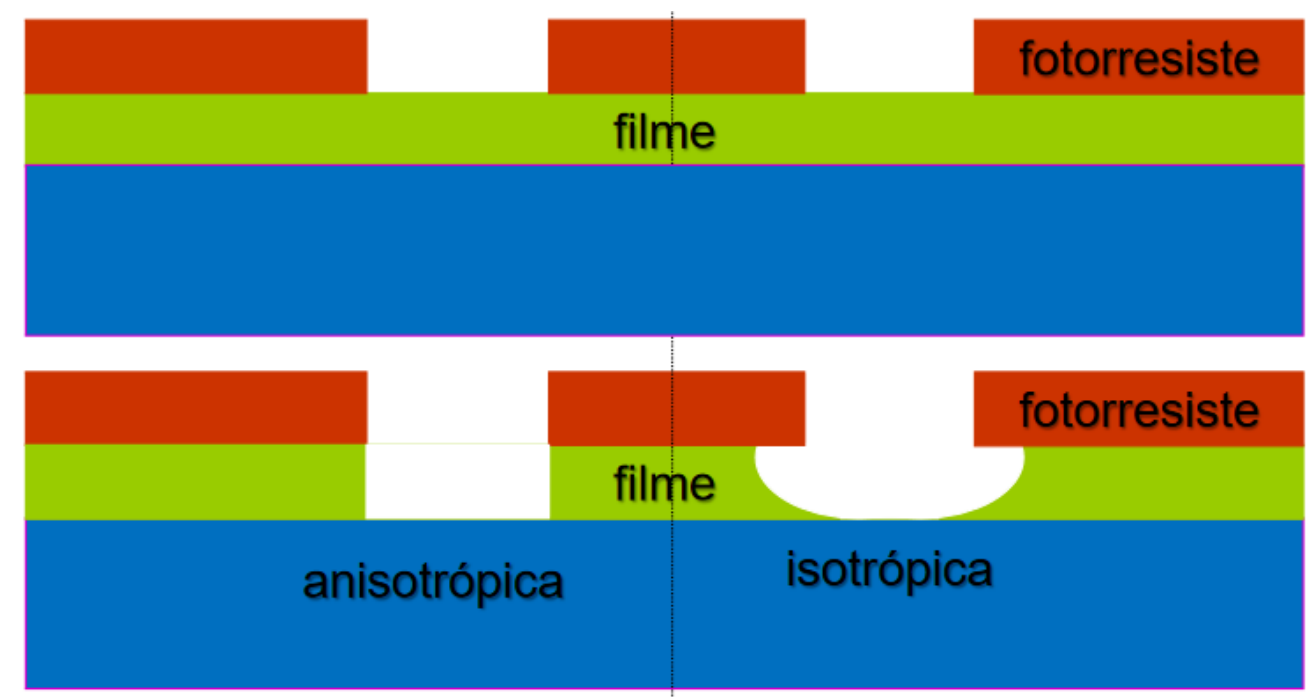

Fonte: Autor.

$\mathrm{Na}$ etapa de abertura de contatos, as lâminas processadas nesse trabalho foram submetidas a uma corrosão úmida através do buffer de HF com taxa de corrosão de $100 \mathrm{~nm} / \mathrm{min}$.

No entanto para a definição da região ativa foi utilizado a corrosão seca por plasma. Isto pois esta etapa exigia paredes de silício bem definidas, e na etapa de abertura de contatos o under etching não atrapalharia o processo já que as cavidades de contato são distantes da região de porta.

Para realizar a corrosão seca por plasma foi utilizado o equipamento ICP (Inductively Coupled Plasma). Este sistema de plasma acoplado indutivamente, foi o primeiro sistema desenvolvido e empregado em estudos de plasmas. Os sistemas ICP atuais são equipamentos 
híbridos, com uma mistura de acoplamento (capacitivo e indutivo). Existem principalmente duas configurações de ICP: a com fonte indutiva planar e a com fonte indutiva cilíndrica. Esta diferença distingue os tipos de ICPs: cilíndricos (helical inductive coupled e helical resonators) e planares (spiral inductive coupleds). Nestes sistemas, o plasma é gerado pelo campo magnético e os íons são acelerados contra a amostra por campo elétrico. Porém, às vezes é interessante não termos nenhum tipo de ataque iônico, por isso, é necessário eliminar até o campo elétrico associados aos indutores utilizados na geração do plasma, com isso, são usados escudos eletrostáticos que tornam o acoplamento puramente indutivo, melhorando a qualidade dos processos de corrosão.

Figura 33- ICP (Inductively Coupled Plasmas) do CCS.

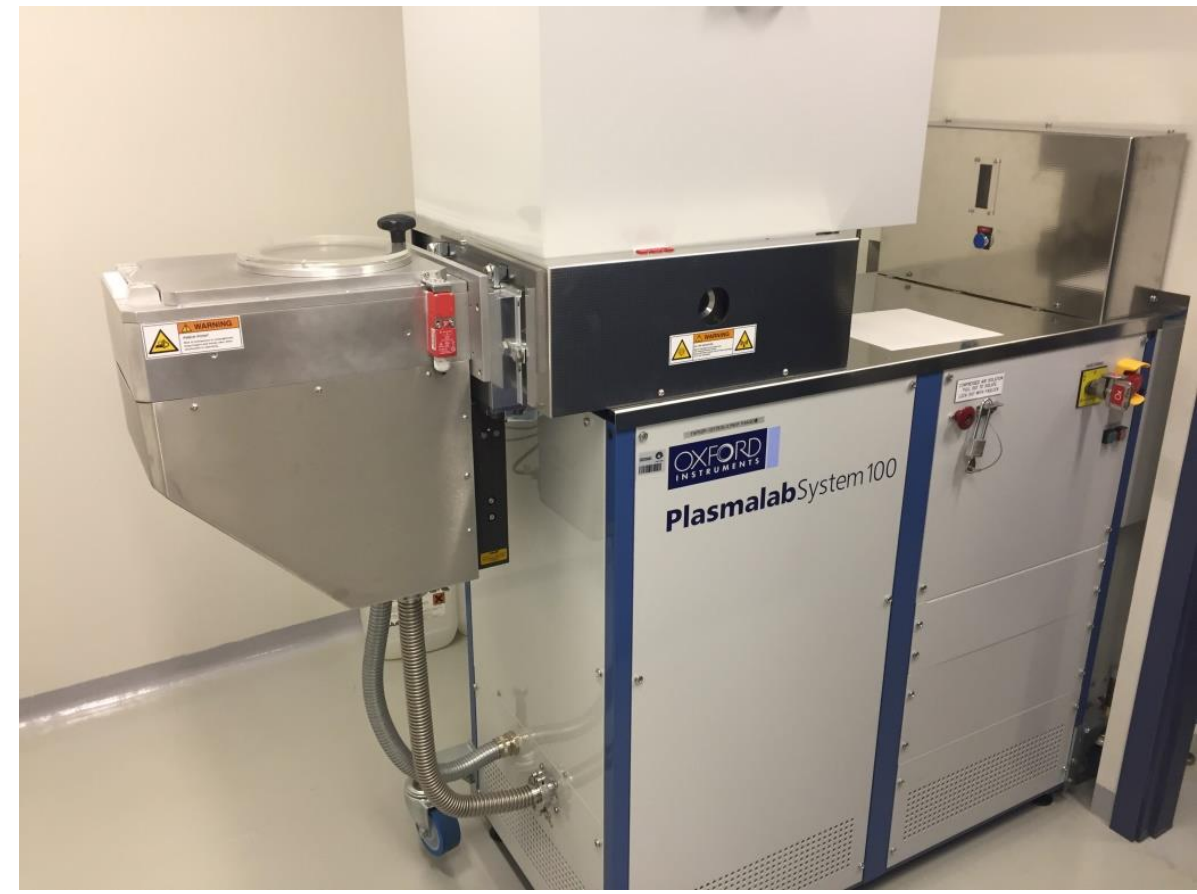

Fonte: Autor. 


\section{PROJETO DO PROCESSO DE FABRICAÇÃO}

O processo de fabricação de um Circuito Integrado consiste de uma série de passos que são elaborados em uma ordem específica. A realização destes passos converte um projeto de circuito em um componente real. Neste capítulo, são apresentados os parâmetros de processo que foram calibrados através de simulações bidimensionais, tais como implantação iônica, oxidação de porta, recozimento térmico. No final do capítulo foram inseridas curvas dos transistores simulados, estas curvas fazem parte do projeto, pois confirmam a tensão de limiar e outros parâmetros esperados. Outras etapas como corrosão úmida e seca, sinterização, doses da litografia, tempo de revelação foram definidas no decorrer do projeto, pois foram feitos testes experimentais e estão descritas no capítulo 4 (fabricação dos transistores).

\subsection{SIMULAÇÃO DO PROCESSO DE FABRICAÇÃO JUNCTINOLESS}

Para a fabricação do junctionless SOI foi utilizado um simulador tridimencional ATHENA e ATLAS da Silvaco. Como este transistor apresenta o mesmo tipo de dopante em toda região de canal, de fonte até dreno, esta sequência do processo apresenta menos etapas quando comparado ao transistor SOI MOSFET, sendo assim apenas um tipo de impureza será implantada simplificando o processo.

Para a simulação do transistor sem junção foram utilizadas as lâminas SOI da empresa SOITEC de $300 \mathrm{~mm}$ com substrato de $700 \mu \mathrm{m}$, óxido enterrado de $20 \mathrm{~nm}$ e espessura de silício de $14 \mathrm{~nm}$.

Para este dispositivo, foi simulado antes da implantação um óxido $\left(\mathrm{SiO}_{2}\right)$ de $60 \mathrm{~nm}$ de espessura, com a função de proteger o canal de fortes colisões no momento da implantação iônica. Deste modo a camada de silício do dispositivo é protegida quando o dopante é implantado.

Para esta simulação foi utilizado o simulador TRIM [61] que é um programa de computador que utiliza o método Monte Carlo para calcular a interação de íons em alvos de diversos materiais. É possível calcular energia de freamento e o alcance de íons na matéria utilizando um modelo baseado em mecânica clássica para colisão entre átomo e íons. A Figura 34 apresenta o perfil de íons de fósforo na estrutura SOI com energia de $20 \mathrm{keV}$ e ângulo de ataque de $7^{\circ}$ para feixe de Fósforo. 
Figura 34- Perfil de íons de fósforo na estrutura SOI.

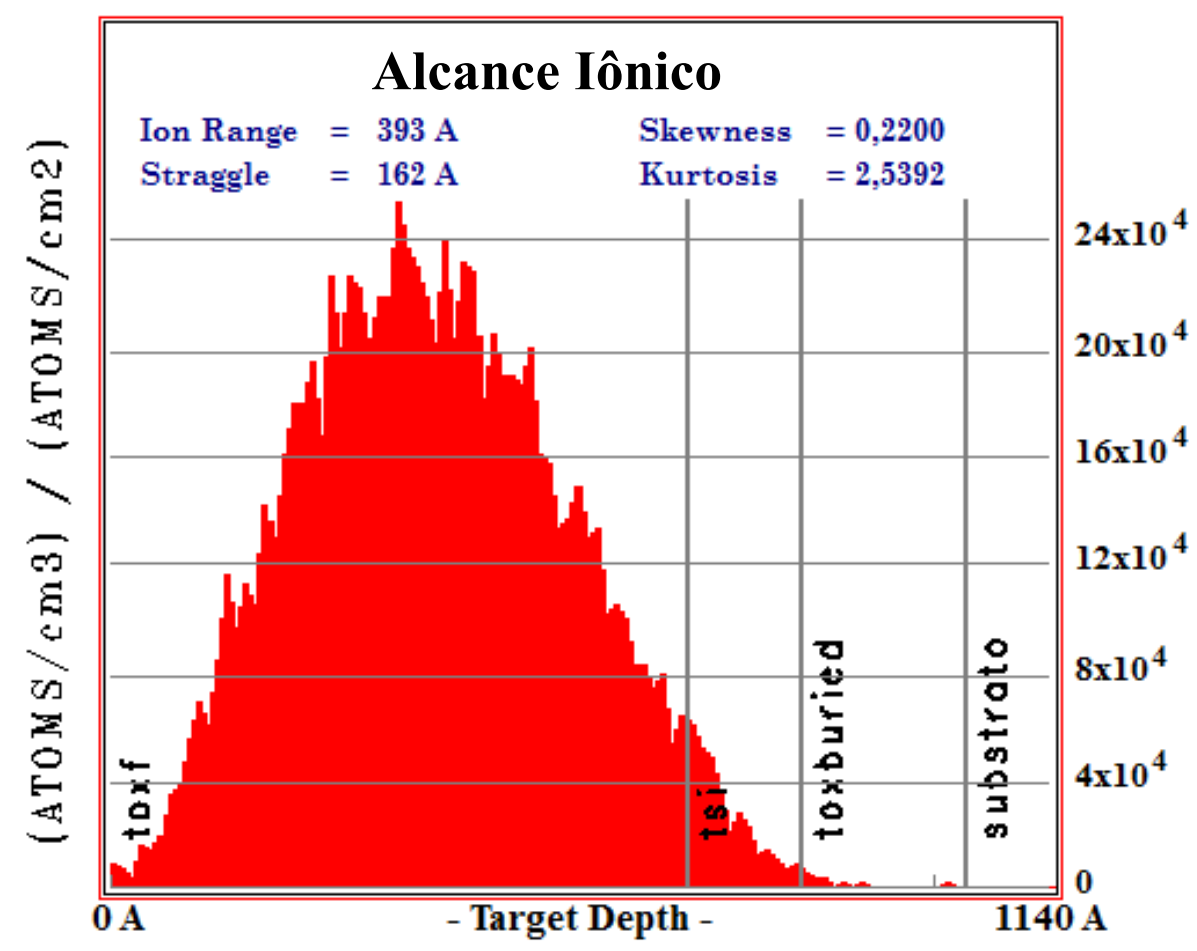

Fonte: Autor.

Legenda: com óxido de sacrifício de $60 \mathrm{~nm}$ de espessura, após implantação (energia de $20 \mathrm{keV}$ e ângulo de ataque de $7^{\circ}$ ).

Nesta figura é possível observar que para a dose implantada a maior energia é subtraída na região do óxido de sacrifício, garantindo que a região ativa apresente menos defeitos na superfície. Após a definição da espessura e implantações foi realizado o recozimento RTA do dispositivo, a $1000^{\circ} \mathrm{C}$ com tempo estimado de $1 \mathrm{~min}$ com uma rampa de $50^{\circ} \mathrm{C} / \mathrm{s} \mathrm{em}$ ambiente inerte, através de simulações tridimensionais no simulados da Silvaco para confirmar a concentração final da lâmina alpha $\mathrm{N}_{\mathrm{D}}=2 \mathrm{e} 18 \mathrm{~cm}^{-3}$ e para lâmina beta $\mathrm{N}_{\mathrm{D}}=5 \mathrm{e} 17 \mathrm{~cm}^{-3}$.

Após esta etapa é realizada a oxidação térmica seca que será o óxido de porta, os parâmetros da oxidação serão apresentados de forma que obtenha uma espessura de aproximadamente $7 \mathrm{~nm}$. Para isto deve-se levar em consideração a espessura do filme de silício, de $14 \mathrm{~nm}$, pois o $\mathrm{SiO}_{2}$ tem aproximadamente o dobro do volume do $\mathrm{Si}$ e, e consequentemente o processo de oxidação consome muito silício.

Para realizar a oxidação são necessárias etapas precedentes a oxidação seca principal apresentada na, Tabela 1. 
Tabela 1- Sequência necessária para oxidação.

\begin{tabular}{ccc}
\hline Etapa & Ambiente & Tempo (min) \\
\hline 1 & $\mathrm{~N}_{2}$ & $>3$ \\
2 & $\mathrm{~N}_{2}$ & 5 \\
3 & $\mathrm{O}_{2}$ & 5 \\
4 & $\mathrm{O}_{2}+1 \% \mathrm{TCE}$ & 30 \\
5 & $\mathrm{O}_{2}$ & 5 \\
6 & $\mathrm{~N}_{2}$ & 5 \\
7 & $\mathrm{~N}_{2}$ & $>3$ \\
\hline Fonte: Autor. & &
\end{tabular}

Etapa 1: Esta etapa visa evitar efeitos de choque térmico, como a quebra pela exposição à ambiente com diferença abrupta da temperatura.

Etapa 2: Esta etapa visa reorganizar a superfície da lâmina que foi modificada pelo processo de implantação iônica, e também realizar a ativação dos dopantes, ou seja, estabelecer ligações covalentes entre o elemento dopante na rede cristalina do silício. Utilizada também para estabilização térmica.

Etapa 3: A etapa de 5min de oxigênio é usada para purgar o nitrogênio presente na etapa anterior, que se misturado ao TCE (tetracloroetileno) à $1000^{\circ} \mathrm{C}$ formaria gás cinza, que é extremamente tóxico. O uso do TCE é necessário para que seja minimizada a presença de metais como o sódio no óxido. Este gás é usado em baixa concentração devido à sua toxicidade.

Etapa 4: Esta etapa é para fabricação do óxido de melhor qualidade e utilizamos o TCE para eliminarmos qualquer tipo de substâncias minerais, sódio, dentro do óxido, porém este gás ao reagir com $\mathrm{N}_{2}$ em altas temperaturas forma um gás cinza muito tóxico.

Etapa 5: Para purgar o TCE.

Etapa 6:Este recozimento necessário para eliminar cargas fixas, fornecendo energia para os óxidos que ainda não fizeram ligação covalente se ligarem ao Si.

Etapa7: Utilizada na retirada da lâmina do forno com objetivo de evitar o choque térmico. 
Contudo, para a determinação do tempo e temperatura foram feitas simulações que chegaram aos valores apresentados na Tabela 2, onde o valor Tx é o tempo correspondente a etapa 4 da oxidação de melhor interface .

Tabela 2 - Parâmetros (tempo e temperatura) da Oxidação de Porta.

\begin{tabular}{|c|c|c|c|c|c|c|c|c|}
\hline \multicolumn{3}{|c|}{ Temperatura $=850^{\circ} \mathrm{C}$} & \multicolumn{3}{|c|}{ Temperatura $=900^{\circ} \mathrm{C}$} & \multicolumn{3}{|c|}{ Temperatura $=1000^{\circ} \mathrm{C}$} \\
\hline $\mathrm{t}_{\mathrm{oxf}}(\mathrm{nm})$ & $\mathrm{t}_{\mathrm{Si}}(\mathrm{nm})$ & $\mathrm{Tx}$ & $\mathrm{t}_{\mathrm{oxf}}(\mathrm{nm})$ & $\mathrm{t}_{\mathrm{Si}}(\mathrm{nm})$ & $\mathrm{Tx}$ & $\mathrm{t}_{\mathrm{oxf}}(\mathrm{nm})$ & $\mathrm{t}_{\mathrm{Si}}(\mathrm{nm})$ & $\mathrm{Tx}$ \\
\hline 3,96 & 13,0 & 1 & 6,65 & 11,9 & 1 & 17,00 & 7,27 & 0,1 \\
\hline 4,22 & 13,0 & 2 & 7,26 & 11,6 & 2 & 18,50 & 6,51 & 0,9 \\
\hline 4,50 & 12,8 & 3 & 7,80 & 11,3 & 3 & 18,60 & 6,46 & $1 \mathrm{~min}$ \\
\hline 4,76 & 12,7 & 4 & 8,4 & 11,1 & 4 & & & \\
\hline 5,03 & 12,6 & 5 & 8,91 & 10,8 & 5 & & & \\
\hline 5,32 & 12,5 & 6 & 9,55 & 10,6 & 6 & & & \\
\hline 5,57 & 12,4 & 7 & 10,10 & 10,3 & 7 & & & \\
\hline 5,84 & 12,3 & 8 & 10,60 & 9,93 & 8 & & & \\
\hline 6,10 & 12,2 & 9 & 11,20 & 9,77 & 9 & & & \\
\hline 6,29 & 12,0 & 10 & 11,70 & 9,58 & 10 & & & \\
\hline 7,60 & 11,5 & 15 & & & & & & \\
\hline 8,78 & 10,9 & 20 & & & & & & \\
\hline 10,00 & 10,3 & 25 & & & & & & \\
\hline 11,30 & 9,8 & 30 & & & & & & \\
\hline
\end{tabular}

Fonte:Autor.

A partir da Tabela 2, nota-se que duas temperaturas são possíveis para realizar esta oxidação com espessura de aproximadamente $7 \mathrm{~nm}, 850^{\circ} \mathrm{C}$ e $900^{\circ} \mathrm{C}$, de 15 e 2 minutos respectivamente. Considerando que quanto maior o tempo que as lâminas ficam no forno maior controle se tem sobre a oxidação. Com isso a temperatura de $850^{\circ} \mathrm{C}$ e tempo de 15 minutos foram selecionados.

Em seguida é realizada a abertura de contatos, e depositado o material de porta e contatos de fonte e dreno. 


\subsection{SIMULAÇÃO DO PROCESSO DE FABRICAÇÃO NWFETS}

Outro dispositivo a ser projetado e implementado neste projeto são os nano fios não dopados em substratos SOI, também pode ser compreendido como um transistor sem junção com a dopagem da lâmina de $1 \mathrm{e} 15 \mathrm{~cm}^{-3}$, este dispositivo foi agregado ao projeto por apresentar inúmeras vantagens aos transistores planares CMOS além de ultimamente estar sendo estudado por diversos grupos de pesquisa pelo mundo e ser apontado como um grande substituto para transistores planares CMOS. Além de apresentar processo de fabricação bem mais simples, pois não apresenta etapas de implantação iônica nem recozimentos térmicos para ativação de dopantes.

Este dispositivo é caracterizado por um nano fio de silício, envolto por um óxido de porta em um substrato SOI. A Figura 35 abaixo apresenta a simulação do dispositivo no simulador 3D ATLAS da Silvaco, evidenciando a concentração de dopantes constante em todo canal entre fonte e dreno, no valor de $\mathrm{N}_{\mathrm{A}}=1 \mathrm{e} 15 \mathrm{~cm}^{-3}$.

Figura 35- Simulação do transistor Nano-fio não-dopado 3D.

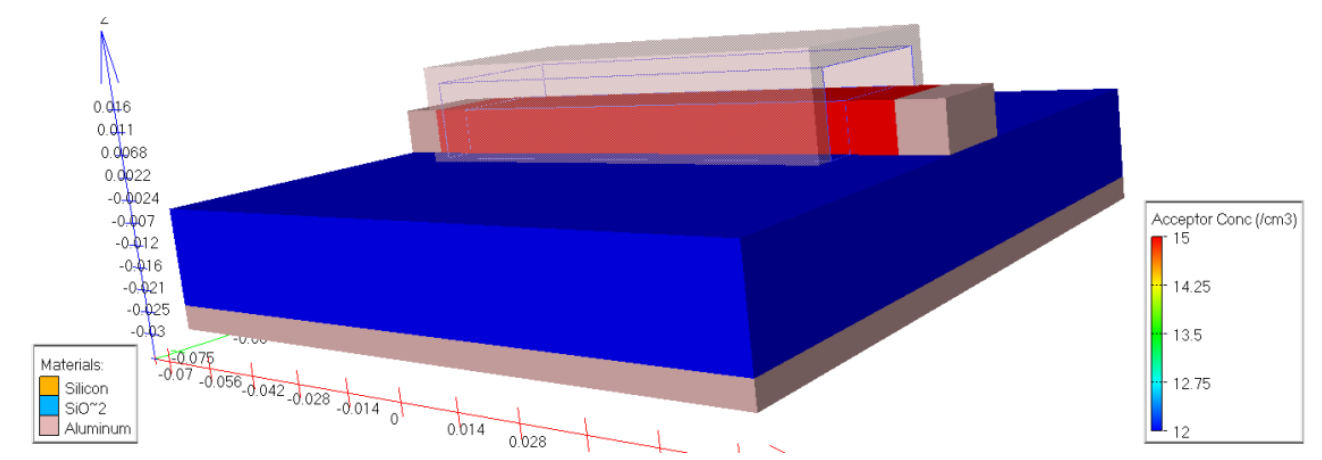

Fonte: Autor.

Estes nano-fios podem se comportar como nMOS e pMOS alterando a tensão aplicada ao substrato $\left(\mathrm{V}_{\mathrm{GB}}\right)$ [62], como apresentado na figura 36 e figura 37 respectivamente. 
Figura 36- Estrutura JNT não dopada com a concentração de elétrons para $\mathrm{V}_{\mathrm{GB}}=+10 \mathrm{~V}$.

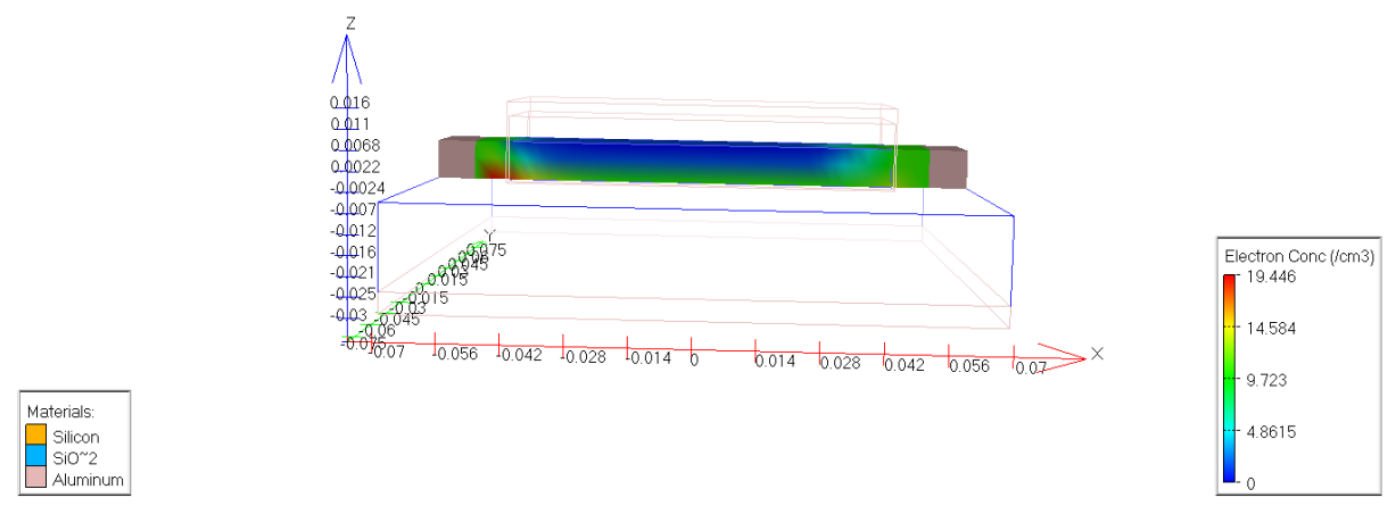

Fonte: Autor.

Figura 37- Estrutura JNT não dopada com a concentração de lacunas para $\mathrm{V}_{\mathrm{GB}}=-10 \mathrm{~V}$.

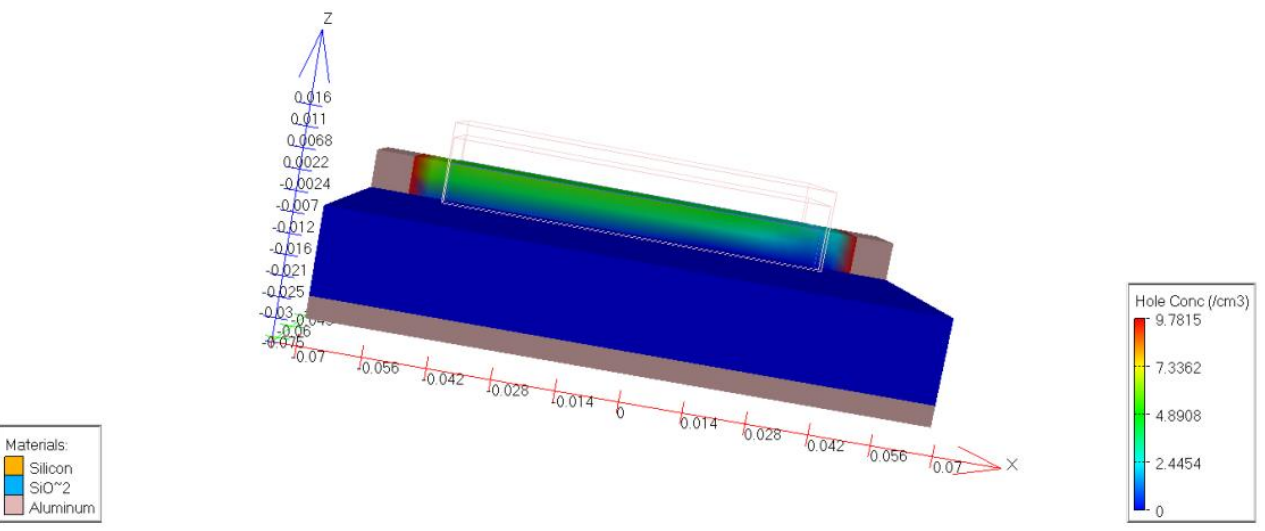

Fonte: Autor.

\subsection{SIMULAÇÃO DAS CARACTERÍSTICAS ELÉTRICAS}

Através das simulações do processo dos dispositivos, realizamos uma série de simulações das caracterizas elétricas. Primeiramente extraímos curvas da corrente de dreno em função da tensão de porta para os JNT NMOS com as duas dopagens simuladas, $\mathrm{N}_{\mathrm{D}}=2 \mathrm{e} 18$ $\mathrm{cm}^{-3}$ e $\mathrm{N}_{\mathrm{D}}=5 \mathrm{e} 17 \mathrm{~cm}^{-3}$. 
Figura 38 - Curvas da corrente de dreno em função da tensão aplicada a porta, em escala linear e logarítmica.

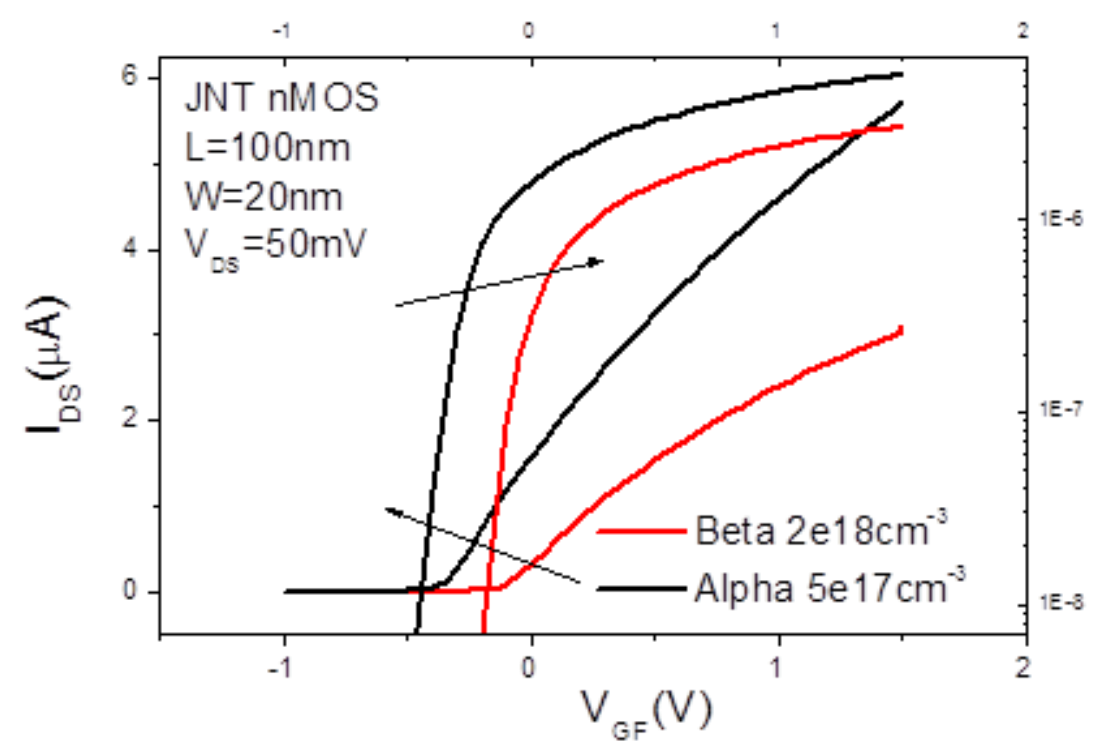

Fonte:Autor.

Através destas curvas extraímos a $\mathrm{V}_{\mathrm{T}}=-0,3 \mathrm{~V}$ e $\mathrm{S}=78,8 \mathrm{mV} / \mathrm{dec}$ da lâmina alpha e $\mathrm{V}_{\mathrm{T}}=$ $0,15 \mathrm{~V}$ e $\mathrm{S}=83 \mathrm{mV} / \mathrm{dec}$ da lâmina beta. Também foram simuladas (Figura 39) curvas da corrente de dreno em função da tensão de porta para $\mathrm{W}=50 \mathrm{~nm}, \mathrm{~V}_{\mathrm{DS}}=50 \mathrm{~nm}, \mathrm{~N}_{\mathrm{D}}=2 \mathrm{e} 18 \mathrm{~cm}^{-3}$, variando comprimento de canal em $\mathrm{L}=50 \mathrm{~nm}, 100 \mathrm{~nm}$, $400 \mathrm{~nm}$ e $1000 \mathrm{~nm}$, dos transistores JNT NMOS.

Figura 39- Curvas simuladas do transistor JNT NMOS.

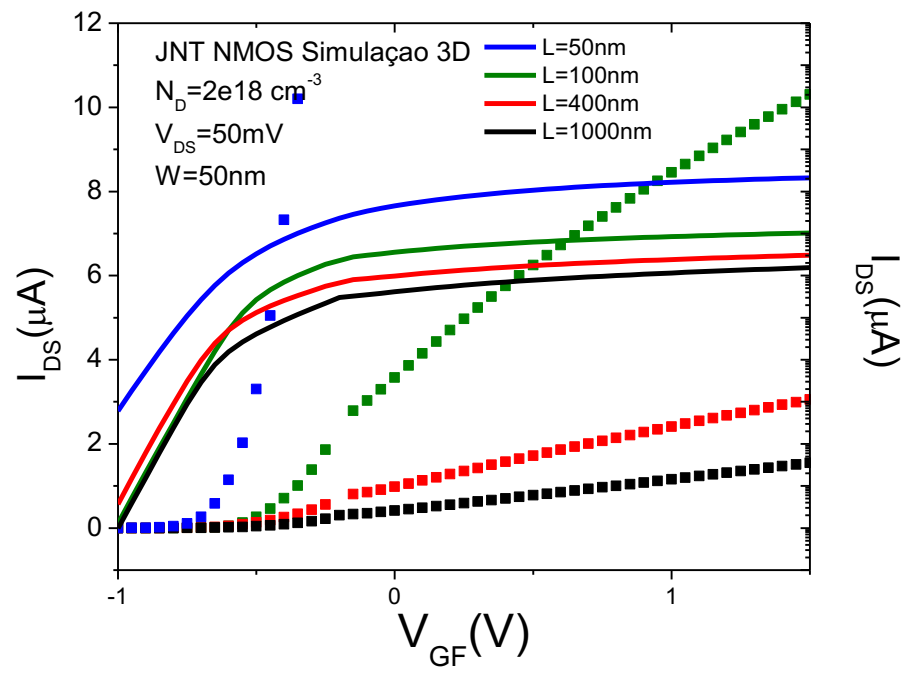

Fonte: Autor. 
Este dispositivo apresentou tensão de limiar $\mathrm{V}_{\mathrm{T}}=-0,3 \mathrm{~V}$ e inclinação de sublimiar de $65,1 \mathrm{mV} / \mathrm{dec}$.

Também foram simulados os dispositivos em saturação $\mathrm{V}_{\mathrm{DS}}=1 \mathrm{~V}$, para os mesmo comprimentos anteriores. Na Figura 40 são apresentadas as curvas da corrente de dreno e a transcondutância em função da tensão de porta.

Figura 40 - Curvas $I_{D S}$ e $g_{m}$ em função da tensão de porta simuladas do transistor JNT NMOS.

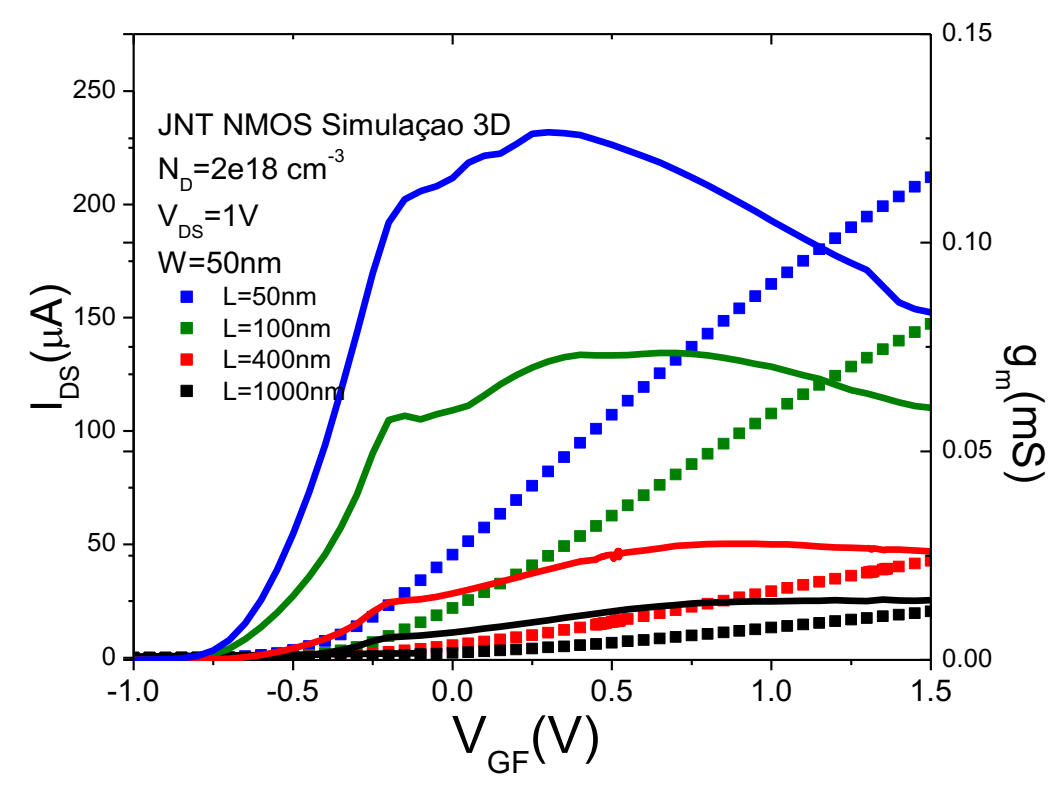

Fonte: Autor.

A Figura 41 apresenta curvas da corrente de dreno e da condutância de saída em função da tensão de dreno do dispositivo JNT nMOS L=50nm e $\mathrm{W}=50 \mathrm{~nm}$ variando $\mathrm{V}_{\mathrm{GT}}$ de $100 \mathrm{mV}$ a $500 \mathrm{mV}$. 
Figura 41 - Curvas $\mathrm{I}_{\mathrm{DS}}$ e $\mathrm{g}_{\mathrm{D}}$ em função da tensão aplicada ao dreno simuladas do transistor JNT NMOS, $\mathrm{L}=50 \mathrm{~nm} \mathrm{~W}=50 \mathrm{~nm}$ para

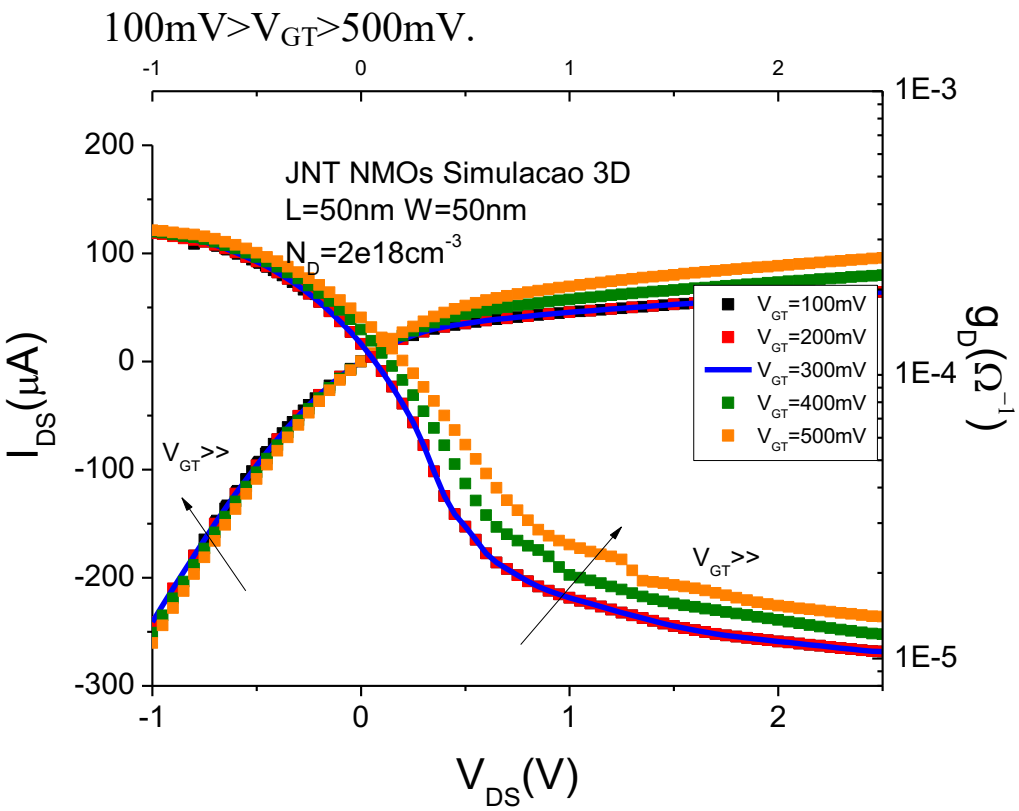

Fonte: Autor.

Foram analisadas a corrente de dreno e transcondutância em função da corrente de dreno com a variação do comprimento de canal $(\mathrm{L}=400 \mathrm{~nm}, 100 \mathrm{~nm}$ e $1000 \mathrm{~nm})$ na Figura $42 \mathrm{e}$ na figura 43 foram simuladas para os comprimentos $L=100 \mathrm{~nm}$ e $W=20 \mathrm{~nm}, \mathrm{~L}=100 \mathrm{~nm}$ e $\mathrm{W}=50 \mathrm{~nm}$, e para $\mathrm{L}=50 \mathrm{~nm}$ e $\mathrm{W}=50 \mathrm{~nm}$.

Figura 42- Curva simulada $I_{D S}$ e $g_{D}$ em função da tensão aplicada ao dreno, com $\mathrm{V}_{\mathrm{GT}}=500 \mathrm{mV}, \mathrm{N}_{\mathrm{D}}=2 \mathrm{e} 18 \mathrm{~cm}^{-}$ ${ }^{3}, \mathrm{~W}=100 \mathrm{~nm}$ variando o comprimento de canal.

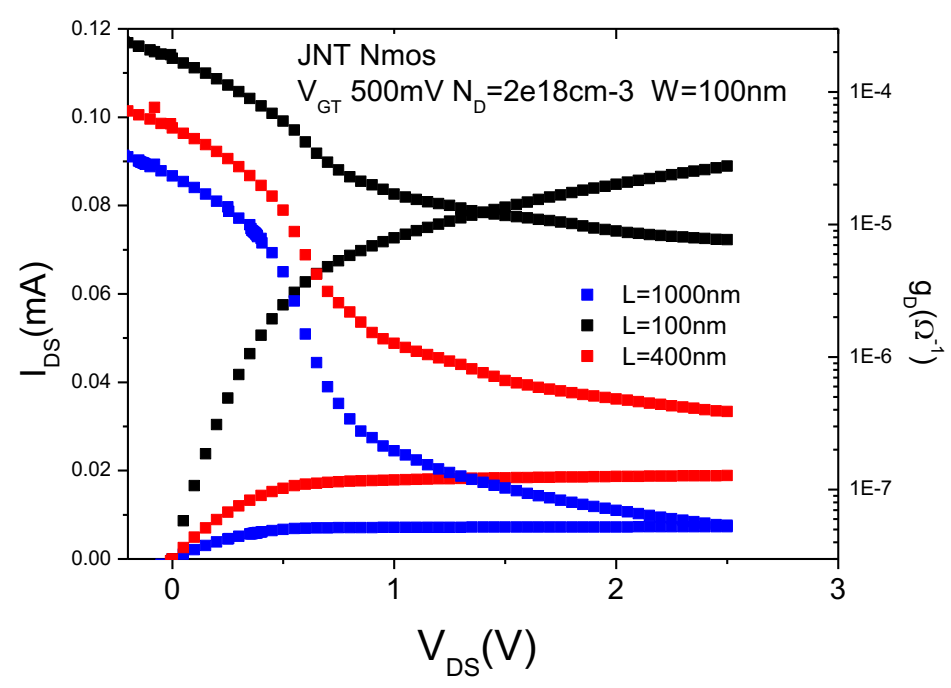

Fonte: Autor. 
Figura 43- Curva simulada $I_{D S}$ e $g_{D}$ em função da tensão aplicada ao dreno, com $\mathrm{V}_{\mathrm{GT}}=500 \mathrm{mV}, \mathrm{N}_{\mathrm{D}}=2 \mathrm{e} 18 \mathrm{~cm}$ 3 , variando o comprimento e largura de canal.

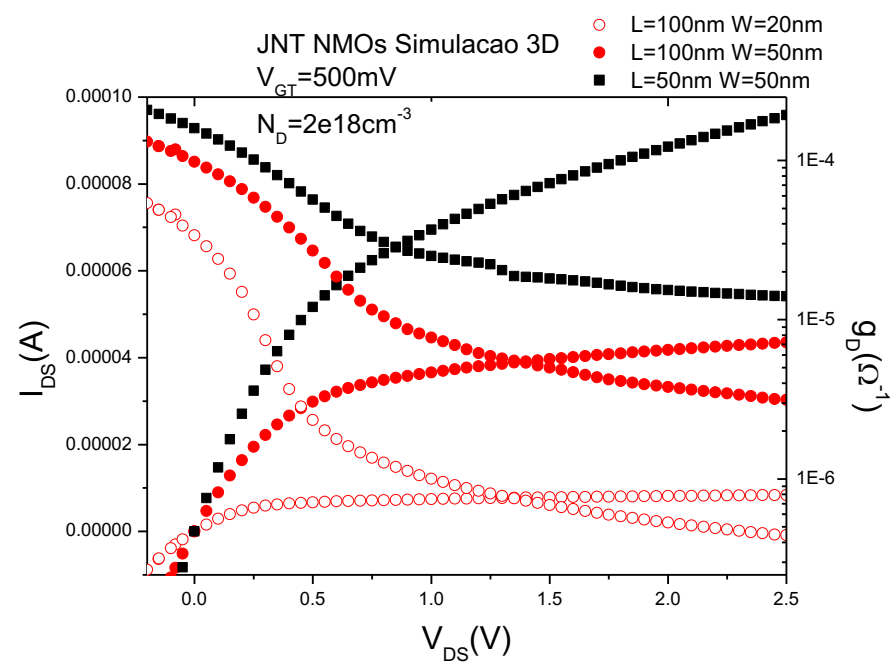

Fonte: Autor.

O ganho de saída também foi extraído de todos os dispositivos, a Figura 44 apresenta a transcondutância utilizada, na Figura 45 é apresentada a condutância de saída e por fim na Figura 46 o ganho dos dispositivos. Todas estas curvas foram feitas para os dispositivos JNT com $\mathrm{N}_{\mathrm{D}} 2 \mathrm{e} 18 \mathrm{~cm}^{-3}$ e $5 \mathrm{e} 17 \mathrm{~cm}^{-3}$ variando o comprimento de canal de $50 \mathrm{~nm}$ a $1500 \mathrm{~nm}$ e a largura de canal de $20 \mathrm{~nm}$ a $800 \mathrm{~nm}$.

Figura 44- Curvas da transcondutância de saída em função do comprimento do canal.

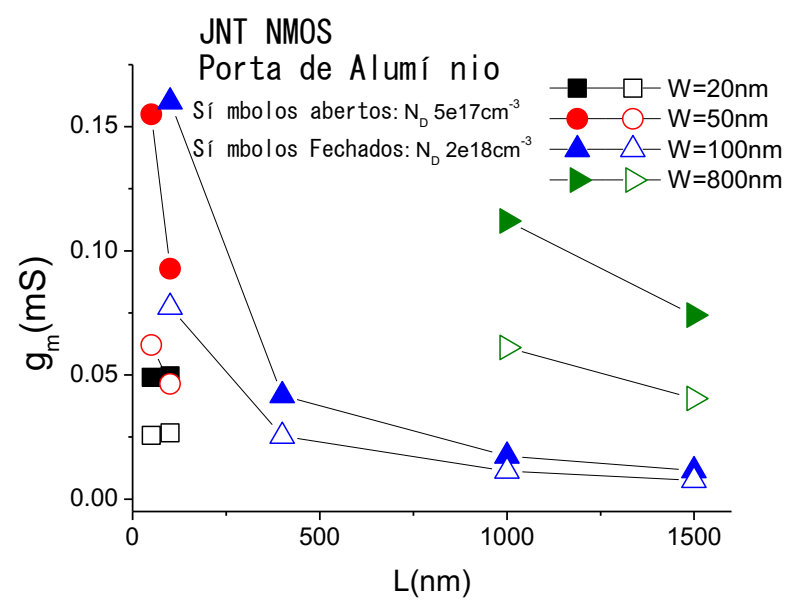

Fonte: Autor. 
Figura 45- Curvas da condutância de saída em função do L.

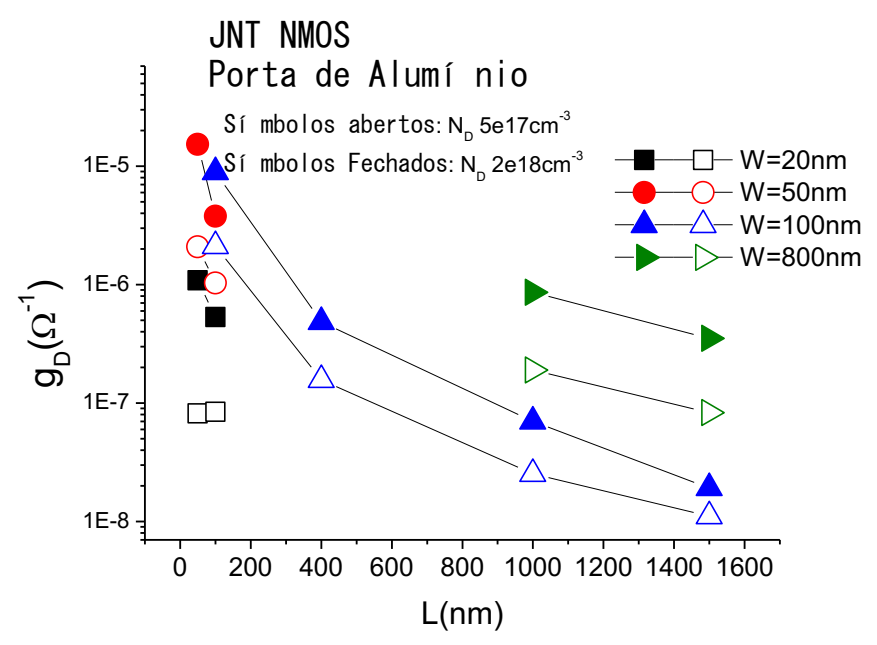

Fonte: Autor.

Figura 46- Curvas do ganho de saída em função do comprimento do canal.

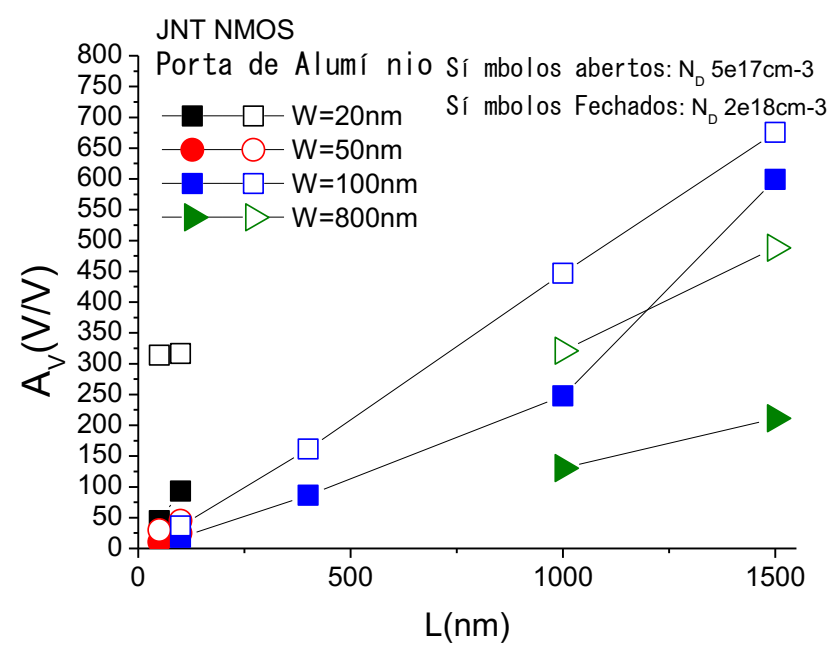

Fonte: Autor.

Através dos gráficos pudemos extrair o ganho máximo dos dispositivos, $\mathrm{A}_{\mathrm{v}}$ máx $=$ $681,82 \mathrm{~V} / \mathrm{V}$ para o dispositivo com dimensões de $\mathrm{L}=1500 \mathrm{~nm}, \mathrm{~W}=100 \mathrm{~nm}, \mathrm{~N}_{\mathrm{D}}=5 \mathrm{e} 17 \mathrm{~cm}^{-3}$, e $\mathrm{A}_{\mathrm{Vmáx}}=598,95 \mathrm{~V} / \mathrm{V}$ para as mesmas dimensões porém para $\mathrm{N}_{\mathrm{D}}=2 \mathrm{e} 18 \mathrm{~cm}^{-3}$. Para todos os dispositivos também notamos que quanto maior o comprimento de canal e menor a dopagem maior o ganho de saída do dispositivo isto, pois quanto maior o comprimento do canal menor a transcondutância de saída do dispositivo. 
Também foi simulada a caracterização elétrica dos nano fios não dopados, a Figura 47 apresenta a curva da corrente de dreno em função da tensão aplicada a porta, com $\mathrm{V}_{\mathrm{DS}}=0,5 \mathrm{~V}$ de um nano fio com $\mathrm{L}=100 \mathrm{~nm}$ e $\mathrm{W}=100 \mathrm{~nm}$. Através dela é possível extrair $\mathrm{V}_{\mathrm{T}}=-0,9 \mathrm{~V}$ e $\mathrm{S}=230 \mathrm{mV} / \mathrm{dec}$.

Figura 47 - Simulação da corrente de dreno em função da tensão aplicada à porta.

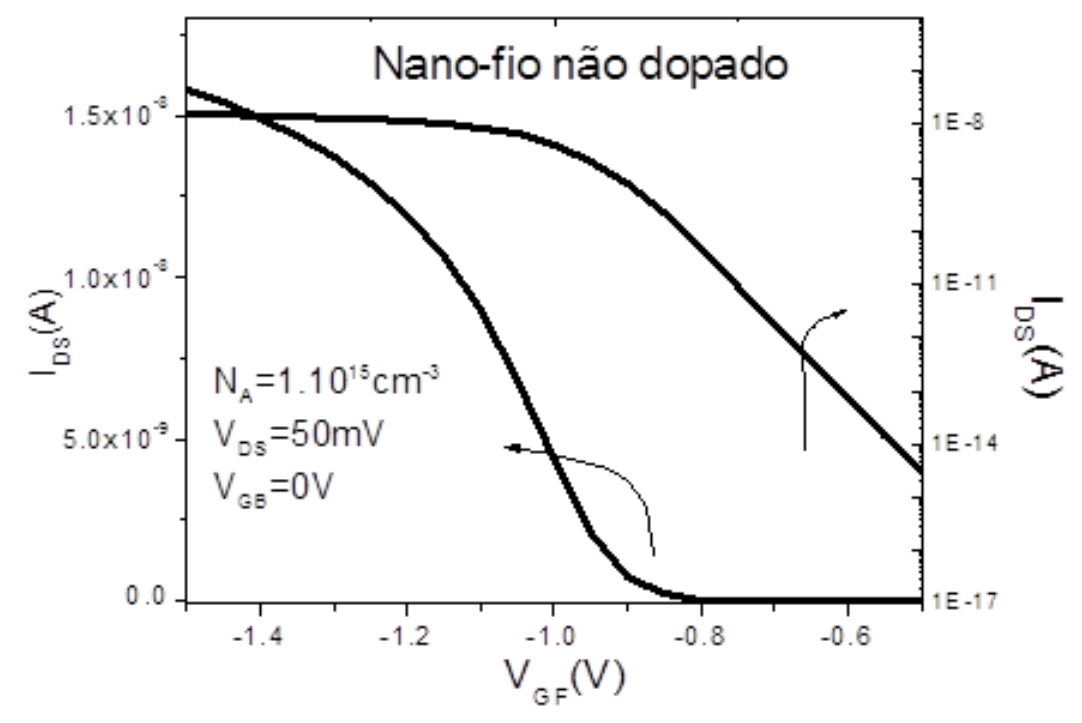

Fonte: Autor. 


\section{FABRICAÇÃO DOS TRANSISTORES}

Nesta seção serão apresentadas as etapas de fabricação, e toda calibração de algumas etapas que foram feitas experimentalmente. O primeiro conjunto a ser detalhado é denominado alpha, compostos por transistores sem junção. Em seguida a segunda rodada de transistores, também composta por JNT denominada beta e por fim o conjunto gama composto por transistores nano-fio não dopado.

\subsection{FABRICAÇÃO LÂMINA ALPHA JNT}

A rodada alpha foi realizada com um conjunto de máscaras que contém 54 transistores e foi utilizada litografia por feixe de elétrons. Neste conjunto a Figura 48 mostra como foram separados os transistores por grupos, e na Tabela 3 são apresentados valores de comprimento e largura de canal de todos os transistores.

Figura 48- Layout dos transistores fabricados com a descrição de número de fins, comprimento de canal, e largura de canal.

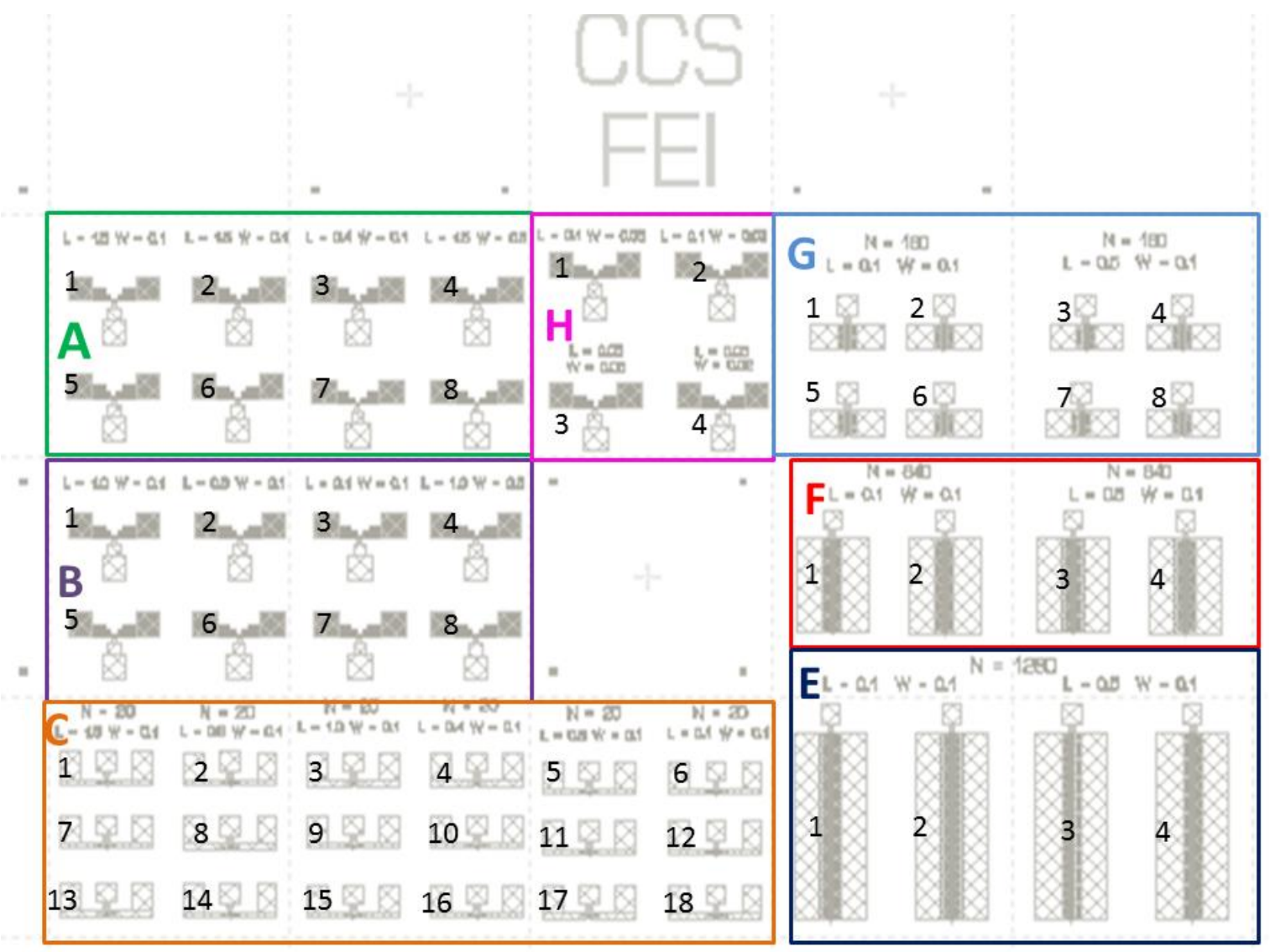

Fonte: Autor. 
Tabela 3- Descrição dos transistores e seus respectivos valores de N, W e L.

\begin{tabular}{|c|c|c|c|}
\hline Nome do transistor & N (número de fins) & $\mathbf{W}(\mu \mathrm{m})$ & $\mathbf{L}(\mu \mathrm{m})$ \\
\hline$A 1=A 5$ & 1 & 0,1 & 1,0 \\
\hline$A 2=A 6$ & 1 & 0,1 & 1,5 \\
\hline $\mathbf{A} 3=\mathbf{A} 7$ & 1 & 0,1 & 0,5 \\
\hline $\mathrm{A4}=\mathbf{A 8}$ & 1 & 0,5 & 1,5 \\
\hline $\mathrm{B} 1=\mathrm{B5}$ & 1 & 0,1 & 1,5 \\
\hline $\mathrm{B} 2=\mathrm{B} 6$ & 1 & 0,1 & 0,6 \\
\hline B3=B7 & 1 & 0,1 & 0,1 \\
\hline $\mathrm{B} 4=\mathrm{B8}$ & 1 & 0,5 & 1,0 \\
\hline $\mathrm{C} 1=\mathrm{C} 7=\mathrm{C} 13$ & 20 & 0,1 & 1,5 \\
\hline $\mathrm{C} 2=\mathrm{C} 8=\mathrm{C} 14$ & 20 & 0,1 & 0,6 \\
\hline $\mathrm{C} 3=\mathrm{C} 9=\mathrm{C} 15$ & 20 & 0,1 & 1,0 \\
\hline $\mathrm{C} 4=\mathrm{C} 10=\mathrm{C} 16$ & 20 & 0,1 & 0,4 \\
\hline $\mathrm{C} 5=\mathrm{C} 11=\mathrm{C} 17$ & 20 & 0,1 & 0,5 \\
\hline $\mathrm{C} 6=\mathrm{C} 12=\mathrm{C} 18$ & 20 & 0,1 & 0,1 \\
\hline $\mathrm{G} 1=\mathrm{G} 2=\mathrm{G} 5=\mathrm{G6}$ & 180 & 0,1 & 0,1 \\
\hline $\mathbf{G 3}=\mathbf{G 4}=\mathbf{G 7}=\mathbf{G 8}$ & 180 & 0,1 & 0,5 \\
\hline $\mathbf{F} 1=\mathbf{F} 2$ & 640 & 0,1 & 0,1 \\
\hline F3 $=$ F4 & 640 & 0,1 & 0,5 \\
\hline $\mathbf{E} 1=\mathbf{E} 2$ & 1280 & 0,1 & 0,1 \\
\hline $\mathbf{E 3}=\mathbf{E 4}$ & 1280 & 0,1 & 0,5 \\
\hline H1 & 1 & 0,05 & 0,1 \\
\hline H2 & 1 & 0,02 & 0,1 \\
\hline H3 & 1 & 0,05 & 0,05 \\
\hline H4 & 1 & 0,02 & 0,05 \\
\hline
\end{tabular}

Fonte: Autor.

Esta rodada obedeceu a seguinte sequência de processo. Foi realizada limpeza RCA [63] para eliminar maior quantidade de impurezas, a primeira etapa da limpeza é composta pela Solução de $\mathrm{H}_{2} \mathrm{SO}_{4} / \mathrm{H}_{2} \mathrm{O}_{2}, 4: 1$ à $80^{\circ} \mathrm{C}$, esta solução tem o nome usual de "piranha", e é utilizada para remover principalmente quantidades de gordura presentes na superfície da lâmina. Em seguida é mergulhada em $\mathrm{HF} / \mathrm{H}_{2} \mathrm{O}, 1: 10$, para remoção de $\mathrm{SiO}_{2}$ na superfície do silício. A próxima solução é $\mathrm{NH}_{4} \mathrm{OH} / \mathrm{H}_{2} \mathrm{O}_{2} / \mathrm{H}_{2} \mathrm{O}, 1: 1: 5$, à $70^{\circ} \mathrm{C}$ responsável por remover a gordura e também alguns metais que possam estar na superfície da lâmina. E por fim, a lâmina é submersa na solução $\mathrm{HCl} / \mathrm{H}_{2} \mathrm{O}_{2} / \mathrm{H}_{2} \mathrm{O}, 1: 1: 5$, à $70^{\circ} \mathrm{C}$ : esta solução é usada especificamente para a remoção de metais na superfície do silício. 
Após a limpeza foi realizada a deposição no sputering de $\mathrm{SiO}_{2}$ de espessura de $60 \mathrm{~nm}$, este óxido é utilizado para proteger a superfície da lâmina dos bombardeamentos realizados no momento da implantação iônica, este que causa inúmeros defeitos entre a interface óxido de porta e silício. Em seguida foi realizado a implantação iônica de impurezas tipo n (fósforo), com dose $3 \times 10^{14}$ átomos $/ \mathrm{cm}^{-2}$, energia $20 \mathrm{kV}$ e inclinação de $7^{\circ}, \mathrm{o}$ que resultou em uma concentração de $1,5 \times 10^{18} \mathrm{~cm}^{-3}$. Em seguida a lâmina foi inserida em uma solução de ácido fluorídrico para a remoção do óxido de sacrifício e assim condicionada ao recozimento (RTA ambiente de $\mathrm{N}_{2}$ e $\mathrm{O}_{2}$, a temperatura de $1000^{\circ} \mathrm{C}$, durante 60 segundos), que resultou em concentração de $5 \times 10^{17} \mathrm{~cm}^{-3}$.

Devido à espessura da lâmina utilizada ser muito fina não foi possível visualizar as marcas de alinhamento que eram feitas apenas com a corrosão do filme de silício e visualizada através do contraste entre Silício e o Óxido de silício enterrado no sistema de fotolitografia ótica.

Deste modo para esta lâmina utilizamos o equipamento Raith E-line que realiza a litografia por feixe de elétrons. A vantagem desse sistema é que podemos fazer as máscaras para as gravações no "Layouteditor" [64] e assim criar uma máscara apenas para as marcas de alinhamento. Isto soluciona o nosso problema, pois podemos realizar a gravação desta máscara e depositar algum metal para lift-off. Em seguida teremos marcas feitas de metal, o que facilita em muito a visualização com contraste do silício, mesmo ele sendo fino. O layout contendo as máscaras utilizadas está apresentado na Figura 49, nos cantos estão as marcas laterais, e ao redor de todo layout com fundo rosa, estão as marcas principais nas quais fazemos os ajustes finos para as gravações. 
Figura 49- Layout utilizado para a fabricação do conjunto de transistores alpha.

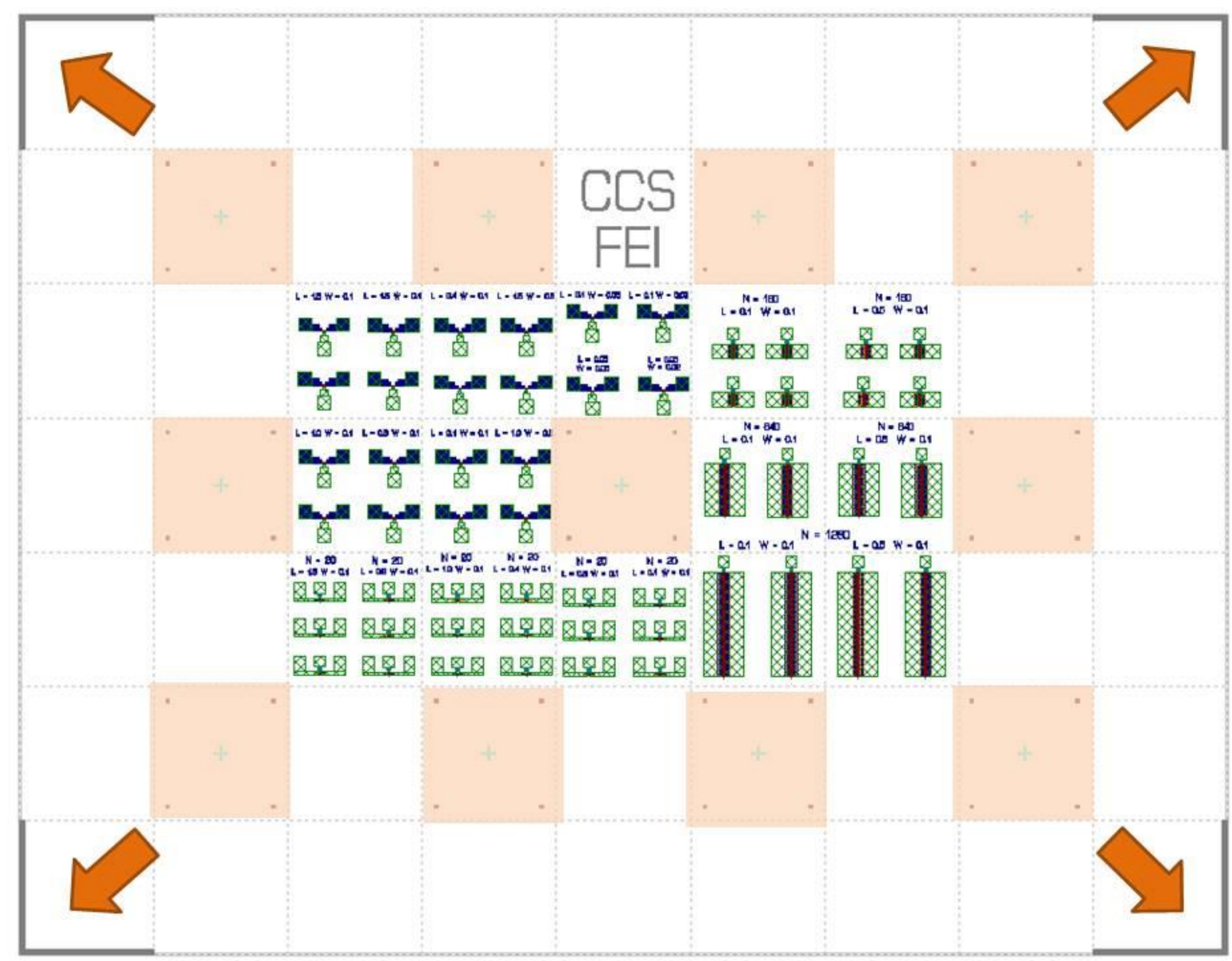

Fonte: Autor.

Legenda: Evidenciando as marcas de alinhamento: laterais em cinza e com fundo rosa as marcas principais.

Assim esta etapa de gravação das marcas de alinhamento (máscara 0) foi realizada seguindo os seguintes passos Tabela 4. Após foi depositado $120 \mathrm{~nm}$ de titânio Ti e em seguida foi realizado o lift-off. 
Tabela 4 Sequência para realizar a litografia da máscara 0 , desde aplicação do resiste até a cura em estufa.

\begin{tabular}{|c|c|c|}
\hline Etapas: & Processo & Parâmetros \\
\hline 1 & $\begin{array}{l}\text { Aquecimento da amostra em hot plate para } \\
\text { desumidificação do substrato }\end{array}$ & $200^{\circ} \mathrm{C}, 10$ minutos \\
\hline 2 & $\begin{array}{l}\text { Aplicação de HMDS (Hexamethyl Disilazane) } \\
\text { para incrementar aderência do resiste ao } \\
\text { substrato }\end{array}$ & $\begin{array}{l}\text { Spinner } 3000 \mathrm{rpm}, 30 \mathrm{~s} \\
\text { Repouso } \rightarrow 1 \text { minuto }\end{array}$ \\
\hline 3 & Aplicação de e-resiste PMMA AR-P 679.04 & Spinner $\rightarrow \quad 1000 \mathrm{rpm}, 30 \mathrm{~s}$ \\
\hline 4 & $\begin{array}{l}\text { Cura em hot plate para evaporação de solvente } \\
\text { e aumento da aderência do resiste ao substrato }\end{array}$ & $180^{\circ} \mathrm{C}, 2$ minutos \\
\hline 5 & Exposição das marcas de alinhamento & $\begin{array}{l}\text { Tensão } \rightarrow \quad 20 \mathrm{kV} \\
\text { Abertura }=30 \mu \mathrm{m} \\
\text { Dose } \rightarrow \quad 160 \mu \mathrm{C} \cdot \mathrm{cm}^{-2} \\
\text { Step size do feixe } \rightarrow \quad 16 \mathrm{~nm}\end{array}$ \\
\hline 6 & $\begin{array}{l}\text { Revelação em MIBK:IPA (1:3) } \\
\text { (Stopper em IPA) }\end{array}$ & 2 minutos \\
\hline 7 & Cura em estufa para densificação do e-resiste & $110^{\circ} \mathrm{C}, 30$ minutos \\
\hline 8 & Sputtering com alvo de Ti & $120 \mathrm{~nm}$ \\
\hline
\end{tabular}

Fonte:Autor.

Com as marcas de alinhamento feitas, realizamos o alinhamento e a nova gravação da máscara 1 responsável por delimitar a região ativa dos transistor. Esta gravação seguiu a seguinte receita Tabela 5 .

Tabela 5- Sequência para realizar a litografia da máscara 1, desde aplicação do resiste até a cura em estufa.

\begin{tabular}{|c|c|c|}
\hline Etapas: & Processo & Parâmetros \\
\hline 1 & $\begin{array}{l}\text { Aquecimento da amostra em hot plate para } \\
\text { desumidificação do substrato }\end{array}$ & $200{ }^{\circ} \mathrm{C}, 10$ minutos \\
\hline 2 & $\begin{array}{l}\text { Aplicação de HMDS (Hexamethyl Disilazane) } \\
\text { para incrementar aderência do resiste ao } \\
\text { substrato }\end{array}$ & $\begin{array}{l}\text { Spinner } 3000 \mathrm{rpm}, 30 \mathrm{~s} \\
\text { Repouso } \rightarrow 1 \text { minuto }\end{array}$ \\
\hline 3 & Aplicação de e-resiste Ma-N 2403 & Spinner $\rightarrow 3000 \mathrm{rpm}, 30 \mathrm{~s}$ \\
\hline 4 & $\begin{array}{l}\text { Cura em hot plate para evaporação de solvente } \\
\text { e aumento da aderência do resiste ao substrato }\end{array}$ & $90^{\circ} \mathrm{C}, 1$ minuto \\
\hline 5 & Exposição do layout ao feixe de elétrons & $\begin{array}{l}\text { Tensão } \rightarrow \quad 20 \mathrm{kV} \\
\text { Abertura } 30 \mu \mathrm{m} \\
\text { Dose } \rightarrow 160 \mu \mathrm{C} \cdot \mathrm{cm}^{-2} \\
\text { Step size do feixe } \rightarrow \quad 16 \mathrm{~nm}\end{array}$ \\
\hline 6 & $\begin{array}{l}\text { Revelação em MIF } 300 \text { puro } \\
\text { (Stopper em } \mathrm{H}_{2} \mathrm{O} \text {, resistividade } 18 \mathrm{M} \Omega . \mathrm{cm} \text { ) }\end{array}$ & 60 segundos \\
\hline 7 & Cura em hot plate para densificação do e-resiste & $135^{\circ} \mathrm{C}, 5$ minutos \\
\hline
\end{tabular}

Fonte:Autor. 
As mesas de silício foram protegidas pelo padrão impresso na litografia, e após a cura em hot plate para a densificação do e-resiste foi realizada a corrosão por RIE. A Corrosão foi realizada com os seguintes parâmetros $\left(12 \mathrm{sF}_{6}+35 \mathrm{Ar}+50 \mathrm{mTorr}+500 \mathrm{~W}+1\right.$ ') afim de corroer $14 \mathrm{~nm}$ de silício. Esta etapa estava calibrada no laboratório com uma taxa de corrosão de $10 \mathrm{~nm} / \mathrm{min}$. As imagens feitas das mesas formadas estão apresentadas na Figura 50.

Figura 50- Foto dos transistores de N=1280, das mesas de silício formadas após a corrosão.

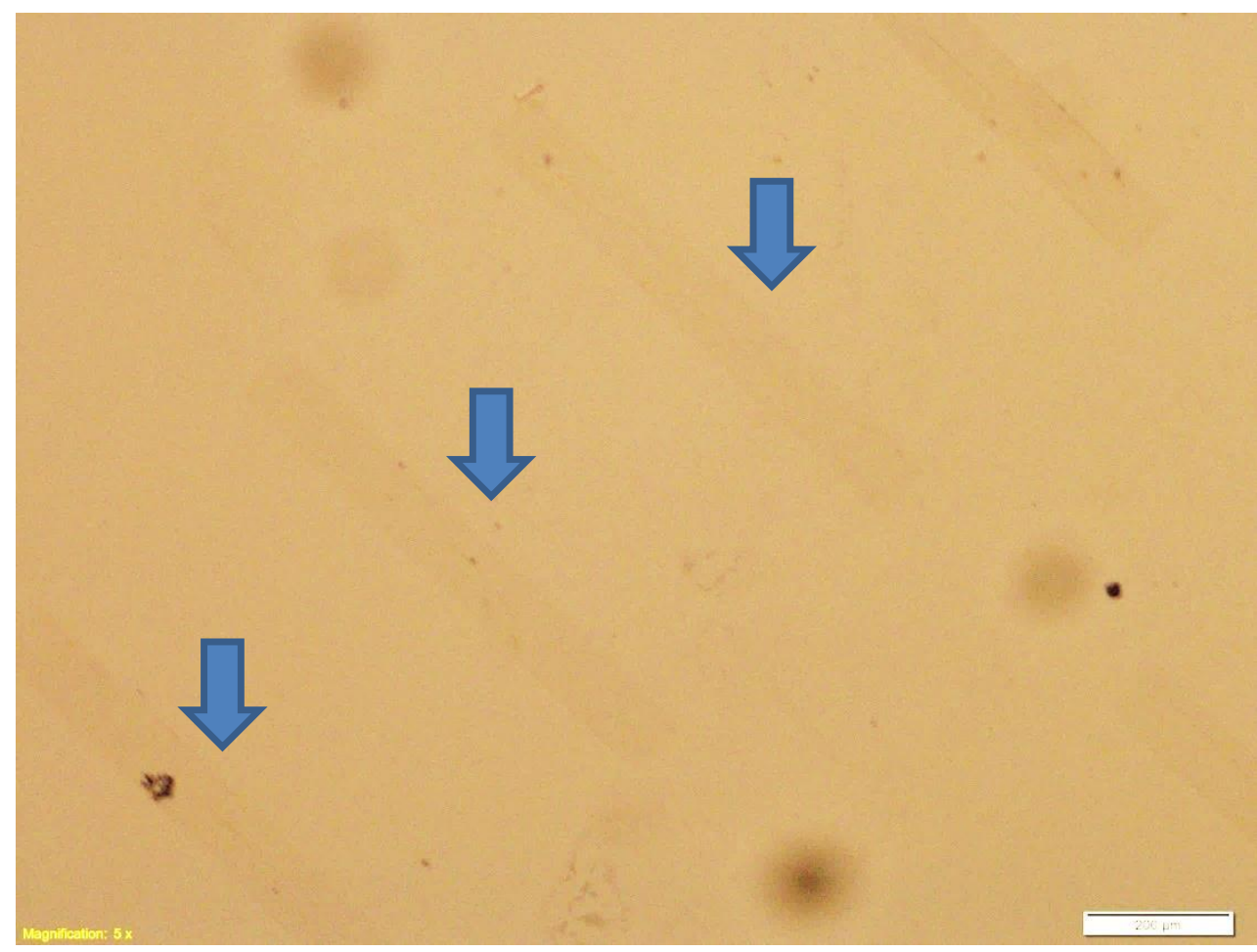

Fonte: Autor.

Assim que as mesas foram feitas a lâmina passou por uma limpeza orgânica e uma por plama $\mathrm{O}_{2}$ para a remoção de todo e-resiste e em seguida passou pelo processo de oxidação no forno convencional e obedeceu a seguinte sequência de oxidação da Tabela 6. 
Tabela 6- Sequência utilizada para oxidação realizada no forno para a lâmina Alpha.

\begin{tabular}{lccc}
\hline Etapa/Descrição & \multicolumn{1}{c}{$\begin{array}{c}\text { Temperatura } \\
\left({ }^{\circ} \mathbf{C}\right)\end{array}$} & Ambiente & $\begin{array}{c}\text { Tempo } \\
(\mathbf{m i n})\end{array}$ \\
\hline $\mathbf{1}^{\circ}$ Entrada da lâmina & 850 & $\mathrm{~N}_{2}$ & 5 \\
\hline $\mathbf{2}^{\circ}$ Estabilização & 850 & $\mathrm{~N}_{2}$ & 5 \\
$\mathbf{3}^{\circ}$ Oxidação & 850 & $\mathrm{O}_{2}$ & 15 \\
$\mathbf{4}^{\circ}$ Saída da lâmina & 850 & $\mathrm{~N}_{2}$ & 5
\end{tabular}

Fonte: Autor.

Esta oxidação realizada foi simulada no simulador Athena da Silvaco, e apresentou uma espessura de 7,6nm aproximadamente, consumindo da camada de silício 2,5nm ainda sim teríamos uma camada de silício de $11,5 \mathrm{~nm}$.

Após esta etapa a lâmina fica com esta aparência Figura 51, onde podemos ver um esquema da lâmina com corte transversal e visualizar as camadas na região da região ativa.

Figura 51- Esquema da etapa de processo de oxidação realizada no forno convencional.

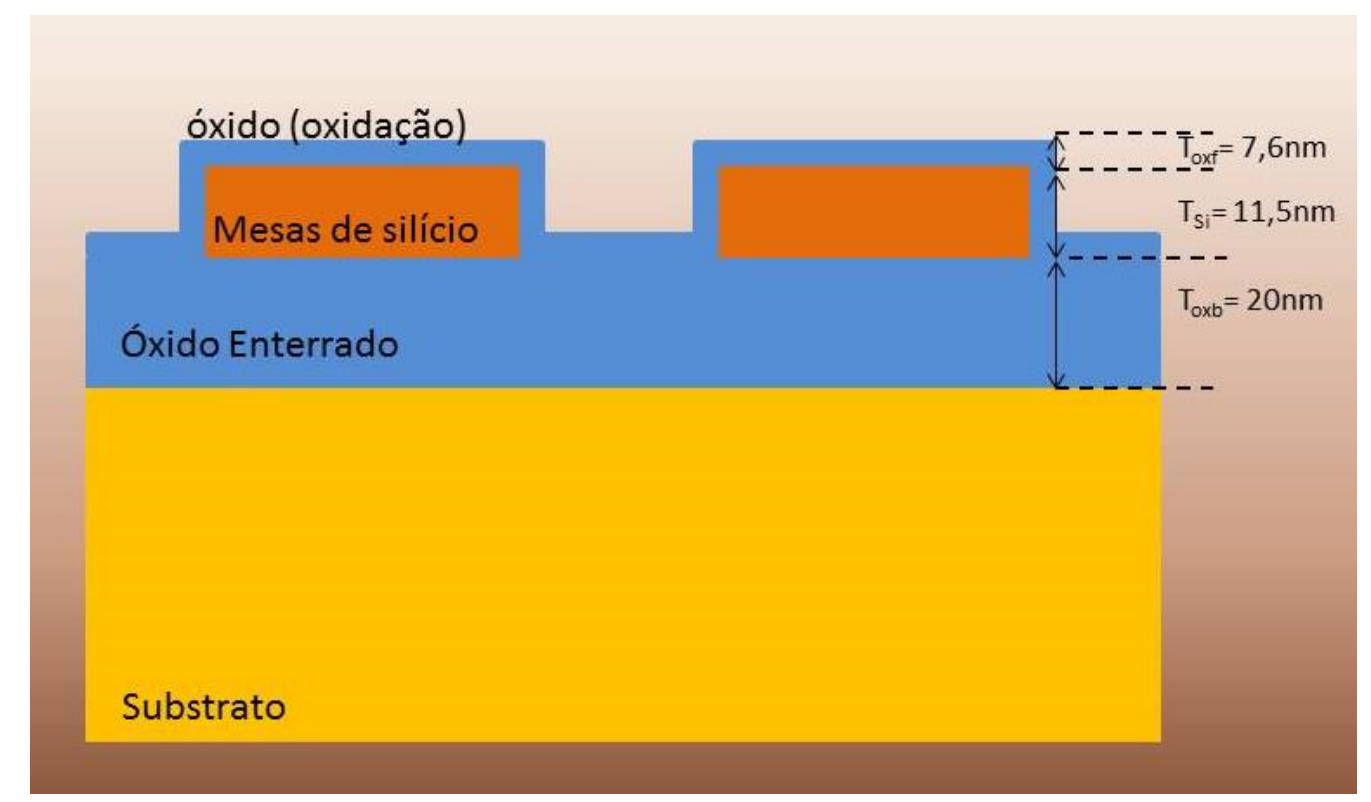

Fonte: Autor.

Em seguida uma nova litografia é realizada para a abertura de contatos que obedece a seguinte sequência. 
Tabela 7- Sequência para realizar a litografia 3, desde aplicação do resiste até a limpeza no plasma ashing.

\begin{tabular}{|c|c|c|}
\hline Etapas: & Processo & Parâmetros \\
\hline 1 & $\begin{array}{l}\text { Aquecimento da amostra em hot plate para } \\
\text { desumidificação do substrato }\end{array}$ & $200{ }^{\circ} \mathrm{C}, 10$ minutos \\
\hline 2 & $\begin{array}{l}\text { Aplicação de HMDS (Hexamethyl } \\
\text { Disilazane) para incrementar aderência do } \\
\text { resiste ao substrato }\end{array}$ & $\begin{array}{l}\text { Spinner } 3000 \mathrm{rpm}, 30 \mathrm{~s} \\
\text { Repouso } \rightarrow 1 \text { minuto }\end{array}$ \\
\hline 3 & Aplicação de e-resiste PMMA AR-P 679.04 & Spinner $\rightarrow \quad 3000 \mathrm{rpm}, 30 \mathrm{~s}$ \\
\hline 4 & $\begin{array}{l}\text { Cura em hot plate para evaporação de } \\
\text { solvente e aumento da aderência do resiste ao } \\
\text { substrato }\end{array}$ & $90^{\circ} \mathrm{C}, 1$ minuto \\
\hline 5 & Exposição do layout ao feixe de elétrons & $\begin{array}{l}\text { Tensão } \rightarrow \quad 20 \mathrm{kV} \\
\text { Abertura } 30 \mu \mathrm{m} \\
\text { Dose } \rightarrow \quad 170 \mu \mathrm{C} \cdot \mathrm{cm}^{-2} \\
\text { Step size do feixe } \rightarrow \quad 16 \mathrm{~nm}\end{array}$ \\
\hline 6 & $\begin{array}{l}\text { Revelação em MIBK:IPA (1:3) } \\
\text { (Stopper em IPA puro) }\end{array}$ & 60 segundos \\
\hline 7 & Cura em estufa para densificação do e-resiste & $135^{\circ} \mathrm{C}, 5$ minutos \\
\hline 8 & $\begin{array}{l}\text { Dip em solução BHF para remoção de } \mathrm{SiO}_{2} \\
\text { sobre regiões de fonte e dreno } \\
\text { (Taxa de corrosão } \sim 100 \mathrm{~nm} / \mathrm{min} \text { para silício) }\end{array}$ & 3 segundos \\
\hline 9 & Limpeza orgânica para remoção do e-resiste & $\begin{array}{l}\text { Acetona } \rightarrow 90^{\circ} \mathrm{C}, 10 \mathrm{~min} \\
\text { Isopropanol } \rightarrow 90^{\circ} \mathrm{C}, 10 \\
\text { min }\end{array}$ \\
\hline 10 & $\begin{array}{l}\text { Plasma ashing para remoção do e-resiste } \\
\text { residual }\end{array}$ & $\begin{array}{l}\text { Potência } \rightarrow \quad 200 \mathrm{~W} \\
\text { Tempo } \rightarrow \quad 10 \mathrm{~min}\end{array}$ \\
\hline
\end{tabular}

Na Figura 52, é apresentado as imagens feitas no microscópio eletrônico da litografia das aberturas de contato. Nestas imagens a corrosão no BHF já havia ocorrido e podemos notar que a coloração amarelada garante que o óxido de porta foi removido. 
Figura 52- Litografia da máscara de abertura de contatos e a abertura realizada com BHF dos transistores $\mathrm{N}=120$.

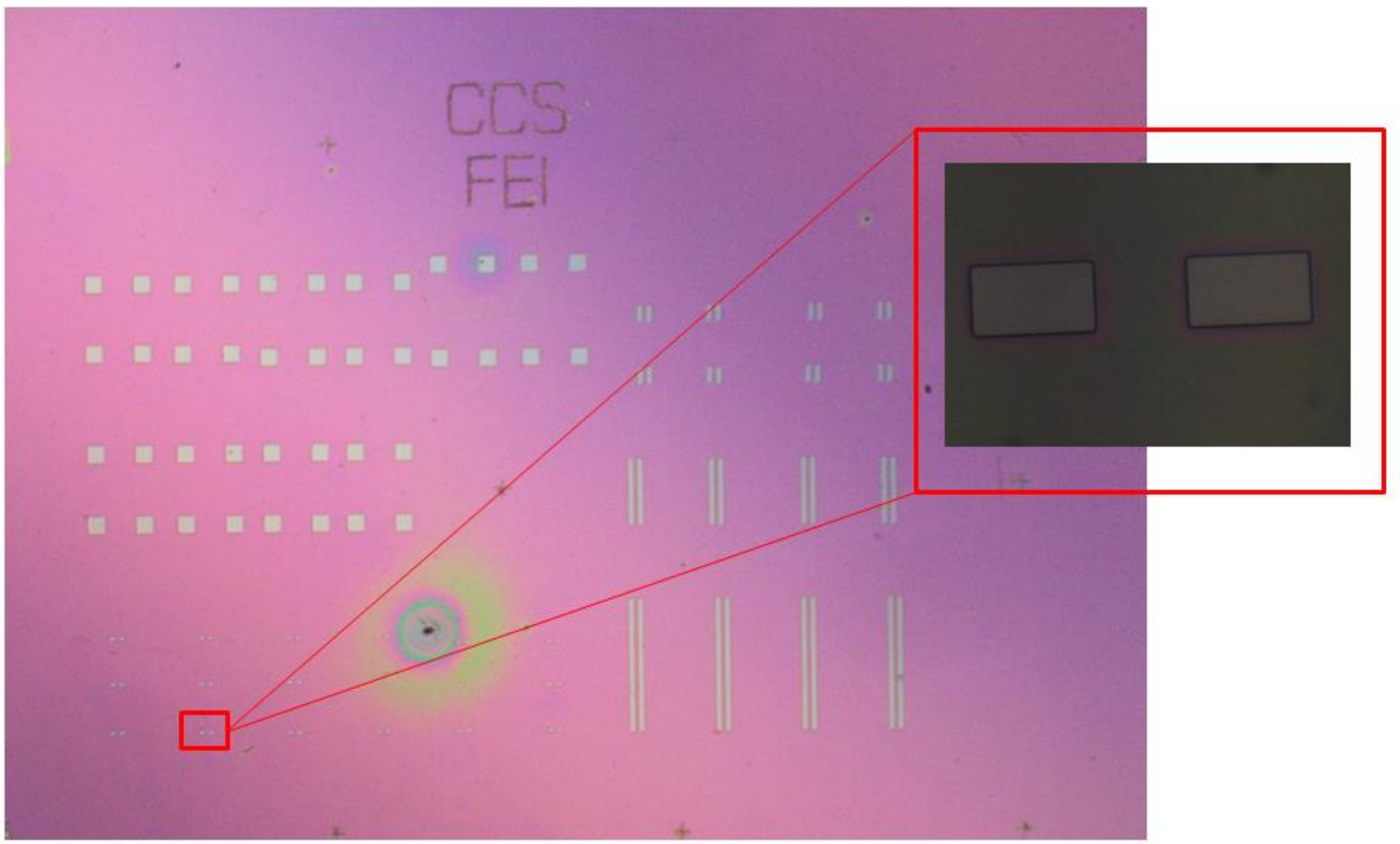

Fonte: Autor.

Logo em seguida a esta etapa é realizada a gravação dos pads de fonte e dreno e porta, através da máscara 3 nano estruturas e máscara 2 microestruturas com a sequencia de etapas apresentada na Tabela 8 . 
Tabela 8- Sequência de etapas para a realização da litografia dos pads de fonte, dreno e porta.

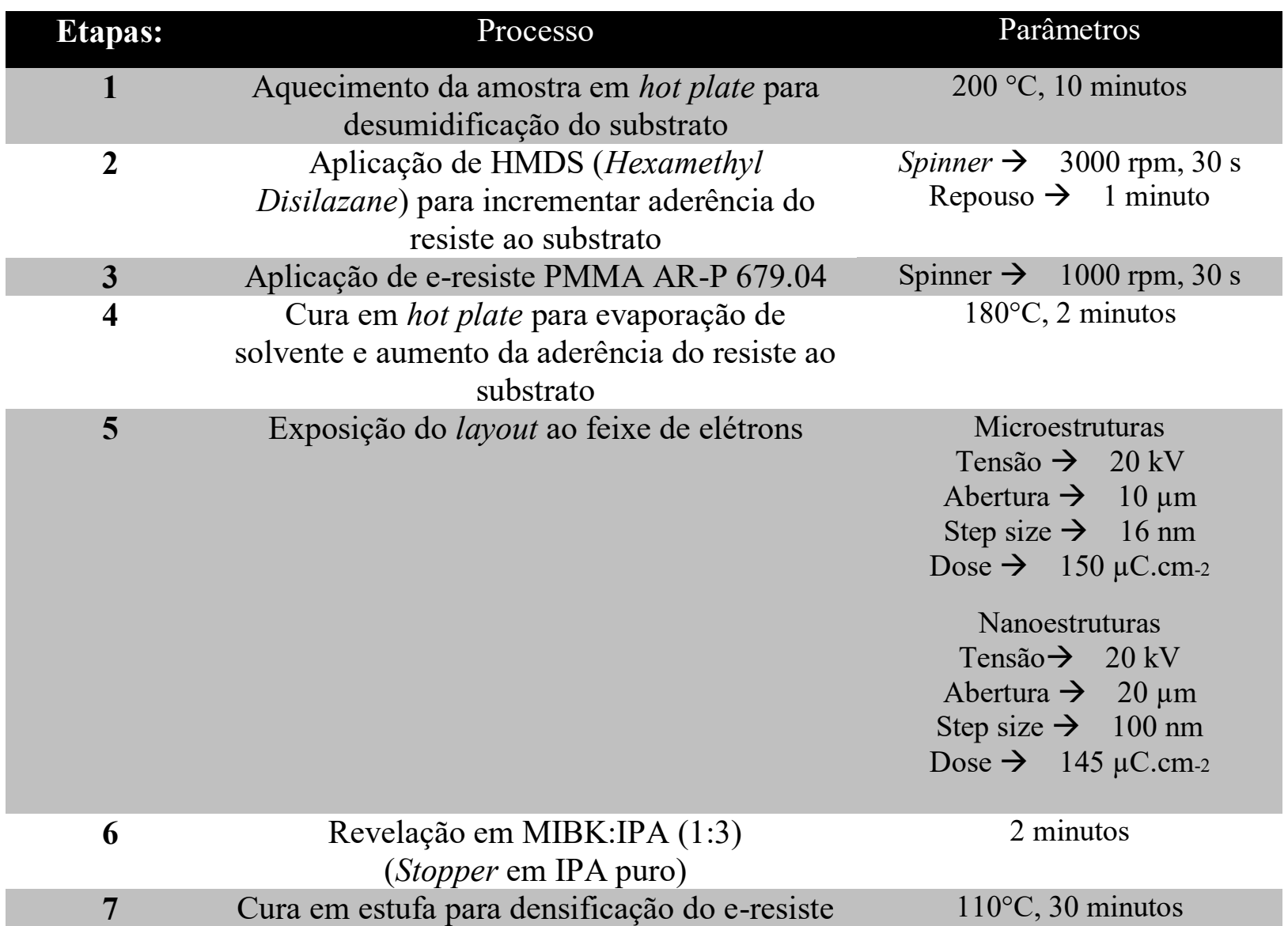

Fonte: Autor.

Assim que o resiste saiu da estufa a lâmina foi levada para o Sputtering para deposição de alumínio com os parâmetros: Potência ${ }_{\mathrm{DC}}=1000 \mathrm{~W}_{\mathrm{DC}}$, fluxo de argônio $=60 \mathrm{sccm}$,pressão=5 x $10^{-5}$ Torr e tempo $=70$ segundos. Em seguida a lâmina foi mergulhada na acetona para realizar o lift-off. Porém, após esta etapa notamos que os pads ficaram deteriorados, como mostra a Figura 53, isto porque no sputtering os íons são bombardeados com muito impacto, o que pode ter danificado o resiste e assim os padrões não saíram como o esperado. 
Figura 53- Foto dos pads de fonte, dreno e porta danificados, transistores com $\mathrm{N}=1280$.

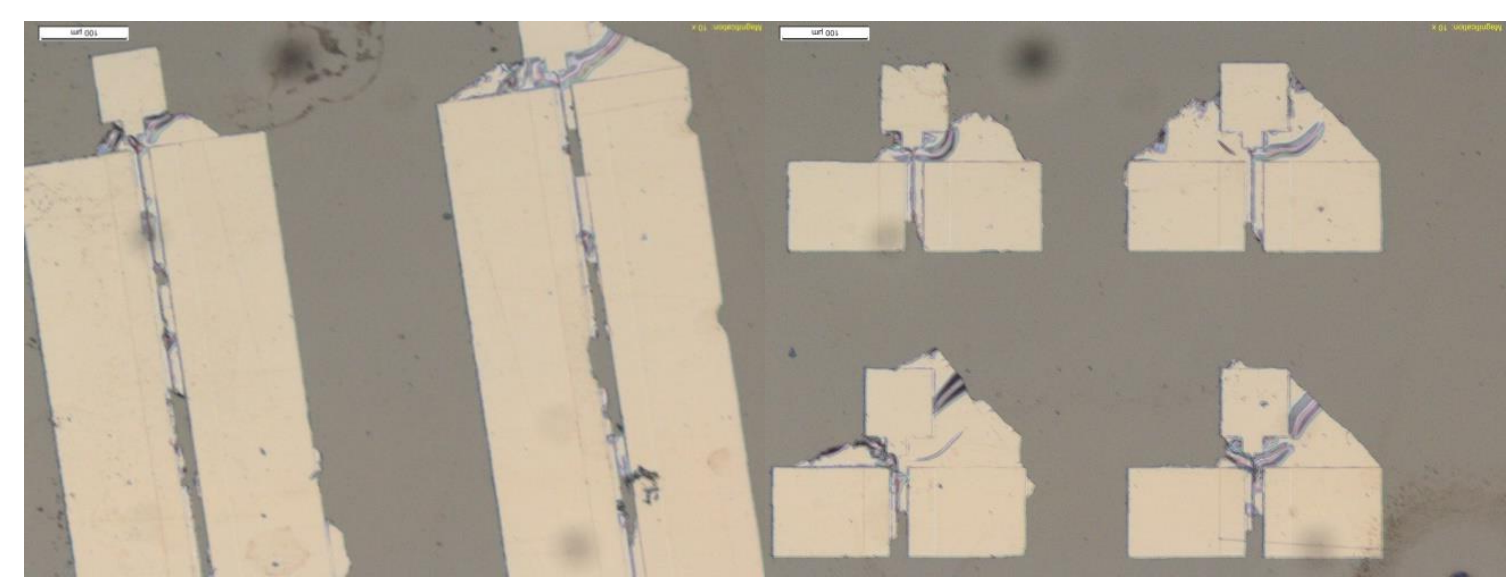

Fonte: Autor.

Como alteranativa para esta etapa de metalização dos pads utilizamos a evaporação de $\mathrm{Al}$ pois ela não deteriora o resiste que protege a lâmina. E assim obtivemos os pads perfeitos desta lâmina como mostramos nas figuras abaixo. Na Figura 53 e na Figura 55, é possível observar o transistor com $\mathrm{L}=0,1 \mu \mathrm{m}$ e $\mathrm{W}=0,1 \mu \mathrm{m}$.

Figura 54- À direita o transistor com 1 dedo de $\mathrm{L}=1 \mu \mathrm{m}$ e $\mathrm{W}=0,1 \mu \mathrm{m}$ e à esquerda $\mathrm{L}=1,5 \mu \mathrm{m}$ e $\mathrm{W}=0,1 \mu \mathrm{m}$.

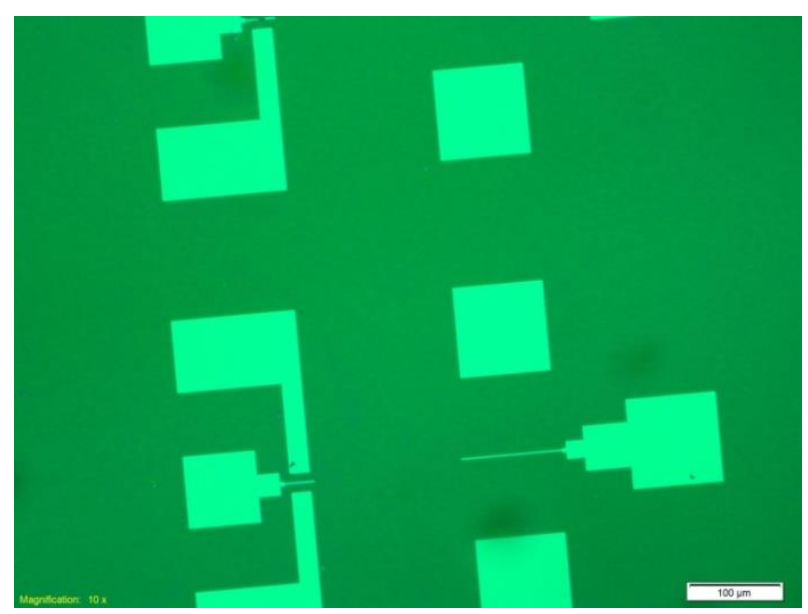

Fonte: Autor. 
Figura 55- Transistor $\mathrm{L}=0,6 \mu \mathrm{m}$ e $\mathrm{W}=0,1 \mu \mathrm{m}$ com magnificação de 50vezes, mostrando os pads de porta, fonte e dreno.

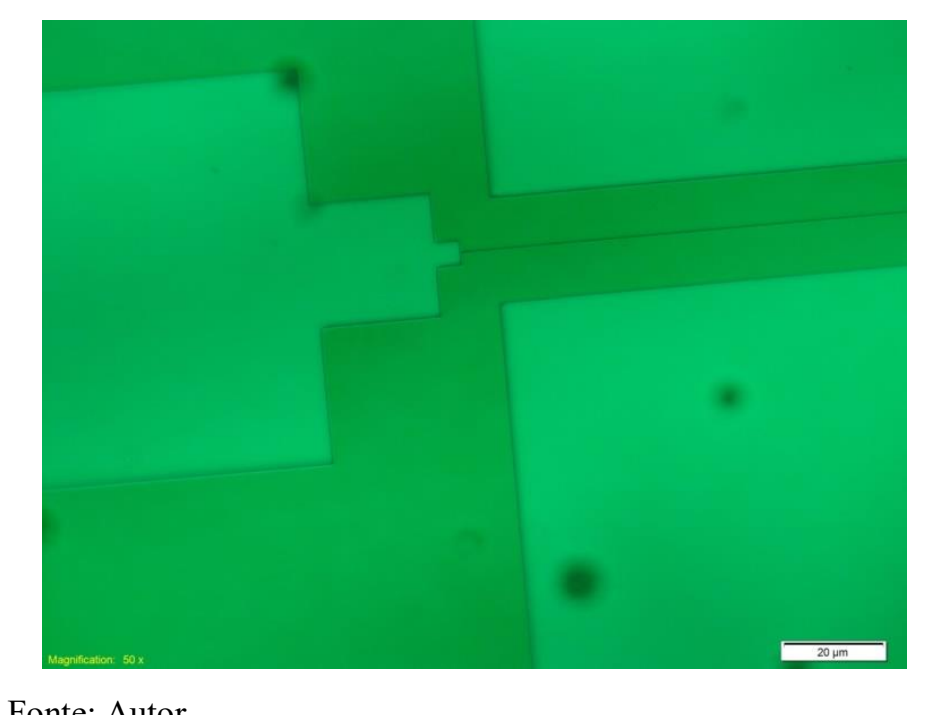

E após esta etapa foi realizada a sinterização a $450^{\circ} \mathrm{C}$ por 4 minutos. Nesta etapa, a fina camada de óxido nativo na superfície do Si é parcialmente absorvida pelo metal, melhorando assim o contato Al-Si. Após a finalização, foram tiradas no FIB algumas fotos de alguns dispositivos fabricados [65] [66] [67]. Na Figura 56, osbervamos o transistor com 1280 dedos, com $\mathrm{L}=0,5 \mu \mathrm{m}$ e $\mathrm{W}=0,1 \mu \mathrm{m}$, com esta magnitude não é possível observar o metal de porta, mas na figura 57 conseguimos observá-la.

Figura 56- Transistor $\mathrm{N}=1280$ dedos $\mathrm{L}=0,5 \mu \mathrm{m} \mathrm{W}=0,1 \mu \mathrm{m}$.

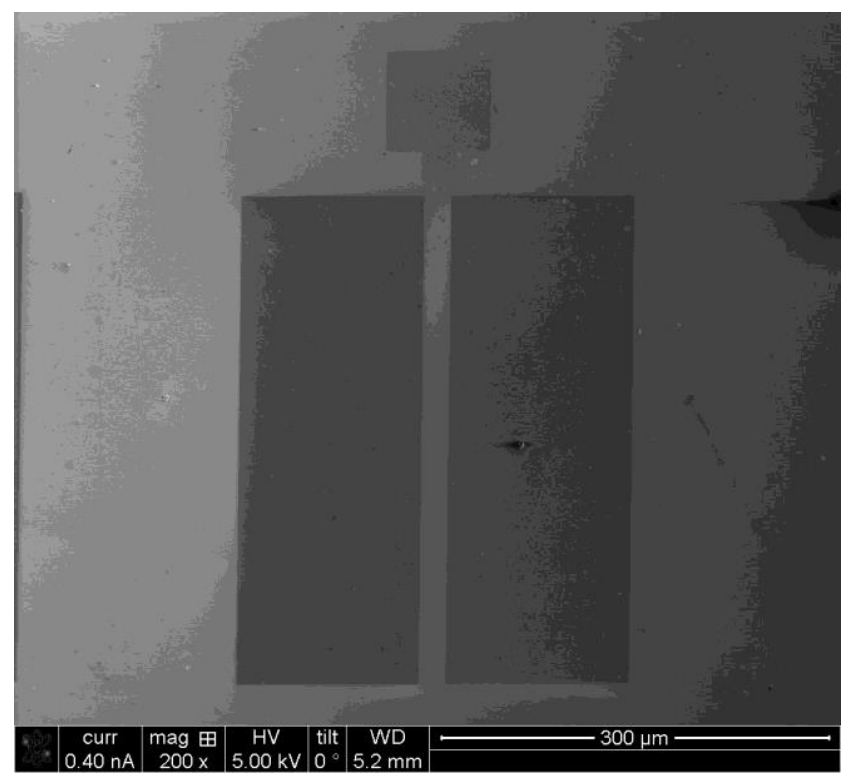

Fonte: Autor. 
Figura 57- Transistor $\mathrm{N}=1280$ dedos $\mathrm{L}=0,5 \mu \mathrm{m} \quad \mathrm{W}=0,1 \mu \mathrm{m}$ com maior magnitude.

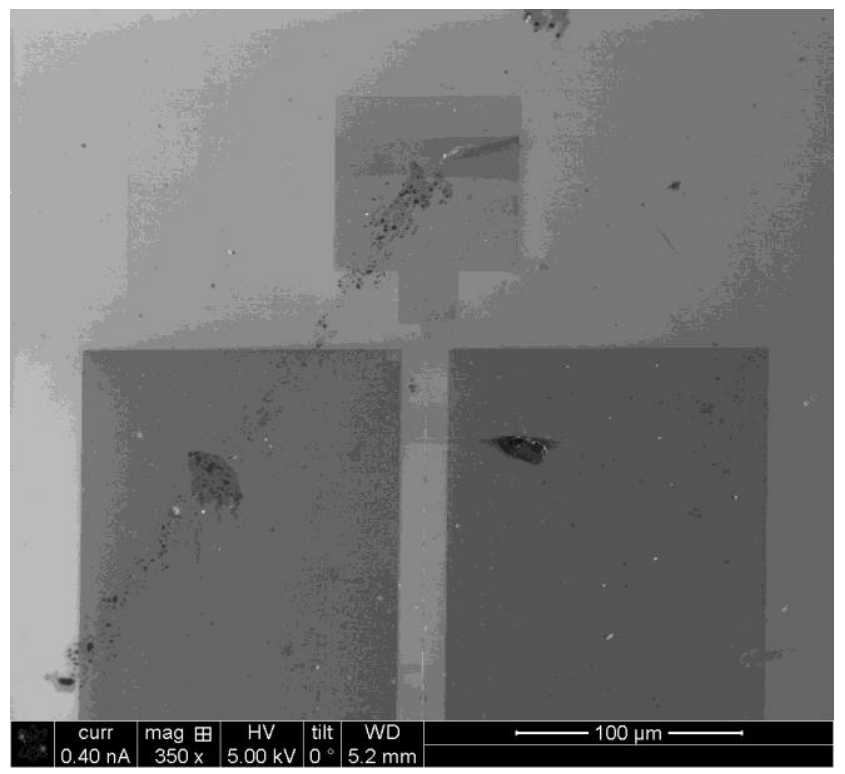

Fonte: Autor.

Figura 58- Transistor $\mathrm{N}=160, \mathrm{~L}=0,5 \mu \mathrm{m}$ e $\mathrm{W}=0,1 \mu \mathrm{m}$.

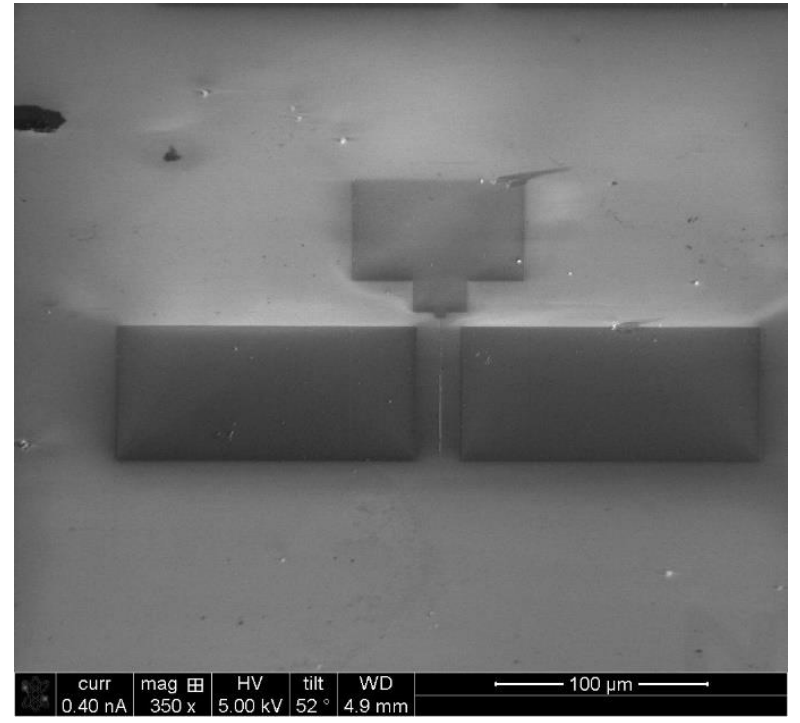

Fonte: Autor. 
Figura 59- Transistor $\mathrm{N}=160, \mathrm{~L}=0,5 \mu \mathrm{m}$ e $\mathrm{W}=0,1 \mu \mathrm{m}$ com maior magnitude.

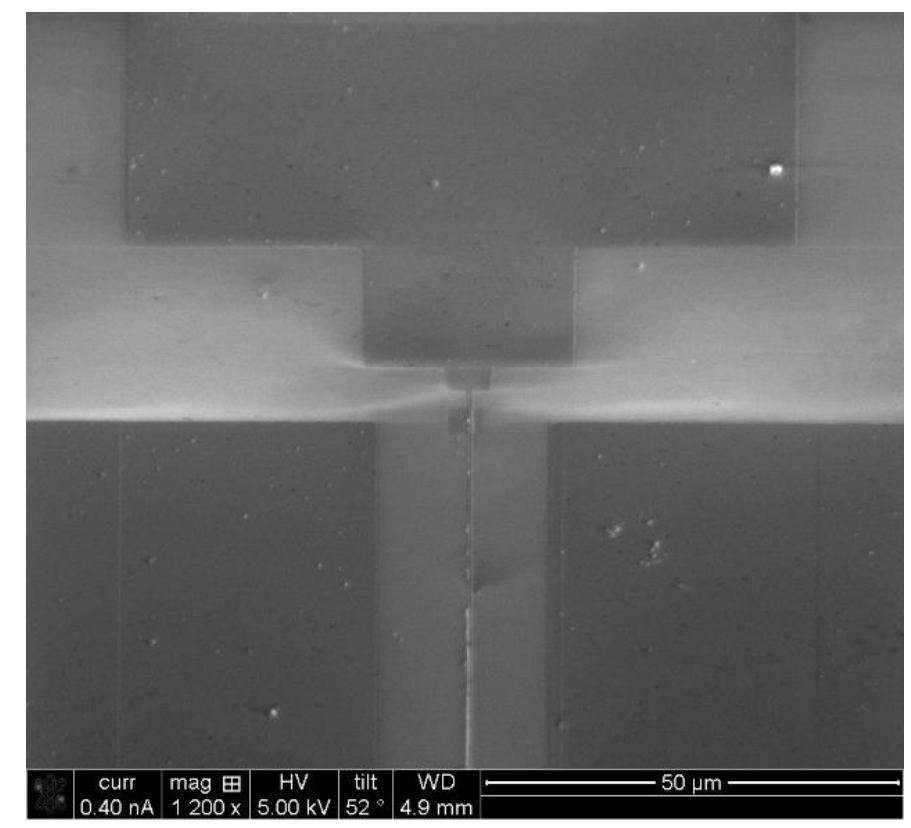

Fonte: Autor.

$\mathrm{Na}$ figura 60 é possível observar a porta de metal que passa pelos nanos fios bem conectada ao pad de porta, com isto podemos dizer que a etapa de litografia anteriormente realizada foi bem revelada com uma ótima dose e não sofreu qualquer tipo de deslocamento no momento da escrita. Podemos observar também o fio de alumínio (porta) com evidência, comprovando também que o comprimento de $0,5 \mu \mathrm{m}$ foi atingido. Assim podemos concluir que a etapa de litografia dos pads obteve uma boa calibração e não sofreu nenhuma alteração durante a escrita. 
Figura 60- Foto do transistor $\mathrm{N}=160$.

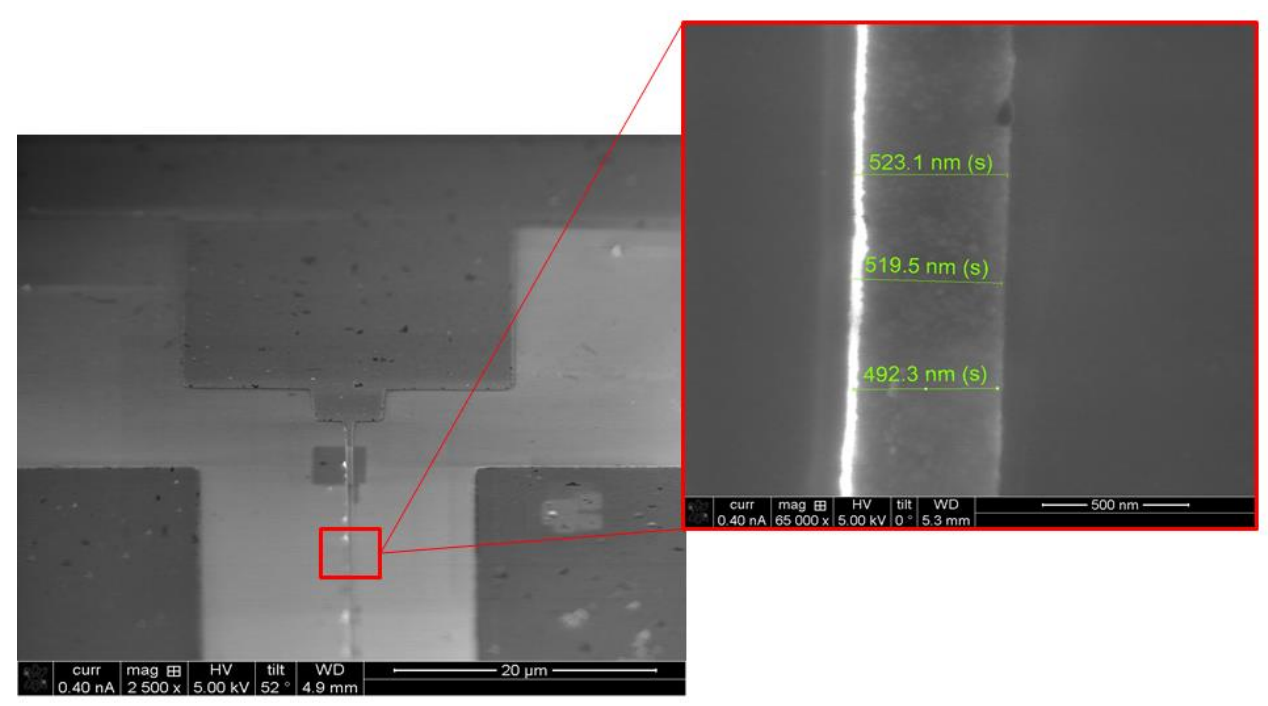

Fonte: Autor.

Legenda: Foto do transistor $\mathrm{N}=160, \mathrm{~L}=0,5 \mu \mathrm{m}$ e $\mathrm{W}=0,1 \mu \mathrm{m}$ com uma inclinação e maior magnitude, e ao lado o fio metal (porta) com L aproximadamente igual a $500 \mathrm{~nm}$.

Após a finalização desta amostra podemos observar alguns pontos a serem alterados para o próximo conjunto de transistores, a princípio o material utilizado para as marcas de alinhamento não apresentou uma ótima visualização no equipamento Raith e-line. Seria necessário alterar a espessura ou o material. Outro problema que tivemos foi com a corrosão das mesas. A taxa de corrosão de $10 \mathrm{~nm} / \mathrm{min}$ ajustado no laboratório do RIE não estava de acordo com o resultado, corroendo o óxido enterrado também. A oxidação utilizada neste conjunto de transistores corroeu mais que o simulado. E por fim também é necessário o novo ajuste de dose dos transistores na fase final da litografia dos pads para um melhor lift-off.

\subsection{FABRICAÇÃO LÂMINA BETA}

A rodada beta foi realizada com o mesmo conjunto de máscaras da rodada anterior, porém algumas alterações foram realizadas e serão detalhadas nesta seção. Na Tabela 9, serão apresentadas as etapas realizadas e em destaque (azul) estão as etapas que sofreram modificação depois da primeira rodada (alpha). 
Tabela 9- Descrição da sequencia de fabricação da lâmina beta.

\begin{tabular}{cc|}
\hline Etapas & Descrição \\
\hline $\mathbf{1}$ & Limpeza RCA \\
$\mathbf{2}$ & Deposição de $60 \mathrm{~nm}$ de $\mathrm{SiO}_{2}$ como óxido de sacrifício \\
\hline $\mathbf{3}$ & Implantação de Fósforo \\
$\mathbf{4}$ & Retirada $\mathrm{SiO}_{2}$ (solução $\left.\mathrm{HF}\right)$ \\
\hline
\end{tabular}

5 Recozimento RTA(ambiente de $\mathrm{N}_{2}$ e $\mathrm{O}_{2}$, a temperatura de $1000^{\circ} \mathrm{C}$, durante 60 segundos).

6 Litografia por feixe de elétrons Máscara 0 (marca de alinhamento)

7 Depositar 10nm de titânio e 60nm de tântalo (lift-off)

8 Litografia por feixe de elétrons Máscara 1 (região ativa)

\begin{tabular}{|c|c|}
\hline 9 & Corrosão ICP e ECR \\
\hline \multirow[t]{2}{*}{10} & Oxidação de porta (forno) $\mathrm{T}=1000^{\circ} \mathrm{C} \mathrm{Tx}=1 \mathrm{~min}$ \\
\hline & Óxido 6.0 \\
\hline 11 & Litografia por feixe de elétrons Máscara 2 (abertura de contatos) \\
\hline 12 & Solução HF 3 segundos \\
\hline 13 & $\begin{array}{l}\text { Litografia por feixe de elétrons Máscara } 3 \text { ( definição de pads } \\
\text { fonte e dreno e porta de } \mathrm{Al} \text { ) }\end{array}$ \\
\hline 14 & Deposição de Al.( evaporação de Al) \\
\hline 15 & Remoção do resiste, ultrassom e limpeza. \\
\hline
\end{tabular}

16

Sinterização 4 minutos

Fonte: Autor.

A primeira alteração foi na dose de implantação de Fósforo, alteramos para $1 \times 10^{15} \mathrm{~cm}^{-}$ 2 e assim abaixamos a tensão de limiar para $-0,5 \mathrm{~V}$. Para as marcas de alinhamento, como segue na etapa 7 da Tabela 9, foi alterado o material, pois na rodada anterior tivemos 
dificuldade de visualizar as marcas feitas de titânio,. O equipamento diferencia as cores quanto maior o número atômico entre os materiais (marcas e silício), então foi utilizado o Tântalo disponível no sputtering do CCS. Como tântalo não tem tanta aderência no Si foi depositado na mesma etapa $10 \mathrm{~nm}$ de titânio. Redefinir esta etapa foi muito importante pois uma boa visualização das marcas de alinhamento propiciam um melhor ajuste e alinhamento das máscaras evitando possíveis deslocamentos entre as gravações. A marca realizada com um bom contraste podemos observar na Figura 61.

Figura 61- Imagem feita no MEV das marcas de alinhamento global com 10nm de Ti e $80 \mathrm{~nm}$ de Ta.

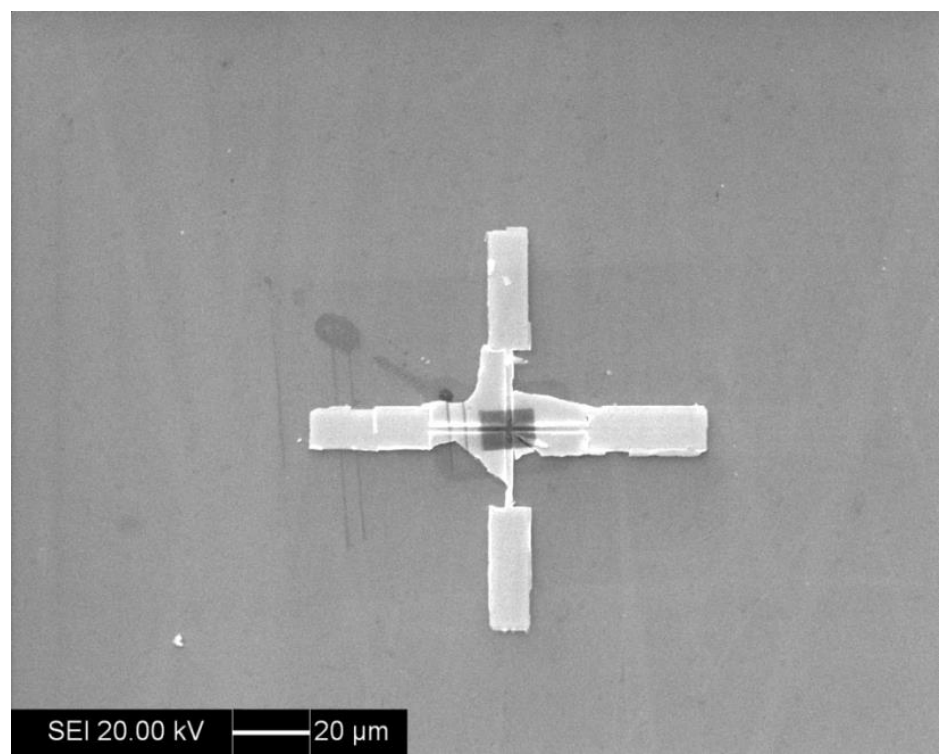

Fonte: Autor.

A etapa 9 da Tabela 9 foi próximo problema encontrado na lâmina alpha. Como a espessura do silício é $14 \mathrm{~nm}$ e do óxido enterrado $20 \mathrm{~nm}$, após realizarmos as corrosões não conseguimos verificar se a corrosão só corroeu o silício ou se avançou para o óxido enterrado ou até se o perfurou atingindo o substrato. A figura 62 demonstra, em um esquema, os possíveis resultados desta corrosão. 
Figura 62- Esquema da litografia máscara 1 (região ativa) e possíveis resultados da corrosão realizada.

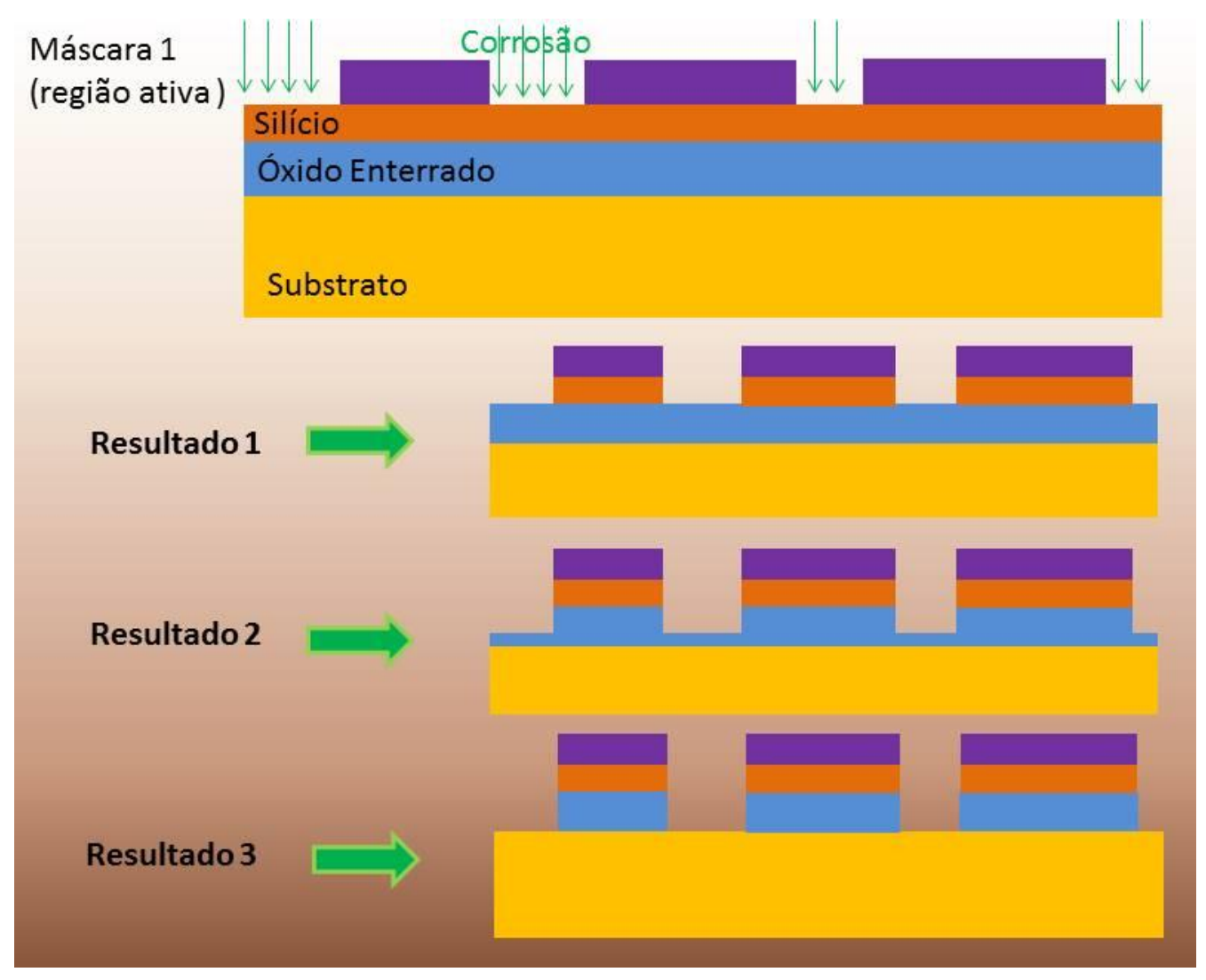

Fonte: Autor.

Legenda: . Resultado 1 seria corroído apenas o silício da região ativo. Resultado 2 seria corroído o silício e uma parte do óxido enterrado e resultado 3 teria corroído silício, óxido e deixaria o substrato exposto.

Conforme vimos na figura 62, dependendo dos parâmetros de corrosão a lâmina pode admitir alguns resultados. O ideal seria o resultado 1 pois faria a corrosão do silício e não atingiria o óxido enterrado, garantindo o isolamento do dispositivo do substrato. Porém outras situações seriam possíveis, a corrosão parcial do óxido enterrado, resultado 2 e corrosão total do óxido enterrado resultado 3, este deixando em curto porta, fonte e dreno. Para isso realizamos testes no ICP-RIE e ECR e em seguida foram feitas medidas no elipsômetro. 
Tabela 10- Teste de corrosão ICP-Rie e ECR.

\begin{tabular}{|llll} 
Teste & Equipamento & $\begin{array}{l}\text { Tempo } \\
\text { (segundos) }\end{array}$ & $\begin{array}{l}\text { Elipsômetro } \\
\text { Espessura (nm) }\end{array}$ \\
\hline $\mathbf{1}$ & ICP & 2 & 20,7 \\
$\mathbf{2}$ & ICP & 5 & 23,3 \\
$\mathbf{3}$ & ECR & 10 & 21,3 \\
\hline
\end{tabular}

Fonte: Autor.

As medidas realizadas no elipsômetro mostraram o índice de refração $=1,462$, próximo do $\mathrm{SiO}_{2}$, portando chegamos a conclusão que estas corrosões estavam perto do resultado 2 da figura 62. Para comprovarmos, sabendo que o óxido de Si é hidrófilo, mergulhamos estas lâminas na água deionizada, se estas ficassem molhadas significaria que havia óxido, porém se ficassem secas saberíamos que havia silício ainda na lâmina. Das três amostras, as de número 1 e 2 ficaram secas. Portanto decidimos fixar o tempo em 3 segundos.

A oxidação desta rodada realizamos no forno com oxigênio com grau 6.0, ou seja 99,999999\% de pureza. Realizamos teste no forno com tempo de 2 minutos e 1 minuto, para os dois casos foram inseridos uma lâmina de silício para controle. Esta lâmina foi essencial para a medida no elipsômetro, pois como as camadas da nossa lâmina SOI são muito finas o elipsômetro não calcula 3 camadas e dá um erro na medida do óxido da superfície.

A sequência de forno utilizada também foi alterada para diminuir ao máximo o óxido formado.

Tabela 11- Sequência para oxidação da lâmina beta.

\begin{tabular}{|lccc|}
\hline Etapa/Descrição & $\begin{array}{l}\text { Temperatura } \\
\left({ }^{\circ} \mathbf{C}\right)\end{array}$ & Ambiente & $\begin{array}{c}\text { Tempo } \\
(\mathbf{m i n})\end{array}$ \\
\hline $\mathbf{1}^{\circ}$ Entrada da lâmina & 1000 & $\mathrm{~N}_{2}$ & 3 \\
\hline $\mathbf{2}^{\circ}$ Estabilização & 1000 & $\mathrm{~N}_{2}$ & 5 \\
$\mathbf{3}^{\circ}$ Oxidação & 1000 & $\mathrm{O}_{2}$ & 1 e 2 \\
$\mathbf{4}^{\circ}$ Saída da lâmina & - & - & -
\end{tabular}

Fonte: Autor. 
Tabela 12- Resultado da oxidação realizada no forno convencional com $\mathrm{O}_{2}$ pureza 4.0 e 6.0 .

\section{Teste Oxidação Forno}

\begin{tabular}{c|c|c}
\multirow{2}{*}{$\begin{array}{c}\text { Tempo } \\
(\mathbf{m i n})\end{array}$} & \multicolumn{2}{|c}{ Espessura (nm) } \\
\cline { 2 - 3 } & $\mathbf{O}_{\mathbf{2}} \mathbf{4 . 0}$ & $\mathbf{O}_{\mathbf{2}} \mathbf{6 . 0}$ \\
\hline $\mathbf{1}$ & 22 & 10 \\
\hline $\mathbf{2}$ & 26 & 14 \\
\hline
\end{tabular}

Fonte: Autor.

Na lâmina alpha ele foi feito com oxigênio com grau 4.0 e isto resultou num óxido com espessura próximo a $30 \mathrm{~nm}$, consumindo quase todo o silício da lâmina. Com este oxigênio conforme na Tabela 12 observamos que com $\mathrm{O}_{2} 6.0$ obtivemos um óxido de 10nm.

A abertura de contatos também foi realizada com outra técnica, com corrosão úmida e foram utilizados 3 segundos em HF. A taxa de corrosão no silício é 100nm/minuto.

Após a abertura de contatos foi necessário realizar a litografia para pads de fonte, dreno e porta. Nesta etapa tivemos problemas com a dose já utilizada na lâmina anterior isto porque o eletroresiste aumenta a viscosidade com o tempo o que altera a dose necessária para sensibilizar o eletroresiste. A dose utilizada anteriormente era de $150 \mu \mathrm{C} / \mathrm{cm}^{2}$ nas microestruturas e $145 \mu \mathrm{C} / \mathrm{cm}^{2}$ nano estruturas. Na Figura 63, podemos observar as máscaras 3 e 2 , nanoestruturas e microestruturas, respectivamente com a variação de dose. Fizemos variação de $140 \mu \mathrm{C} / \mathrm{cm}^{2}, 150 \mu \mathrm{C} / \mathrm{cm}^{2}, 160 \mu \mathrm{C} / \mathrm{cm}^{2}, 170 \mu \mathrm{C} / \mathrm{cm}^{2}$. 
Figura 63- Layout das doses nas máscaras 3 e 2 , nanoestruturas e microestruturas.

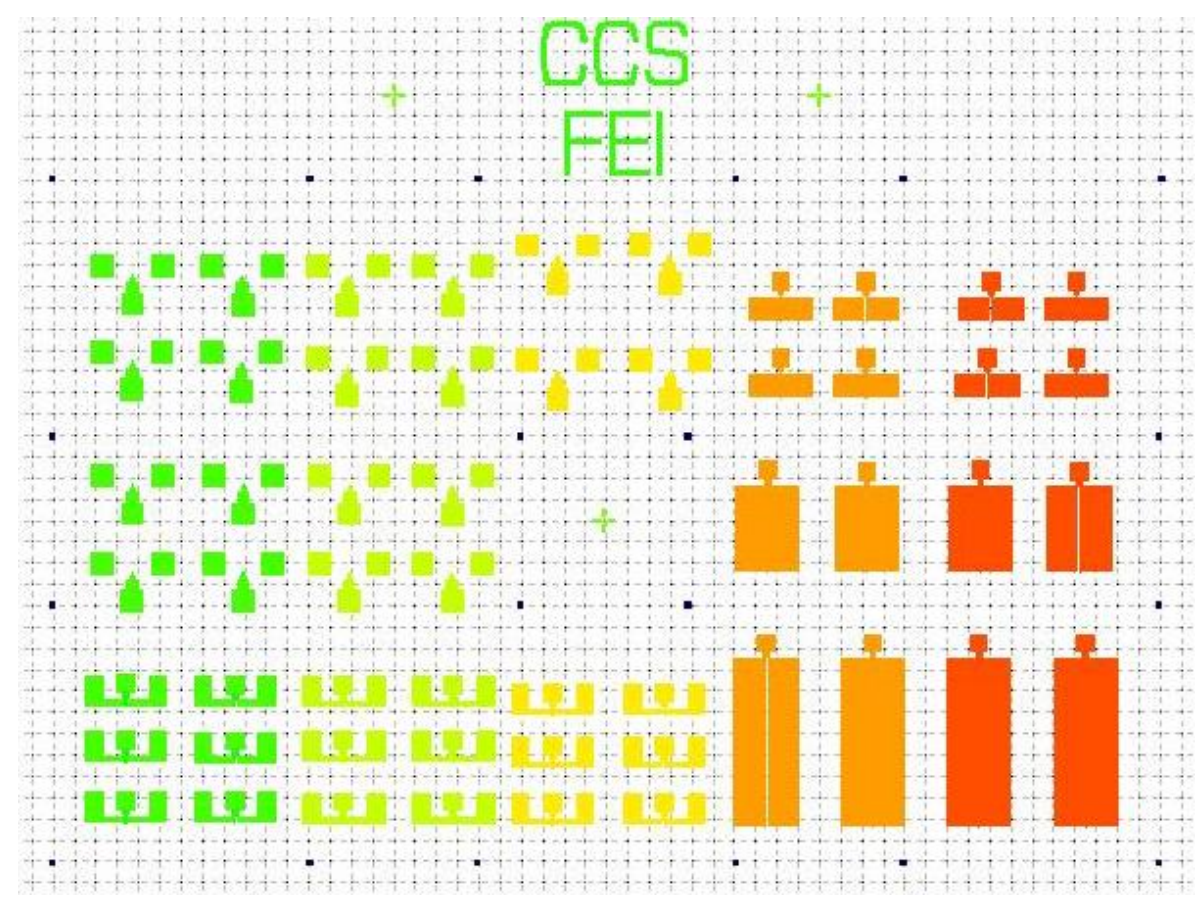

Fonte: Autor.

Com a revelação das lâminas testes definimos a dose $165 \mu \mathrm{C} / \mathrm{cm}^{2}$ nanoestruturas e 150 $\mu \mathrm{C} / \mathrm{cm}^{2}$ microestruturas.

Deposição de Al foi realizada com a evaporadora, e foi realizado o lift-off. Porém algumas as linhas da máscara 3 nanoestruturas e pads da máscara 2, não permaneceram como podemos ver Figura 64 feitas no MEV.

Figura 64- Imagem feita no MEV da lâmina beta.

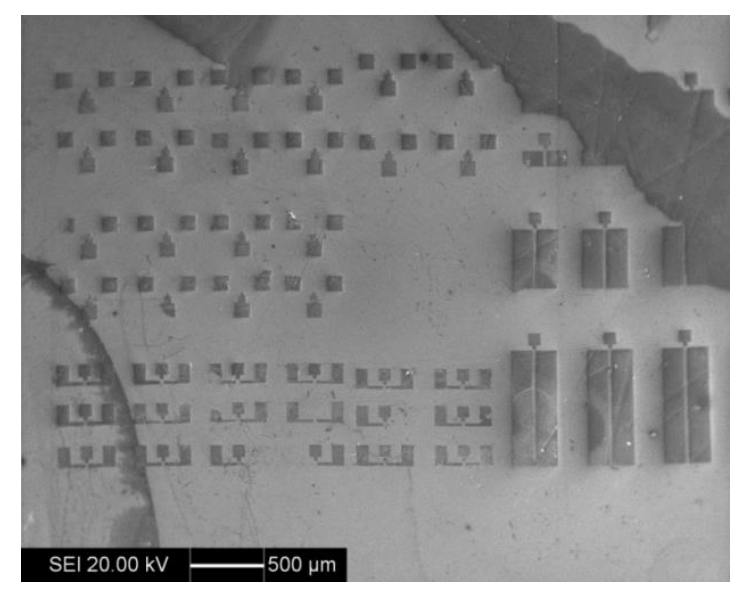

Fonte: Autor. 
Outra imagem feita foi a Figura 64, que mostra o pad de porta em contato com a via de metal que cobre os nano fios. Nesta imagem podemos observar a parte superior do pad e a via sofreram um deslocamento para direita, e a via foi parcialmente rompida. Este problema que tivemos foi devido àa litografia, pois o foco do equipamento e-line pode ter variado durante a escrita, esta que tem tempo de duração de aproximadamente 6 horas, o que ocasionou este deslocamento do quadrado superior do pad. A via de metal que cobre os nanofios, manteve a posição pois ela é sempre escrita primeiro que os pads, e sua escrita demora em torno de 15 minutos, por isso creio que o feixe não teve tempo de sofrer alterações.

O processo de lift-off nesta rodada caracteriza-se basicamente pela inicial produção de uma estrutura por e-beam (exposição/revelação) em um sistema de resistes positivos colocado sobre um substrato. Em seguida, realiza-se uma etapa de deposição de um filme fino sobre todo o substrato do material desejado por sputtering ou por evaporação. Após a etapa de deposição é feita a remoção do resiste mediante a imersão da amostra em solventes aquecidos adequados durante um determinado tempo, o solvente utilizado foi acetona. Este processo acontece baseado nas espessuras do resiste aplicado em relação ao metal depositado, o que acontece é que a parte central do objeto litografado fica mais espessa enquanto que as bordas ficam mais finas. A existência da parede lateral do resiste acaba formado uma "sombra" durante a deposição do filme fino que impede a deposição homogênea (de mesma espessura) ao longo de toda a estrutura litografada. Deste modo algumas partes do filme depositado que não deveriam sair com o resiste acabam saindo ao ser mergulhado no solvente. 
Figura 65- Imagem do transistor A2 da lamina beta, evidenciando o pad de porta com ligação parcialmente rompida com a via de metal de porta.

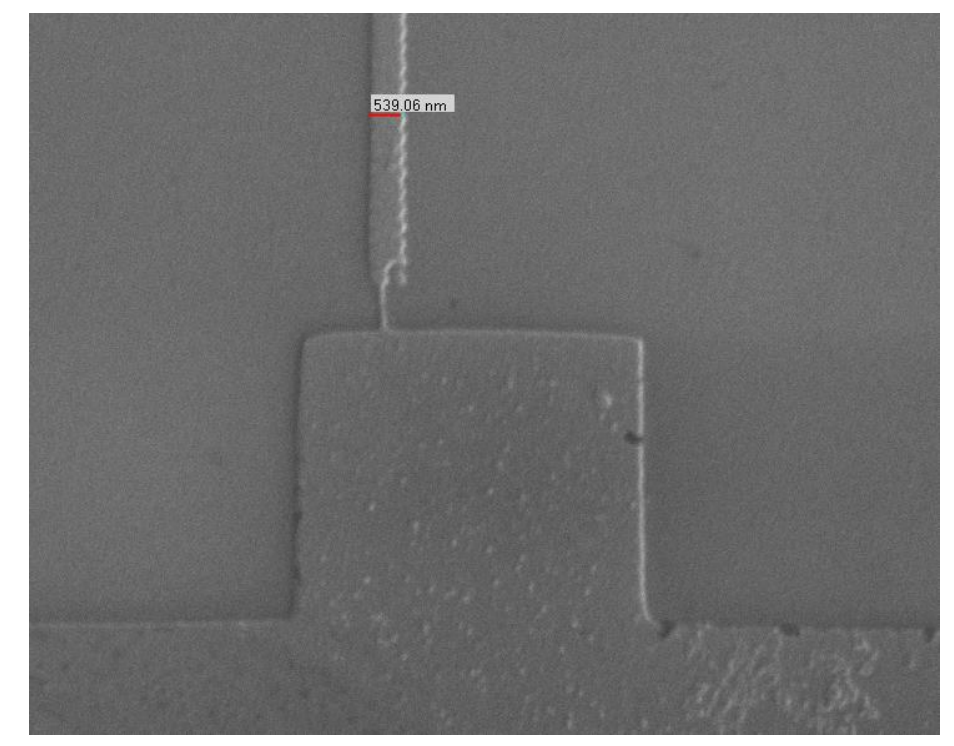

Fonte: Autor.

Mesmo assim demos continuidade na sinterização, pois nem todos os pads tinham sido danificados e retirar o $\mathrm{Al}$ e refazer esta etapa poderíamos perder os nano fios desta rodada. Assim foi realizado 4 minutos de sinterização à $450^{\circ} \mathrm{C}$ e em seguida testes elétricos foram feitos.

Neste conjunto de transistores conseguimos corrigir as deficiências de visualização das marcas de alinhamento depositando Titânio e Tântalo. Conseguimos aumentar a concentração de dopantes através de uma nova dose de implantação e alteramos o $\mathrm{V}_{\mathrm{T}}$ para $-0,5 \mathrm{~V}$. O óxido de porta foi alterado para um $\mathrm{O}_{2}$ mais puro apresentando uma espessura do óxido de porta mais perto do projetado. Por outro lado ainda apresentamos problemas com a metalização final, devido à alteração do resiste utilizado na lâmina alpha.

\subsection{FABRICAÇÃO LÂMINA GAMA}

A terceira rodada de transistores denominada gama é composta por 54 transistores. Para sua fabricação foi utilizado o mesmo conjunto de máscaras do conjunto beta de transistores; Os dispositivos deste conjunto podem ser compreendidos como um transistor sem junção com a dopagem da lâmina de $1 \times 10^{15} \mathrm{~cm}^{-3}$, este dispositivo foi agregado ao projeto por apresentar inúmeras vantagens aos transistores planares CMOS além de ultimamente estar 
sendo estudado por diversos grupos de pesquisa pelo mundo e ser apontado como um grande substituto para transistores planares CMOS.

Esta rodada apresenta processo de fabricação mais simples, pois não apresenta etapas de implantação iônica nem recozimentos térmicos para ativação de dopantes.

Na Tabela 13, observamos duas alterações em azul, de corrosão e oxidação que foram utilizadas como alternativa para os problemas apontados na lâmina alpha; E uma alteração na litografia dos pads foi novamente necessária.

Tabela 13- Sequência de fabricação da lâmina gama.

$\begin{array}{cc}\text { Etapas } & \text { Descrição } \\ \mathbf{1} & \text { Limpeza RCA }\end{array}$

2 Litografia por feixe de elétrons Máscara 0 (marca de alinhamento)

3 Depositar 10nm de titânio e 60nm de tântalo (lift-off)

$4 \quad$ Litografia por feixe de elétrons Máscara 1 (região ativa)

\begin{tabular}{cc}
\hline $\mathbf{5}$ & Corrosão ICP 3 segundos \\
\hline $\mathbf{6}$ & Oxidação de porta ECR 10 segundos \\
\hline $\mathbf{7}$ & Litografia por feixe de elétrons Máscara 2 (abertura de contatos) \\
\hline $\mathbf{8}$ & Solução HF 3 segundos \\
\hline $\mathbf{9}$ & Litografia por feixe de elétrons Máscara $3($ definição de pads \\
& $\begin{array}{r}\text { fonte e dreno e porta de Al) } \\
\hline\end{array}$
\end{tabular}

10 Deposição de Al.( evaporação de Al)

11 Remoção do resiste, ultrassom e limpeza.

12

Sinterização 4 minutos

Fonte: Autor.

Nesta etapa pudemos corrigir a dose da litografia inicial também e obtivemos marcas de alinhamento muito melhor que na etapa anterior como podemos ver na Figura 66. 
Figura 66- Marcas de alinhamento de Titânio e tântalo, (a) marca lateral (b) marcas manuais.

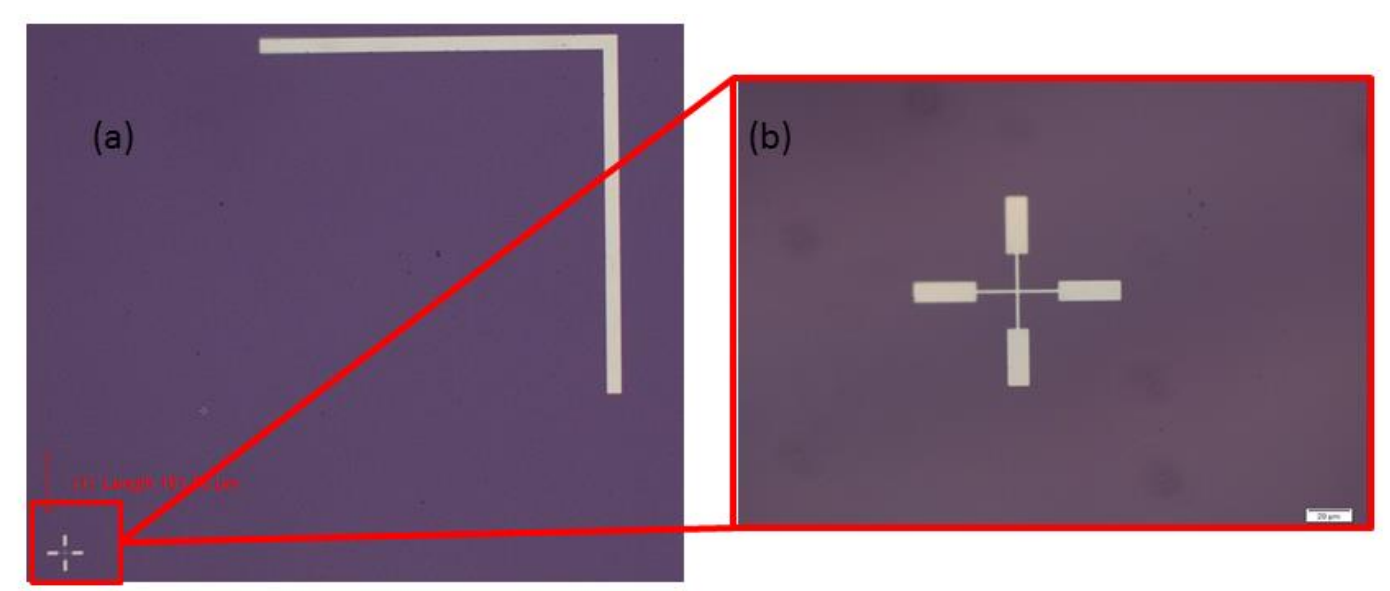

Fonte: Autor.

Como neste conjunto de transistores não fizemos a implantação iônica o próximo passo após as marcas de alinhamento foram a definição das mesas de silício. Para esta lâmina alteramos o tempo de corrosão no ICP. Quando realizamos a corrosão na lâmina beta notamos que as mesas de silício não ficaram muito bem definidas, então resolvemos aumentar o tempo de corrosão para 5 segundos e após a corrosão notamos que as mesas de silício ficaram bem definidas. Na foto tirada na Figura 67 será possível visualizar.

Figura 67- Definição da mesa de silício do transistor com $\mathrm{W}=0,1 \mu \mathrm{m}$ e $\mathrm{L}=0,5 \mu \mathrm{m}$.

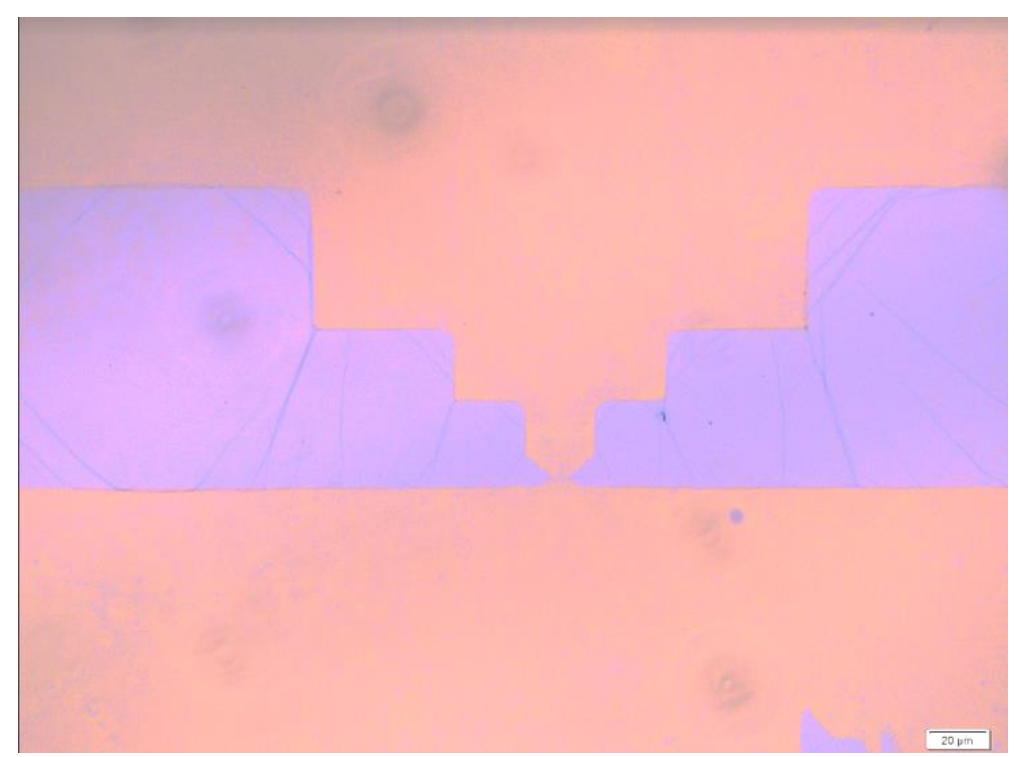

Fonte: Autor. 
Imagens feitas no FIB foram realizadas para a verificação do nanofio, foi necessário realizar as imagens com o nanofio coberto pelo eletroresiste utilizado na litografia, isto pois sem esta camada de eletroresiste não é possível observar o nanofio por contraste. A Figura 68 (a) apresenta o transistor de $\mathrm{W}=0,1 \mu \mathrm{m}$ com o campo de $200 \mu \mathrm{m}$, nele notamos as bordas escuras isso referente a camada de eletroresiste. Na Figura 68 (c) é possível verificar que o nanofio observado foi de aproximadamente $\mathrm{W}=0,15 \mu \mathrm{m}$.

Figura 68- Imagens realizadas no FIB da mesa de silício.

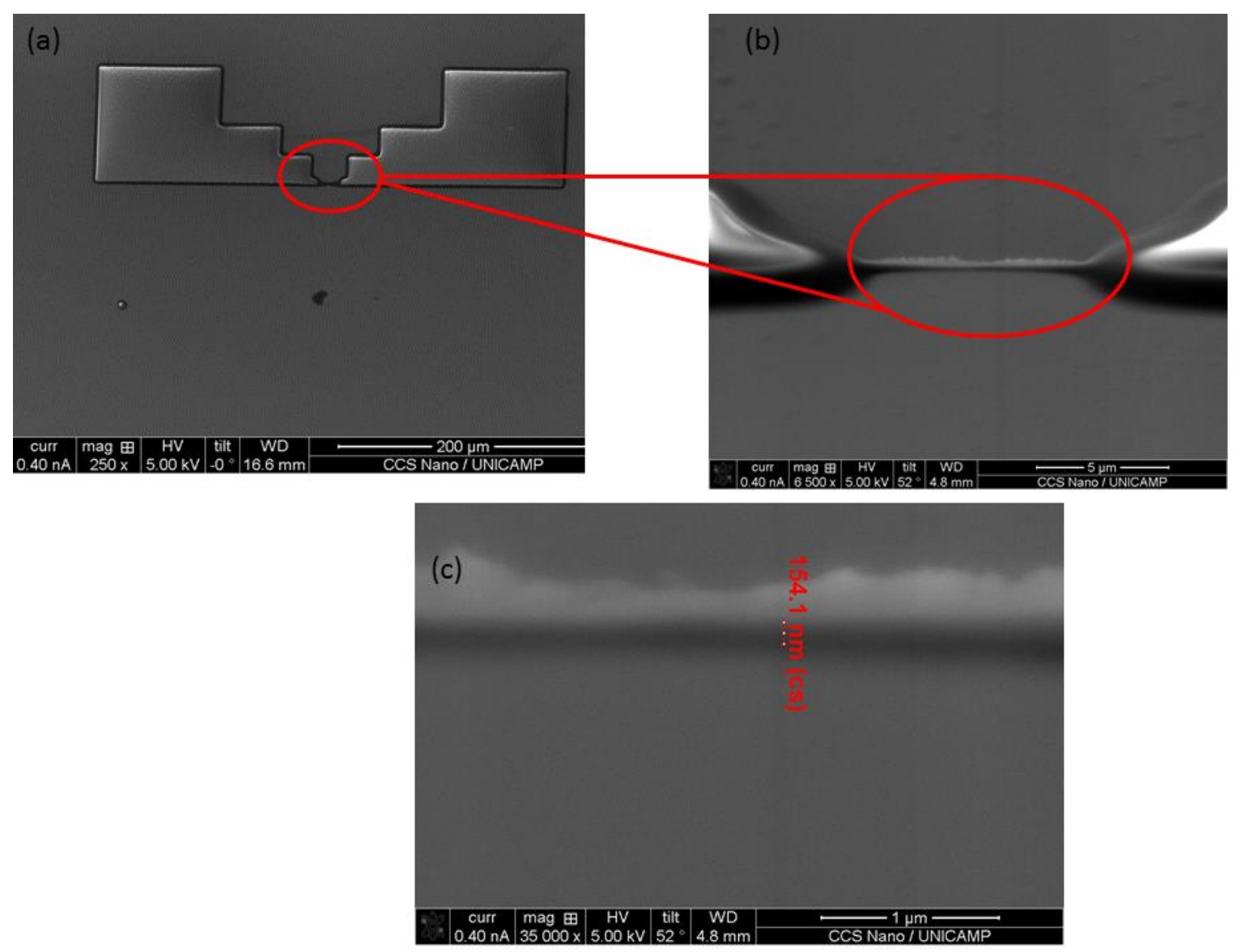

Fonte: Autor.

Legenda: mesa de silício. formada do transistor de $\mathrm{W}=0,1 \mu \mathrm{m}$. (a) Imagem geral do transistor com a mesa de silício para os pads de fonte e dreno, (b) Imagem com campo de $5 \mu \mathrm{m}$ de magnitude é possível observar o nano fio de silício porém coberto por uma camada de eletroresiste, (c) Imagem do nanofio com magnitude de $1 \mu \mathrm{m}$.

Após as mesas de silício definidas e as lâminas limpas do eletroresiste passamos para a etapa da oxidação. Ao realizarmos testes de oxidação no forno convencional, vimos a possibilidade de realizar a oxidação no ECR e esta oxidação já estava calibrada, então realizamos a oxidação em uma lâmina teste e após medirmos por elipsômetria a espessura de 10nm realizamos esta oxidação por plasma ECR. O que resulta em uma camada de silício 
restante te aproximadamente $10 \mathrm{~nm}$, sendo que o $\mathrm{SiO}_{2}$ consome aproximadamente $40 \%$ de silício.

Em sequência, tivemos problemas na litografia dos pads, primeiramente para revelar, depois as vias de metal não ficavam na lâmina, e os pads ficaram todos deteriorados. Na figura 69 abaixo realizada no MEV notamos como esta etapa ficou ruim. Um novo ajuste de dose foi realizado para recalibrar esta etapa.

Figura 69- Imagem MEV dos transistores da lâmina gama. Os pads estão bem deteriorados.

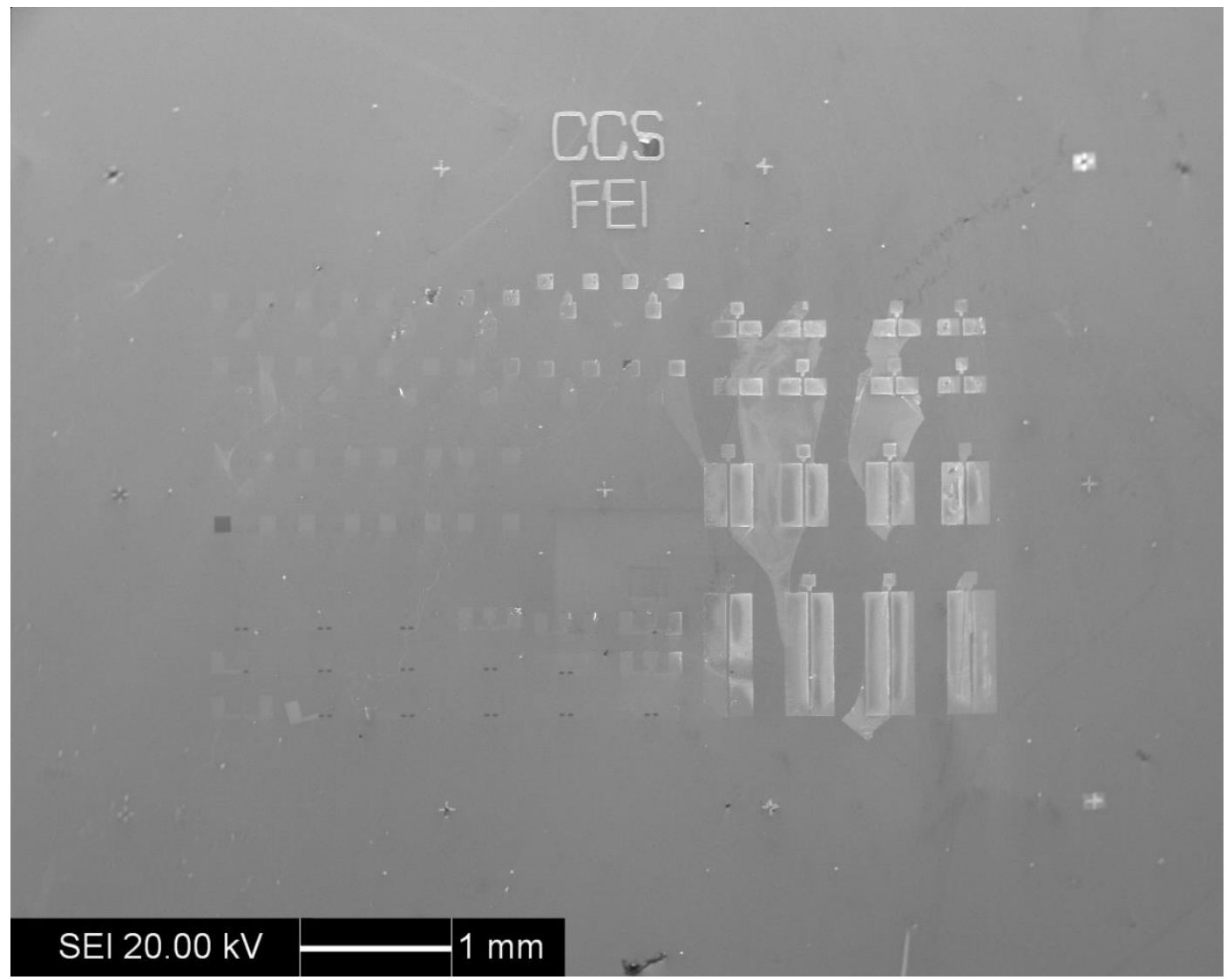

Fonte: Autor.

Após ter realizado o ajuste as doses finais diminuíram em aproximadamente 10\%. E após a litografia e o lift-off realizado observamos o die final da estrutura gama na figura 70 . 
Figura 70- Imagem da lâmina gama após o lift-off de alumínio.

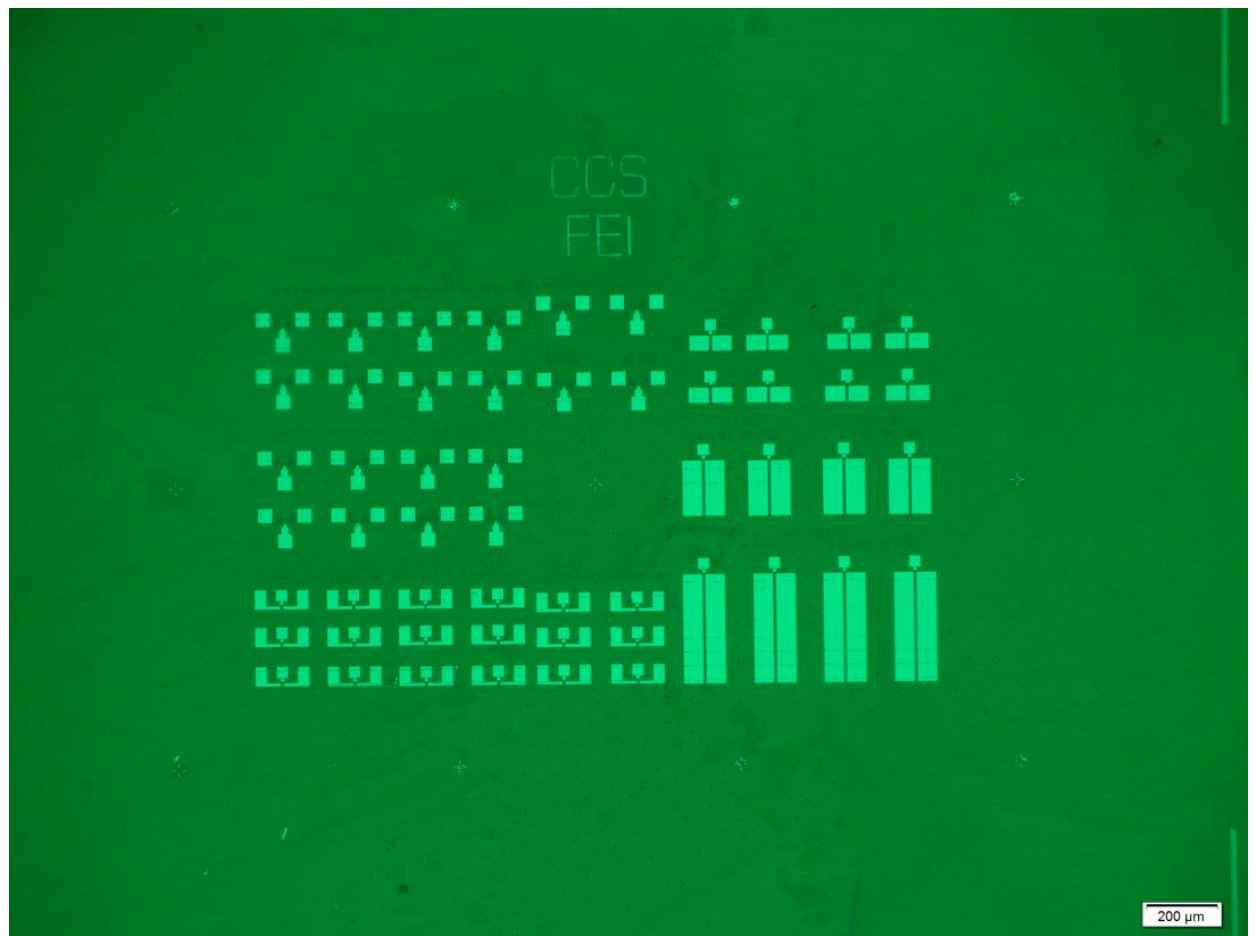

Fonte: Autor.

$\mathrm{Na}$ figura 71 observamos o transistor com $\mathrm{L}=1,5 \mu \mathrm{m} \mathrm{W}=0,1 \mu \mathrm{m}$ com o fio metálico com espessura de $2,11 \mu \mathrm{m}$, ou seja, $0,61 \mu \mathrm{m}$ maior que o esperado. Nesta imagem também observamos a mesa de silício e uma extremidade do nano fio. 
Figura 71- Medição do comprimento de canal $\mathrm{L}=2,11 \mu \mathrm{m}$ no transistor $\mathrm{A} 1 \mathrm{~L}=1,5 \mu \mathrm{m}$ e $\mathrm{W}=0,1 \mu \mathrm{m}$.

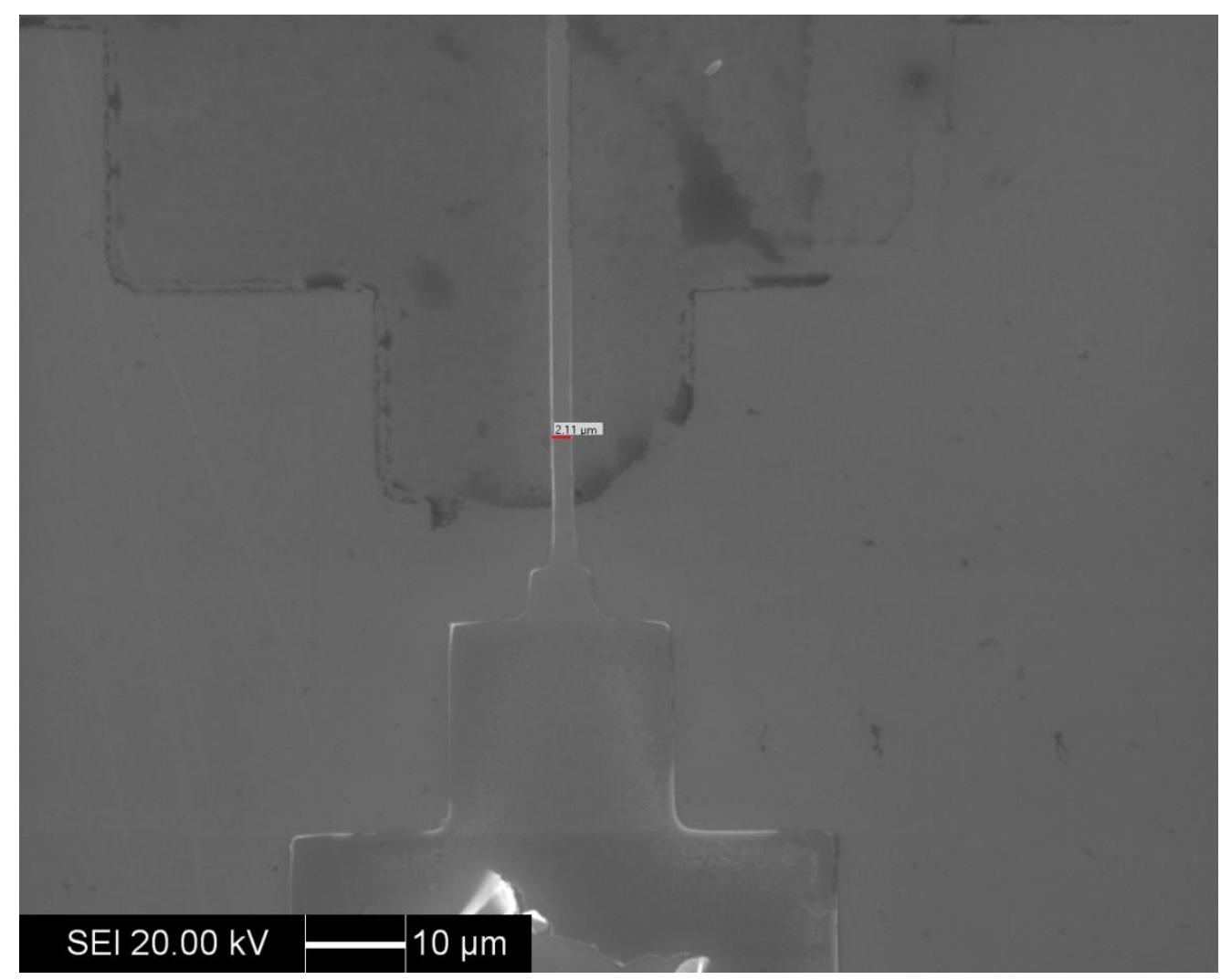

Fonte: Autor.

Em seguida algumas imagens foram retidas do microscópio ótico, onde era possível uma melhor visualização dos nano fios. Na figura 72 e na figura 73, podemos observar os nanofios dos transistores com $\mathrm{L}=1,0 \mu \mathrm{m}$ e $\mathrm{W}=0,5 \mu \mathrm{m}$ e $\mathrm{L}=0,6 \mu \mathrm{m}$ e $\mathrm{W}=0,1 \mu \mathrm{m}$, respectivamente. E na Figura 74 , do outro transistor com $\mathrm{L}=0,6 \mu \mathrm{m}$ e $\mathrm{W}=0,1 \mu \mathrm{m}$ é possível notar que o nano fio está rompido, isto pois a dose necessária para revelar este pedaço do resiste não foi suficiente. 
Figura 72- Imagens tiradas pelo microscópio ótico visualizando a mesa de silício formada com $\mathrm{L}=1.0 \mu \mathrm{m}$ e $\mathrm{W}=0.5 \mu \mathrm{m}$.

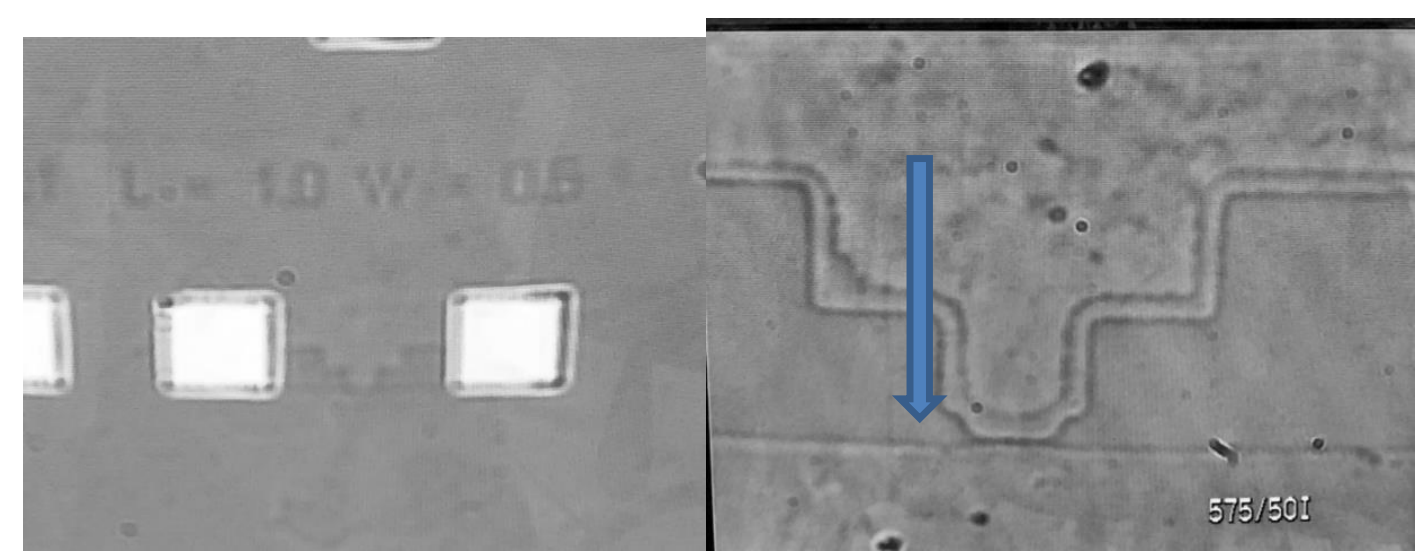

Fonte: Autor.

Figura 73- Imagens tiradas pelo microscópio ótico visualizando a mesa de silício formada com $\mathrm{L}=0,6 \mu \mathrm{m}$ e $\mathrm{W}=0.1 \mu \mathrm{m}$.

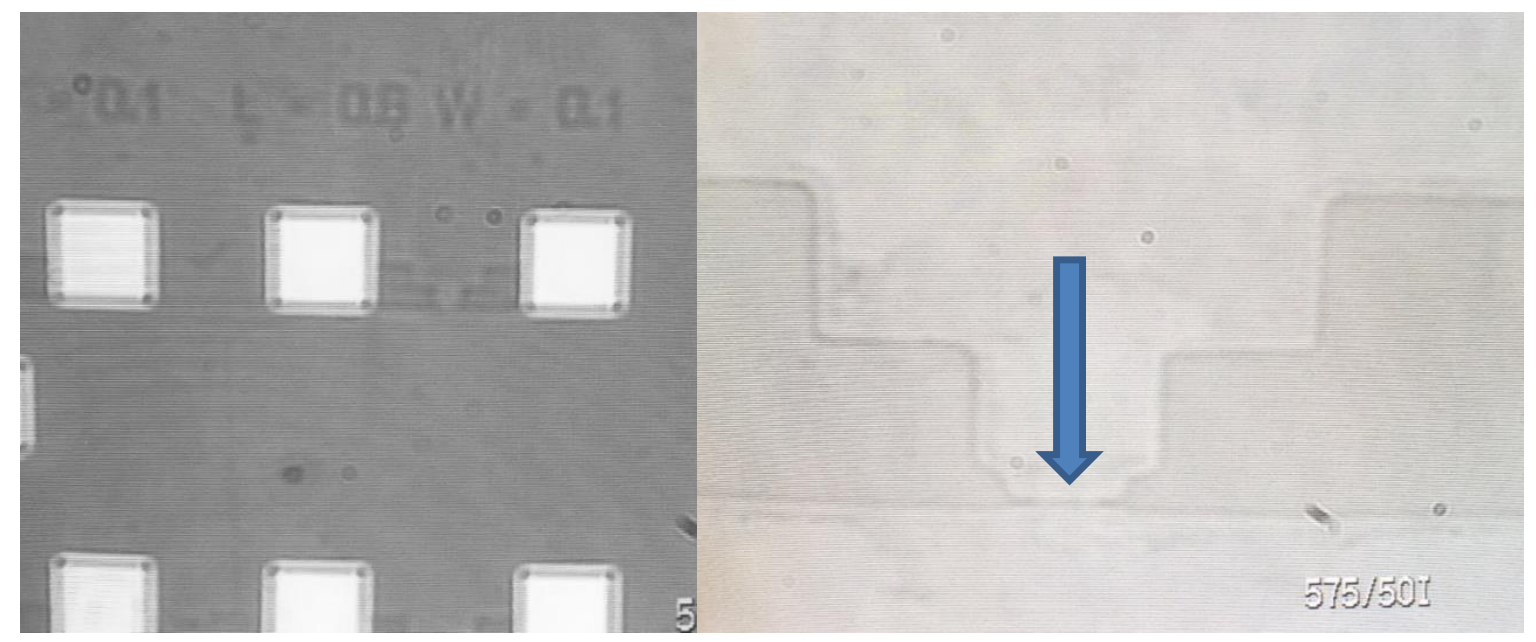

Fonte: Autor. 
Figura 74- Imagem da mesa de silício formada porém com o nano fio rompido, este transistor apresentaria $\mathrm{L}=0.6 \mu \mathrm{m}$ e $\mathrm{W}=0.1 \mu \mathrm{m}$.

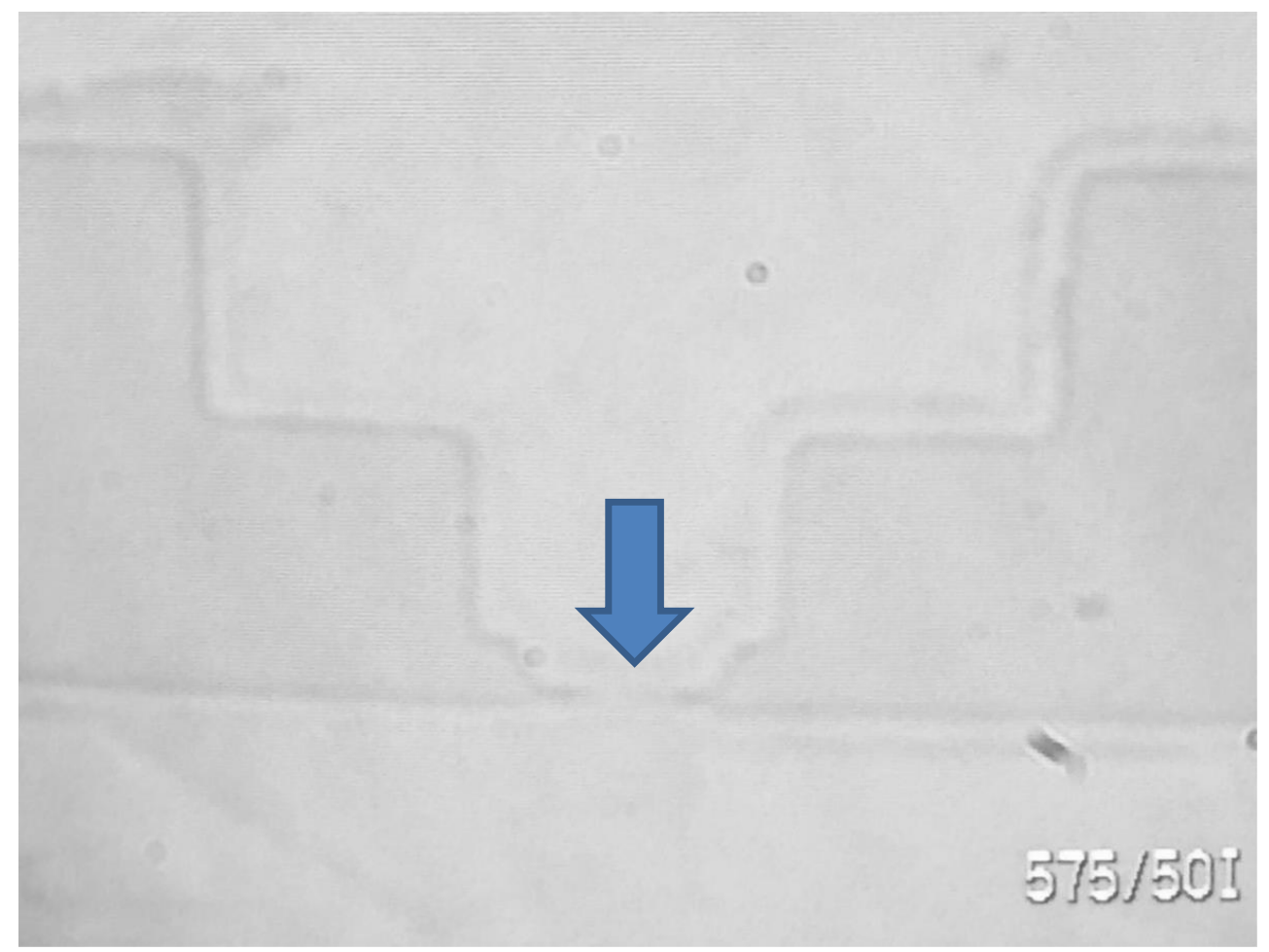

Fonte: Autor.

Esta lâmina gama obteve melhores marcas de alinhamento devido ao ajuste de dose da máscara inicial. Também obtivemos mesas de silício bem definidas e garantimos que o óxido enterrado não foi totalmente consumido através de medidas do EDS (microscopia por raios-X dispersivos) que apresentaram uma boa quantidade de $\mathrm{SiO}_{2}$ nas regiões fora da mesa. Obtivemos um óxido de porta de $10 \mathrm{~nm}$ e camada de silício de $10 \mathrm{~nm}$ medidos pelo elipsômetro. E por fim finalizamos com um ótimo lift-off dos pads, devido ao novo ajuste de dose da litografia final. 


\section{CARACTERIZAÇÃO ELÉTRICA}

Nesta seção serão apresentadas medidas elétricas nos conjuntos de transistores fabricados como também da estrutura Pseudo MOS na lâmina SOI utilizada para fabricação.

\subsection{ESTRUTURA PSEUDO MOS}

Para início da caracterização realizou-se medidas na lâmina da SOITEC através da estrutura Pseudo MOS. Esta medida foi realizada em um caco que passou por limpeza RCA para toda retirada do óxido inativo e então foi extraída a curva da corrente de dreno, fonte e substrato em função da tensão de substrato, apresentada na figura 75 , com espaçamento entre as pontas de prova de fonte e dreno de $0,5 \mathrm{~mm}$.

Figura 75- Curva da corrente de dreno, fonte e substrato em função da tensão aplicada na porta.

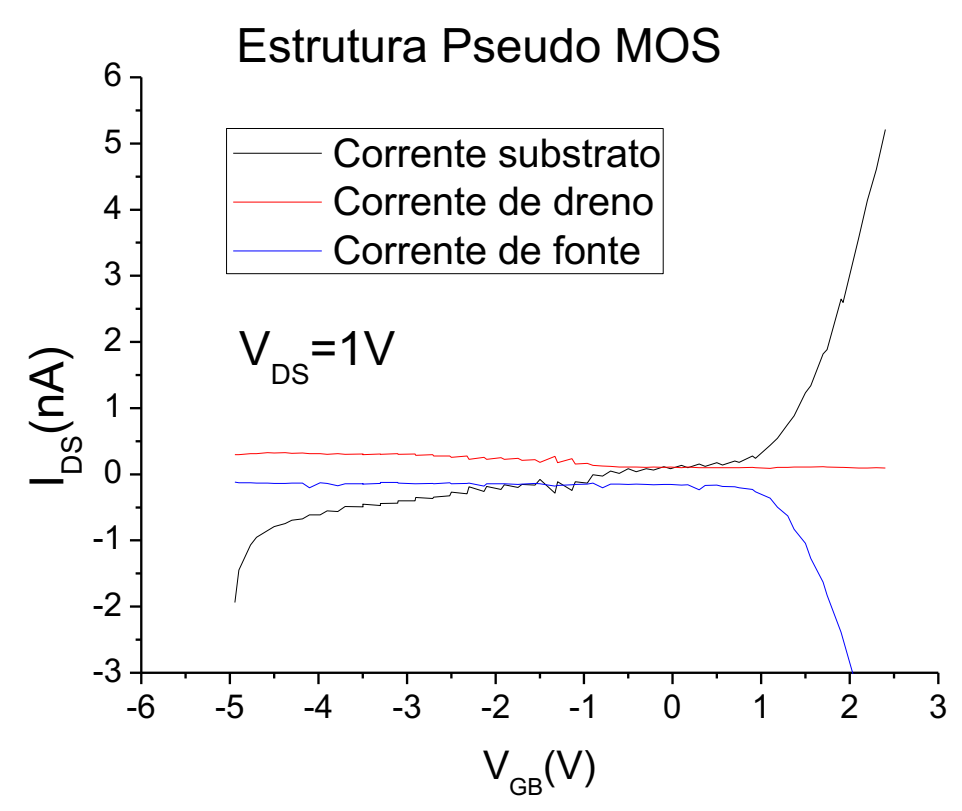

Fonte: Autor.

Através da figura 75 pode-se notar que para a região de $-2 \mathrm{~V}>\mathrm{V}_{\mathrm{GB}}<1 \mathrm{~V}$ a corrente sai da fonte e entra no dreno porém para $\mathrm{V}_{\mathrm{GB}}>1 \mathrm{~V}$ a corrente de substrato em preto começa $\mathrm{a}$ predominar. A partir deste valor a corrente de tunelamento pelo óxido enterrado ganha importância. Com isso temos duas observações importantes a serem consideradas: que este óxido enterrado da lâmina é permeável e que não podemos aplicar tensões muito altas, pois o que predominará é esta corrente que vai para o substrato. 


\subsection{LÂMINA ALPHA}

Nesta seção serão apresentadas medidas elétricas realizadas nos dispositivos Alpha. E resultados que podem ser concluídos através desta caracterização. O conjunto de dispositivo Alpha a princípio apresentou curvas com corrente constante de dreno por tensão de porta. $\mathrm{Na}$ figura 76 podemos observar as curvas das correntes de substrato, fonte, dreno e porta, sendo monitoradas em função da tensão aplicada à porta de cima, com $\mathrm{V}_{\mathrm{DS}}=100 \mathrm{mV}$.

Figura 76- Curva experimental da lâmina alpha transistor A1, da corrente de dreno, fonte, substrato e porta, em função da tensão aplicada na porta.

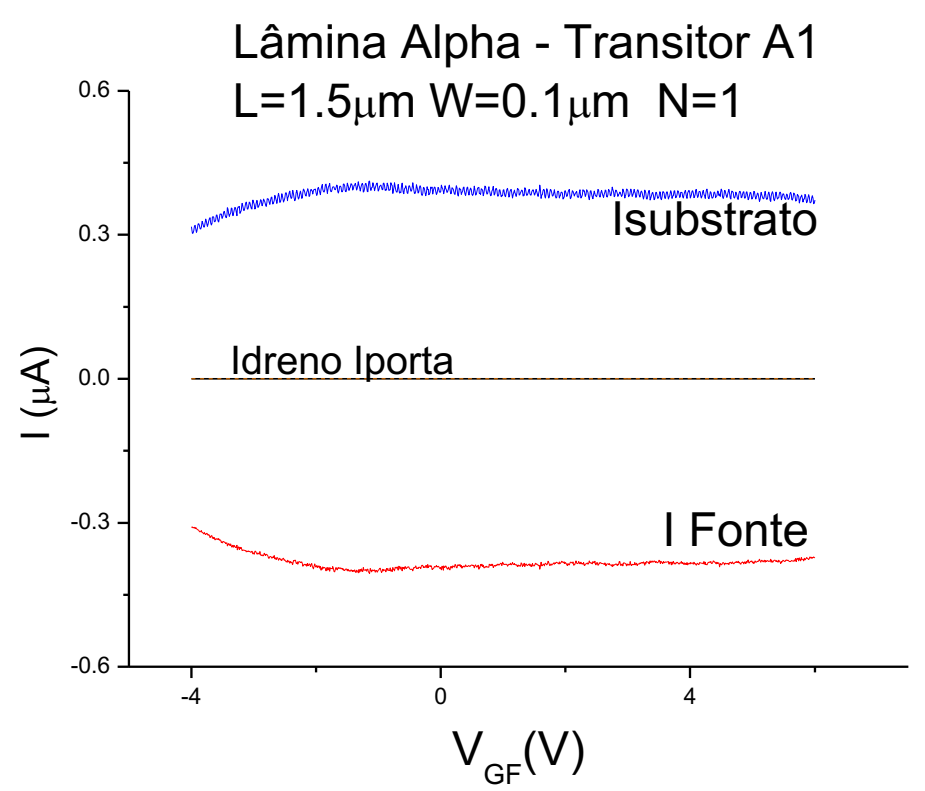

Fonte: Autor.

Podemos observar que as curvas de fonte e substrato são iguais em módulo $\left|\mathrm{I}_{\text {Fonte }}\right|=\left|\mathrm{I}_{\text {substrato }}\right|$ isto acontece pois a fonte deve estar em contato com o substrato, ou seja, as etapas de corrosão podem ter corroído o óxido e este ficou em contato com substrato ou na etapa de abertura de contato o HF perfurou o óxido enterrado.

Foi realizado um teste de oxidação no forno convencional, colocamos 3 cacos para oxidar com os tempos simulados $\left(10,15\right.$ e 20 minutos com temperatuda de $\left.850^{\circ} \mathrm{C}\right)$ e o tempo que realizamos nesta amostra em seguida utilizamos uma máscara de capacitor circular com diâmetro de $400 \mu \mathrm{m}$, depositamos $\mathrm{Al}$ e realizamos o lift off.

Quando estes capacitores foram finalizados realizamos medidas c-v apresentadas na figura 77, para extrairmos o óxido de porta oxidado (Tabela 14). 
Tabela 14- Tempo de oxidação e óxido de porta extraído.

\section{Tempo de oxidação Cmáx (F) Xox (nm)}

\begin{tabular}{lll}
$\mathbf{1 0}$ & $3,20 \cdot 10^{-11}$ & 135,4 \\
\hline $\mathbf{1 5}$ & $3,00 \cdot 10^{-11}$ & 144,5 \\
\hline $\mathbf{2 0}$ & $3,15.10^{-11}$ & 137,6
\end{tabular}

Fonte: Autor.

Figura 77- Curva $\mathrm{C}-\mathrm{V}$ dos capacitores testes, com oxidações com tempo de $10 \mathrm{~min}, 15 \mathrm{~min}$ e $20 \mathrm{~min}$.

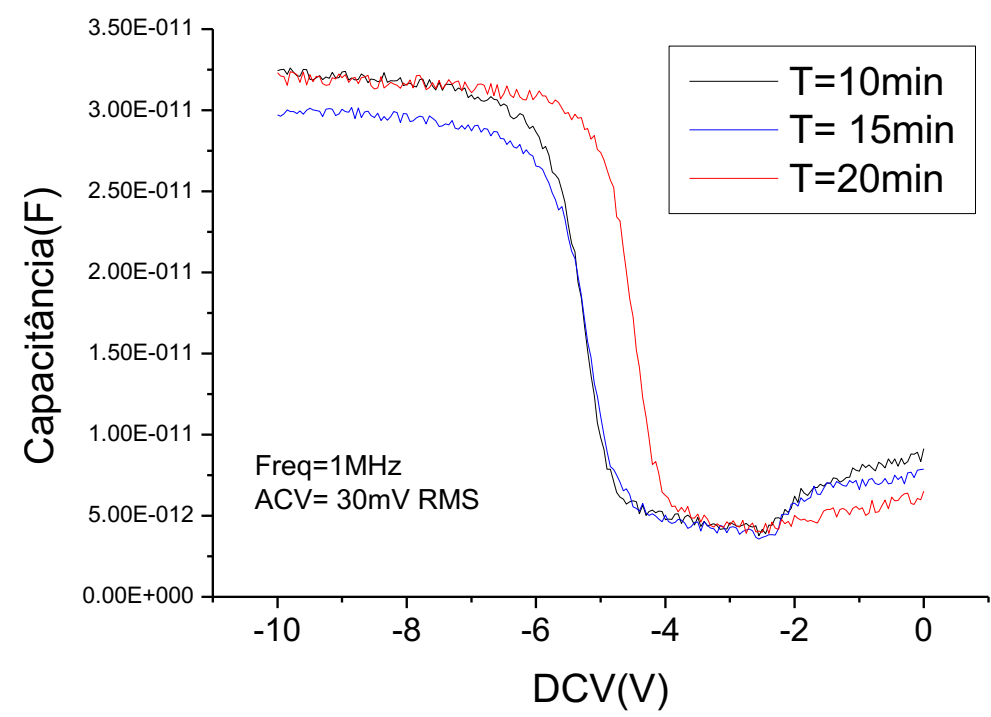

Fonte: Autor.

Com as espessuras dos óxidos extraídas, observamos que para todos os tempos as espessuras superaram muito o esperado. Isto, pois o óxido foi simulado com pureza de 99,999999\%(6.0), e o utilizado nestes oxidações foi de 99,9999\% (4.0). Assim as espessuras de óxido obtidas foram muito maiores do que as projetadas, e como a ela consome aproximadamente $44 \%$ do $\mathrm{Si}$, todo filme de silício foi consumido. 


\subsection{LÂMINA BETA}

Curvas da corrente de dreno, de fonte, de substrato e de porta em função da tensão de porta com $\mathrm{V}_{\mathrm{DS}}=100 \mathrm{mV}$ e com $\mathrm{V}_{\mathrm{GB}}=3 \mathrm{~V}$ ou $\mathrm{V}_{\mathrm{GB}}=4 \mathrm{~V}$ foram realizadas utilizando equipamento Keithley 4200. Alguns transistores foram analisados, são eles B5 na figura 78, figura 79 corresponde ao B1 e B8 na figura 80.

Figura 78- Curva da corrente de dreno, fonte, substrato e porta em função da tensão da porta, com $\mathrm{V}_{\mathrm{DS}}=100 \mathrm{mV}$ e $\mathrm{V}_{\mathrm{GB}}=3 \mathrm{~V}$.

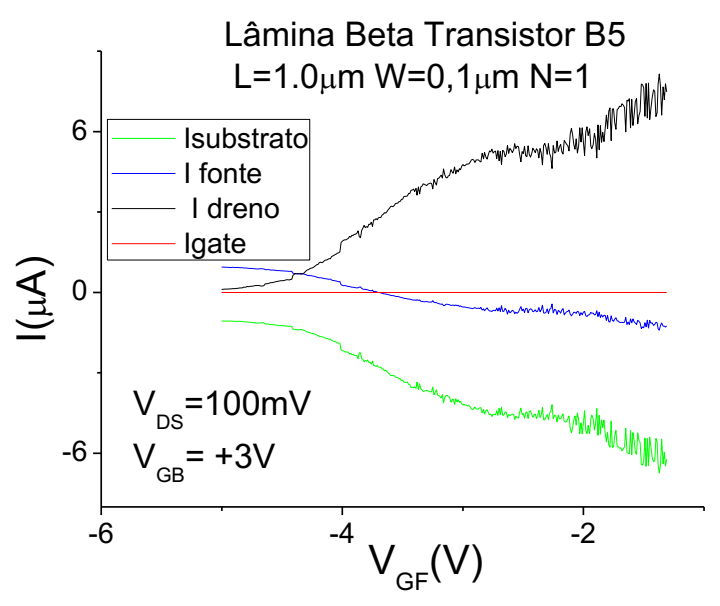

Fonte: Autor.

Figura 79- Curva da corrente de dreno, fonte, substrato e porta em função da tensão da porta, com $\mathrm{V}_{\mathrm{DS}}=100 \mathrm{mV}$ e $\mathrm{V}_{\mathrm{GB}}=3 \mathrm{~V}$, do transistor $\mathrm{B} 1$.

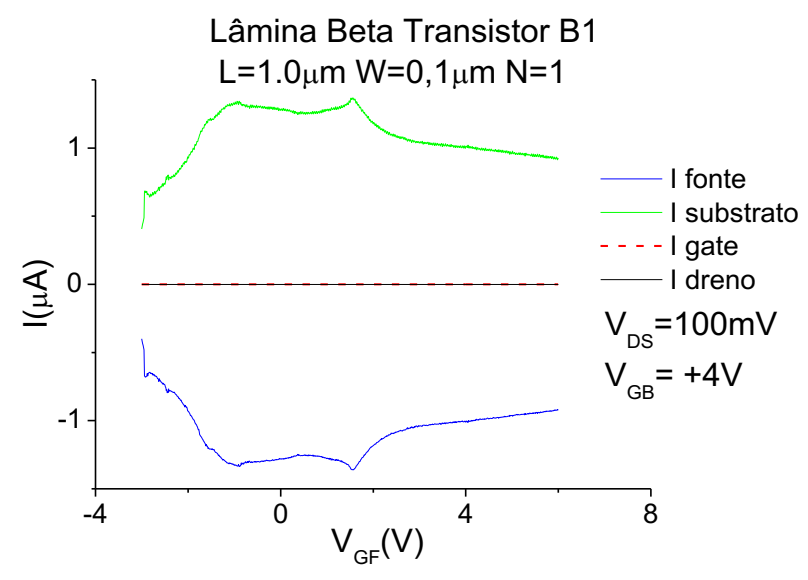

Fonte: Autor. 
Figura 80- Curva da corrente de dreno, fonte, substrato e porta em função da tensão da porta, com $\mathrm{V}_{\mathrm{DS}}=100 \mathrm{mV}$ e $\mathrm{V}_{\mathrm{GB}}=3 \mathrm{~V}$ do transistor $\mathrm{B} 8$.

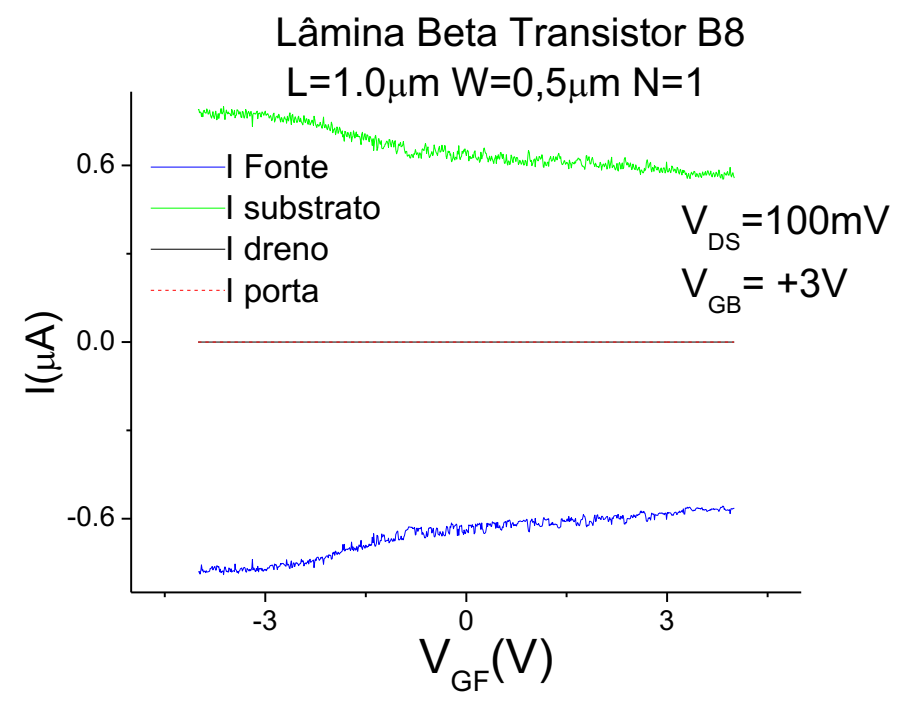

Fonte: Autor.

Através destas curvas podemos observar alguma modulação da corrente de dreno pela aplicação de tensão na porta, principalmente nos transistores B5 na figura 81, que apresenta a corrente de dreno em função da tensão de porta com $\mathrm{V}_{\mathrm{DS}}=100 \mathrm{mV}$ e $\mathrm{V}_{\mathrm{GB}}=3 \mathrm{~V}$.

Figura 81- Curva da corrente de dreno em função de $\mathrm{V}_{\mathrm{GF}}$ do transistor B5.

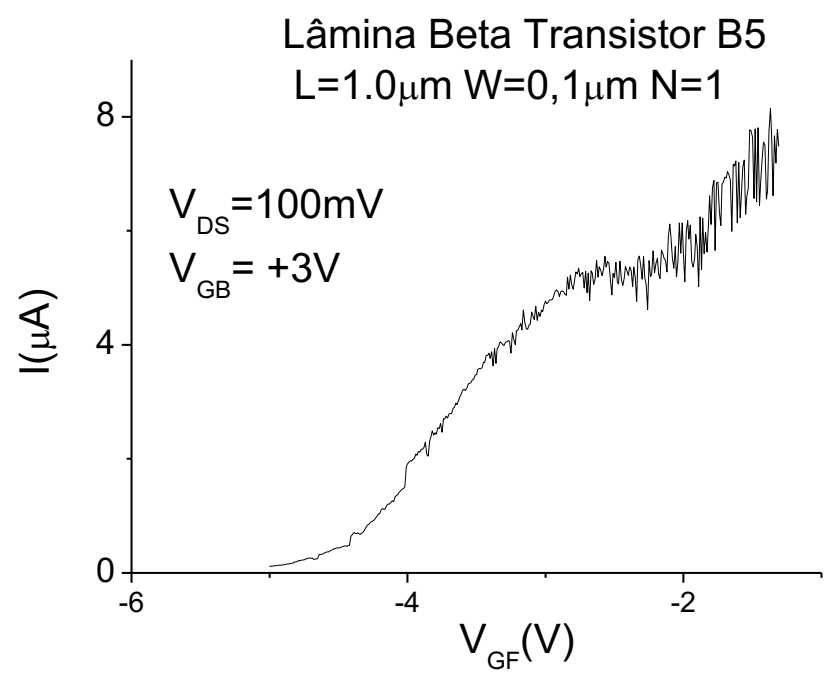

Fonte: Autor. 
Nesta curva podemos observar que o transistor B5 apresenta efeito de campo, evidenciando o funcionamento do transistor e corrente da ordem de microampère.

\subsection{LÂMINA GAMA}

A capacitância foi extraída do transistor E1 e F2 pelo pad de porta e os d fonte e dreno aterrados. A Figura 82 apresenta as curvas $\mathrm{CV}$ desses dois transistores com de $\mathrm{L}=1 \mu \mathrm{m}$ e $\mathrm{W}=0,1 \mu \mathrm{m}$, e o que diferencia é o número de fins $\mathrm{N}_{(\mathrm{E} 1)}=1280$ e $\mathrm{N}(\mathrm{F} 1)=640$. Nela podemos observar, pelo patamar da inversão, que há Si na lâmina e a oxidação não a consumiu por completo.

Figura 82- Curva C-V do transistor E1 e F2, extraída pelo pad de porta (80 $\mu \mathrm{m} \times 80 \mu \mathrm{m})$.

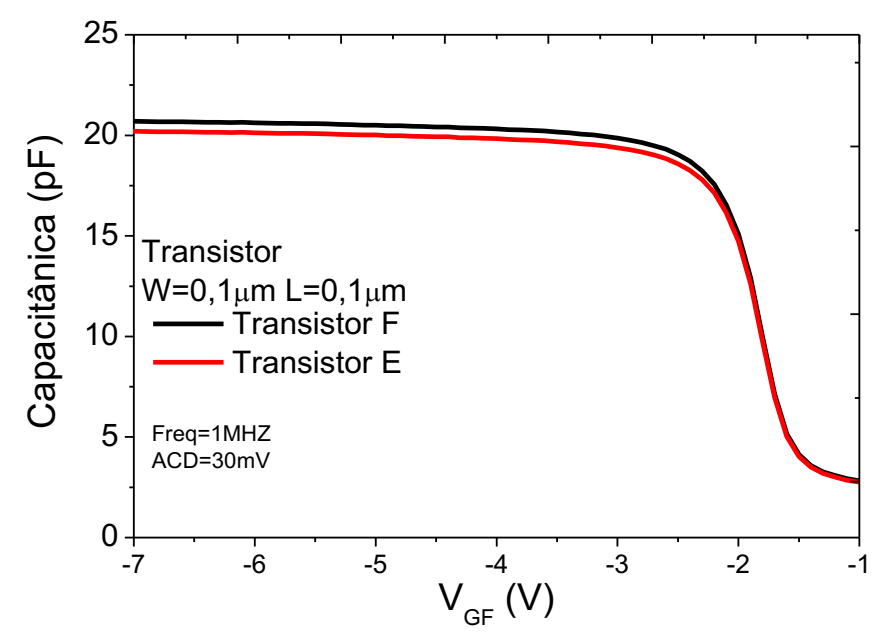

Fonte: Autor.

Através das curvas $\mathrm{CV}$ dos transistores $\mathrm{E} 1$ e $\mathrm{F} 2$, temos os valores de $\mathrm{C}_{\text {máx }}=20,67 \mathrm{pF}$ e $20,13 \mathrm{pF}$ e $\mathrm{C}_{\min }=2,75 \mathrm{pF}$ e através destas capacitâncias extraímos o valor do óxido enterrado no valor de $t_{\text {oxf }}=11,04 \mathrm{~nm}$ para transistor $\mathrm{F} 2$ e $t_{\mathrm{oxf}}=10,96 \mathrm{~nm}$ para o transistor E1. Como é sabido que o óxido consome aproximadamente $0,44 \%$ do silício para esta lâmina sobraram aproximadamente $t_{\mathrm{Si}}=9,31 \mathrm{~nm}$ e $\mathrm{t}_{\mathrm{Si}}=9,52 \mathrm{~nm}$.

Curvas da corrente de dreno em função da tensão de substrato foram extraídas do transistor 640 fins, $\mathrm{W}=0,1 \mu \mathrm{m}$ e $\mathrm{L}=0,1 \mu \mathrm{m}$ e são apresentadas na figura 83. Foram aplicados a tensão de dreno de $0,5 \mathrm{~V}, 1,0 \mathrm{~V}$ e $1,5 \mathrm{~V}$ e na tensão de porta foi aplicado $0 \mathrm{~V}$ a qual formou no canal uma região de fonte e dreno tipo $n$. 
Figura 83- Curva da corrente de dreno em função da tensão de substrato $\mathrm{V}_{\mathrm{DS}}=0,5$ e $1 \mathrm{~V}$ e $1,5 \mathrm{~V}$.

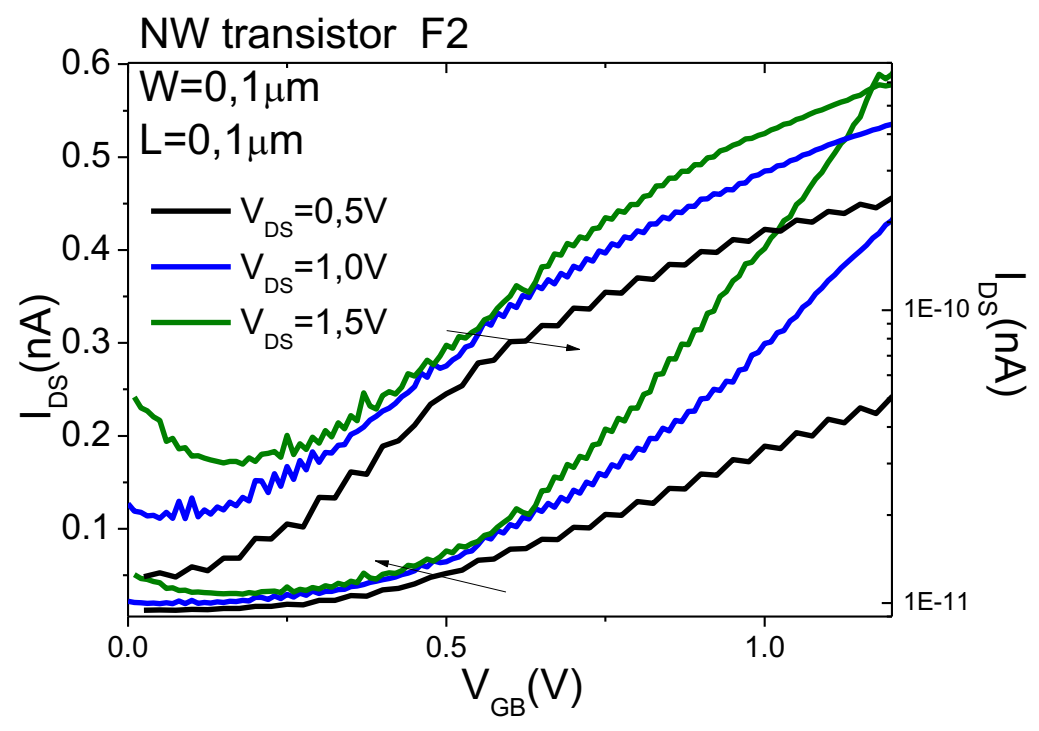

Fonte: Autor.

Através destas curvas foram extraídas a transcondutância máxima para a tensão de limiar $V_{T}=0,4 \mathrm{~V} S=731 \mathrm{mV} /$ dec. Também foram realizadas medidas da $I_{D S} \times V_{D S}$ com $\mathrm{V}_{\mathrm{GB}}=1,0 \mathrm{~V}$ e $1,5 \mathrm{~V}, \mathrm{~F} 2(\mathrm{~N}=640)$ com $\mathrm{W}=0,1 \mu \mathrm{m}$ e $\mathrm{L}=0,1 \mu \mathrm{m}$ apresentadas na figura 84 .

Figura 84- Curvas $\mathrm{I}_{\mathrm{DS}}$ em função de $\mathrm{V}_{\mathrm{DS}}$ para $\mathrm{V}_{\mathrm{GB}}=1 \mathrm{~V}, 1,5 \mathrm{~V}$.

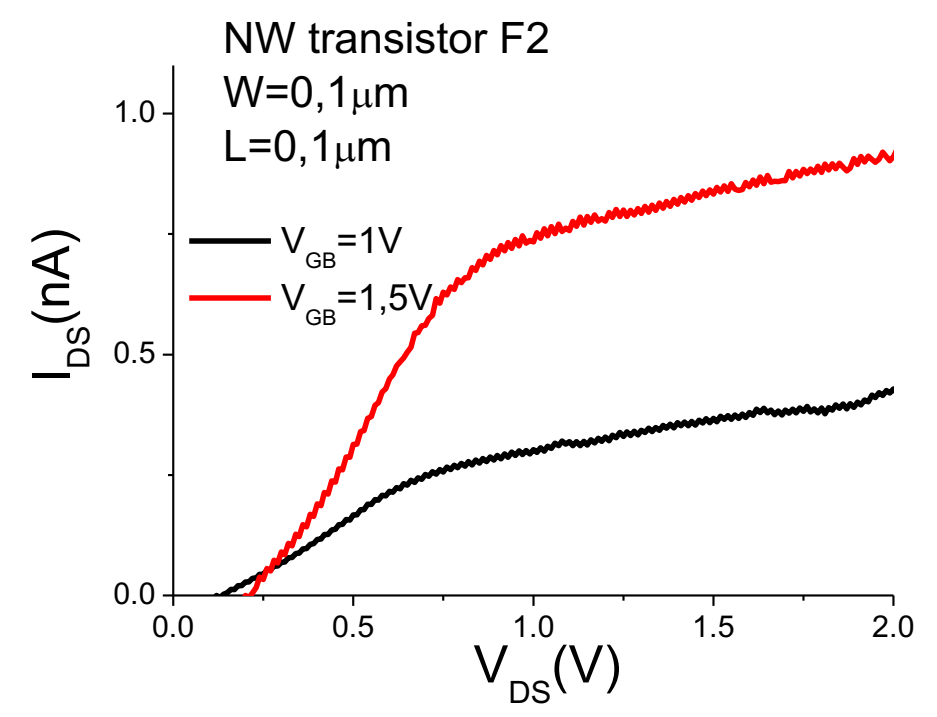

Fonte: Autor. 
As mesmas medidas ( $I_{D S}$ em função de $V_{G B}$ ) e ( $I_{D S}$ em função de $V_{D S}$ ) foram realizadas para os transistores G6 (Figura 85, Figura 86) e E1 (Figura 87, Figura 88) os quais apresentam W e L iguais porém número de fins de 120 e 1280, respectivamente. Através destas curvas esperamos observar se a tensão de limiar desses transistores é constante e observar inclinação de sublimiar.

Figura 85- Curva $\mathrm{I}_{\mathrm{DS}}$ em função de $\mathrm{V}_{\mathrm{GB}}$ do transistor $\mathrm{G6}$ com $\mathrm{W}=0,1 \mu \mathrm{m}$, $\mathrm{L}=0,1 \mu \mathrm{m}$ e $\mathrm{N}=120$.

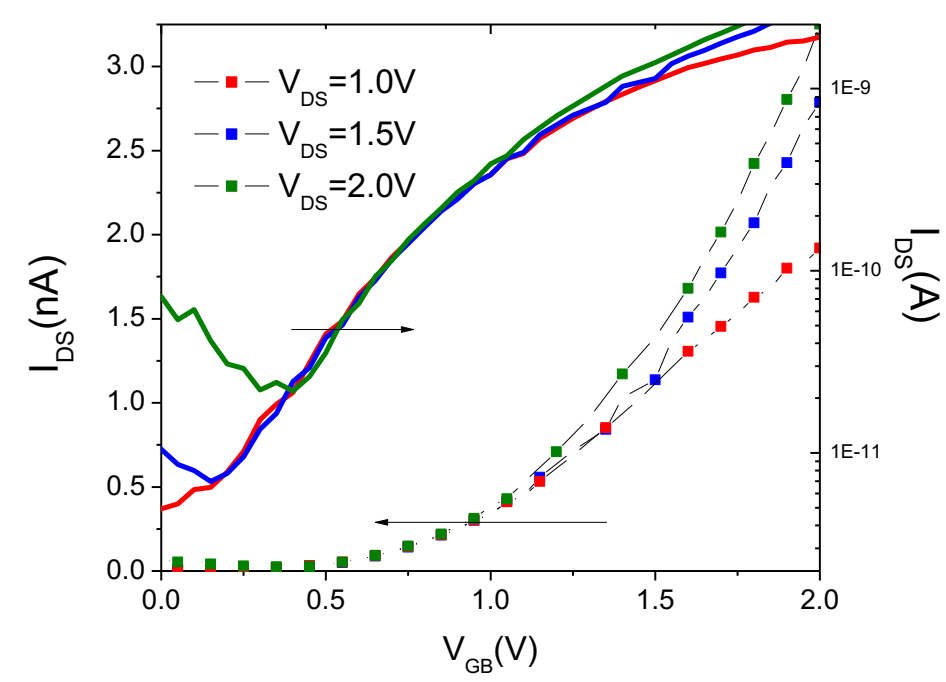

Fonte: Autor.

Figura 86 - Curva $\mathrm{I}_{\mathrm{DS}}$ em função de $\mathrm{V}_{\mathrm{DS}}$ do transistor $\mathrm{G} 6$ com $\mathrm{W}=0,1 \mu \mathrm{m}, \mathrm{L}=0,1 \mu \mathrm{m}$ e $\mathrm{N}=120$, para $\mathrm{V}_{\mathrm{GB}}=0,5 \mathrm{~V} 1,0 \mathrm{~V}$ e $1,5 \mathrm{~V}$.

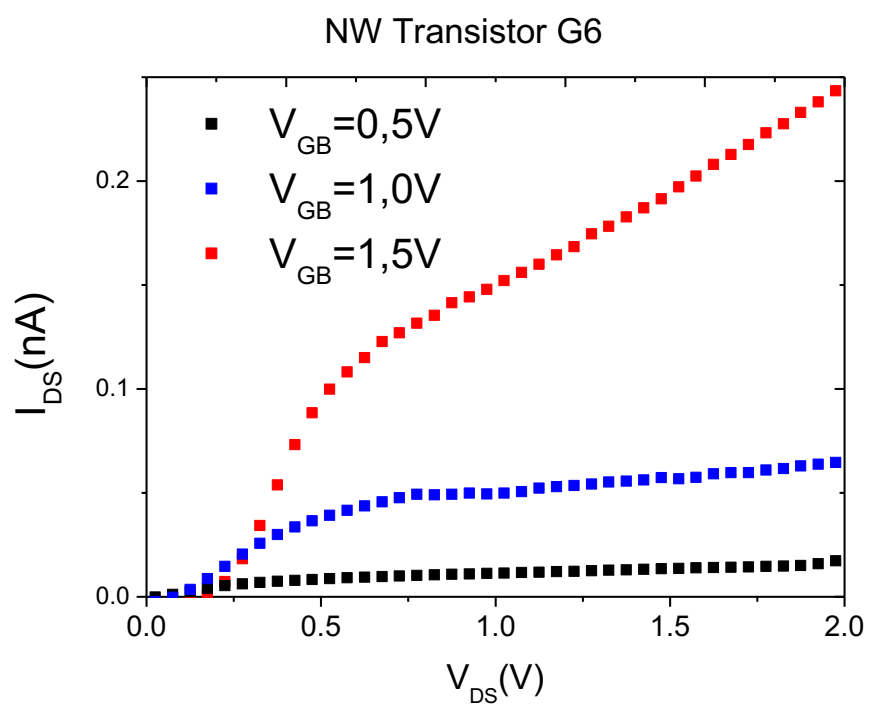

Fonte: Autor. 
Figura 87- Curva $\mathrm{I}_{\mathrm{DS}}$ vem função de $\mathrm{V}_{\mathrm{GB}}$ do transistor $\mathrm{E} 1$ com $\mathrm{W}=0,1 \mu \mathrm{m}, \mathrm{L}=0,1 \mu \mathrm{m}$ e $\mathrm{N}=1280$.

NW Transistor E1

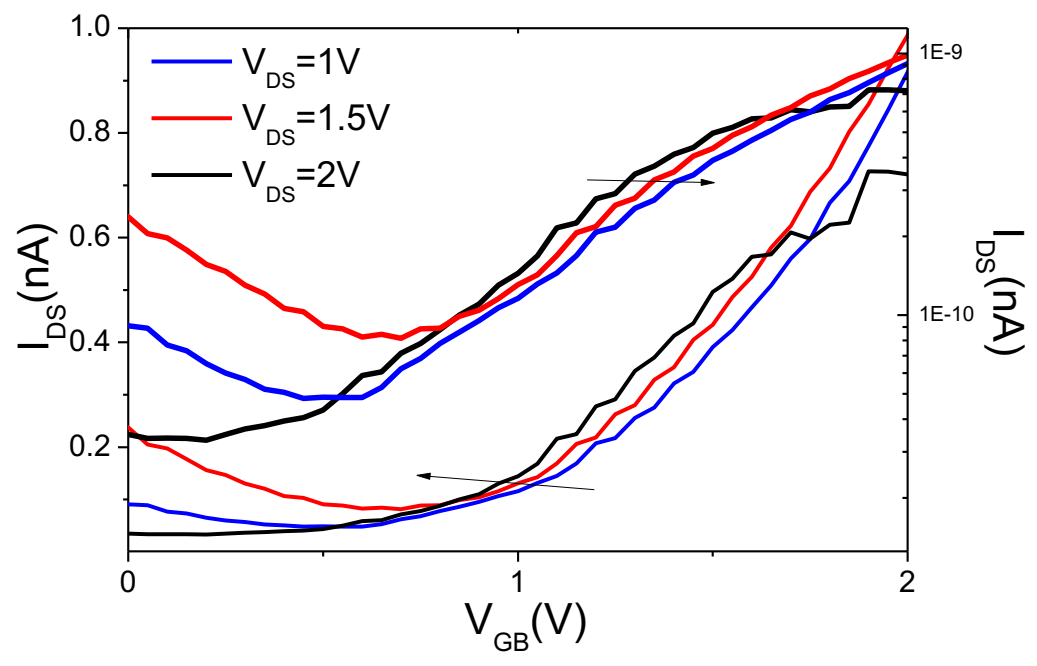

Fonte: Autor.

Figura 88- Curva $\mathrm{I}_{\mathrm{DS}}$ em função de $\mathrm{V}_{\mathrm{DS}}$ do transistor $\mathrm{E} 1 \mathrm{com} \mathrm{W}=0,1 \mu \mathrm{m}$, $\mathrm{L}=0,1 \mu \mathrm{m}$ e $\mathrm{N}=1280$, para $\mathrm{V}_{\mathrm{GB}}=0,5 \mathrm{~V}, 1,0 \mathrm{~V}, 1,5 \mathrm{~V}$ e $2,0 \mathrm{~V}$.

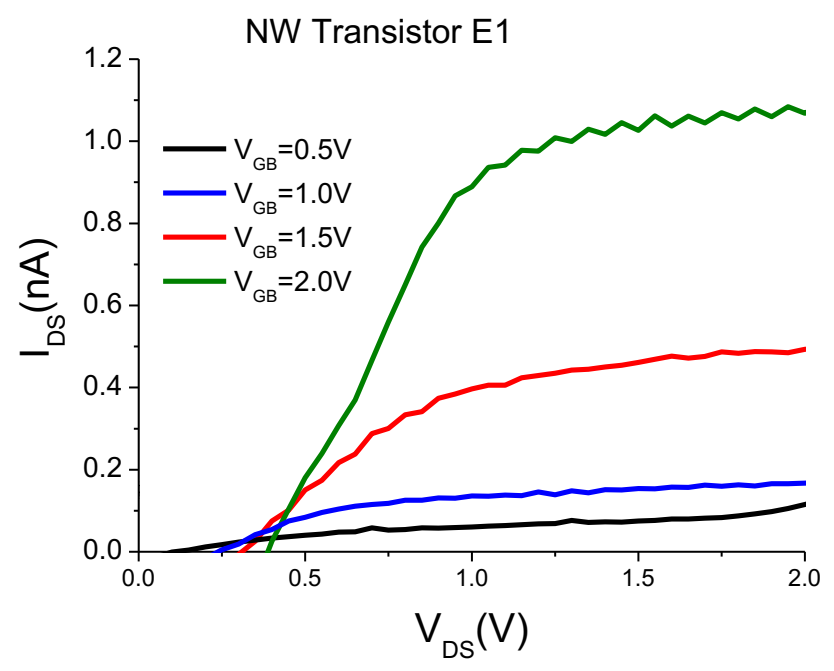

Fonte: Autor.

A partir destes gráficos extraímos os parâmetros para esses 3 transistores ( F2, G6 e E1), através da Tabela 15 notamos que os transistores G6 e E1 apresentaram o mesmo valor de $\mathrm{V}_{\mathrm{T}}$ porém o $\mathrm{F} 2$ apresentou uma pequena alteração de $0,15 \mathrm{~V}$ ( é possível observar também 
uma que com aumento da corrente de dreno com o aumento de $\mathrm{V}_{\mathrm{DS}}$ e como aumento de $\mathrm{V}_{\mathrm{DS}}$ não afeta a inclinação de sublimiar mostrando uma boa imunidade ao efeito de canal curto). Como foi citado na seção de caracterização elétrica do Pseudo MOS, há corrente de fuga para $\mathrm{V}_{\mathrm{DS}}=2 \mathrm{~V}$ este aumento da corrente de fuga é associado com a corrente que está sofrendo tunelamento pelo substrato, limitando à $2 \mathrm{~V}$ de $\mathrm{V}_{\mathrm{DS}}$ que pode ser aplicado.

$\mathrm{Na}$ figura 86, notamos que para tensões menores que $200 \mathrm{mV}$, a relação $\mathrm{I}_{\mathrm{DS}}$ em função de $\mathrm{V}_{\mathrm{DS}}$ é não linear, isso devido à alta resistência de contato entre o metal de fonte/dreno com o silício não dopado. Vale mencionar que devido à diferença entre os níveis de Fermi, o contato fica do tipo Schottky.

A tabela 15 apresenta os parâmetros extraídos das curvas anteriores.

Tabela 15- Parâmetros elétricos dos transistores F2, G6 e E1.

$\begin{array}{lllll}\text { NWFETS } & \mathbf{V}_{\mathbf{T}}(\mathbf{V}) & \mathbf{S}(\mathbf{m V} / \mathbf{d e c}) & \mathbf{g}_{\mathrm{m}, \max }(\mathbf{n S}) & \mathbf{g}_{\mathbf{D}}\left(\mathbf{p} \mathbf{\Omega}^{-1}\right) \\ & & & \mathbf{V}_{\mathbf{G B}}=\mathbf{1 V} & \mathbf{V}_{\mathbf{G B}}=\mathbf{1 V} \\ \mathbf{F 2} & 0,4 & 731 & 3,49 & 10,43 \\ \mathbf{G 6} & 0,55 & 950 & 3,86 & 7,55 \\ \mathbf{E 1} & 0,55 & 980 & 1,19 & 15,6\end{array}$

Fonte: Autor.

Também foi realizada uma comparação da corrente de dreno em função da tensão de substrato para dois transistores com $\mathrm{W}$ diferentes $(0,1 \mu \mathrm{m}$ e $0,5 \mu \mathrm{m})$ e apresentados na figura 89. Através desta curva observamos a mesma tensão de limiar e a mesma inclinação de sublimiar. Notamos também maior nível de corrente para os transistores com W maior, seguindo o esperado para a lâmina. 
Figura 89- Curvas $\mathrm{I}_{\mathrm{DS}} \times \mathrm{V}_{\mathrm{GB}}$ comparando transistores com $\mathrm{W}$ $=0,1 \mu \mathrm{m}$ e $\mathrm{W}=0,5 \mu \mathrm{m}$.

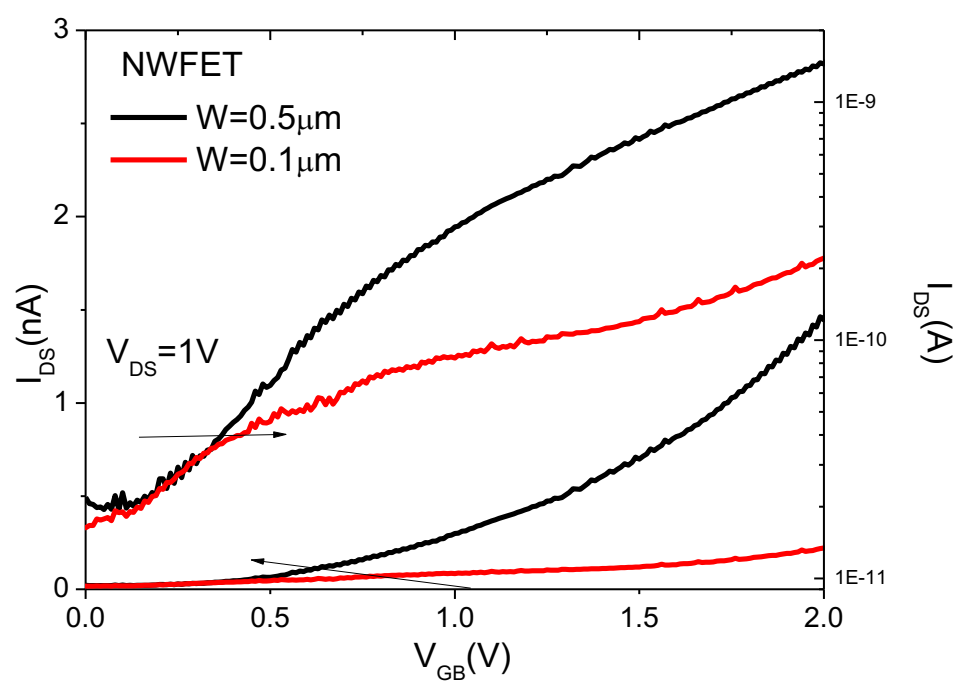

Fonte: Autor.

Também observamos a influência da porta de cima no NWFET através das curvas $\mathrm{I}_{\mathrm{DS}}$ em função de $\mathrm{V}_{\mathrm{GB}}$ para $\mathrm{V}_{\mathrm{GF}}$ igual a $-0,5 \mathrm{~V}, 0 \mathrm{~V}$ e $+0,5 \mathrm{~V}$, e apresentadas na figura 90 .

Figura 90- Curva da corrente de dreno em função da tensão aplicada ao substrato com $\mathrm{V}_{\mathrm{GF}}=-0,5 \mathrm{~V}, 0 \mathrm{~V}$ e $+0,5 \mathrm{~V}$, em escala linear e logarítmica.

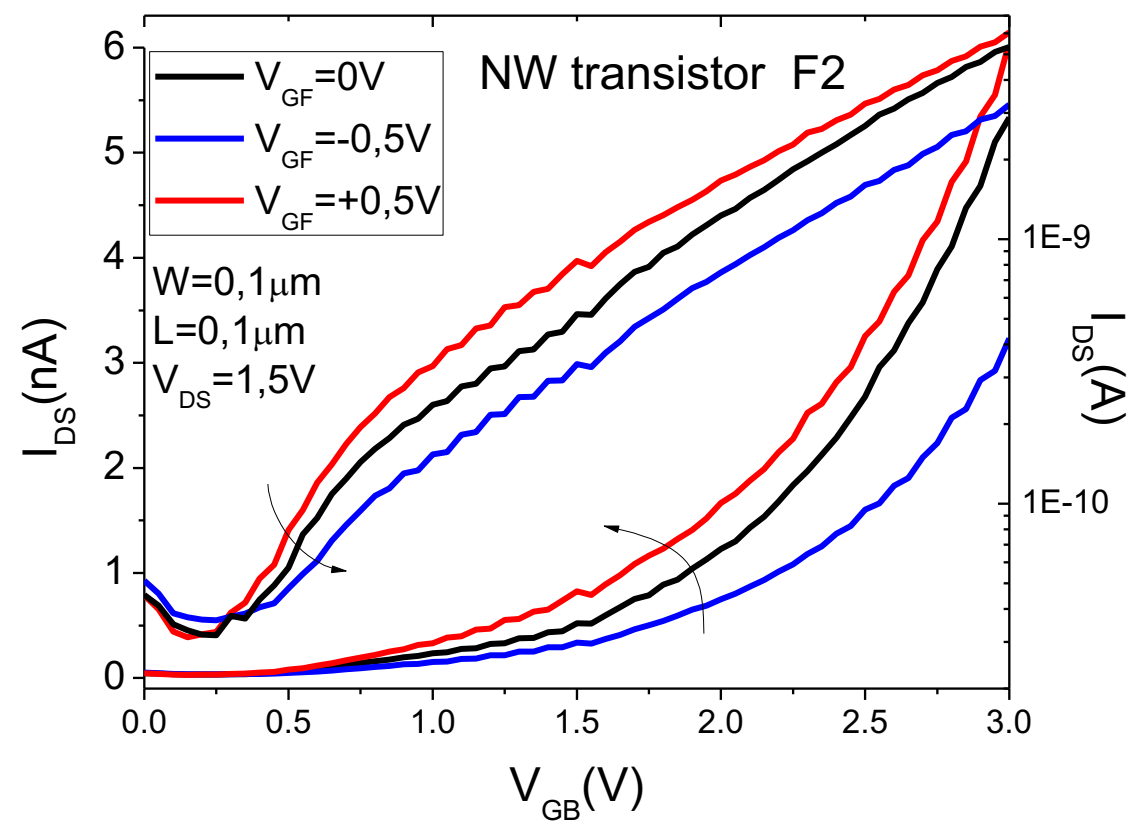

Fonte: Autor. 
Através da figura 90, é possível extrair $\mathrm{V}_{\mathrm{T}}=0,4 \mathrm{~V}$ e $\mathrm{S}=731 \mathrm{mv} / \mathrm{dec}$ correspondentes a $\mathrm{V}_{\mathrm{GF}}=0 \mathrm{~V}$. Aplicando a tensão na porta de cima notamos a variação da tensão de limiar $\mathrm{V}_{\mathrm{T}}\left(\mathrm{V}_{\mathrm{GF}}=-0.5 \mathrm{~V}\right)=0,52 \mathrm{~V}$ e $\mathrm{V}_{\mathrm{T}}\left(\mathrm{V}_{\mathrm{GF}}=0.5 \mathrm{~V}\right)=0,31 \mathrm{~V}$. A variação da tensão de limiar com $\mathrm{V}_{\mathrm{GF}}$ está de acordo com a teoria do FD SOI MOSFETs e indica o acoplamento entre a porta de cima e a do substrato.

Comparações entre as amostras foram feitas curvas $\mathrm{IxV}$, realizadas para o transistor com $\mathrm{N}=1280, \mathrm{~W}=0,1 \mu \mathrm{m}$ e $\mathrm{L}=0,5 \mu \mathrm{m}$ e apresentadas na figura 91. Lembrando que a lâmina alpha apresenta uma dopagem $\mathrm{N}_{\mathrm{D}}=2 \times 10^{18} \mathrm{~cm}^{-3}$, a lâmina beta $\mathrm{N}_{\mathrm{D}}=5 \times 10^{17} \mathrm{~cm}^{-3}$ e a lâmina gama apresenta a dopagem inicial da lâmina.

Figura 91- Curvas experimentais $I_{D} \times V_{D}$ realizadas no transistor com $W=0,1 \mu \mathrm{m}$ e $\mathrm{L}=0,5 \mu \mathrm{m}$, para as três lâminas fabricadas neste projeto.

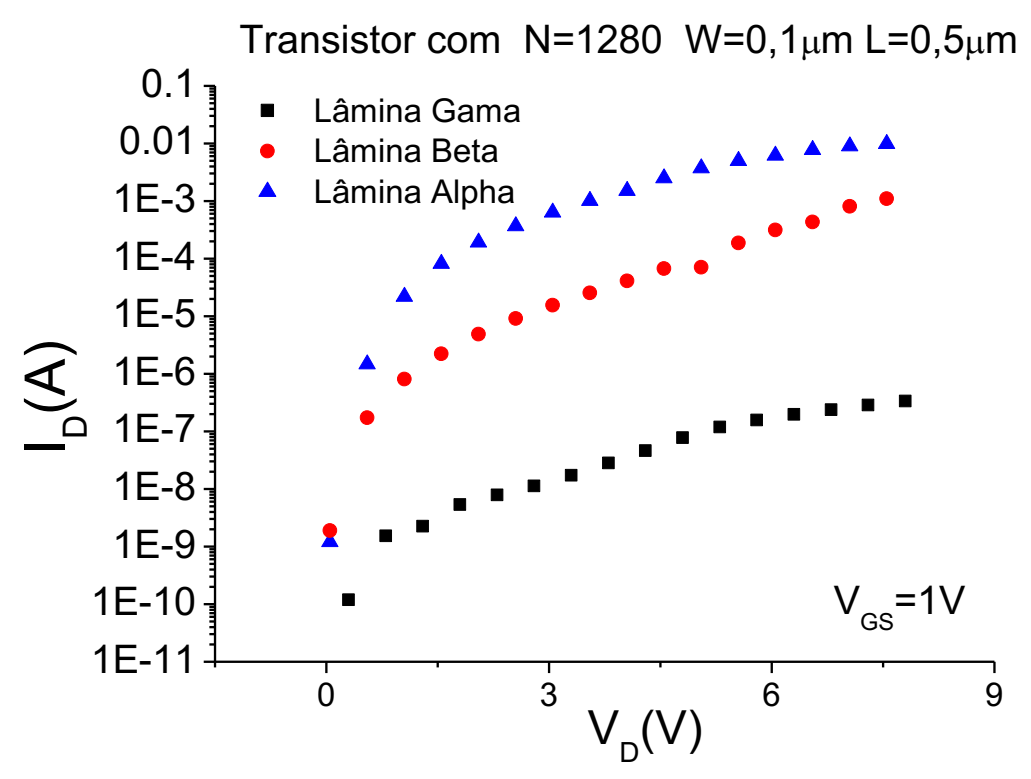

Fonte: Autor.

Através da análise da Figura 91 podemos observar que a corrente máxima para lâmina alpha foi $I_{D}=9,8 m A$, para a lâmina beta $I_{D}=1,009 \mathrm{~mA}$ e para a lâmina gama $I_{D}=0,291 \mu$ A.

Através destas curvas foi extraída a resistência elétrica desses transistores e a lâmina alpha apresentou $\mathrm{R}=900 \Omega$, lâmina beta $\mathrm{R}=3 \mathrm{~K} \Omega$, lâmina gama $\mathrm{R}=22,5 \mathrm{M} \Omega$. 


\section{CONCLUSÃO}

Neste trabalho foi proposto o projeto, fabricação e caracterização dos transistores sem Junção e Nano-fio não dopado. Para isto, simulações bidimensionais e tridimensionais das etapas de processo destes dispositivos foram realizadas. Nestas simulações foram ajustados parâmetros de implantação iônica, recozimento, oxidação térmica, para atingirmos tensões de limiar, espessuras de óxidos e de porta esperadas.

O processo de fabricação dos transistores sem junção realizado no Raith e-line é um processo novo e inédito no país por apresentar espessuras (camada de silício, óxido enterrado, óxido de porta) tão reduzidas da ordem de nanômetros. Isto nos proporcionou novos avanços com relação aos transistores fabricados no Brasil. Através deste avanço foi possível aprimorar mais uma vertente de fabricação inédita no país, a fabricação de Nano-fios não dopados (Undoped Nanowire).

Vale ressaltar que transistores UTBB com corpo e óxido enterrado muito reduzidos, no nosso caso $10 \mathrm{~nm}$ e $20 \mathrm{~nm}$ respectivamente, foram um desafio complementar atingido. Os equipamentos do CCS, de oxidação, recozimento, corrosão, litografia, estão calibrados para processos com espessuras bem maiores. Portanto, todas as etapas tiveram que ser calibradas, e desenvolvidos modos de verificação destes processos tiveram que ser aprimorados pois equipamentos como microscópio ótico, FIB, Raith E-line, não eram suficientes para visualizar as camadas realizadas na lâmina. Através disto o laboratório CCS ficou habilitado a realizar transistores muitos menores.

Foram fabricados 2 transistores sem junção com dopagens diferentes, $\mathrm{N}_{\mathrm{D}}=5 \times 10^{17} \mathrm{~cm}^{-3}$ e $\mathrm{N}_{\mathrm{D}}=2 \times 10^{18} \mathrm{~cm}^{-3}$. A primeira geração de transistores denominada lâmina alpha proporcionou resultados iniciais que nos capacitaram evoluir para as próximas gerações. Ajuste das oxidações, doses de litografia, tempos e potências e equipamentos de corrosão foram necessárias para aprimorar o projeto da segunda geração.

Esta denominada lâmina beta apresentou melhoras em alguns aspectos à primeira geração. As marcas de alinhamento melhoraram com a troca da dose e do material Ti/Ta. Também o ajuste da oxidação no forno com $\mathrm{O}_{2}$ 6.0, fez atingir um óxido de porta de aproximadamente 10nm, este medido no elipsômetro. Consequentemente a camada de silício pôde ser estimada em 10nm. Porém este conjunto apresentou alguns problemas na corrosão da mesa de silício, e litografia de pads. A caracterização elétrica destes transistores apresentou curto entre a fonte dreno e substrato. 
Foi fabricado também um die de nano-fios não dopados com 54 transistores com variadas quantidades de fins 1, 20, 640, 1280. Esta terceira geração de transistores pode corrigir os problemas encontrados na lâmina beta, como a corrosão da mesa de silício calibrada no ICP- RIE com 5 segundos, e o ajuste de dose da última etapa dos pads de fonte, dreno e porta. Com este conjunto de transistores foi feita caracterização elétrica com curvas $\mathrm{C}-\mathrm{V}, \mathrm{I}_{\mathrm{DS}} \times \mathrm{V}_{\mathrm{GB}}$ e $\mathrm{I}_{\mathrm{DS}} \times \mathrm{V}_{\mathrm{DS}}$ de três transistores com $\mathrm{W}=0,1 \mu \mathrm{m}$ e $\mathrm{L}=0,1 \mu \mathrm{m}$ porém com $\mathrm{N}=120$, 640 e 1280. Através destas curvas foram extraídos tensão de limiar, inclinação de sublimiar, condutância e transcondutância.

Realizamos medidas elétricas também de dois transistores com W diferentes e observamos mesma tensão de limiar $0,55 \mathrm{~V}$, mesma inclinação de sublimiar $980 \mathrm{mV} / \mathrm{dec}$, e apresentaram nível de corrente diferentes referente à largura de canal.

Observamos também a influência da tensão aplicada da porta de cima do transistor demonstrando um bom acoplamento entre as portas.

Foi feita também uma comparação entre os transistores para observar a concentração das lâminas e notamos que para os transistores sem dopagem foram os que apresentaram a maior resistência elétrica e menor nível de corrente passando pelo fin, na sequência o transistor com beta e por fim o gama o que apresenta maior concentração de fósforo, os valores foram lâmina alpha $\mathrm{R}=900 \Omega$, lâmina beta $\mathrm{R}=3 \mathrm{~K} \Omega$, lâmina gama $\mathrm{R}=22,5 \mathrm{M} \Omega$.

Este trabalho gerou um trabalho submetido a revista, Journal of Nanoelectronics and Optoelectronics, com tema, "Back-biased undoped nanowire-based FETs in SOI substrates with nanometric thicknesses".

Temos como perspectiva futura redução de efeitos de proximidade no processo litográfico para minimizar distorções da geometria dos dispositivos e comprimento efetivo do canal (SiNW); refinamento da dose do resiste PMMA e dos parâmetros do sistema eletroóptico do sistema e-Line para redução da dimensão da porta; fabricação de dispositivos NWFETs com outro dielétrico de porta de alto-K como oxinitreto; fabricação de dispositivos NWFETs com outro material de porta; reduzir as dimensões dos nanofios e dos dispositivos utilizando resistes de melhor resolução. 


\section{REFERÊNCIAS}

1 SEDRA, A. S.; SMITH, K. C. Microeletrônica. 1. ed. São Paulo: Markon Books,1995.

2 CHEN, H. S.; S.S., L. Comparison of statistical variation of threshold voltage in bulk and SOI MOSFETs. Solid-State Electronics, v. 35, p. 1233-1239, 1992.

3 FRANK, D. J. et al. Device scaling limits of Si MOSFETs and their application dependencies. Proceedings of the IEEE, Piscataway, v. 89, n. 3, p. 259-288, Mar. 2001.

4 COLINGE. J. P. Silicon-On-Insulator Technology: materials to VLSI. 3. ed. Massachusetts: Kluwer Academic, 2004.

5 LERAY, J.L., et al. From substrate to VLSI: investigation of hardened SIMOX without epitaxy, for dose rate and SEU phenomena. IEEE Transaction on Nuclear Science, v.35, p. $1355,1988$.

6 KRULL, W. A., LEE, J. C., Demonstration of the benefits of SOI for high temperature operation. In: SOS/SOI TECHNOLOGY WORKSHOP, 1988, USA, Proceedings..., 2002, p. $3-5$.

7 COLINGE, J. P. et al. Junctionless Nanowire Transistor (JNT): properties and design guidelines. Solid-State Electronics, v. 65, p. 33-37, 2011.

8 SENTAURUS Process User's Manual. SYNOPSYS, 2010.

9 ATHENA User's Manual. SILVACO, 2008.

10 COLINGE, J. P. FinFETs and Other Multi-Gate Transistors. 1. ed. New York: Springer, 2008.

11 SEKIGAWA, T.; HAYASHI, Y. Calculated threshold-voltage characteristics of an XMOS transistor having an additional bottom gate. Solid-State Electronics, v. 27, p. 827-828, 1984.

12 HISAMOTO, D. et al. A fully depleted lean-channel transistor (DELTA) - A novel vertical ultrathin SOI MOSFET. IEEE Electron Device Letters, v. 11, p. 36-38, 1990.

13 HUANG, X. L. W. C. et al. Sub 50-nm FinFET: PMOS. In: INTERNATIONAL ELECTRON DEVICES MEETING. 1999, Washington. Anais... Washington: IEDM Technical Digest, p. 67-70, 1999.

14 HISAMOTO, D. et al. FinFET - A self-aligned double-gate MOSFET scalable to $20 \mathrm{~nm}$. IEEE Transactions on Electron Devices, v. 47, p. 2320-2325, 2000.

15 COLINGE, J. P. et al. Silicon-on-insulator 'gate-all-around device'. In: INTERNATIONAL ELECTRON DEVICES MEETING - IEDM '90. 1990, San Francisco. Anais... San Francisco: Technical Digest, p. 595-598, 1990.

16 PARK, J. T.; COLINGE, J. P.; DIAZ, C. H. Pi-Gate SOI MOSFET. IEEE Electron Device Letters, v. 22, p. 405-406, 2001. 
17 YANG, F. L. et al. $25 \mathrm{~nm}$ CMOS Omega FETs. In: INTERNATIONAL ELECTRON DEVICES MEETING - IEDM '02. 2002, San Francisco. Anais... San Francisco: Technical Digest, 2002, p. 255-258.

18 MIYANO, S.; HIROSE, M.; MASUOKA, F. Numerical analysis of a cylindrical thinpillar transistor (CYNTHIA). IEEE Transactions on Electron Devices, v. 39, p. 1876-1881, 1992.

19 LANDGRAF, E. et al. Influence of crystal orientation and body doping on trigate transistor performance. Solid-State Electronics, v. 50, p. 38-43, 2006.

20 SUBRAMANIAN, V. et al. Impact of fin width on digital and analog performances of nFinFETs. Solid-State Electronics, v. 51, p. 551-559, 2007.

21 CRISTOLOVEANU, S.; LI, S. S. electrical characterization of silicon-on-insulator materials and devices. 2. ed. Boston: Kluwer Academic, 1995.

22 COLINGE, J. P. Conduction mechanisms in thin-film accumulation-mode SOI p-channel MOSFETs. IEEE Transactions on Electron Devices, v. 37, p. 718-723, 1990.

23 SU, K. W.; KUO, J. B. Analysis of current conduction in short-channel accumulationmode SOI PMOS devices. IEEE Transactions on Electron Devices, v. 44, p. 832-840, 1997.

24 SZE, S. M. Physics of semiconductor devices. New York: John Wiley and Sons, 1981. v. 2.

25 KRISHNAN, S.; FOSSUM, J. G. Grasping SOI floating-body effects. IEEE Circuits and Devices Magazine, v. 14, p. 32-37, 1998.

26 SHAHIDI, G. G. SOI technology for the GHZ era. IBM Journal of Research and Development, v. 46, p. 1217-1221, 1994.

27 HIROAKI, M. SOI Becomes Practicable. Seiko Epson: Watch Type IC with Partially Depleted SOI. Semiconductor World, v. 19, p. 74-77, 2000.

28 CURRAB, B. et al. Power-constrained heigh-frequency circuits for the IBM POWER microprocessor. IBM Journal of Research and Development, v. 51, p. 715-731, 2007.

29 YOSHIMI, M. et al. Observation of mobility enhancement in ultrathin SOI MOSFETs. Electronics Letters, v. 24, n. 17, p. 1078-1079, 1988.

30 YOSHIMI, M. et al. Two-dimensional simulation and measurement of high-performance MOSFETs made on a very thin SOI film. IEEE Transactions on Electron Devices, v. 36, p. 493-503, 1989.

31 GROESENEKEN, G. et al. Temperature dependence of threshold voltage in thin-film SOI MOSFETs. IEEE Electron Device Letters, v. 11, p. 329-331, 1990. 
32 YOUNG, K. K. Short-channel effect in fully depleted SOI MOSFETs. IEEE Transaction on Electron Device Letters, v. 36, p. 399-402, 1989.

33 ICHIKAWA, F. E. A. Fully depleted SOI process and device technology for digital and RF applications. Solid-State Electronics, v. 48, p. 999-1006, 2004.

34 VEERARACHAVAN, S.; FOSSUM, J. G. A Short-channel effects in SOI MOSFETs. IEEE Transactions on Electron Devices, v. 36, n. 3, p. 522-528, 1989

35 CRISTOLOVEANU, S.; LI, S. S. Electrical Characterization of Silicon-on-Insulator Material and Devices. Kluwer Academic, Boston, 1995.

36 LIM, H. K.; FOSSUM, J. G. Threshold voltage of thin-film silicon-on-insulator(SOI) MOSFET`s. IEEE Transactions on Electron Letters, v. 30, p. 1244-1251, 1983.

37 FLANDRE, D. E. A. Comparison of SOI versus bulk performances of CMOS micropower single-stage OTAs. Electronics Letters, v. 30, p. 1933-1934, 1994.

38 GUTIERREZ, E. A, Deen J., Claeys C. Low Temperature Electronics: Physics, Devices, Circuits and Applications. Academic Press, San Diego, 1. ed., 2001.

39 SAH, C. T. et al. Effect of zinc impurity on silicon solar-cell efficiency. IEEE Transactions on Electron Devices, v. 28, p. 304-313, 1981.

40 CAUGHEY, D.; THOMAS, R. E. Carrier mobilities in silicon empirically related to dopingand field. Proceedings of the IEEE, v. 55, p. 2192-2193, 1967.

41 DORKEL, J. M.; LETURCQ, P. Carrier mobilities in silicon semi-empirically related to temperature, doping and injection level. Solid-State Electronics, v. 24, p. 821-825, 1981.

42 LI, S. S.; THURBER, W. R. The dopant density and temperature dependence of electron mobility and resistivity in n-type silicon. Solid-State Electronics, v. 20, p. 609-616, 1977.

43 COLINGE, J. P.; COLINGE, A. C. Physics of Semiconductor Devices,Springer, US, 2002 , p. 449.

44 BREWS, J. R. Subthreshold behavior of uniformly and nonuniformly doped long-channel MOSFET. IEEE Transactions on Electron Devices, v. 26, p. 1282-1291, 1979.

45 COLINGE, J. P. Advanced CMOS devices made in thin SOI films. In: EXTENDED ABSTRACTS OF 5TH INTERNATIONAL WORKSHOP ON FUTURE ELECTRON DEVICES. 5., 1998, Miyagi-Zao, Japão. Anais... Miyagi-Zao, 1998, p. 105-112.

46 VEERARAGHAVAN, S.; FOSSUM, J. G. A. Short-channel effects in SOI MOSFETs. IEEE Transactions on Electron Devices, v. 36, p. 522-528, 1989.

47 MULLER, R. S.; KAMINS, T. I. Device Electronics for Integrated Circuits. WileyInterscience, 1986. 
48 VEERARAGHAVAN, S.; FOSSUM, J. G. A Physical short-channel model for the thinfilm SOI MOSFET applicable to device and circuit CAD. IEEE Transactions on Electron Devices, v. 35, p. 1866-1875, 1988.

49 COLINGE, J. P. Thin-film SOI technology: the solution to many submicron CMOS problems. In: IEEE INTERNATIONAL ELECTRON DEVICES MEETING IEDM, 1989,Washington. Anais... Washington: IEEE, 1989, p. 817-820.

50 LILIENFELD, J. E. Method and apparatus for controlling electric current. US patent ,US1745175A, 8 de outubro de 1925.

51 LILIENFELD, J. E. Device for controlling electric current. US patent, US26537228A, 28 de março de 1928.

52 COLINGE, J. P. et al. SOI Gated Resistor: CMOS without Junctions. In: IEEE SOI CONFERENCE PROCEEDINGS. 2009, Foster City. Anais... Foster City: IEEE, 2009. p. 12.

53 COLINGE, J. P. E. A. Silicon-on-Insulator "Gate-All-Around Device". In: TECHNICAL DIGEST OF IEDM. 1990, San Francisco. Anais... San Francisco: IEDM, 1990. p.595-598.

54 TSUCHIYA, R. E. A. Silicon on thin BOX: a new paradigm of the CMOSFET for lowpower and high-performance application featuring wide-range back-bias control. In: IEEE INTERNATIONAL ELECTRON DEVICES MEETING (IEDM). 2004, Washington. Anais... Washington: IEDM, 2004, p.631-634.

55 APPENZELLER, J. Toward nanowire electronics. IEEE Transactions On Electron Devices, v. 55, p.2827-2845, 2008.

56 KOO S.-M.. "Silicon nanowires as enhancement-mode Schottky barrier field-effect transistors. Nanotechnology, v. 16, p.1482-1485, 2005.

57 CRISTOLOVEAM, S.; MUNTEANU, D.; LIU, M. S. T. A Review of the Pseudo-MOS Transistor in SOI Wafers: Operation, Parameter Extraction, and Applications. IEEE Transaction On Electron Devices, v. 47, p. 1018-1027, MAY 2000.

58 SWART, J. W. Semicondutores: fundamentos, técnicas e aplicações. 1. ed. Campinas: Unicamp, 2008.

59 MADOU, M. Fundamentals of Microfabrication. Boca Raton: CRC, 1997.

60 PIERSON, H. O. Handbook of Chemical Vapor Deposition, Principles, Technology and Applications. Westwood: Noyes, 1992.

61 ZIEGLER, J. F. Interactions of ions with matter, 2000. Disponivel em: $<$ http://www.srim.org/>. Acesso em: 11 fev. 2015.

62 WESSELY, F.; KRAUS, T.; SCHWALKE, U. CMOS without doping: Multi-gate siliconnanowire field-effect-transistors. Solid-State Electronics, v. 70, p. 33-38, 2012. 
63 KERN, W. The Evolution of Silicon Wafer Cleaning Technology. Journal of the electrochemical society, v. 137, n. 6, p. 1887-1892, 1990.

64 THIES, J. Layouteditor, 2009. Disponivel em: <http://layouteditor.net/>. Acesso em: may 2013.

65 UTKE, I, STAINSLAIV. M, RUSSEL, P. Nanofabrication using focused ion beams and electron beams. 1. ed. Oxford: Oxford University, 2012.

66 PUYDINGER M. V., E. A. Fabrication of p-type silicon nanowires for 3D FETs using focused ion beam. Journal of Vacuum Science \& Technology B, Nanotechnology and Microelectronics, v. 31, p. 1-2, 2013. 
ANEXO A- CÓDIGO SIMULAÇÃO 2D JNT MOSFET 
go athena

\#grade na direção $x$

line $x$ loc $=0$ spacing $=0.05$ tag=left

line $x$ loc $=1$ spacing $=0.05$

line $x$ loc $=1.7$ spacing $=0.01$

line $x$ loc $=2$ spacing $=0.005$

line $x$ loc $=2.5$ spacing $=0.01$

line $x$ loc $=3.5$ spacing $=0.05$

line $x$ loc $=4.5$ spacing $=0.05$ tag=right

\#grade na direção y

line $y$ loc $=0$ spacing $=0.001$ tag=top

line $y$ loc $=0.014$ spacing $=0.01$ tag=topox

line $y$ loc $=0.034$ spacing $=0.5$ tag=bottomox

line $y$ loc=1 spacing=0.5 tag=bottom

\#definição da lamina

region silicon $x l o=l e f t$ xhi=right ylo=top yhi=bottom

region oxide xlo=left xhi=right ylo=topox yhi=bottomox

\#expose bound $x l o=l e f t$ xhi=right ylo=top yhi=top

\# Observa estrutura resultante

\#structure outf=estrutura.str two.dim

\#definição da concentração inicial da lâmina

INIT SILICON C.BORON=1.0E15 ORIENTATION=100

\#structure outf=lamina.str two.dim

\#1 definição da ativa plasma etch

etch silicon start $x=0.0 \quad y=0.0$

etch continue $\mathrm{x}=1.0 \mathrm{y}=0.0$

etch continue $x=1.0 \quad y=0.014$

etch done $\mathrm{x}=0.0 \mathrm{y}=0.014$

etch silicon start $x=3.5 y=0.0$

etch continue $\mathrm{x}=4.5 \mathrm{y}=0.0$

etch continue $\mathrm{x}=4.5 \mathrm{y}=0.014$

etch done $x=3.5 y=0.014$

structure outf=1definicao_regiao_ativa.str two.dim

$\# 3$ * *the implant

implant phoshporus dose $=1$ e15 energy=10 gauss 
structure outf=ajusteVT_dosele15.str two.dim

\#4 recozimento2

diffuse time=15 temp=1000 nitrogen

structure outf=recozimentoFORNO_15min.str two.dim

\# Óxidação de porta térmica seca

diffuse time $=5$ temp $=850$ nitrogen

diffuse time $=5$ temp $=850$ dry

oxide hcl.pc=0.3 hclp=1 hclT=1000 hcl.lin=3 hcl.par=2.5

diffuse time $=20$ temp $=850$ dry

oxide hcl.pc=0

diffuse time $=5$ temp $=850$ dry

diffuse time=5 temp=850 nitrogen

\# Observa estrutura resultante após a oxidação

structure outf=oxidacaoseca $20 \mathrm{~min}$.str two.dim

\#abertura de contatos

etch oxide start $\mathrm{x}=1.50 \mathrm{y}=-0.006$

etch continue $\mathrm{x}=1.7 \mathrm{y}=-0.006$

etch continue $x=1.7 \quad y=0.003$

etch done $\mathrm{x}=1.5 \mathrm{y}=0.003$

etch oxide start $x=2.8 \quad y=-0.006$

etch continue $\mathrm{x}=2.9 \mathrm{y}=-0.006$

etch continue $\mathrm{x}=2.9 \mathrm{y}=0.003$

etch done $x=2.8 y=0.003$

\# Etapas 8 -Deposição de 20 nm de Aluminum

deposit aluminum thick $=0.020$ div $=5$

\# Etapa 9 -Definição do Al

etch aluminum start $\mathrm{x}=1.90 \mathrm{y}=-0.06$

etch continue $\mathrm{x}=2.0 \mathrm{y}=-0.06$

etch continue $\mathrm{x}=2.0 \mathrm{y}=0.003$

etch done $\mathrm{x}=1.90 \mathrm{y}=0.003$

etch aluminum start $\mathrm{x}=2.5 \mathrm{y}=-0.06$

etch continue $\mathrm{x}=2.6 \mathrm{y}=-0.06$

etch continue $x=2.6 \quad y=0.003$

etch done $\mathrm{x}=2.5 \mathrm{y}=0.003$

structure outf=aluminum_porta.str two.dim 
ELECTRODE Name=gate $X=2.3 \quad Y=-0.02$

ELECTRODE Name=source $X=1.2 \quad Y=-0.02$

ELECTRODE Name=drain $\mathrm{X}=3.2 \mathrm{Y}=-0.02$

ELECTRODE NAME=substrate backside

structure outf=jnt_teste_1.str two.dim

quit 
ANEXO B- CÓDIGO SIMULAÇÃO 2D - NWFET MOSFET 
go athena

\#grade na direção x

line $x$ loc $=0$ spacing $=0.05$ tag=left

line $x$ loc $=1$ spacing $=0.05$

line $x$ loc $=1.7$ spacing $=0.01$

line $x$ loc $=2$ spacing $=0.005$

line $x$ loc $=2.5$ spacing $=0.01$

line $x$ loc $=3.5$ spacing $=0.05$

line $x$ loc $=4.5$ spacing $=0.05$ tag=right

\#grade na direção y

line $y$ loc $=0$ spacing $=0.001$ tag=top

line $y$ loc $=0.014$ spacing $=0.01$ tag=topox

line $y$ loc $=0.034$ spacing=0.5 tag=bottomox

line $y$ loc=1 spacing=0.5 tag=bottom

\#definição da lamina

region silicon xlo=left xhi=right ylo=top yhi=bottom

region oxide $x l o=l e f t$ xhi=right ylo=topox yhi=bottomox

\#expose bound $x l o=l e f t$ xhi=right ylo=top yhi=top

\# Observa estrutura resultante

\#structure outf=estrutura.str two.dim

\#definição da concentração inicial da lâmina

INIT SILICON C.BORON=1.0E15 ORIENTATION=100

\#structure outf=lamina.str two.dim

\#1 definição da ativa plasma etch

etch silicon start $\mathrm{x}=0.0 \mathrm{y}=0.0$

etch continue $\mathrm{x}=1.0 \mathrm{y}=0.0$

etch continue $\mathrm{x}=1.0 \mathrm{y}=0.014$

etch done $x=0.0 \quad y=0.014$

etch silicon start $x=3.5 y=0.0$

etch continue $\mathrm{x}=4.5 \mathrm{y}=0.0$

etch continue $x=4.5 y=0.014$

etch done $x=3.5 y=0.014$ 


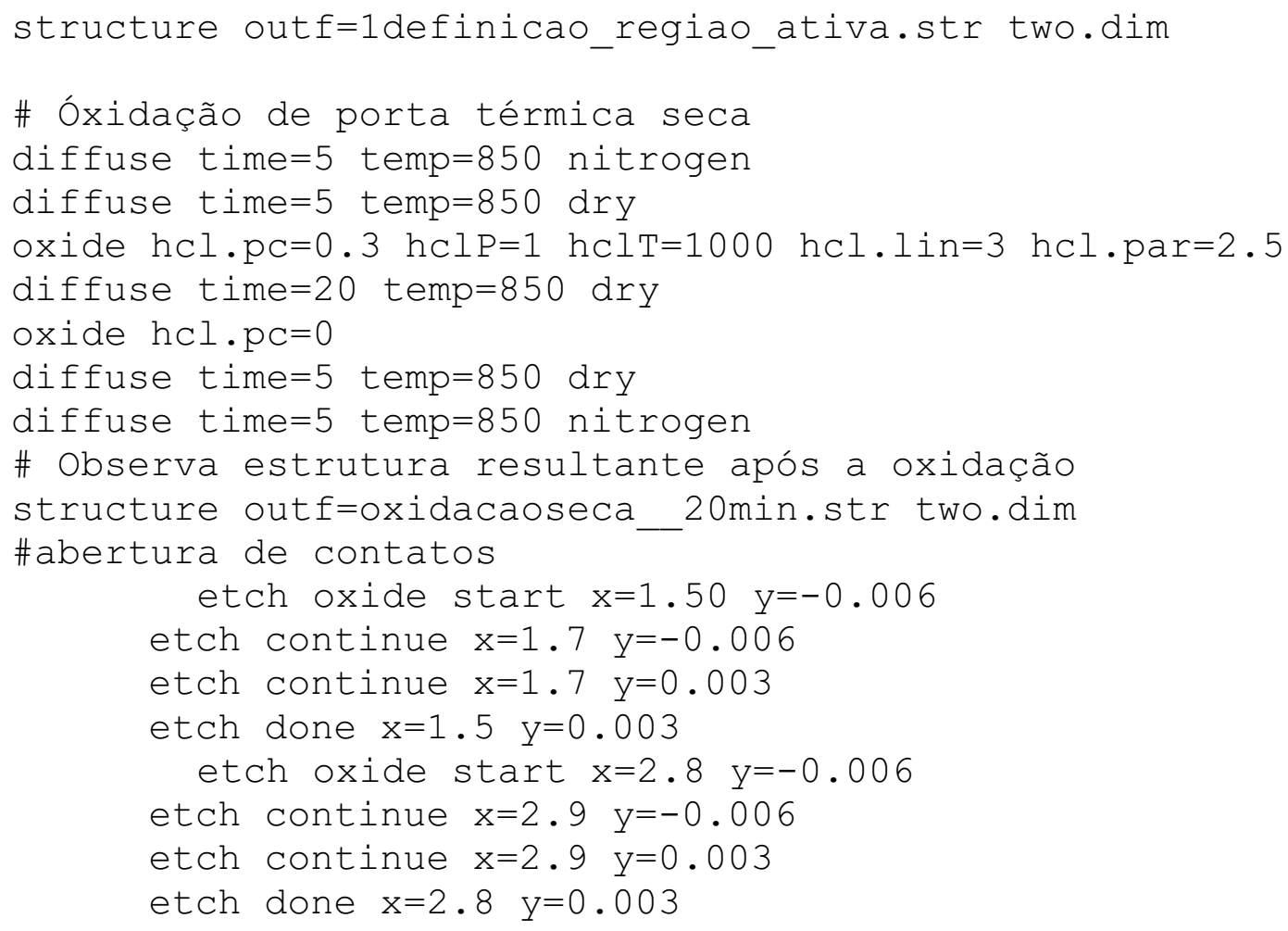

\# Etapas 8 -Deposição de 20 nm de Aluminum

deposit aluminum thick $=0.020$ div $=5$

\# Etapa 9 -Definição do Al

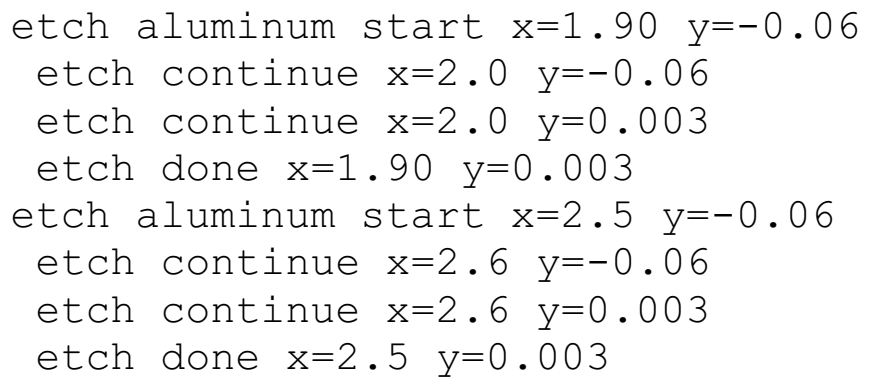

ELECTRODE Name=gate $X=2.3 \quad Y=-0.02$

ELECTRODE Name=source $X=1.2 \quad Y=-0.02$

ELECTRODE Name=drain $\mathrm{X}=3.2 \quad \mathrm{Y}=-0.02$

ELECTRODE NAME=substrate backside

structure outf=jnt_teste_1.str two.dim 
quit 